\title{
THE DEVELOPMENT AND MAINTENANCE OF CUSTOMER
} RELATIONSHIPS THROUGH COMMUNICATION: A CONSUMER PERSPECTIVE

By

Nicholas Paul Thompson

\begin{abstract}
A thesis
Submitted to the Victoria University of Wellington

in fulfilment of the requirements for the degree of

Doctor of Philosophy

in Marketing
\end{abstract}

Victoria University of Wellington

2010 


\section{Contents}

$\begin{array}{llr}1.0 & \text { Abstract } & 8\end{array}$

1.1 Overview $\quad 8$

$\begin{array}{ll}1.2 \text { Research Gap } & 10\end{array}$

1.3 Research Value 13

1.4 Research Objectives 15

1.4.1 Primary Research Objective $\quad 15$

1.4.2 Secondary Research Objective $\quad 16$

$\begin{array}{ll}1.5 \text { Introduction Summary } & 17\end{array}$

$\begin{array}{lll}2.0 & \text { Literature Review } & 18\end{array}$

2.1 Relationship Marketing 19

2.2 The Relationship Marketing Paradigm 20

2.3 Relationship Marketing Definition 23

2.4 Customer Relationship Management 24

2.5 Customer Relationships with Brands 26

$\begin{array}{ll}2.6 \text { Relationship Quality } & 27\end{array}$

2.7 Communication in Relationships 31

2.8 Consumer Participation in Relationships 32

2.9 The Internet 36

2.10 Internet Based Media 38

2.11 Internet Based Media and Customer Relationships 40

2.12 Access to Internet Based Media 43

2.13 Use of Internet Based and Non-Internet Based Media 46

2.14 Literature Summary $\quad 49$

3.0 Conceptual Model 51

3.1 Construct Definitions $\quad 54$ 
3.1.1 Brand Personality Connection 54

3.1.2 Brand Advertising 57

3.1.3 Communication with the Brand 59

3.1.4 Communication with Consumer Communities 62

3.1.5 Relationship Quality 63

3.1.6 Relational Orientation 66

3.1.7 Customer Brand Loyalty 68

$\begin{array}{ll}\text { 3.2 Hypotheses and Full Conceptual Model } & 71\end{array}$

$\begin{array}{lll}4.0 & \text { Research Methodology } & 75\end{array}$

$\begin{array}{ll}\text { 4.1 Construct Measurement } & 77\end{array}$

4.1.1 Brand Personality Connection 77

4.1.2 Brand Advertising 78

4.1.3 Communication with the Brand and Consumer Communities $\quad 79$

4.1.4 Relationship Quality 80

4.1.5 Relational Orientation $\quad 81$

4.1.6 Customer Brand Loyalty 82

4.2 Overview of Research Approach 83

4.3 Approach to Developing Measures 84

4.4 Sampling Frame $\quad 85$

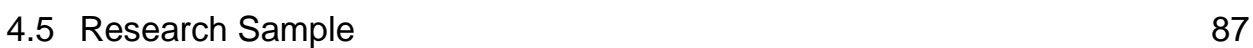

$\begin{array}{ll}\text { 4.6 Pretesting } & 87\end{array}$

4.6.1 Expert Evaluation 88

4.6.2 Question Testing 88

$\begin{array}{lll}4.6 .3 \text { Pretest } & 90\end{array}$

$\begin{array}{lll}4.7 & \text { Research Implementation } & 91\end{array}$

$\begin{array}{lll}5.0 & \text { Research Findings } & 93\end{array}$

$\begin{array}{ll}5.1 \text { Response Rate } & 93\end{array}$

5.2 Descriptive Analysis, Non-Response Considerations and Distribution 95

5.2.1 Missing Data 96

$\begin{array}{ll}\text { 5.2.2 } & \text { Age Group } \\ & 97\end{array}$

5.2.3 Residential Region 99

$\begin{array}{lll}\text { 5.2.4 Gender } & 101\end{array}$

5.2.5 Personal Annual Income Level 101 
5.2.6 Airline Travel 103

5.2.7 Customer Lifetime Value 105

$\begin{array}{ll}5.3 \text { Overview of Data Analysis } & 106\end{array}$

$\begin{array}{ll}5.4 \text { Scale Validation } & 109\end{array}$

5.4.1 Exploratory Construct Analysis 109

5.4.1.1 Communication with the Brand 110

5.4.1.2 Communication with Consumer Communities $\quad 114$

5.4.1.3 Brand Personality Connection $\quad 117$

$\begin{array}{ll}5.5 \text { Measurement Evaluation } & 119\end{array}$

$\begin{array}{lll}\text { 5.5.1 Scale Validity } & 119\end{array}$

5.5.2 Scale Reliability 119

$\begin{array}{ll}5.6 \text { Hypotheses Testing } & 121\end{array}$

5.7 Partial Least Square Analysis 122

5.7.1 Partial Least Square Analysis Results 123

5.7.1.1 Measurement Model 123

5.7.1.2 Structural Model 125

5.7.1.3 Final Model Selection $\quad 127$

$\begin{array}{lll}\text { 6.0 Discussion of Findings } & 129\end{array}$

6.1 Conceptual Model and Measurement 129

$\begin{array}{ll}6.2 \text { Relationships among Constructs } & 130\end{array}$

6.3 Theoretical and Methodological Contributions 133

$\begin{array}{ll}\text { 6.4 Managerial Considerations } & 135\end{array}$

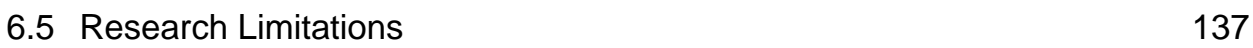

$\begin{array}{ll}6.6 \text { Future Research } & 138\end{array}$

$\begin{array}{ll}6.7 \text { Conclusions } & 139\end{array}$

$\begin{array}{lll}7.0 & \text { Appendices } & 142\end{array}$

Appendix A: Internet Based and Non-Internet Based Media 142

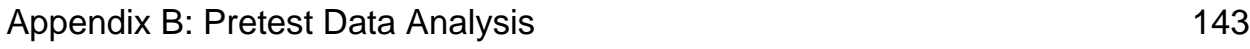

Appendix C: Copy of Pretest Questionnaire 152

$\begin{array}{ll}\text { Appendix D: Reminder Card } & 160\end{array}$ 
$\begin{array}{ll}\text { Appendix F: Reasons Provided for Non-Participation } & 169\end{array}$

Appendix G: Skewness, Kurtosis, and Missing Data 170

$\begin{array}{ll}\text { Appendix H: All Items Correlation Matrix } & 175\end{array}$

$\begin{array}{ll}\text { Appendix I: Partial Least Square Output } & 179\end{array}$

$\begin{array}{lll}8.0 & \text { References } & 183\end{array}$ 
Figures and Tables

\begin{tabular}{|c|c|c|}
\hline & Title & Page \\
\hline Figure 1 & Communication Flows Regarding a Brand & 12 \\
\hline Figure 2 & Literature Review & 18 \\
\hline Figure 3a & Conceptual Model & 53 \\
\hline Figure 3b & Conceptual Model with Construct Definitions & 70 \\
\hline Figure 3c & Conceptual Model with Construct Definitions and Hypotheses & 74 \\
\hline Table $4 a$ & Brand Personality Connection Items & 78 \\
\hline Table $4 \mathrm{~b}$ & Brand Advertising Items & 79 \\
\hline Table 4c & Communication with the Brand Items & 80 \\
\hline Table 4d & Communication with Consumer Communities Items & 80 \\
\hline Table $4 \mathrm{e}$ & Relationship Quality Items & 81 \\
\hline Table $4 \mathrm{f}$ & Relational Orientation Items & 82 \\
\hline Table $4 \mathrm{~g}$ & Customer Brand Loyalty Items & 83 \\
\hline Table $5 a$ & Data Collection Pretest Response Rate & 91 \\
\hline Table $5 b$ & Research Response Rate & 94 \\
\hline Table 6 & Research Response Frequency & 95 \\
\hline Table $7 a$ & Age of Research Respondents & 97 \\
\hline Table $7 \mathrm{~b}$ & Age (Single Years) for the Census Usually Resident Population Count 2006 & 98 \\
\hline Figure 7c & Age of Research Respondents Compared to Population & 98 \\
\hline Table 8a & Regional Residence of Research Respondents & 100 \\
\hline Table 8b & Regional Council for the Census Usually Resident Population Count 2006 & 100 \\
\hline Table 9 & Urban/Rural Residence of Research Respondents & 101 \\
\hline Table 10a & Gender of Research Respondents & 101 \\
\hline Table 10b & Usually Resident New Zealand Population Gender & 101 \\
\hline Table 11a & Personal Income of Research Respondents & 102 \\
\hline Table 11b & $\begin{array}{l}\text { Total Personal Income for the Census Usually Resident Population Count Aged } \\
15 \text { Years and Over }\end{array}$ & 102 \\
\hline Table 12 & Primary Purpose for Travel of Research Respondents & 104 \\
\hline Table 13 & Most Frequently Travelled Airline of Research Respondents & 104 \\
\hline Table 14a & Air New Zealand Airpoints Membership of Research Respondents & 105 \\
\hline Table 14b & Air New Zealand Airpoints Status of Research Respondents & 105 \\
\hline Table 15 & Air New Zealand Koru Club Membership of Research Respondents & 105 \\
\hline Table 16 & Total Annual Airline Travel Spend of Research Respondents & 106 \\
\hline Table 17 & Measurement Model Summary & 108 \\
\hline Table 18a & Communication with the Brand (frequency) Indicator Collinearity & 111 \\
\hline Table 18b & Communication with the Brand (experience) Indicator Collinearity & 111 \\
\hline Table 18c & Communication with the Brand (total) Indicator Collinearity & 112 \\
\hline Table 19a & Communication with the Brand (frequency) Individual Item Correlation Matrix & 112 \\
\hline Table 19b & Communication with the Brand (experience) Individual Item Correlation Matrix & 112 \\
\hline Table 19c & Communication with the Brand (total) Individual Item Correlation Matrix & 113 \\
\hline Table 20a & Communication with the Brand (frequency) Collective Item Correlation Matrix & 113 \\
\hline Table 20b & Communication with the Brand (experience) Collective Item Correlation Matrix & 113 \\
\hline Table 20c & Communication with the Brand (total) Collective Item Correlation Matrix & 113 \\
\hline Table 21a & Communication with Consumer Communities (frequency) Indicator Collinearity & 115 \\
\hline Table 21b & Communication with Consumer Communities (experience) Indicator Collinearity & 115 \\
\hline Table 21c & Communication with Consumer Communities (total) Indicator Collinearity & 115 \\
\hline
\end{tabular}




\begin{tabular}{|c|c|c|}
\hline Table 22a & $\begin{array}{l}\text { Communication with Consumer Communities (frequency) Individual Item } \\
\text { Correlation Matrix }\end{array}$ & 116 \\
\hline Table 22b & $\begin{array}{l}\text { Communication with Consumer Communities (experience) Individual Item } \\
\text { Correlation Matrix }\end{array}$ & 116 \\
\hline Table 22c & $\begin{array}{l}\text { Communication with Consumer Communities (total) Individual Item Correlation } \\
\text { Matrix }\end{array}$ & 116 \\
\hline Table 23a & $\begin{array}{l}\text { Communication with Consumer Communities (frequency) Collective Item } \\
\text { Correlation Matrix }\end{array}$ & 117 \\
\hline Table 23b & $\begin{array}{l}\text { Communication with Consumer Communities (experience) Collective Item } \\
\text { Correlation Matrix }\end{array}$ & 117 \\
\hline Table 23c & $\begin{array}{l}\text { Communication with Consumer Communities (total) Collective Item Correlation } \\
\text { Matrix }\end{array}$ & 117 \\
\hline Table 24 & Brand Personality Connection Indicator Collinearity & 118 \\
\hline Figure 25 & Brand Personality Connection (perceived and ideal brand personality scales) & 120 \\
\hline Table 26 & Research Hypotheses & 121 \\
\hline Table 27a & AVE Matrix & 124 \\
\hline Table 27b & Latent Variable Correlation Matrix & 125 \\
\hline Table 27c & Path Coefficients Matrix & 126 \\
\hline Table 27d & Path Coefficients T-Statistics Matrix & 126 \\
\hline Table 27e & R-Square and Q-Square Matrix & 127 \\
\hline Figure $27 f$ & $\begin{array}{l}\text { Final Selected Partial Least Square Model with Path Coefficients and Summary } \\
\text { of Support for Hypotheses }\end{array}$ & 128 \\
\hline Table 28 & Pretest Age & 143 \\
\hline Table 29 & Pretest Residential Region & 144 \\
\hline Table 30 & Pretest Urban/Rural Residence & 144 \\
\hline Table 31 & Pretest Gender & 144 \\
\hline Table 32 & Pretest Personal Income & 145 \\
\hline Table 33a & Pretest Most Frequently Travelled Airline & 146 \\
\hline Table 33b & Pretest Primary Purpose of Travel & 146 \\
\hline Table 34a & Brand Personality Connection Data Range & 147 \\
\hline Table 34b & Brand Personality Connection (Ideal) Data Range & 147 \\
\hline Table 35a & Brand Advertising Data Range & 148 \\
\hline Table 35b & Brand Advertising Cronbach's Coefficient Alpha & 148 \\
\hline Table 36 & Communication with the Brand Valid Data & 149 \\
\hline Table 37 & Communication with Consumer Communities Valid Data & 149 \\
\hline Table 38a & Relationship Quality Data Range & 150 \\
\hline Table 38b & Relationship Quality Cronbach's Coefficient Alpha & 150 \\
\hline Table 39a & Relational Orientation Data Range & 150 \\
\hline Table 39b & Relational Orientation Cronbach's Coefficient Alpha & 151 \\
\hline Table 40a & Customer Brand Loyalty Data Range & 151 \\
\hline Table 40b & Customer Brand Loyalty Cronbach's Coefficient Alpha & 151 \\
\hline
\end{tabular}




\subsection{Abstract}

Consumers increasingly control their relationships with brands, including how and with whom they choose to communicate. Bringing together elements of relationship marketing and brand theory, this research examines the process by which consumers form brand relationships. Results highlight the influence of advertising and social networking upon relationships, and confirm that a consumer's connection with a brand impacts brand performance. In doing so the manner in which customer relationships are developed and maintained from a consumer perspective is identified, as well as the benefits of relationships for brand owners.

\section{$1.1 \quad$ Overview}

This thesis focuses on customer relationships from a consumer perspective. Specifically, it examines the process by which individual consumers build and maintain relationships with brands through communication. Bringing together elements of relationship marketing and branding theory, the underlying purpose is to identify key factors influencing a consumer's perceived relationship with a brand and determine their measurement. The literature suggests that individual consumers form a connection with brands, seeing them as relationship partners (Fournier, 1998). They do so to varying extents, depending on the brand. The relevance of a brand to a consumer, therefore, extends further than brand image or the signals associated with a brand. Relationships between consumers and brands involve an emotional connection. A consumer's perceived connection with a brand then influences the manner in which they behave regarding that brand.

Authors mention the likes of Harley-Davidson (Ballantyne, 2006; Day, 2000) and Nestle (Arnott \& Bridgewater, 2002) as brands with which consumers form an emotional connection. Yet how an emotional connection can be measured, as well as the antecedents and consequences of such a connection, remain largely unexplored. While consumer participation is recognised as central to customer relationships (Gruen, Summers, \& Acito, 2000), current theory falls short of properly understanding the formation of relationships from a consumer perspective. The present research focuses on relationship marketing within a branding domain. Such a focus is an application of relationship and branding theory, combining two distinct areas of research that are fundamental to marketing. Although important work has been done in this area (Aaker, Fournier, \& Brasel, 2004; Fournier, 1998), a complete understanding of how consumers form relationships with brands has not yet been gained. The present research attends to this by examining the process by which consumers form relationships with brands through communication, including the consequences of such relationships for brand owners. 
Consumer relationships with brands are complex, with consumers perceiving relationships with brands that they view as possessing human-like characteristics (Aggarwal, 2004; Patterson \& O'Malley, 2006). Although it is accepted that the extent to which a brand expresses a significant aspect of the self is a dimension of relationship quality (Fournier, 1998), how consumers choose to connect with brands has not been explicitly examined. Self congruity is used to describe an alignment between a consumer's self-image and perceived product image (M. Sirgy, 1982). It is well-known that marketers consider this concept when promoting products to individual consumers, as congruity results in self-enhancement regarding the product (Grubb \& Hupp, 1968). This notion is further extended to consider congruity amongst self-image and the perceived image of a brand (Aaker, et al., 2004). Brands have a symbolic image beyond the physical attributes and characteristics of a product or service (Graeff, 1996). It is recognised that brands perceived as similar to the self concept enhance the self (Dolich, 1969). The alignment of a consumer's self-image with perceived brand image is, consequently, of interest to marketers. The degree of congruence between a brand's image and the set of knowledge and beliefs about one's self is noted as influencing consumer brand evaluations and purchase intention (Graeff, 1996). The present research determines connection with a brand according to an alignment between a consumer's perceived brand personality and their ideal brand personality for the product or service category. Ideal brand personality addresses the issue that consumers may be unwilling or unable to articulate category specific self-image (Aaker, 1999).

Communication is identified as a critical element in the formation of a relationship (Duncan \& Moriarty, 1998). Marketing practitioners communicate with consumers, often with the intention of establishing and maintaining customer relationships. From an organisational perspective actively engaging in the development and maintenance of a customer relationship through communication involves sending planned messages to, as well as receiving and replying to messages from, individual consumers. The nature of a relationship, however, implies participation by both a brand owner and consumer. Therefore, consumers need to participate in the communication process for a customer relationship to develop and be maintained. It is acknowledged that a brand is any feature, such as a name, term, design, or symbol, identifying one seller's goods or services as distinct from those of others (American Marketing Association, 2007). Consequently, although consumers can perceive relationships with brands, a brand is not capable of sending and receiving communication in a literal sense. This is done by representatives of the brand. As such, branding is noted as particularly important in the context of services, in which brand encounters are highly experiential (Brodie, Glynn, \& Little, 2006). For simplicity, this research refers to consumer communication with brand representatives as being sent and received by the brand. Consumers engage in numerous forms of communication regarding a brand that may influence a customer relationship. This includes interactive communication with the brand and consumer communities, as well as the receiving of advertising. The Marketing Science Institute (2007) has highlighted the fact that 
consumers are increasingly connected in the modern marketplace. Consumers are connected with organisations and third party information providers, as well as each other. They are also increasingly in control of many marketing processes, choosing with whom they communicate and how they forge relationships. As such consumer communication regarding a brand, with parties other than the brand owners, becomes increasingly important. The present research suggests that a consumer's connection with a brand will be influenced by the various forms of communication that they engage in regarding the brand. Additionally, the research recommends that such consumer brand connection directly influences relationship quality.

There is also a call to connect the development and maintenance of customer relationships with the financial performance of a brand (Keller \& Lehmann, 2006; Marketing Science Institute, 2007). In addressing the outcomes of relationship marketing, the research further addresses the consequences of customer relationships for brand owners. This is of interest to marketing practitioners as relationship quality is directly linked to brand performance. In summary, consumers are acknowledged to be increasingly active co-producers of value (Prahalad \& Ramaswamy, 2004; Sheth \& Parvatiyar, 1995; Veloutsou, et al., 2002), making a consumer perspective on customer relationships particularly important. The present research considers customer relationships from a consumer point of view. More specifically, it examines from a consumer perspective the development and maintenance of customer relationships between an individual consumer and a brand through communication. This builds upon research in the fields of both branding and relationship marketing, explicitly examining a consumer's connection with a brand as well as the antecedents and consequences of brand relationships.

\subsection{Research Gap}

Although theory regarding relationship marketing acknowledges the importance of developing and maintaining relationships with end consumers (O'Malley \& Tynan, 2000; Sheth \& Parvatiyar, 1995), the extant literature largely reflects an organisational perspective. Authors discuss the benefits to an organisation of customer relationship management (Day \& Montgomery, 1999; Gronroos, 1994; Kotler, 1992; Webster, 1992), as well as the manner in which organisations can strive to develop relationships with customers (Morgan \& Hunt, 1994). It is suggested, for example, that relationships are built through commitment and trust between parties (Morgan \& Hunt, 1994). Interestingly, commitment and trust in turn are recognised as being influenced by communication (Li \& Dant, 1997; Mohr \& Nevin, 1990; Morgan \& Hunt, 1994). Further practitioner focussed research has examined the organisational implementation of customer relationship management (Coviello, Brodie, Danaher, \& Johnston, 2002). The nature of a customer relationship in a business-to- 
consumer context, however, implies and in fact requires mutual involvement of both an organisation and consumer.

As co-producers of value (Gruen, et al., 2000; Prahalad \& Ramaswamy, 2004; Sheth \& Parvatiyar, 1995; Veloutsou, Saren, \& Tzokas, 2002) consumers necessarily must be active participants in customer relationships. Accordingly, the manner in which consumers choose to form customer relationships becomes a significant consideration. The importance of a consumer perspective on relationship marketing is acknowledged within the extant literature (Fournier, 1998; Garbarino \& Johnson, 1999). Research in this area needs to be advanced so that marketers can better understand how consumers participate in the development and maintenance of customer relationships, as well as the outcomes of such relationships. Customer relationships are formed between individual consumers and brands, with certain brands perceived as being active relationship partners (Aggarwal, 2004; Fournier, 1998). The sending and receiving of messages between an organisation and end consumers in a process of communication, therefore, represents an essential element in the formation of customer relationships (Duncan \& Moriarty, 1998; Gronroos, 2004; V Liljander \& Roos, 2002). Consequently, brand representatives engage in the development and maintenance of a customer relationship by sending messages to consumers, as well as receiving and responding to consumer messages. Consumers correspondingly engage in the development and maintenance of a customer relationship by receiving such messages and sending messages of their own. Consumers can be noted as actively participating in customer relationships by responding to and initiating communication regarding a brand. Such communication response and initiation by a consumer is referred to as interactive communication (Ballantyne, 2004; Gronroos, 2004), and typically occurs between a consumer and a brand.

Accordingly, the development and maintenance of customer relationships in a business-toconsumer context will involve the flow of communication between an end consumer and brand. In addition to communication with a brand, interactive communication regarding a brand also occurs amongst consumer communities. Consumer communities comprise other consumers and third party commentators, such as brand review and comparison services (Marketing Science Institute, 2007). As consumers increasingly become co-creators of value (Prahalad \& Ramaswamy, 2004), the communication they participate in regarding a brand with consumer communities is likely to influence the formation of customer relationships between themselves and a brand. The communication flows regarding a brand between a consumer and brand, as well as amongst consumer communities, are illustrated in Figure 1 below. 
Figure 1. Communication Flows Regarding a Brand

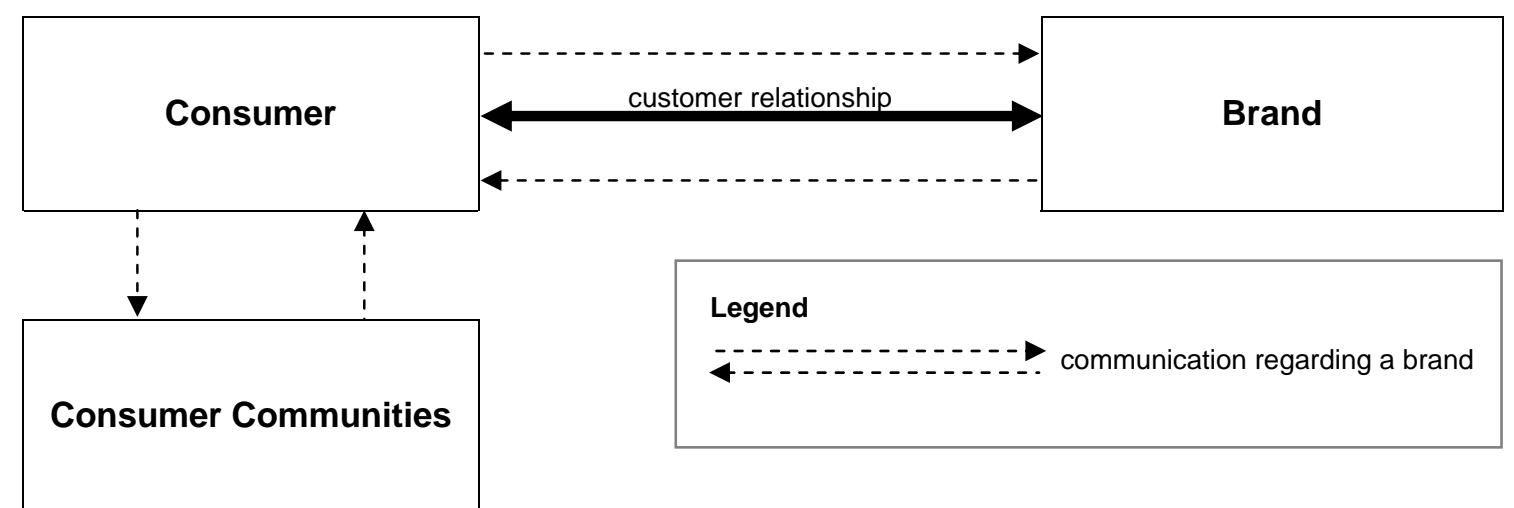

Interactive communication, acknowledged as improving the quality of customer relationships (Gronroos, 2004), can be facilitated by both Internet based and non-Internet based media. Internet based media include all media enabled via the common protocol of the Internet. NonInternet based media comprise interpersonal communications, either face-to-face, paper based, or via telephone. The facilitation of marketing activity intended to develop and maintain relationships by Internet based media has received considerable attention within the marketing literature (O'Leary, Rao, \& Perry, 2004; Rowley, 2001). This may be attributed to an increase in the number of Internet based marketing media, as well as growth in spending. For example, in New Zealand online advertising expenditure was \$53 million during the first quarter of 2010; an increase of 12 per cent 2009 (Interactive Advertising Bureau New Zealand, 2010). It has been suggested that organisations can develop and maintain customer relationships through such media (Day \& Montgomery, 1999; Peterson, Balasubramanian, \& Bronnenberg, 1997). However, a formal examination of a consumer perspective regarding the development and maintenance of customer relationships through Internet based media is needed. It is foreseen that the interactive communication facilitated by Internet based and non-Internet based media that a consumer engages in, will in aggregate increasingly affect the development and maintenance of customer relationships. Furthermore, advertising regarding a brand, sent from a brand and received by a consumer, must continue to be considered. Although advertising is not in itself interactive, given that a consumer receives but cannot respond directly to such communication, their evaluation of advertising is nevertheless likely to influence the brand relationship. Consequently, it is of interest to consider how all the forms of communication that a consumer engages in regarding a brand influence a customer relationship.

In examining the process by which consumers develop and maintain customer relationships, the consumer's emotional connection with a brand is a significant consideration. While it is acknowledged that consumers form relationships with brands (Fournier, 1998) and that brands strive to achieve connection with consumers (Marketing Science Institute, 2007), there 
are uncertainties regarding how a consumer's connection with a brand can be measured. A consumer's self-image is maintained or enhanced by brands with an image perceived as similar to their own (Dolich, 1969). As such, self congruence may help determine connection with a brand. However, although consumer self-image has been successfully determined within the extant literature (Dolich, 1969; M. J. Sirgy, Grewal, Mangleburg, Park, Chon, Claiborne, Johar, \& Berkman, 1997) consumers may be unable or unwilling to articulate their self-image for a specific product or service category (Aaker, 1999). A consumer's connection with a brand may, therefore, be determined by the extent to which the consumer perceives that a brand's personality aligns with their ideal brand personality for a category. Furthermore, it is plausible that the communication a consumer engages in regarding a brand influences this connection with the brand. This is a research area that requires further investigation.

A consumer's connection with a brand is likely to influence relationship quality; relationship quality reflecting a consumer's evaluative judgement regarding the excellence or otherwise of a relationship. The link between a consumer's connection with a brand and relationship quality may be influenced by the extent to which the consumer favours being involved in customer relationships in the product or service category. It is recognised that consumers vary in the extent to which they favour being involved in customer relationships with brands depending on their 'relational orientation' (Garbarino \& Johnson, 1999). The literature implies that organisations can benefit from a transactional or relational focussed approach to consumer exchanges depending on their target consumers' favourability towards having a customer relationship (Coviello, et al., 2002; Garbarino \& Johnson, 1999; Pels, Coviello, \& Brodie, 2000). It is, therefore, of value to establish the extent to which an organisation's target consumers favour and engage in customer relationships. There is also a call to link the development and maintenance of customer relationships to financial outcomes (Keller \& Lehmann, 2006). It would, accordingly, be worthwhile to determine the consequences of customer relationships for brand owners. The literature recognises a consumer perspective regarding relationship marketing (Fournier, 1998), but not explicitly the process through which consumers participate in relationships. This research addresses the gap by examining how various forms of communication consumers participate in regarding a brand influence their connection with the brand, as well as the consequences of customer relationships for brand owners.

\section{$1.3 \quad$ Research Value}

The following paragraphs discuss the specific value of the research. Given the importance of a consumer perspective towards customer relationships with brands (Keller \& Lehmann, 2006) the examination of the process by which consumers participate in the development and maintenance of relationships provides an invaluable research opportunity. This research 
considers the role of communication in customer relationships by providing insight into how consumers form relationships with brands through communication. In addition to offering findings concerning the process by which consumers form relationships with brands, this study acknowledges the consequences of customer relationships for brand owners. A consistent and tested instrument to measure the communication that consumers engage in regarding a brand is created. The research also investigates the influence of a consumer's connection with a brand upon the overall relationship quality between the consumer and brand, as well as the effect of a consumer's relational orientation. In doing so, this study assists researchers and marketing practitioners in developing knowledge of customer relationships from a consumer perspective.

In further examining the process by which consumers develop and maintain relationships through communication, the research provides a measure of a consumer's connection with a brand, as well as the quality of a customer relationship. According to the Marketing Science Institute (2007) customers have increasing opportunity to switch brands, therefore, practitioners are interested in creating and sustaining emotional connections with their brands. Although congruity between a consumer's self-image and the perceived image of a brand is recognised as influencing consumer behaviour (Dolich, 1969; Graeff, 1996), image congruity and connection with a brand have not been specifically examined in the context of consumer relationships. The research anticipates that connection with a brand is an important part of the process by which relationships are developed and maintained. Research regarding the outcomes of customer relationships for brand owners is also acknowledged as being important (Keller \& Lehmann, 2006). An instrument was therefore developed to assess a consumer's favourability towards being involved in customer relationships in a product or service category, in addition to the outcomes of relationship quality for the owners of brands.

Although some significant work in this area is acknowledged (Aaker, et al., 2004; Fournier, 1998), this research intends to provide a more complete understanding of how consumers form relationships with brands. Two research strands pertinent to relationship marketing from a consumer perspective are extended. From an examination of the literature a new conceptual model with well defined and measurable variables, as well as empirically testable propositions (Varadarajan, 1996), is presented. New constructs capturing the various forms of communication that consumers engage in regarding a brand are conceptually defined, including; Brand Advertising, Communication with the Brand, and Communication with Consumer Communities. A consumer's Relational Orientation is also conceptually defined. Similarly, the variable of Relationship Quality is defined from a consumer perspective in a branding context. Secondly, the research tests theoretical linkages between constructs (Summers, 2001). The linkage between a consumer's connection with a brand and the quality of a relationship had, prior to this study, not been established. This is also true of the linkage between the quality of a relationship and consumer determined loyalty. Accordingly, value is 
provided by determining the linkage between Relationship Quality and the constructs of Brand Personality Connection and Customer Brand Loyalty.

\section{$1.4 \quad$ Research Objectives}

This research seeks to examine the manner in which consumers form relationships with brands. In doing so, it considers the process by which consumers connect with a brand. Specifically, it is anticipated that the communication a consumer participates in concerning a brand affects the consumer's connection with the brand. Such a connection with a brand, as perceived by the consumer, is further expected to directly influence the quality of a relationship and ultimately customer brand loyalty. The following section identifies two key objectives of the research.

\subsubsection{Primary Research Objective}

Consumers engage in various types of communication regarding a brand. Communication sourced from a consumer, in response to communication received or otherwise, is identified as interactive communication (Ballantyne, 2004; Gronroos, 2004). Interactive communication between parties is believed to improve the quality of customer relationships (Gronroos, 2004). The interactive communication between consumers and brands, as well as consumer communities, is examined from a consumer perspective. Interactive communication can be both positive and negative. Therefore, a consumer may engage in interactive communication with another party that is positive and/or negative in nature. It is expected that positive interactive communication will improve a consumer's connection with a brand, but that interactive communication that is negative in nature will have a contrary influence. A consumer can also engage in interactive communication regarding a brand through both Internet based and non-Internet based media. It is recognised that organisations can improve the quality of customer relationships through media that is Internet based (Day \& Montgomery, 1999; Peterson, et al., 1997). This is because Internet based media is well suited to the development and maintenance of customer relationships. It is not well known, however, how the interactive communication that a consumer participates in regarding a brand, facilitated by different media channels, affects a customer relationship. In addition, it is expected that a consumer's evaluation of a brand's advertising, will affect a consumer's sense of connection with the brand. Accordingly, the type, frequency, nature, and channel of communication that a consumer participates in regarding a brand are anticipated to influence a customer relationship. The primary objective of the present research is, therefore, to investigate how consumers participate in the development and maintenance of a customer relationship through communication, in all of its forms. 
A research question follows regarding how consumers participate in the development and maintenance of customer relationships through communication. It is foreseen that the process by which a relationship is formed requires a consumer to be emotionally connected to a brand. In this instance, a connection between a consumer and a brand occurs when the perceived personality of the brand aligns with a consumer's ideal brand personality for a product or service category. This connection between consumer and brand is likely to be affected by the communication that a consumer engages in regarding a brand. Furthermore, it is acknowledged that the communication that consumers engage in regarding a brand varies in type, frequency, nature, and channel. Thus, the principal research question addresses how the communication a consumer participates in regarding a brand influences consumer connection with the brand. Do certain forms of communication that a consumer participates in regarding a brand have more or less influence on their brand connection?

\subsubsection{Secondary Research Objective}

The research also looks to link the benefits of consumer determined relationship quality to a brand. This makes the research results pertinent for brand owners. It is, ultimately, foreseen that the quality of a customer relationship impacts upon the performance of a brand. Brand performance, in this study, is determined by customer brand loyalty. A consumer's connection with a brand is expected to directly influence relationship quality. Therefore, relationship quality is indirectly influenced by the communication that a consumer participates in regarding a brand. A consumer's favourability towards being involved in customer relationships with brands in a product or service category, or relational orientation (Garbarino \& Johnson, 1999), may also moderate the linkage between brand personality connection and relationship quality. Accordingly, all research constructs are anticipated to either directly or indirectly influence customer brand loyalty. A secondary research objective is, therefore, to examine the consequences of customer relationships for the owner of a brand. This ensures that the research is of relevance to brand owners and fulfils the need for strategy to be associated with marketing metrics (Marketing Science Institute, 2007). In addressing the objectives discussed the research recognises a consumer perspective regarding the process by which customer relationships are developed and maintained, while also acknowledging the outcomes of relationships for brand owners.

Communication is expected to directly influence the consumer's connection with the brand. The extent to which engaging in communication regarding a brand is conscious and intentional consumer behaviour is not well understood. Deliberate or not, such communication is almost certainly significant in the development and maintenance of customer relationships. It is expected that a consumer's connection with a brand subsequently influences the quality 
of a customer relationship. Relationship quality reflects a consumer's evaluation regarding the excellence of a relationship and is comprised of several dimensions. Furthermore, the linkage between a consumer's connection with a brand and relationship quality may be moderated by the extent to which a consumer favours being involved in customer relationships in a product or service category. This is referred to as a consumer's relational orientation (Garbarino \& Johnson, 1999). Accordingly, a second research question addresses how connection with a brand influences relationship quality. To what extent does a consumer's connection with a brand influence perceived relationship quality, and what is the impact of a consumer's relational orientation on the process by which brand relationships are formed?

Although the present research focuses upon the process by which consumers participate in the development and maintenance of customer relationships, it is important to acknowledge the consequences of relationships for brand owners. It is intended that the significance of consumer participation in customer relationships will be emphasised through the association of relationship quality with brand performance. In this way marketing strategy will be aligned with quantifiable outcomes. Brand performance can be measured by a number of marketing metrics. In this research brand performance is determined by customer brand loyalty. A third research question, therefore, addresses how customer relationship quality influences the performance of a brand. Ultimately, how does a consumer's perceived relationship with a brand impact upon customer brand loyalty?

\subsection{Introduction Summary}

Chapter one has introduced the central research area, clearly identifying that it is a fusion of relationship marketing and branding theory. The significance of the research has also been discussed, highlighting its impact on marketing theory and practice. Varying aspects of the process by which consumers form relationships with brands have been discussed and, ultimately, it has been shown that consumer involvement in customer relationships with brands through a process of communication is worthy of consideration. In addressing the identified research objectives and successive questions, this thesis takes the following structure. A review of current literature concerning the key concepts addressed by the research is conducted in chapter two. This review thoroughly examines the specific areas of literature brought together in the study, as well as important author perspectives. Chapter three then identifies the conceptual model and construct definitions. Subsequently, an appropriate research methodology is reviewed in chapter four, as well as data analysis techniques in chapter five. Finally, results are considered and the findings are discussed in chapter six. 


\subsection{Literature Review}

The following chapter comprises a review of current literature regarding the key concepts addressed by the research. While this is a thorough examination of the literature, its scope is limited to work relevant to the research objectives and questions. Consequently, literature at the interface of relationship marketing (RM), customer relationship management (CRM), and branding theory is discussed. The diagram in Figure 2 below provides a visual representation of the structure of the literature review for this study.

Figure 2. Literature Review

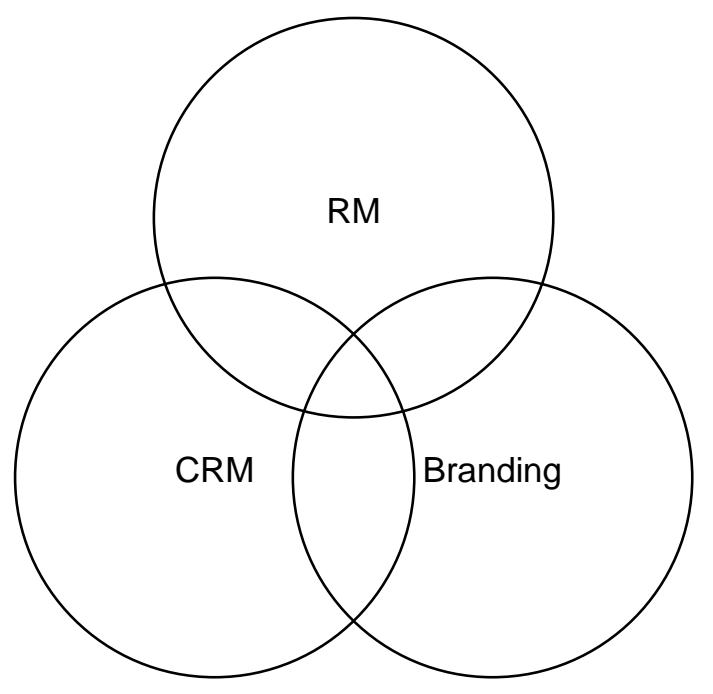

The intention is to identify key theory and concepts relevant to the research. With an overarching relationship marketing focus, sections 2.1 to 2.3 of the review intitally explore the origins of RM theory as well as its domain. Section 2.4 then examines customer relationship management between organisations and consumers; highlighting that extant CRM literature predominantly adopts an organisational approach to relationships. Subsequently, sections 2.5 and 2.6 explore a consumer perspective of relationships, as well as how consumers evaluate relationships with brands. The manner in which consumers participate in relationships with brands through various forms of communication is then discussed in sections 2.7 and 2.8 . Once the development and maintenance of customer relationships through communication is discussed, attention is placed on the Internet. As a relatively recent and evolving media by which consumers can communicate regarding brands, sections 2.9 to 2.13 of the literature review identify consumer communication via the Internet and new opportunites for forging relationships. Finally, a summary of findings from the literature is provided in section 2.14 . 


\section{$2.1 \quad$ Relationship Marketing}

Relationship marketing involves the development and maintenance of relationships between an organisation and other marketplace parties in an attempt to support ongoing exchanges. Although its definition and origins are debated the establishment and strengthening of relationships is regarded as beneficial to the success of many organisations (Day \& Montgomery, 1999; Gronroos, 1994; Gummesson, 1997; McKenna, 1992; Morgan \& Hunt, 1994; Webster, 1992). This includes the development and maintenance of relationships between an organisation and end consumer in a business-to-consumer context (Garbarino \& Johnson, 1999; O'Malley \& Tynan, 2000; Sheth \& Parvatiyar, 1995). It is suggested that a process of communication between parties is critical to relationship building (Duncan \& Moriarty, 1998). Accordingly, relationships between organisations and consumers may be fostered through the sending and receiving of messages. The sending and receiving of communication with the intention of developing and maintaining a customer relationship is one, arguably salient, relationship marketing activity. Other examples of relationship marketing activities include customer profiling (O'Leary, et al., 2004), database management (Day \& Montgomery, 1999), and product or service customisation (Bardakci \& Whitelock, 2003). The nature of a relationship implies that both consumers and organisations will identify value in any customer relationship (Ravald \& Gronroos, 1996). The literature examines a consumer perspective of relationship marketing (Fournier, 1998; Garbarino \& Johnson, 1999; V Liljander \& Roos, 2002), if not explicitly through a process of communication. Consumers vary regarding their involvement in customer relationships (Day, 2000). Therefore, it is likely that they differ in the extent to which they engage in communication intended to develop and maintain a customer relationship. In accordance with a mid-range perspective of relationship marketing (Coviello, et al., 2002), organisations may need to adopt a more relationship or transaction focussed approach to marketing depending on the communication that their target consumers engage in.

Two viewpoints regarding the development of relationship marketing are evident within the literature. What could be referred to as 'the European perspective' suggests that a relationship approach to marketing interactions has existed for as long as trade and commerce have taken place (Gronroos, 2004). However, what has been described as 'the North American perspective' suggests that relationship marketing was introduced during the early 1980s in response to changing market conditions. Some European authors recognise that before the term 'relationship marketing' was used within the literature a relationship marketing perspective existed in what is acknowledged as the Nordic School of Thought (Gronroos, 1980, 1983; Gummesson, 1983, 1987). The Nordic School is renowned for its predominant focus on relationships within a services context and appeared in the late 1970s in response to perceived limitations with a transactional approach to marketing (Palmer, Lindgreen, \& Vanhamme, 2005). The notion of relationship marketing is also identified as an 
integral component of industrial marketing thought originating from the European based IMP, Industrial or International Marketing and Purchasing Group (Hakansson, 1982; Hakansson \& Snehota, 1995). The IMP Group also emerged in the 1970's and is acknowledged for focussing on marketplace relationships based on continual engagement, rather than isolated transactions (Palmer, et al., 2005). Gronroos (1994) indicates that industrial marketers have long recognised the benefit of ongoing relationships, as time spent on each sale is made worthwhile due to the potential size of business-to-business exchanges. Service marketers have similarly acknowledged the need for an organisational culture built on customer relationships due to a high customer interface level. Notable European scholars are in agreement that relationship marketing is a gradual extension of the Nordic School approach to services marketing and the network approach to industrial marketing as developed by the IMP Group (Gummesson, 1997; V Liljander \& Roos, 2002).

The North American School of Thought has a differing view regarding the evolution of relationship marketing. Whereas European academics formally acknowledge the advance of the concept in the 1970's, through the Nordic School and IMP Group, North American academics recognised relationships in the literature over a decade later. Scholars from North America are noted as focussing on consumer transactions up until the early 1980s (Palmer, et al., 2005). Webster (1992) notes that the marketing literature from North America throughout the 1970s identified transactions as a central construct and basic unit of analysis used in assessing marketing activity. This transactional view of marketing, or micro-economic perspective, sees firms connected to customers through isolated transactions rather than ongoing relationships (Webster, 1992). During the 1980's, however, North American scholars deemed the perception that marketing is a series of profit maximising transactions to be narrow and out of touch with a focus on long-term customer relationships (Webster, 1992). It was realised that most transactions take place in the context of ongoing relationships and the term 'relationship marketing' was introduced in a 1983 conference paper, regarding the marketing of services (Berry, Shostack, \& Upah, 1983). Consequently, the large, vertically integrated corporate structures, that were the dominant organisational form in North America at the time, dissolved in favour of smaller firms with a relationship focus (Webster, 1992).

\subsection{The Relationship Marketing Paradigm}

Despite their differences, significant European and North American academics agree that a relationship perspective needs to be considered in conjunction with the marketing mix approach advocated within traditional marketing theory (Gronroos, 1994; Gummesson, 1997; Kotler, 1992; Webster, 1992). The marketing mix concept and the Four P's of marketing were recognised in the 1960's and swiftly became treated as the unchallenged basic model of the marketing discipline. As a result this model is now firmly entrenched within the marketing 
literature and it has been suggested that only modest acceptance is given to any theories that stray from its path (Gronroos, 1994). In addition, it is identified that the rationale behind the Four $\mathrm{P}$ (place, price, product, and promotion) categories of the marketing mix has never been adequately articulated, other than for its convenience of use (Gronroos, 1994). Other writers suggest that the marketing mix paradigm is theoretically based on a loose foundation (Van Waterschoot \& Van den Bulte, 1992). It is also implied that the implementation of the marketing mix is an oversimplification that sees the marketer as an individual who should utilise different resources in a 'toolbox' to complete various marketing tasks (Gronroos, 1994). The marketing department is essentially isolated from the rest of the firm as they are viewed as the only organisational members equipped with the tools of the marketing discipline.

Furthermore, the marketing mix sees marketers as being distanced from the consumer, utilising their marketing mix tools as the only link between the organisation and other marketplace contacts. The needs and importance of the customer may not be fully acknowledged and the organisation is viewed as the primary authority of marketing exchanges. It is suggested that according to the marketing mix paradigm the customer has no personalised relationship with the marketer of a product (Gronroos, 1994). Day and Montgomery (1999) agree that the one-off transactional focus of the marketing mix is dated; identifying that marketing has shifted its emphasis from transactional to relational exchanges. McKenna (1992) also shares this view, commenting that company-centred marketing approaches are ineffective and that organisations should adopt what the author terms 'a customer-centred approach' to marketing. The marketing mix conceptualises the marketer as an influencer of passive consumers (Gronroos, 1994). However, in reality consumers cannot be viewed as though they are an element open to manipulation. Although the marketing mix is important, it is recognised that there needs to be a shift of focus more towards that of longer term relationship marketing (Gronroos, 1994; Kotler, 1992).

Relationship marketing's different perspective from the marketing mix has been illustrated through what is termed 'the marketing strategy continuum'. According to Gronroos (1994) relationship marketing exists at one end of the marketing strategy continuum and transactional marketing at the other. Relationship marketing concentrates on linkages, cooperative exchanges, mutual understanding, and long-term interaction. While transactional marketing is the polar opposite, with an emphasis on one-off exchanges, a product orientation, and independence from others. The notion of a continuum implies that there is a middle ground in which an organisation may demonstrate elements of both transactional and relationship marketing. Therefore, any given organisation can potentially place itself along the relationship marketing continuum depending on how it prioritises its marketing efforts. Kotler (1992) describes a similar relationship continuum offering five levels of relationship marketing. These five levels include Basic, Reactive, Accountability, Proactive, and Partnerships. At a Basic level it is proposed that organisations do not really involve themselves with building 
relationships, however, a Partnership perspective sees the organisation existing intimately with the customer (Kotler, 1992). At the levels in between Basic and Partnership relationships organisations are described as starting to answer their customers' queries, finding out from the customer what they can do better, and beginning to solve customer problems before customers themselves are aware of them. Webster (1992) supports the marketing strategy continuum, providing a range of marketing relationships including singular transactions, longterm relationships, and vertical integration. Rao and Perry (2002) note that relationship marketing is the opposite of transaction marketing and offer a distinction between transactional marketing: a single exchange with a beginning and ending, and a relationship perspective: "multiple linked exchanges extending over time [that] usually involves both economic and social bonds" (Rao \& Perry, 2002, p. 598).

An alternative perspective to that of a relationship marketing continuum and the dichotomy of relationship and transactional marketing is offered by Coviello, et al (2002). It is suggested that in practice transactional and relational marketing are not mutually exclusive opposites (Coviello, et al., 2002). This notion has been referred to as a 'mid-range perspective' of relationship marketing. Coviello, et al (2002) empirically examined such a mid-range perspective by identifying the relative emphasis of relational and transactional marketing within various types of organisations. The authors established that in practice many firms concurrently implement different aspects of relationship marketing as well as transactional marketing. It was, therefore, concluded that both transactional and relationship marketing approaches are important components of many firms' business practice. Transaction marketing may, for example, be used to attract customers, database marketing may be incorporated to target selected customer groups, and interaction marketing can be employed to build interpersonal relationships with customers. Palmer, et al (2005) also acknowledge a mid-range perspective whereby relationship marketing is not as substitute for transaction marketing. These authors agree that relationship and transaction marketing are practiced concurrently depending on the context in which an organisation operates.

It is suggested by some academics that the notion of relationship marketing has been extended to the point where relationship marketing is regarded as a new marketing paradigm (Aijo, 1996; Gronroos, 1994; Kotler, 1992; Veloutsou, et al., 2002). However, it is apparent within the relationship marketing literature that this is not a universal standpoint. Gummesson (1997), for example, disputes that there has been a fundamental shift in marketing, recognising that "RM is a new term but an old phenomenon" (Gummesson, 1997, p. 268). It is suggested that relationship marketing may be increasingly appropriate, but that the concept is only new in the fact that it has been relatively recently formally recognised within the literature. However, the importance of relationship marketing is not dismissed. Rather, further grounded theory in the field is called for. Brodie, et al (1997) and Rao and Perry (2002) support the perspective that perhaps relationship marketing has not brought about a 
paradigm shift. It is agreed that an emphasis on relationships has existed for many years and that in practice a relationship marketing approach has not replaced transactional marketing. In accordance with the mid-level perspective of relationship marketing presented by Coviello, et al (2002), it is recognised that many businesses simultaneously practice transactional and relationship marketing. If not an absolute paradigm change, authors acknowledge that there has at least been a shift in emphasis to relationships and the retention of valuable customers (Day \& Montgomery, 1999). Zineldin (2000) agrees, identifying that "marketing thought is shifting from an emphasis on transactions and acquisition to relationships and customer retention" (Zineldin, 2000, p. 11). It is conceded that relationship marketing may not be a new paradigm as such, "however, there appears to have been a fairly long period of time when it was not a top priority" (Webster, 1992, p. 6); at least from a North American perspective. Regardless, however, of whether or not there has been an underlying paradigm shift towards relationship marketing, it is recognised by many authors that relationship marketing is an increasingly important organisational consideration.

\subsection{Relationship Marketing Definition}

Although significant attention has been given to relationship marketing within the marketing literature there lacks a universally accepted definition of the concept. Accordingly, various interpretations regarding relationship marketing can be identified within the extant literature. A highly cited definition of relationship marketing is that of Morgan and Hunt (1994). These authors acknowledge relationship marketing as "all marketing activities directed towards establishing, developing, and maintaining successful relational exchanges" (Morgan \& Hunt, 1994, p. 20). While useful this is a broad definition of relationship marketing which could be interpreted to encompass all of an organisation's marketing activities. It also raises a question as to what a relational exchange refers to. Numerous authors contrast relational with transactional exchange (Gronroos, 1994; Kotler, 1992; Rao \& Perry, 2002). At its simplest relationship marketing may therefore be regarded as ongoing, repeated exchanges rather than independent, isolated transaction, between at least two parties within a marketplace. A relationship is the perceived linkage between the parties which supports ongoing exchange. Exchange between the parties within a relationship may involve the giving and receiving of anything that the parties deem of value (Day, 2000; Ravald \& Gronroos, 1996). Such exchange does not necessarily need to be of a product or service. It is suggested that relationships require at least two parties who interact with each other (Gummesson, 1994). Other authors agree that "as the exchange of product is the core of transaction marketing, the management of an interaction is the core of relationship marketing" (Gronroos, 2004, p. 100). Thus, exchange in this context comprises the ongoing passing of value to and from the parties involved in a relationship. 
Relationship marketing is defined as an attempt "to establish, maintain, and enhance relationships with customers and other parties, at a profit, so that the objectives of the parties involved are met" (Gronroos, 1994, p. 9). Notably this author also raises the notion that each party benefits from their involvement in the relationship. This mutually beneficial nature of a relationship implies that the linkages formed between parties provide value to all concerned. Following an examination of numerous relationship marketing definitions, Harker (1999) concludes that "an organisation engaged in proactively creating, developing and maintaining committed, interactive and profitable exchanges with selected customers (partners) overtime is engaged in relationship marketing" (Harker, 1999, p. 16). Like Gronroos (1994) and Morgan and Hunt (1994), Harker (1999) includes the concept of network exchange within his definition of relationship marketing. It is believed that relationship marketing involves the maintenance of relations between the company and the actors in its micro-environment (Ravald \& Gronroos, 1996). Relationship marketing therefore includes mutually beneficial linkages between numerous marketplace parties, or networks. Gummesson (1997) recognises that an organisation may be involved in some thirty marketplace relationships and suggests that relationship marketing encompasses all possible network interactions. Relationship marketing includes relationships with both internal and external stakeholders and therefore the organisation itself and society are included in a network of relationships (Gummesson, 1996). Relationship networks can be thought of as three-dimensional webs. Each point where the web crosses represents a party within the marketplace, such as the organisation, a supplier, customer, or other business contact. The web itself represents the relationships between each party. It becomes apparent that the relationship web that exists within any given marketplace will be very intricate and complex and as such organisations are charged with the task of establishing, developing, and maintaining marketing relationships with a great number of contacts. Morgan and Hunt (1994) present ten forms of relationships between network parties that can be grouped to include relational exchanges that involve: suppliers, lateral organisations, customers, an organisation's own employees, and business units. Webster (1992) further suggests that collaborative relationships should be formed with rivals to stimulate innovative new product development. Coviello, et al (1997) recognise that exchange occurs across organisations, where firms commit resources to develop relationship. Consequently, relationship marketing may involve many parties linking together in a network that is beneficial to all concerned.

\subsection{Customer Relationship Management}

The network approach to relationship marketing suggests that an organisation may develop and maintain relationships with many parties within its market system (Gummesson, 1997; Morgan \& Hunt, 1994; Webster, 1992). However, customer relationship management refers specifically to the development and maintenance of relationships between organisations and 
customers. Two types of customer relationship are considered within the extant literature; those between two businesses and those between a business and end consumer. The concept of relationship marketing has been recognised as originating in European industrial purchasing (Gronroos, 1994; Gummesson, 1996) and is, therefore, traditionally associated with a business-to-business context. Accordingly, customer relationship management is examined both conceptually (Webster, 1992) and empirically (Morgan \& Hunt, 1994) within the business-to-business marketing literature. It is also recognised that relationship marketing has foundations within the Nordic School of services marketing (Palmer, et al., 2005). It is suggested that relationships with all customers are an essential component of such a servicecentred dominant logic (Vargo \& Lusch, 2004). Relationship marketing is consequently acknowledged in a business-to-consumer context. The development and maintenance of relationships between organisations and end consumers has been examined more explicitly in other literature (Garbarino \& Johnson, 1999; V Liljander \& Roos, 2002; O'Malley \& Tynan, 2000; Sheth \& Parvatiyar, 1995). Following in this tradition, the focus of the current research is on the development and maintenance of customer relationships between businesses and final consumers. Consumers being individual end users, rather than intermediaries, with whom relationships are forged.

Customer relationship management, therefore, comprises the development and maintenance of relationships between businesses and end user consumers. The mutual nature of customer relationships implies that the consumer must be involved in such relationships in order for them to manifest. Consumers are acknowledged as active co-producers of value throughout numerous marketing processes (Gruen, et al., 2000; Sheth \& Parvatiyar, 1995; Veloutsou, et al., 2002). Accordingly, the concept of co-production, prevalent in industrial marketing theory (Wikstrom, 1996), is applicable in a consumer context. Co-production is regarded as a voluntary behaviour on behalf of a consumer (Gruen, et al., 2000) that contributes towards the creation of value for the consumer themselves, as well as the organisation. Such coproduction may involve any number of activities (Gruen, et al., 2000) and is recognised as occurring during the design, production, and consumption of an organisation's offering (Wikstrom, 1996). The concept of co-production is particularly relevant in customer relationships. Gruen, et al (2000), for example, acknowledge that in long-term relationships customers go beyond consuming products to become co-producers who participate in value creation. This co-production, or co-creation, of value is noted as occurring in service settings in which consumers participate in communication regarding a brand with various groups (Prahalad \& Ramaswamy, 2004). Consumer co-production typically occurs in the process of communication between a consumer and organisation. Without the consumer such communication cannot take place. The consumer is needed to receive, respond to, and initiate communication. Consequently, consumer participation is significant in the development and maintenance of customer relationships through communication. 


\section{$2.5 \quad$ Customer Relationships with Brands}

Furthermore, it is acknowledged that consumers develop and maintain relationships with brands (Aggarwal, 2004; Fournier, 1998; Jevons, Gabbott, \& de Chernatony, 2005; Muniz \& O'Guinn, 2001). As consumers experience brands they recognise them as active relationship partners (Woodside, 2004). Subsequently, it is with brands that consumers forge a relationship. Aggarwal (2004) suggests that although relationships are generally formed between people, consumers interact with brands in ways that closely mirrors their social interactions. Consumers may appreciate that brands are owned and controlled by organisations; however, they often do not make a distinction between a brand and a brand owner. The brand and the organisation are perceived as the same. One explanation of this refers to literature concerning animism (Aggarwal, 2004) or anthropomorphisation (Patterson \& O'Malley, 2006), which suggest that consumers treat brands as possessing human-like characteristics. Consumers may perceive that they have social relationships with brands that are seen as having human qualities. Consequently, individual consumers form many different types of relationships with brands (Fournier, 1998) which influence consumer behaviour and attitudes in response to brand actions (Aggarwal, 2004). It is recognised that the notion of consumers developing and maintaining relationships with brands is not without criticism (Aggarwal, 2004). Social judgments regarding people may be made differently to non-social judgements made concerning brands. Kardes (1986), for example, provides several reasons why non-social judgements made by consumers differ to social judgements. These include that people often use themselves as a frame of reference when judging others, a reference that cannot be used when assessing non-social stimuli, and that social stimuli are dynamic in nature and therefore constantly changing (Kardes, 1986). Despite such reservations, it is accepted that although brand relationships may not be as rich as relationships with people, consumers behave as though they have relationships with brands (Aggarwal, 2004).

The consumer must perceive a higher value from being involved in the relationship with the brand than would be achieved were the relationship not to exist (Ravald \& Gronroos, 1996). Should there be a low perceived relationship value a consumer may desire not to be in a customer relationship with the brand. The value that a customer perceives they are receiving from involvement in a relationship is regarded as the perceived benefits that the customer obtains in relation to the perceived sacrifice that they must make when engaging in exchange (Gronroos, 2004). This is developed from a definition of customer perceived value offered by Day (1990) of customer perceived benefits relative to perceived costs. Perceived value is attributed to both the current exchange episode and the overall relationship (Ravald \& Gronroos, 1996). Overall customer perceived relationship value may, therefore, be increased by either enhancing the perceived benefits or decreasing the perceived sacrifice of the consumer. The perceived benefits to the customer of a long-term relationship with an 
organisation can include safety, credibility, and security. An organisation may attempt to increase the perceived benefits of a relationship by adding something to the core product that the customer perceives important (Ravald \& Gronroos, 1996). The perceived sacrifice to the consumer of being involved in a relationship includes direct costs, such as financial sacrifice and time, as well as psychological costs, acknowledged as cognitive effort such as worry that the consumer may incur throughout an exchange (Ravald \& Gronroos, 1996). A consumer will, therefore, receive a level of perceived value from being involved in a relationship with a brand.

Day (2000) acknowledges that some customers want nothing more than exchange with a minimum of hassles. In accordance with the marketing strategy continuum (Gronroos, 1994), consumers who desire not to be involved in relationships with brands could be said to desire more transactional exchanges. Therefore, consumers may vary in their favourability towards being involved in customer relationships with brands. Such consumer favourability towards being involved in relationships with brands is acknowledged in the literature. Fournier (1998), for example, recognises that consumers engage in customer relationships to various levels. Investigating consumer relationships with brands, this author provides frameworks for the examination of relationship marketing theory in a business-to-consumer context. Garbarino and Johnson (1999) segment an organisation's customer base according to customer responsiveness to transactional or relational marketing. The authors recognise customers as having, what is regarded as, a high or low relational orientation according to their desire to engage in relational or transactional exchange. Liljander and Roos (2002) similarly discuss the perceived customer benefits of being involved in a relationship with an organisation that the customer would not be offered should exchanges be transactional. It is acknowledged, however, that relationship marketing research from the customer's perspective has been scarce (V Liljander \& Roos, 2002). Consequently, relationship marketing theory would benefit from further research examining consumer involvement in the formation of relationships between themselves and brands.

\subsection{Relationship Quality}

A relationship between parties can be assessed by what is referred to as relationship quality (Crosby, Evans, \& Cowles, 1990; Dorsch, Swanson, \& Kelley, 1998). This includes a customer relationship in a business-to-consumer context (De Wulf, Odekerken-Schroder, \& Lacobucci, 2001), such as between a consumer and a brand. Quality is defined broadly in the marketing literature as superiority or excellence (Zeithaml, 1988). Perceived product quality is defined as a "consumer's judgement about a product's overall excellence or superiority" (Zeithaml, 1988, p. 3). Relationship quality can, therefore, be thought of as an overall assessment regarding the superiority or excellence of a relationship involving exchange 
partners. Relationship quality between a consumer and brand, as perceived by a consumer, is a consumer's evaluative judgement regarding the superiority or excellence of their relationship with a brand. Relationship quality is recognised as a higher-order construct comprised of several first-order dimensions (Crosby, et al., 1990; Dorsch, et al., 1998; Dwyer \& Oh, 1987). Universal agreement does not exist within the extant literature concerning the identification and conceptualisation of these dimensions. Research examining the quality of customer relationships between individual consumers and brands suggests that relationship quality comprises up to eight dimensions. These dimensions include commitment, interdependence, intimacy, love and passion, partner quality, satisfaction, self-connection, and trust (Aaker, et al., 2004; De Wulf, et al., 2001; Fournier, 1998; Garbarino \& Johnson, 1999).

The relationship quality dimension of commitment is regarded as an integral component of any relational exchange (Gundlach, Achrol, \& Mentzer, 1995; Morgan \& Hunt, 1994). Relationships between parties are developed and maintained through repeated exchange over time (Day, 2000; Gronroos, 1994; Gummesson, 1997; Rao \& Perry, 2002). Without relationship commitment, however, this temporal requirement cannot be fulfilled. Dwyer, et al (1987) suggest that this dimension of relationship quality captures the desire to continue a relationship. This is reflected in their definition of relationship commitment as "an implicit or explicit pledge of relational continuity between exchange partners" (Dwyer, Schurr, \& Oh, 1987 , p. 19). This is further developed by authors who conceptualise relationship commitment in a business-to-business setting as including the intention to develop and maintain the relationship, the provision of inputs by exchange partners, as well as a temporal element (Dorsch, et al., 1998; Gundlach, et al., 1995). Although varying conceptualisations of relationship commitment exist within the literature (Dorsch, et al., 1998; Garbarino \& Johnson, 1999; Gundlach, et al., 1995), two central components of relationship commitment are apparent. These include a desire of those involved to continue the relationship, as well as a willingness to make effort to maintain the relationship (De Wulf, et al., 2001; Morgan \& Hunt, 1994). From a consumer perspective relationship commitment, therefore, comprises a desire to continue a relationship with a brand, in addition to making effort with the intention of developing and maintaining the customer relationship.

Customer relationships are also recognised as comprising a degree of interdependence between a consumer and brand (Fournier, 1998). It is acknowledged that relationship interdependence occurs when there is mutual dependency among parties (Kressmann, Sirgy, Herrmann, Huber, Huber, \& Lee, 2006). The consumer, therefore, depends on the brand and the brand depends on the consumer. Consequently, both consumer and brand consider the other to be of high importance. Fournier (1998) recognises that interdependence from a consumer perspective involves frequent brand interactions, increased scope and diversity of brand-related activities, as well as heightened intensity of individual interaction events. In 
research regarding online brand relationships, interdependence is referred to as the degree to which the actions of relationship partners are intertwined (Thorbjornsen, Supphellen, Nysveen, \& Pedersen, 2002). In more recent research the relationship quality dimension of interdependence is determined according to the extent to which a brand plays an important role in a consumer's life (Kressmann, et al., 2006).

Knowledge or understanding concerning a relationship partner, regarded as relationship intimacy, is further recognised as a dimension of relationship quality (Aaker, et al., 2004; Fournier, 1998; Kressmann, et al., 2006; Thorbjornsen, et al., 2002). For a relationship to develop and be maintained individual consumers and brands require a level of knowledge regarding each other. It is identified that consumers develop elaborate knowledge structures around strongly held brands (Fournier, 1998) with the relationship quality dimension of intimacy referring "to the degree of closeness, mutual understanding, and openness between relationship partners" (Thorbjornsen, et al., 2002). Aaker, et al (2004) identify that relationship intimacy is determined according to the perceived depth of consumer understanding exhibited by the brand, consumer understanding of the brand, and consumer willingness to share information toward the goal of more intimate relational ties. Relationship intimacy from a consumer perspective is measured according to the extent to which a consumer thinks they are knowledgeable or understand a brand, as well as believes a brand is knowledgeable or understands them (Aaker, et al., 2004; Thorbjornsen, et al., 2002).

An affective grounding towards a brand is also recognised as being central to brand relationships (Fournier, 1998). This consumer affection towards a brand is referred to in the relationship literature as love and passion (Kressmann, et al., 2006; Thorbjornsen, et al., 2002). As such, love and passion is acknowledged as another dimension of relationship quality. According to Fournier (1998) feelings of love exhibited by consumers towards a brand range from warmth to selfish, obsessive dependency (Fournier, 1998). This dimension of relationship quality is, therefore, determined according to a consumer's perceived feelings towards a brand (Kressmann, et al., 2006; Thorbjornsen, et al., 2002).

According to Fournier (1998) partner quality between a consumer and brand reflects the consumer's evaluation of the brand's performance in its partnership role. Five components to this dimension of relationship quality are identified: a felt positive orientation of the brand toward the consumer, judgements of the brand's overall dependability, reliability, and predictability in executing its partnership role, judgements of the brand's adherence to the various 'rules' composing the implicit relationship contract, trust or faith that the brand will deliver what is desired versus that which is feared, and comfort in the brand's accountability for its actions (Fournier, 1998). The extent to which a consumer perceives a brand fulfils each of the components listed above determines partner quality. 
Relationship satisfaction is conceptualised as an affective state resulting from an overall appraisal of a cumulative relationship (De Wulf, et al., 2001). It is, therefore, an evaluation concerning the extent to which an individual is satisfied with a relationship that they are involved in. Perceived value is recognised as an important aspect of relationship satisfaction (Dorsch, et al., 1998). The more value that an individual perceives they are receiving from being involved in a relationship the more relationship satisfaction they will have. Authors distinguish between transaction-specific satisfaction and cumulative satisfaction (Garbarino \& Johnson, 1999). Transaction-specific satisfaction is recognised as an immediate postpurchase evaluation. Cumulative satisfaction, however, is an overall evaluation based on experience with a brand over time. Consequently, cumulative satisfaction is a more appropriate measure of relationship quality and transaction-specific satisfaction more relevant to transaction-based exchanges. As such, an individual's overall satisfaction with a cumulative relationship is determined by the value that the individual perceives they obtain from being involved in the relationship over time. In a business-to-consumer context relationship satisfaction is, therefore, determined by a consumer's assessment of the value that they receive from having a relationship with a brand.

A consumer's self-connection with a brand is also recognised as a dimension of relationship quality between a consumer and brand (Aaker, et al., 2004; Fournier, 1998). Such selfconnection with a brand is determined by a consumer's perceived alignment between their self-image and the image of a brand. This dimension of relationship quality reflects the extent to which a brand delivers on significant aspects of a consumer's identity and helps express the consumer's self (Aaker, et al., 2004; Fournier, 1998). A consumer's perception regarding whether a brand's image is similar to how they see themselves will, therefore, contribute towards the quality of a customer relationship between the consumer and a brand.

The literature reveals that trust is also a dimension of relationship quality. Trust is an important and much researched component of relationship marketing. However, a number of definitions regarding trust exist within the literature. Such definitions suggest various determinants of relationship trust (Moorman, Deshpande, \& Zaltman, 1993; Morgan \& Hunt, 1994). Despite this, there exists some agreement that relationship trust involves confidence, reliability, and integrity amongst relationship parties (De Wulf, et al., 2001; Dorsch, et al., 1998; Morgan \& Hunt, 1994). Relationship trust is accordingly regarded as "confidence in an exchange partner's reliability and integrity" (Morgan \& Hunt, 1994, p. 23). In addition, there exists varying perspectives concerning the evaluation of relationship trust. Consequently, both trust as a cognitive evaluation and behaviour are discussed within the literature (Moorman, et al., 1993). Although relationship trust has been conceptualised as consisting of both cognitive as well as behavioural elements, a number of authors suggest that cognitive evaluations of relationship trust are necessary and sufficient determinants of the construct (De Wulf, et al., 2001; Morgan \& Hunt, 1994; Sirdeshmukh, Singh, \& Sabol, 2002). As such, relationship trust 
between a consumer and a brand can be determined by the consumer's cognitive evaluation regarding confidence in the brand's reliability and integrity.

\subsection{Communication in Relationships}

Communication is regarded as significantly important in the development and maintenance of relationships (Duncan \& Moriarty, 1998), including relationships between a consumer and a brand. It could be argued that the sending and receiving of communication is a necessary element in the exchange of value. Any product or service exchange, or indeed any interaction, between an organisation and consumer requires a level of communication. Therefore, the establishment, development, and maintenance of relational exchanges (Morgan \& Hunt, 1994) is reliant upon communication between parties. In the absence of communication a relationship cannot develop or be maintained (Duncan \& Moriarty, 1998). A number of authors acknowledge that communication can contribute towards the development of relationships amongst network parties (Duncan \& Moriarty, 1998; Gronroos, 2004; V Liljander \& Roos, 2002). As such, organisations are able to develop and maintain customer relationships through a process of communication.

Four sources of communication intended to develop and maintain a customer relationship that can be sent by an organisation to a consumer through the communication process have been identified (Duncan \& Moriarty, 1998; Gronroos, 2004). These sources include planned, product, service, and unplanned messages. Planned messages are sent by an organisation to the consumer as part of a planned marketing communication process. This includes activities such as advertising, direct marketing, and personal selling. Product messages are conveyed through intrinsic factors such as the design/performance, features, and product processes. Service messages are sent via factors such as service processes, delivery, claims handling, and invoicing. Finally, unplanned messages are messages regarding the organisation that are sent between consumers or sourced from media experts. It is also recognised that an absence of communication may affect a customer relationship (Duncan \& Moriarty, 1998; Gronroos, 2004). According to Gronroos (2004) an organisation is able to develop customer relationships through planned marketing communication in combination with messages conveyed through product and service processes. Product, service, and unplanned messages are received by consumers in conjunction with the planned communication efforts of organisations. Although an organisation has more control over planned messages sent to consumers, customer relationships are also affected by the other messages received by consumers regarding a brand. The current research focuses upon the development and maintenance of customer relationships through planned marketing communication in the form of advertising and interactive brand communication, as well as unplanned brand communication amongst consumer communities. Planned marketing 
communication intended to develop and maintain a customer relationship may be unmediated, and therefore sent and received in a face-to-face context between individuals, or sent via a number of media. A relationship can be studied in terms of episodes, as well as the overall relationship (Gronroos, 2004; Veronica Liljander \& Strandvik, 1997; Woo \& Ennew, 2004). Each relationship comprises a number of relationship episodes. In the context of the development and maintenance of customer relationships through communication, a relationship episode may be the sending and receiving of a message between a brand and consumer or a dialogue between the two parties. The overall relationship is any ongoing perceived linkage. As such, an organisation may be identified as participating in the development and maintenance of a customer relationship by sending communication to a consumer. Correspondingly, a consumer can be regarded as participating in the development and maintenance of a customer relationship by receiving messages from a brand, as well as sending messages of their own concerning the brand. While it is acknowledged that other processes are also likely to impact upon a customer relationship, the present research addresses how consumer communication influences the formation of relationships.

\subsection{Consumer Participation in Relationships}

Communication in a customer relationship requires participation from both a brand and a consumer to be produced. In this way consumers are considered the co-producers of value (Gruen, et al., 2000; Sheth \& Parvatiyar, 1995; Veloutsou, et al., 2002) in the process of communication. The literature suggests that consumers participate in the development and maintenance of customer relationships through numerous forms of communication (Duncan \& Moriarty, 1998; Gronroos, 2004). It is identified that interactive communication is an important aspect of a customer relationship (Ballantyne, 2004; Yadav \& Varadarajan, 2005). Fundamentally, an interactive process of communication comprises the two-way flow of messages between parties. This is also referred to as two-way or bidirectional communication (Andersen, 2001; Mohr, Fisher, \& Nevin, 1996; Mohr \& Nevin, 1990; Yadav \& Varadarajan, 2005). Communication sent from an organisation focussed on the facilitation of transactions, rather than relationships, subjects consumers to one-way messages (Duncan \& Moriarty, 1998). Such one-way communication is facilitated by broadcast media, of which radio and television are examples (Belch \& Belch, 2004), as well as print media and billboards. Marketers send communication to consumers; however, there is no consumer response or initiation of communication. Communication response and shared understanding are regarded as important to relationship formation (Duncan \& Moriarty, 1998; Gronroos, 2004). Therefore, if communication is intended to contribute towards a relationship it should facilitate a response from consumers. Two-way communication has been recognised as permitting the sharing of knowledge between parties (Ballantyne, 2004; Duncan \& Moriarty, 1998). Those 
involved in communication are able to receive knowledge regarding each other, thus fostering a customer relationship.

It is recognised that "feedback is central to two-way communication" (Duncan \& Moriarty, 1998, p. 4). Organisations should therefore practice market sensing in which feedback is received openly, knowledge from feedback is distributed throughout the business, multiple viewpoints within the organisation are used to interpret the knowledge, and knowledge acquired from the feedback is made available for use in future exchanges with customers (Duncan \& Moriarty, 1998). Such market sensing is exhibited in a consumer context by the Amazon.com inference engine which recommends products to customers based on customer profiles (Zeithaml, Parasuraman, \& Malhotra, 2002). A consumer's set of reactions after receiving a message is referred to as their response to the message (Belch \& Belch, 2004). It has been suggested that interaction begins when an action generates a response (Ballantyne, 2004). From a consumer perspective feedback is a response to a message received that is communicated back to the sender (Belch \& Belch, 2004). Further to responding to messages sent by others, consumers may initiate two-way communication by creating and sending their own messages which require a response from another party.

Two-way or bidirectional communication may build cumulatively upon previous messages in a process of dialogue (Ballantyne, 2004; Gronroos, 2004; Yadav \& Varadarajan, 2005). A brand can attempt to engage in dialogue with a consumer through the sending and receiving of consecutive messages over time. Ballantyne (2004) regards communication dialogue as twoway communication based on trust, learning, and adaptation. Communication dialogue can be established with time through a process of reciprocal message receiving and sending. From a consumer perspective dialogue involves both receiving messages from and sending messages to other parties regarding a brand. Such reciprocal dialogue can occur in a delayed manner as parties send messages to and receive messages from each other in a delayed communication process. However, reciprocal dialogue can also be conducted in real-time (Hoffman \& Novak, 1996). Customer relationships may, therefore, be developed and maintained through real-time dialogue regarding a brand.

The literature, therefore, indicates that interactive communication regarding a brand occurs between consumers and brands (Ballantyne, 2004). Furthermore, it is acknowledged that such communication also takes place amongst consumers themselves. Individual consumers interact in, what are described as, 'consumer communities'. Consumers receive, reply to, and initiate communication with other consumers who are part of the community. Consumer communities enhance customer relationships (Szmigin, Canning, \& Reppel, 2005). Discussion regarding communities of consumers and their interaction with each other is well established within the marketing literature. Communities bring individuals together through a common interest and are acknowledged as being instrumental to human well-being 
(McAlexander, Schouten, \& Koening, 2002). They, consequently, exist throughout society and "tend to be identified on the basis of commonality or identification among their members, whether a neighbourhood, an occupation, a leisure pursuit, or devotion to a brand" (McAlexander, et al., 2002, p. 38). Those comprising communities come together for various reasons. However, it is recognised that they do so because interaction between individuals in communities allows the creation and negotiation of meaning to be shared among community members (McAlexander, et al., 2002). Therefore, people participate in communities due to the value that they receive from interacting socially with others.

Examining communities within a marketing context, it is suggested that "a customer community is a body of consumers who are involved with a company in a social relationship. They are involved because the product represents a significant aspect of their lifestyle" (Achrol \& Kotler, 1999, p. 160). Consumers are, accordingly, brought together through a common interest in a product. It is recognised that a key feature of a consumer community is the ability of customers to interact among themselves (Achrol \& Kotler, 1999). Therefore, consumer community participation is focussed on interactive communication sent and received between consumers. Muniz and O'Guinn (2001) develop this further introducing the concept of a brand community. According to these authors "a brand community is a specialized, non-geographically bound community, based on a structured set of social relations among admirers of a brand" (Muniz \& O'Guinn, 2001, p. 412). Such brand communities exhibit, what the authors refer to as 'markers of community'; including shared consciousness, rituals and traditions, and a sense of moral responsibility (Muniz \& O'Guinn, 2001). Bagozzi and Dholakia (2006) examine the behaviour and determinants of behaviour of consumers involved in small group brand communities. According to these authors "a small group brand community is a friendship group of consumers with a shared enthusiasm for the brand and a well-developed social identity, whose members engage jointly in group actions to accomplish collective goals and/or to express mutual sentiments and commitments" (Bagozzi \& Dholakia, 2006, p. 45). Group members engage in activities centred around the brand, as well as other social activities (Bagozzi \& Dholakia, 2006). Therefore, a brand community is a specific type of community in which members are brought together by a common interest in a brand. Individuals acquire value through the sending and receiving of communication regarding the brand. Although Muniz and O'Guinn (2001) and Bagozzi and Dholakia (2006) focus on social relations among admirers of a brand, it is conceivable that interaction within a consumer community may not only comprise positive communication regarding a brand. Consumers may receive, reply to, and initiate negative communication. It is recognised that anti-brand communities exist, particularly online, in which individuals discuss their discontents with a brand (Maclaran \& Catterall, 2002). As such, interaction within a consumer community comprises interactive communication regarding a brand, whether it is positive or negative in nature. 
Algesheimer, et al (2005) measure a consumer's relationship with a brand community through what is referred to as 'brand community identification'. This is a shared identity determined according to the extent to which the individual consumer perceives themselves as belonging to a brand community. Such brand community identification is recognised as comprising both cognitive and affective components. Cognitively "the consumer formulates and maintains a self-awareness of his or her membership within the community" (Algesheimer, Dholakia, \& Herrmann, 2005, p. 20). Therefore, they perceive themselves as a community member. Affectively the consumer feels an emotional connection with a group; meaning that they agree with the community's norms, traditions, rituals, and objectives and promote its well-being (Algesheimer, et al., 2005). Accordingly, consumer identification with a brand community is discussed in regards to a consumer's sense of community belonging.

It is recognised that consumer communities require considerable maintenance (Achrol \& Kotler, 1999). As such, a party must maintain the consumer community if it is to exist. The literature suggests that this can be done by a brand owner (McWilliam, 2000), however, as recognised by Achrol and Kotler (1999) such corporate maintenance of consumer communities can be expensive and hierarchical. Consumer communities can, consequently, be managed by independent firms or by community leaders (Achrol \& Kotler, 1999). Such community leaders are consumers themselves who are rewarded in some manner by the brand. In this way the brand may indirectly manage the consumer community. Other consumer communities may be maintained by third party organisations, such as brand review and comparison services (Marketing Science Institute, 2007) or independent consumers with no linkage to the brand. This includes unofficial brand websites run by consumers (Muniz \& O'Guinn, 2001). Accordingly, a consumer community can be maintained by a brand, a third party organisation, or by independent consumers.

According to McAlexander, et al (2002) brand communities comprise several relationships; including those between customers and the institutions that own and manage a brand, customers and branded possessions, customers and marketing agents, as well as amongst customers themselves. This may be further extended to include third party organisations that engage in communication with consumers regarding a brand. Regardless of those involved in a community, it is noted that brand/consumer communities are customer-centric (McAlexander, et al., 2002). The literature reveals that consumer communities exist both online and offline (McWilliam, 2000; Szmigin, et al., 2005). Therefore, communication within a consumer community regarding a brand is mediated by Internet based, as well as nonInternet based, media. Communication mediated by Internet based media is ideally suited to the facilitation of consumer communities (Szmigin, et al., 2005). Such 'virtual communities', as they are referred to, "are viewed as consumer groups of varying sizes that meet and interact online for the sake of achieving personal as well as shared goals of their members" (Dholakia, Bagozzi, \& Pearo, 2004, p. 242). Consumers, consequently, participate in consumer 
communities so that they can interact with others regarding a brand and share their collective experience. Consumers do so by engaging in interactive communication with other consumers and third party organisations through Internet based and non-Internet based media. As with interactive communication regarding a brand sent and received between consumers and brands, it is expected that interactive communication sent and received amongst consumer communities will affect a consumer's connection with a brand.

Customer relationships need the participation of those in control of brands, as well as consumers. For this to occur both parties must perceive the relationship to be valuable (Gronroos, 2004; Ravald \& Gronroos, 1996). In some situations consumers will engage in transactional exchanges rather than a relationship with an organisation (Day, 2000). A consumer desiring one-off discrete transactions will engage in a relatively low level of communication regarding a brand. They will prefer not to engage in communication and communication that does occur will be intended to facilitate a transaction. Relationships require communication to develop and be maintained (Duncan \& Moriarty, 1998). However, whether an organisation can forge a relationship with a consumer through communication will be influenced by a consumer's involvement. It is, therefore, of benefit for marketers to establish how the communication that a consumer engages in regarding a brand affects a customer relationship.

\section{$2.9 \quad$ The Internet}

The Internet is reported to have been initially developed by the US government Department of Defence's Advance Projects Research Agency, known as ARPA or DARPA (Jackson, 2001), during the late 1950's as a communications system. Although originally a military and then academic resource, the Internet became more accessible in the 1990s and has since been integrated into much of developed society. Internet based media have become accessible to consumers at a faster rate than any other known marketing communications media. It took radio seven times as long as the Internet to become accessible to 50 million worldwide users and television more than twice the time it took the Internet to reach the same milestone (Roberts, 2003). A significant contributor to its rapid rate of access is the exponential value provided by Internet based media. Consequently, more value is provided by Internet based media as more people connect to it. Usage of the Internet has been accepted both within organisations and amongst individual consumers to the point where access throughout the world exceeded 1 billion users in 2005 (Internet World Stats, 2006). Such accessibility has seen Internet based media become an everyday part of marketing practice and an increasingly researched aspect of the marketing literature. 
The world wide web was created in the early 1990s as an information sharing system which utilises the connectivity of the Internet (Jackson, 2001). However, the Internet is not restricted to a world wide web on which information can be conveyed. Rather, it is an interconnected multimedia resource encompassing many present and possible future communications media capable of influencing the field of marketing. The Internet has been recognised as a "massive global network of packet-switched computer networks" (Hoffman \& Novak, 1996, p. 50). It is a network of networks connected by common protocols that allow information to be exchanged across numerous technological platforms. HyperText Transfer Protocol (HTTP), for example, permits the movement of text files and the subsequent global connection of Internet based websites. This connection of international websites, or the world wide web as it is commonly referred to, is a part but not a complete representation of the Internet and the communications technologies it encompasses. Any device operating a programme with Transmission Control Protocol/Internet Protocol, or TCP/IP, can be thought of as being potentially connected to and therefore a part of the Internet (UC Berkeley, 2004). Personal computers are capable of being connected to the Internet through TCP/IP, as are wireless devices such as mobile telephones and Personal Digital Assistants. In fact, given the continuous advance of technology, everincreasing numbers of new platforms are capable of connecting to the Internet by way of common communication procedures. It is identified that the next generation of computers will allow access to the Internet from almost anywhere (Jackson, 2001). Advancements identified as generation three technologies are enhancing wireless Internet connection, permitting more devices to be linked to the Internet and facilitating further marketing communications. As such, the Internet should not be thought of as merely a collection of interconnected websites, exemplified in the world wide web, but rather a dynamic network of networks in which many communications platforms are connected through common protocols.

It is generally accepted that the Internet is a significant technological advancement of our time. As such, its distinct capabilities and subsequent implications are of interest and concern to marketing academics and practitioners. In a comprehensive review and classification of Internet marketing literature, Ngai (2003) identifies that an increasing volume of Internet marketing research has been conducted; particularly in the five years prior to the turn of the millennium. A synthesis of the literature dating back to 1986 identified that 96 per cent of papers investigating Internet marketing were published between 1996 and the year 2000 (Ngai, 2003). The significant growth in the literature during this time, as well as subsequent publications following the research of Ngai (2003), illustrates the importance of Internet marketing within modern academic theory and the impact that marketing communications facilitated by the Internet has had upon the practice of marketing.

Communication facilitated by Internet based media has become an established component of business practice and consumer behaviour. Consequently, Internet marketing is prominent in recent literature and a central consideration for many practitioners. The Internet comprises a 
great number of connected communications platforms which may become increasingly more advanced as the development of technology continues. The literature reveals that the Internet is a part of many peoples' lives. The effect of marketing activity facilitated by Internet based media is, therefore, of great significance to both marketing practice and theory.

\section{$2.10 \quad$ Internet Based Media}

A traditional model of communication includes a source, channel, noise, receiver, and feedback (Duncan \& Moriarty, 1998). In the case of communication regarding a brand many parties can be identified as the source or receiver of communication. The source encodes thoughts, ideas, or information to be sent to the receiver into a message, which is then transmitted via a communication channel and media. The channel by which the communication is sent may be personal or non-personal. Personal communication involves direct interpersonal message exchange between an individual message sender and receiver (De Wulf, et al., 2001; Hulbert \& Capon, 1972). Non-personal communication, however, does not involve direct message exchange between individuals. Marketing messages are sent from an organisation to consumers through marketing media. Non-personal marketing media include mass communications tools such as direct mail, magazines, newspapers, outdoor, radio, and television, as well as Internet based media (Belch \& Belch, 2004). Although personal communication is recognised as a communications channel in itself, it may be regarded as a media in that it facilitates the sending and receiving of messages. Noise refers to any interference concerning the processing of the communication message by the receiver, who decodes the message and may respond by sending a message back to the originator (Duncan \& Moriarty, 1998).

Marketing messages may be sent to consumers from an organisation in the form of planned marketing communication. Planned marketing communication is deliberate. It comprises thoughts, ideas, or information that a marketer intentionally encodes into a message and is sent through a media so that it may be received by target consumers. A brand may attempt to develop and maintain a relationship by sending communication regarding the brand to a consumer. A relationship may also be influenced through the sending and receiving of what are referred to as product, service, and unplanned marketing messages. Customer relationships, however, involve both brands and consumers. Given communication is identified as a critical element in the development and maintenance of any relationship (Duncan \& Moriarty, 1998), customer relationships require consumers to engage in communication regarding a brand. Therefore, in the establishment, development, and maintenance of customer relationships consumers not only receive communication concerning a brand, but also send their own communication. The consumer becomes the communication source; deliberately encoding thoughts, ideas, and information into a 
message that is sent to others through a media. In this way customer relationships can be developed and maintained through a process of communication in which parties send and receive communication regarding a brand.

Relationships support the ongoing exchange between parties and, therefore, their existence is regarded as beneficial to many organisations (Day \& Montgomery, 1999; Gronroos, 1994; Gummesson, 1997; McKenna, 1992; Morgan \& Hunt, 1994; Webster, 1992). This includes customer relationships formed between organisations and end consumers (Garbarino \& Johnson, 1999). Communication is a critical element in the development of such relationships (Andersen, 2001; Duncan \& Moriarty, 1998; V Liljander \& Roos, 2002). Consequently, customer relationships can be developed and maintained through the sending and receiving of communication. Such communication is mediated by media that is connected to the Internet, as well as media that is not. A distinction can be made between what have been referred to as 'traditional' and 'new' media. According to Hoffman and Novak (1996), traditional media include both mass media and personal communications. Mass media include communications tools such as magazines, newspapers, radio and television that are not connected to the Internet (Belch \& Belch, 2004). Personal communications include direct interpersonal message exchange between an individual message sender and receiver (De Wulf, et al., 2001; Hulbert \& Capon, 1972). Such interpersonal communication is regarded as 'unmediated' if sent and received directly between individuals in a face-to-face context (Hoey, 1998; Hoffman \& Novak, 1996). New media essentially encompasses any media enabled through the common protocol of the Internet capable of facilitating communication. This includes what have been referred to as computer-mediated environments, or CMEs (Hoffman \& Novak, 1996). Yadav and Varadarajan (2005) imply that computer-mediated environments permit computer-mediated communication. CMEs comprise media connected to the Internet that facilitate the exchange of messages. The world wide web is a current example of a CME. New media, therefore, includes such Internet based media as the world wide web, e-mail, and short message services (SMS). New media is also noted within the literature as any resource capable of being encoded with information in a digital form (Negroponte, 1995). Therefore, for simplicity traditional and new media may be respectively thought of as non-Internet based and Internet based media. In the present research non-Internet based media is regarded as interpersonal communication only, either unmediated, paper based, or mediated by telephone not connected to the Internet. This is because non-Internet based mass communications tools lack interactivity (Hoffman \& Novak, 1996; Shih, 1998; Stewart \& Pavlou, 2002). As such, Internet based media includes all media enabled through the common protocol of the Internet, while non-Internet based media includes face-to-face, paper based, and non-Internet connected telephone interpersonal communications. 


\subsection{Internet Based Media and Customer Relationships}

Internet based media have been recognised as being able to facilitate the development and maintenance of customer relationships (Arnott \& Bridgewater, 2002; Artis, Stewart, Berry, Narus, \& Sheth, 2001; Brady, Saren, \& Tzokas, 2002; Gilbert, Powell-Perry, \& Widijoso, 1999; Srirojanant \& Thirkell, 1998; Wang, Head, \& Archer, 2000; Zineldin, 2000). This may in part be due to Internet based media supporting communication between parties. It has even been suggested that Internet based media are better at facilitating the development and maintenance of customer relationships than non-Internet based media (Brady, et al., 2002; Gilbert, et al., 1999; Wang, et al., 2000; Zineldin, 2000). Specifically examining communication on the world wide web, Gilbert, et al (1999) recognise that the unique features of the Internet offer a communication opportunity which is ideally suited to relationship marketing. Other authors similarly acknowledge that "the web is better for facilitating relationship-building than other conventional means" (Wang, et al., 2000, p. 376). Furthermore, Zineldin (2000) and Brady, et al (2002) examine Information Technology, including Internet based media, and identify that IT is important in developing marketplace relationships.

Communication mediated by Internet based media is recognised as providing perceived value to consumers, thus contributing to the development and maintenance of customer relationships. Hoffman and Novak (1996) attribute this to the 'hypermedia content' of Internet based media. A consumer can accordingly receive various concurrent messages regarding a brand. Such communication can cumulate to provide consumers with experiences that are far superior to non-Internet based mass media (Peterson, et al., 1997). Consequently, consumers acquire perceived value from communication regarding a brand mediated by Internet based media. Day and Montgomery (1999) recognise that Internet based media also have a profound effect upon the reach/richness trade-off associated with non-Internet based media. Communication mediated by Internet based media is less restricted by "the traditional trade-off between reach (determined by the number of people who share the same information at the same time) and richness (the amount of information that can be communicated at one time, plus the extent of tailoring of the information and the likelihood of two-way interaction)" (Day \& Montgomery, 1999, p. 7). It is suggested that when communication is sent through non-Internet based media the more consumers that are reached by the communication the less information, and therefore less perceived value, is conveyed. Internet based media, however, allow brands to improve the reach of their communication whilst also maintaining a high level of information content.

It is identified that Internet based media can also be accessed by anyone, anywhere, at anytime, because Internet based media are 'always on'. Accordingly, Internet based media are regarded as providing a facility for people to communicate directly with one another 
regardless of where or when they wish to communicate (Blattberg \& Deighton, 1991). Aijo (1996), for example, recognises that Internet based media support "close, constant, instant and location-free communication and access between suppliers and customers" (Aijo, 1996, p. 17). Hoffman and Novak (1996) support this perspective, acknowledging that anyone can both access and provide content to the Internet. It is suggested that consumers can access Internet based media regardless of where they are located (Gilbert, et al., 1999; Kiani, 1998). Rowley (2001) agrees that Internet based media can mediate communication at any time and in any location. As such, consumers can engage in communication mediated by Internet based media wherever they are geographically situated and at any time. From a consumer point of view the fact that Internet based media can be accessed regardless of time and location implies that they can engage in communication concerning a brand whenever they desire. This reduces the perceived sacrifice of disturbance and time associated with receiving and sending communication, thus increasing the perceived value of the communication and overall relationship.

It is further recognised that brands are able to send customised messages to consumers through Internet based media. The literature acknowledges that customer data collection, distribution, analysis, and retention permitted by Internet based media accommodates one-toone communication (O'Leary, et al., 2004; Veloutsou, et al., 2002). This includes the individual identification of consumers and the generation of individually relevant communication. Data regarding previous exchanges between a brand and a consumer mediated by Internet based media can be recorded, shared, analysed, and stored by an organisation to help profile consumers (Hammond, Pluim, \& Eynde, 1995; Peterson, et al., 1997; Wang, et al., 2000). As such, Internet based media can help support the passive collection of consumer data; data which the consumer may not be aware they are providing. Authors caution, however, that the collection, sharing, and storage of such passive data may be perceived as an invasion of consumer privacy (Horne \& Horne, 2002). Internet based media can also support the active collection of consumer data through permission-based communications, such as solicited e-mail (O'Leary, et al., 2004). Consumer data collected passively is likely to provide organisations with behavioural information concerning consumer communication mediated by Internet based media. Cognitive data regarding the demographic and psychographic characteristics of consumers may be collected actively through permission-based communications.

Consumer data collected actively or passively through Internet based media can be distributed to various organisational members, analysed, and retained to support future communication. Internet based media are, therefore, recognised as capable of supporting the collection of large amounts of consumer data that need to be managed in order for organisations to implement customised communication. Such consumer data can be warehoused and mined to create profiles for different customers (Gilbert, et al., 1999; Wang, 
et al., 2000). Customer profiles based on passively collected behavioural data and actively collected demographic and psychographic data may then be used to tailor communications to individual consumers. Accordingly, consumer data can be used to produce customised marketing communication based on consumers' individual characteristics and behaviour (McGoon, 1999). It is recognised that Internet based media supports increased customer understanding and adaptation of the marketing offer to specific needs and wants (Arnott \& Bridgewater, 2002). Thus, allowing organisations to consider consumers individually (Kiani, 1998; Rowley, 2001). Consequently, consumers can not only be identified and targeted individually, but they may also be sent personalised, individually relevant messages. Internet based media are, therefore, acknowledged as mediating one-to-one communication regarding a brand between organisations and consumers.

It is suggested that a relationship between two parties can develop and be maintained through repeated exchange (Day, 2000; Gronroos, 1994; Gummesson, 1997; Morgan \& Hunt, 1994). Such repeated exchange can occur through traditional or Internet based media. As with non-Internet based media, organisations are able to send repeated communication to consumers via media enabled through the common protocol of the Internet. It is recommended that repeated communication sent from an organisation convey a consistent message if it is to contribute towards the development and maintenance of a customer relationship (Duncan \& Moriarty, 1998; Gronroos, 2004). Communication may be received by a consumer from an organisation through various Internet based media. Similarly, a consumer may receive multiple messages regarding a brand through one Internet based media, such as via various pages on the world wide web. Internet based media are capable of supporting numerous marketing communications functions; such as advertising, public relations, and sales promotions (Schultz, 1999). It is further recognised that various organisational representatives are capable of sending communication to consumers (Day, 2000; Rao \& Perry, 2002). This is true of Internet based media. Multiple organisational members may be able to send communication to consumers through an organisation's website, for example. Therefore, as with communication facilitated by non-Internet based media; an organisation may attempt to send consistent communication to consumers through media connected to the Internet. An organisation is able to utilise, what is referred to as, a content management system or CMS to ensure that they are sending consistent communication to consumers through Internet based media. Content management systems are intended to manage communication on the world wide web (McKeever, 2003) and, therefore, may be utilised to ensure consistent communication is sent to consumers through Internet based media.

Internet based media are also acknowledged as strongly facilitating interactive communication. The interactive potential of Internet based media is identified as one of its most important capabilities compared to most traditional media (Yadav \& Varadarajan, 2005). 
In their research investigating the implications of the Internet upon marketing practice, Hoffman and Novak (1996) note that the interactivity of Internet based media alters the manner in which organisations communicate with their customers. These authors recognise that communication between a buyer and seller facilitated by many non-Internet based mass communications tools often "follow a passive one-to-many communication model, whereby a firm reaches many current and potential customers, segmented or not, through marketing efforts that allow only limited forms of feedback" (Hoffman \& Novak, 1996, p. 50). Internet based media, however, allow consumers to engage in two-way communication with organisations relatively easily, cost effectively, and in real time; much like communication between an organisation and customer in a personal face-to-face context (Hoffman \& Novak, 1996). Kiani (1998) supports this perspective, suggesting that Internet based media facilitate a shift from 'one-way' to 'two-way' information flows. Gronroos (2004) similarly agrees that Internet based media facilitate two-way communication including customer response to planned marketing messages. Other authors suggest that Internet based media support communication dialogue whereby parties can be both message originators and recipients. This perspective is supported by Rowley (2001), who adds that the interactive nature of the Internet means that messages can be communicated through dialogue. Hoffman and Novak (1996) further suggest that real-time communication between an organisation and consumer, or 'temporal synchronicity', applies to interactive but not mass media. As such, real-time dialogue is acknowledged as being facilitated by non-Internet based personal communications, as well as Internet based media.

The literature therefore reveals that, like non-Internet based media, Internet based media can facilitate the development and maintenance of a customer relationship through a process of communication. Customised and consistent, as well as interactive communication is sent and received through Internet based media. Customised and consistent communication regarding a brand is sent by an organisation and received by a consumer. Such communication is accordingly controlled by the brand. The current research focuses on a consumer perspective regarding the development and maintenance of customer relationships through communication. A consumer may passively participate in a customer relationship through the receiving of communication from a brand and actively participate through engaging in interactive communication regarding a brand.

\subsection{Access to Internet Based Media}

Media enabled through the common protocol of the Internet are recognised as facilitating the sending and receiving of communication. However, in order to receive or respond to such communication consumers need to be able to access Internet based media. The literature reveals that many consumers currently do have access to Internet based media and that such 
media may become more accessible with time (Negroponte, 1995). Accordingly, a considerable number of consumers, particularly living in developed countries, have the ability to engage in communication through Internet based media. Consumers can also engage in communication via media not connected to the Internet. Consequently, consumers can receive, respond to, and initiate communication through traditional or Internet based media. In 2010, the number of networked computers worldwide reached 1.2 billion (Young and Rubicam, 2010). New Zealanders have a relatively high level of access, with Internet based media reaching 75 per cent of households in 2009 (Statistics New Zealand, 2010). Given such levels of accessibility, engaging in communication through Internet based media has become a component of everyday life for many consumers (Conrades, 1998; Hannemyr, 2003; Hoffman, Novak, \& Venkatesh, 2004; Negroponte, 1995).

Negroponte (1995) suggests that we may have moved into a post-information age in which the transfer of digital information significantly affects the daily lives of consumers. Digital technology has evolved from large mainframe computers towards networks of significantly smaller devices with the compatibility to connect together. Such networks are exemplified by Internet based media. The transfer of digital information is relatively inexpensive and instantaneous when compared to the cost and time involved in the transfer of physical items. As such, digital devices are predicted to continue to evolve; becoming smaller, more mobile, and increasingly compatible. Should this transpire the use of devices capable of transferring vast amounts of digital information may become progressively more permeated into the behaviour of consumers (Negroponte, 1995). Thus, permitting consumers to be able to engage in further communication through Internet based media. Internet based media may even become indistinguishable from traditional media from a consumer perspective (Conrades, 1998).

Although it is recognised that Internet based media are able to be accessed by many consumers it is also acknowledged that a gap exists between consumers who do and do not engage in communication through Internet based media. Such a gap is commonly referred to as a 'digital divide'. Cullen (2001) advises that digital divides exist due to certain groups within society, or throughout the world, being unable or unwilling to access Internet based media. It is identified that Internet based media have a potentially global reach as such media can be accessed throughout the world (Gilbert, et al., 1999; Kiani, 1998; Rowley, 2001). However, it is also recognised that access to Internet based media is uneven across countries (Dutta \& Roy, 2003). It is suggested that there exists a digital divide internationally between developed and non-developed nations as a result of more developed countries having considerably advanced access to Internet based media. This divide is expected to increase as developed countries continue to become more advanced in their access to Internet based media and less developed nations are left behind (Cullen, 2001). Murray and Ko (2002) also acknowledge such a digital divide. These authors suggest that the greatest numbers of 
connected individuals throughout the globe are relatively equally distributed among a traditional triad of trading partners which includes Asian-Pacific, European, and North American nations.

It is further noted that a digital divide is present within a significant number of nations. The term digital divide has become an accepted reference for "the gap that exists in most countries between those with ready access to the tools of information and communication technologies, and the knowledge that they provide access to, and those without such access or skills" (Cullen, 2001, p. 311). Accordingly, it is suggested that certain societal groups are disadvantaged due to relatively limited access to Internet based media. Authors indicate that, in general, those with restricted access to Internet based media can be identified as individuals on lower incomes, people with lower education or literacy levels, those living in rural locations, the unemployed, the elderly, the disabled, sole parents, and females (Cullen, 2001; Mossberger, Tolbert, \& Stansbury, 2003; Prieger, 2003). Hoffman, et al (2004) agree that there is a digital divide within many countries throughout the world, identifying that the Internet has not touched all segments of society equally. Reports issued by Statistics New Zealand reveal that New Zealand is not exempt from the digital divide. Although as a nation New Zealand ranks highly within the OECD in terms of access to Internet based media (Statistics New Zealand, 2004), there exist pockets of society who have a notably limited amount of access compared to others (Statistics New Zealand, 2010). In support of international trends variables identified as influencing household Internet connectivity levels in New Zealand include household income, location of residence, and household composition (Statistics New Zealand, 2004, 2010). It is suggested that specific barriers to access regarding Internet based media may stimulate a digital divide. Barriers have been identified as including physical access, user skills and support, attitude, and perceptions regarding the relevance of content provided by Internet based media (Cullen, 2001; Mossberger, et al., 2003). It is implied that these barriers should be addressed in order to bridge the digital divide. Therefore, while Internet based media may be accessible to a significant number of consumers it is also recognised that other consumers, globally and within societal segments, have limited access.

On a global and national scale Internet based media are regarded as generally accessible in developed countries. The scope of the current study is within a developed western economy, focusing on customer relationships in a New Zealand context. New Zealand consumers remain highly connected to Internet based media and their behaviour is expected to reflect that of consumers in developed nations. As such, although limited access to Internet based media is acknowledged, this does not detract from the relevance of the research. 


\subsection{Use of Internet Based and Non-Internet Based Media}

It is acknowledged that consumers engage in communication through both non-Internet based and Internet based media. 'Hybrid consumers', as they have been referred to, reportedly engage in communication via Internet based and non-Internet based media to varying degrees (Wind \& Mahajan, 2002; Wind, Mahajan, \& Gunther, 2002). Accordingly, marketers need to consider their target consumers' behaviour regarding Internet based, as well as non-Internet based media, when implementing marketing communication. Marketers are cautioned that consumers may not wish to only communicate via Internet based media. However, they are also warned that communicating exclusively through non-Internet based media may similarly disregard the behaviour of consumers. When engaging in communication regarding a brand a consumer may do so via different forms of media. If organisations are to communicate effectively it is advised that they consider the behaviour of consumers concerning receiving and responding to communication, via both Internet based and nonInternet based media.

Although Internet based media are reported to be increasingly accessible (Pallab, 1996; Roberts, 2003), consumers may not necessarily wish to engage in communication facilitated only by such media (Wind \& Mahajan, 2002). Rather, consumers may choose to receive and respond to communication via Internet based and non-Internet based media. Wind, et al (2002) recognise that some established behaviours, such as receiving and responding to communication through non-Internet based media, are likely to endure in the presence of advancing technology. As such, there may continue to be a consumer desire to engage in communication through traditional media. Consumers can, and do, engage in communication through media connected to the Internet. However, it is recognised that people typically do not choose to exclusively engage in communication through such media (Wind, et al., 2002). In a sociological context communication facilitated by Internet based media has not replaced personal face-to-face communication. Research suggests that communication sent via Internet based media does not replace traditional forms of contact, but rather complements them (Wellman, 2004). Therefore, Internet based media are reported to actually increase the overall volume of communication (Koku, Nazer, \& Wellman, 2001; Wellman, 2004). According to Wellman (2004), most people e-mail other individuals that they already know as a means of keeping in touch between personal face-to-face communication or to arrange to meet together. Similarly, telephone calls are often intermixed with e-mail contact. As a result, people do not engage in communication facilitated by Internet based media rather than communicating personally, but communicate via both forms of media more regularly. This implies that access to Internet based media results in individuals communicating more both through Internet based and non-Internet based media. Further, Wind and Mahajan (2002) identify that consumers favour receiving communication from organisations facilitated by traditional and Internet based media to varying degrees, according to their individual 
preferences. Consumers could therefore exist on a continuum, "coming in many shades along the spectrum from cyber to traditional" (Wind \& Mahajan, 2002, p. 78). Depending on the consumer and organisation, individuals may wish to engage in more or less communication through Internet based media. Should consumers choose to engage in communication via Internet based and non-Internet based media to varying degrees then brands need to communicate accordingly.

It is recognised that demographic variables influence the extent to which a consumer communicates through Internet based and non-Internet based media. Authors suggest that age, for example, influences the media which consumers communicate through (Katz \& Aspden, 1997; Katz, Rice, \& Aspden, 2001; Russell, 1998). The literature implies that consumers of different ages possess varying attitudes towards using Internet based media (Eastman \& lyer, 2004; Trocchia \& Janda, 2000). Consequently, younger consumers are thought to communicate more through Internet based media and older consumers via nonInternet based media. Similarly, a consumer's education level is also recognised as influencing their use of media; with less educated consumers communicating more through non-Internet based media and more educated consumers through media that is connected to the Internet (DiMaggio, Hargittai, Neuman, \& Robinson, 2001; Hoffman, Kalsbeek, \& Novak, 1996; Katz \& Aspden, 1997; Katz, et al., 2001). Additionally, geographic residence is acknowledged as affecting consumers' media use (Cullen, 2001). Consumers living in urban areas are identified as communicating more via Internet based media and consumers living in rural areas through non-Internet based media.

The extent to which consumers use Internet based and non-Internet based media is also influenced by psychographic consumer characteristics. Psychographic characteristics are acknowledged as providing additional information to demographic measures (Wells, 1975) and concern the psychological attributes of people (Vyncke, 2002). Such psychological attributes are recognised as being rich and multi-dimensional (Plummer, 1974). In a marketing context, psychographic attributes allow organisations to uncover detailed information concerning the personality of consumers. It is suggested that psychographic characteristics present a link between an individual's personality and consumer behaviour (Lastovicka, 1982). Two such psychographic characteristics that may influence a consumer's use of Internet based media are extroversion and innovativeness. Extroversion is a complex consumer trait and a much researched subject in the literature regarding personality dimensions. Everyone is acknowledged as being extroverted to some extent, with individuals possessing lesser levels of extroversion being described as more introverted. The degree to which people are either extrovert or introvert is regarded as a central component of personality (Wheeler, Petty, \& Bizer, 2005). Research in this area is based on the notion that extroverts and introverts experience different levels of arousal to stimuli. Introverted individuals experience higher levels of arousal than extroverts and therefore find social 
interaction, for example, less arousing (Stelmack, 1981; Wheeler, et al., 2005). This difference in arousal levels experienced by individuals with more or less extroversion is recognised as affecting their behaviour. A typology of extroverted and introverted individuals is reported to have been originally devised by Swiss psychiatrist Carl Jung (Mischel, 1986) and has been developed subsequently by other personality researchers (Eysenck \& Rachman, 1965). Extroverts are energized by being with others (Shank \& Langmeyer, 1994). Among exhibiting other behaviour, a typical extrovert is profiled as being sociable and needing people to talk to (Eysenck \& Rachman, 1965). Conversely, more introverted people favour the world of concepts and ideas (Shank \& Langmeyer, 1994). Introverts are reported to be reserved except to intimate friends and prefer to be alone, tending to avoid others (Eysenck \& Rachman, 1965; Mischel, 1986).

Due to the fundamental importance of extroversion as a personality dimension, the extent to which individuals are extroverted is relevant to consumer behaviour. This may include consumer behaviour regarding the use of Internet based and non-Internet based media. Research regarding organisational online communities, for example, has suggested that more introverted individuals take an active role in discussions facilitated by Internet based media, whereas extroverts prefer non-Internet based interpersonal communication (Cothrel \& Williams, 1999). Considering the recognised profiles of extrovert and introvert individuals it is apparent that sociable extroverts may prefer to communicate via non-Internet based media, such as face-to-face and via the telephone. Distant (Eysenck \& Rachman, 1965) introverts, however, may prefer to communicate through media that is connected to the Internet.

Consumers' use of Internet based media may also be determined by their level of innovativeness. Innovativeness is recognised as a normally distributed personality trait (Goldsmith, d'Hauteville, \& Flynn, 1998). It is possessed, to some extent, by all consumers (Citrin, Sprott, Silverman, \& Stem Jr, 2000; Hirschman, 1980; Midgley \& Dowling, 1978). Levels of innovativeness can, therefore, be utilised as a trait by which consumers are segmented. Innovativeness concerns individuals' adoption of innovations; described as new products, services, behaviours, or ideas (Rogers, 2003). It is acknowledged that members operating within a social system adopt innovations at different rates. These different rates of adoption have been attributed to the characteristic of innovativeness (Rogers, 1983). Conceptually innovativeness is defined as "the degree to which an individual is receptive to new ideas and makes innovation decisions independently of the communicated experience of others" (Midgley \& Dowling, 1978, p. 236). Goldsmith, et al (2003) propose attitude towards change is the measure of innovativeness. As such, innovativeness captures the extent to which individuals react positively to new products, services, behaviours, or ideas.

A distinction is made within the literature between, what are referred to as, general innovativeness and domain-specific innovativeness (Goldsmith, et al., 1998; Goldsmith, Flynn, 
\& Goldsmith, 2003). Theory regarding general innovativeness, also recognised as global, innate, and open-processing innovativeness, implies that people are inherently more or less innovative (Citrin, et al., 2000). Innovativeness in this context is expressed as a generalised predisposition toward new ideas (Im, Bayus, \& Mason, 2003). Consequently, this personality trait dictates consumers' reactions to all ideas. Such a notion of innovativeness as a general predisposition is reported to be well supported within the literature (Goldsmith, et al., 1998; Im, et al., 2003). Theory concerning domain-specific innovativeness suggests that people are more or less receptive to new ideas depending on the product or service category (Goldsmith, 2001; Goldsmith, et al., 2003). Domain-specific innovativeness is determined by an alignment between the specific innovation and the consumer's area of interest. Although two types of innovativeness are present within the literature, it is acknowledged that innovativeness can be measured at both a general and category specific level (Citrin, et al., 2000; Mowen, Christia, \& Spears, 1998). As such, an individual consumer will have a general tendency to receive new products, services, behaviours, and ideas; as well as a level of favourability towards receiving domain specific innovations. It is suggested that consumer innovativeness may influence the extent to which a consumer communicates through Internet based media (lyer \& Eastman, 2006; Yoh, Damhorst, Sapp, \& Laczniak, 2003). Innovative consumers are generally receptive towards new products, services, behaviours and ideas. Given the continual development of Internet based media (Negroponte, 1995), it follows that generally innovative consumers will react positively towards engaging in communication through media enabled through the common protocol of the Internet. Conversely, less innovative consumers may favour communicating via traditional non-Internet based media.

This discussion illustrates that consumers engage in communication facilitated by Internet based and non-Internet based media to varying degrees. This may be attributable to the fact that some consumers have better access to Internet based media than others, highlighted by the concept of a digital divide. Use of Internet based media is associated with the demographic characteristics of consumers, such as age and geographic location. However, it may also be linked to the psychological attributes of consumers. Two examples of such attributes are the extent to which a consumer is extroverted and innovativeness. Depending on the consumer and the brand, it is likely that consumers participate in different levels of communication regarding a brand through Internet based and non-Internet based media.

\subsection{Literature Summary}

The preceding literature review discusses the importance of customer relationships, with a particular focus on customer relationships with end consumers. It is revealed that consumer participation in customer relationships is salient. A consumer perspective regarding the process by which customer relationships are developed and maintained is, accordingly, of 
significance. Furthermore, it is often brands with which consumers form customer relationships. As such, the process by which consumers form relationships with brands specifically requires examination. Consumers participate in the development and maintenance of customer relationships by receiving, responding to, and initiating communication regarding a brand. This communication can take a variety of forms and be facilitated by both Internet based and non-Internet based media. In being involved in customer relationships consumers then form a connection with a brand. The literature indicates that such a connection may depend on the extent to which the consumer feels that the brand's personality aligns with their ideal brand personality for a product or service category. Literature concerning relationship marketing, branding, and consumer communications have accordingly been brought together in a discussion of the development and maintenance of customer relationships from a consumer perspective.

Chapter three identifies and, subsequently, defines key constructs regarding the process by which consumers develop and maintain relationships with a brand. These constructs are based on the literature review. The relationship between constructs is also discussed and presented within a conceptual model. 
Communication is regarded as a critical element in the establishment, development, and maintenance of any relationship (Duncan \& Moriarty, 1998). Customer relationships between a brand and end consumer can, therefore, be built through a process of communication. A brand may over time acquire a philosophical commitment to relationship marketing, leading in turn to activities such as customer profiling and database management in an effort to forge customer relationships (Day \& Montgomery, 1999; O'Leary, et al., 2004). However, a consumer does not directly experience these activities. They do however experience communication regarding a brand in all its various forms, as communication in this context implicitly requires consumer participation. Accordingly, consumers are in effect co-creators of value in the communication process (Prahalad \& Ramaswamy, 2004). From a consumer perspective, activity contributing towards the establishment, development, and maintenance of a customer relationship fundamentally requires communication activity to occur. The owners of brands engage in planned communication with consumers in a bid to create a relationship between the two parties. Due to the inherently mutual nature of a relationship, however, both the organisation and the consumer need to engage in communications regarding a brand in order for a customer relationship to form, be maintained, and in some instances flourish. The primary objective of the present research is to investigate how consumers participate in the development and maintenance of a customer relationship through communication. This chapter discusses the conceptual model guiding this research, and the hypothesised linkages between the research constructs.

For a customer relationship to exist a consumer must form an emotional connection with a brand at some level (Fournier, 1998). This connection is conceptualised as the 'Brand Personality Connection' construct. Consumers develop perceptions regarding brands referred to as brand image (Faircloth, Capella, \& Alford, 2001; Stern, 2006), an important part of which comprises brand personality (Aaker, 1997). Brand Personality Connection is determined according to the extent to which the consumer perceives that the personality of a brand aligns with their ideal brand personality for the product or service category. This in turn is expected to affect the relationship that they have with the brand. The literature indicates that consumers engage in various forms of communication regarding a brand (Ballantyne, 2004; Gronroos, 2004). Brand Personality Connection, therefore, becomes dependent upon the communication regarding a brand with which the consumer engages.

Brand representatives communicate with consumers in an attempt to develop and maintain a relationship. While consumer reciprocity and participation in such communication is essential, the conceptual model further suggests that advertising sourced from a brand and received by a consumer will also affect the nature of the relationship. Although the consumer is a more passive participant in such communication, their attitude towards a brand's advertising 
nevertheless influences his or her connection with the brand. Consumers actively participate in the development and maintenance of a customer relationship by responding to and initiating communication regarding a brand. Such communication response and initiation is referred to as interactive communication (Ballantyne, 2004; Gronroos, 2004), which involves two-way message sending and receiving regarding a brand. It occurs between a consumer and brand, as well as amongst consumer communities (Bagozzi \& Dholakia, 2006; Cova \& Cova, 2002). Accordingly, it is anticipated that Brand Personality Connection is directly influenced by the independent effects of Brand Advertising, Communication with the Brand, and Communication with Consumer Communities.

A customer relationship can be evaluated according to the quality of the relationship, which is an overall assessment regarding the strength and nature of a relationship (Crosby, et al., 1990; Dorsch, et al., 1998). It is well-reported in the literature, acknowledged as a higherorder construct (Dwyer \& Oh, 1987) reflecting an evaluative judgement concerning relationship excellence. In the present research Relationship Quality is comprised of five elements and is determined by an individual consumer, in reference to a brand with which they have some form of relationship. The five elements of Relationship Quality are interdependence, intimacy, love and passion, satisfaction, and trust. These five elements are drawn from literature concerning relationship quality as conceptually distinct dimensions of the construct (Aaker, et al., 2004; De Wulf, et al., 2001; Fournier, 1998; Garbarino \& Johnson, 1999; Kressmann, et al., 2006). It is proposed that the quality of a customer relationship is directly influenced by a consumer's connection with a brand. As such, Relationship Quality is dependent upon Brand Personality Connection. Consumers vary in the extent to which they favour being involved in customer relationships with brands in a product or service category. This predisposition towards being involved in customer relationships with brands in a category is conceptualised as a consumer's Relational Orientation (Garbarino \& Johnson, 1999). It is further proposed that the relational orientation of a consumer will moderate the linkage between Brand Personality Connection and Relationship Quality.

Finally, the conceptual model recognises that the quality of a customer relationship will in turn directly affect Customer Brand Loyalty. This is because Customer Brand Loyalty reflects repetitive same-brand or same brand-set purchasing (Oliver, 1999), likely perceived behaviour when a relationship is evaluated highly. Overall, the conceptual model acknowledges possible outcomes for brand owners of a customer relationship. The conceptual model is illustrated in figure $3 \mathrm{a}$. The research methodology sought to test the proposed linkages between the main constructs. This was achieved by applying an instrument intended to measure the research constructs to a representative sample of consumers. 
Figure 3a. Conceptual Model

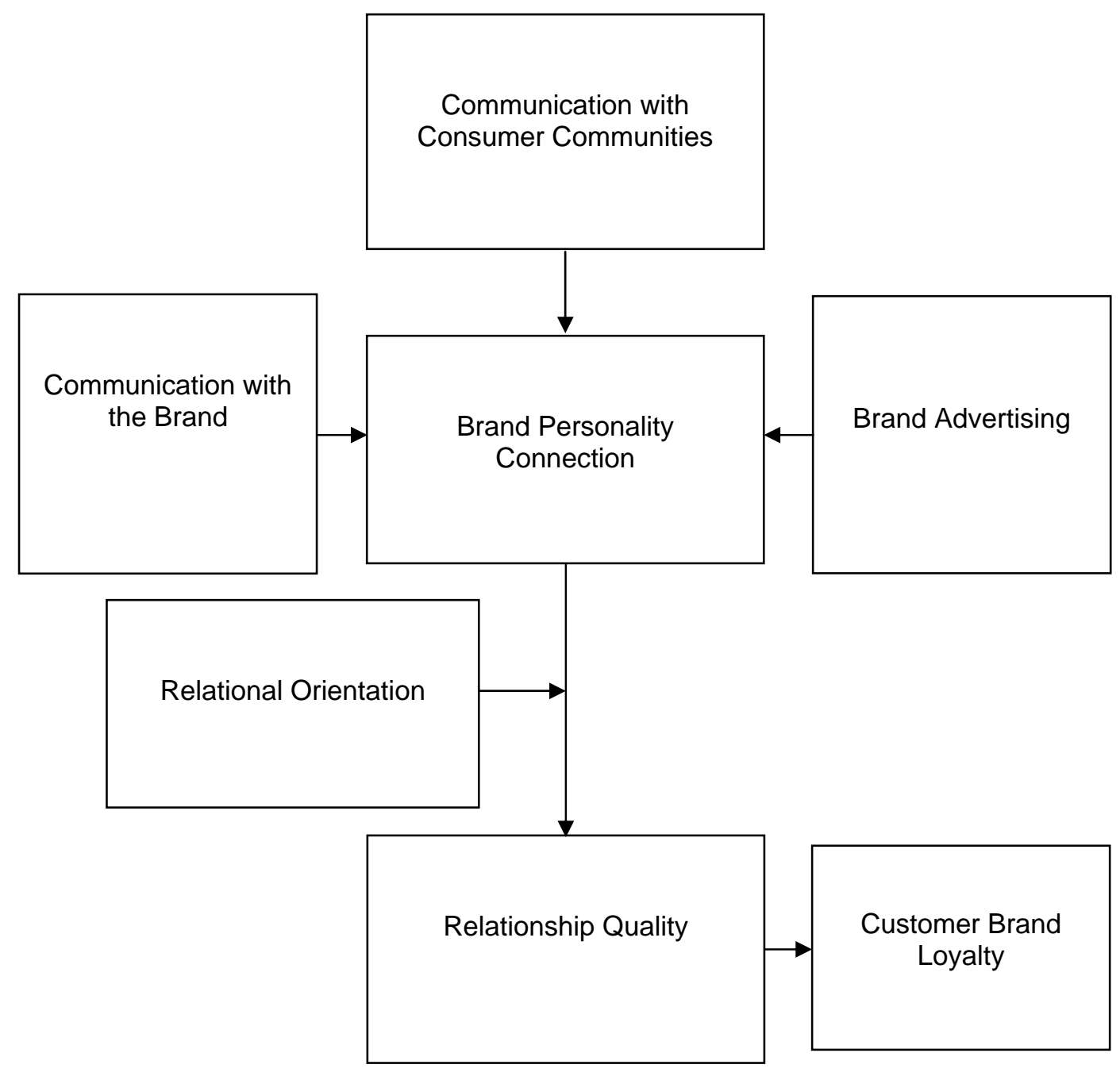




\subsection{Construct Definitions}

A broad overview of the conceptual model and construct inter-relationships has been provided in Figure 3a. This section provides a full explanation of the main constructs in the model, as well as an operational definition of each drawn from the literature. In some instances these are defined as new measures, where pre-existing measures could not be found or where they had to be modified in some respects.

\subsubsection{Brand Personality Connection}

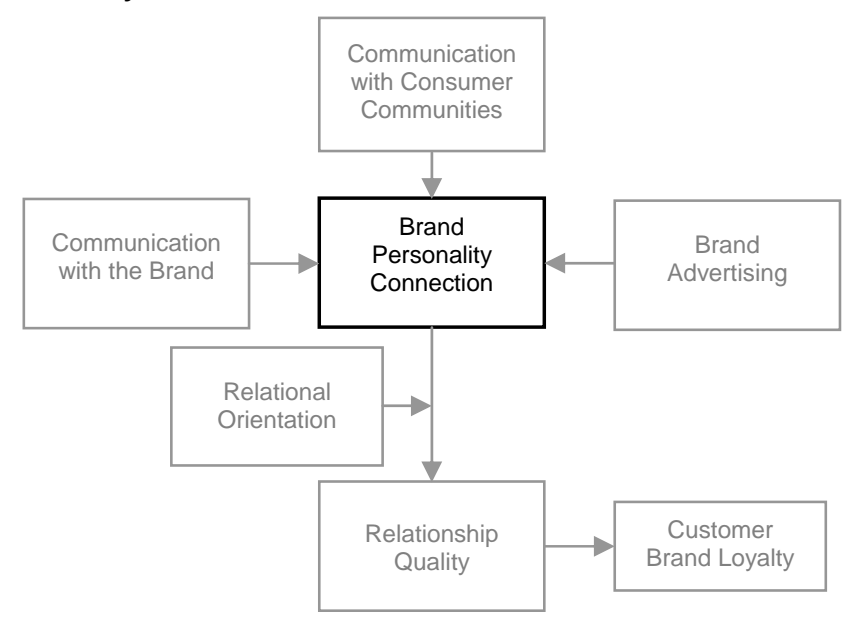

In perceiving a customer relationship a consumer forms an emotional connection with a brand. It is upon this connection, or association with the brand, that a customer relationship is based. Such a connection may be determined by the extent to which a consumer perceives that a brand's personality aligns with their ideal brand personality for a product or service category. Similarities between the consumer's personality and the perceived personality of a brand are part of this connection. Alignment of the self with perceived brand image is regarded in the literature as consumer self-connection with a brand (Fournier, 1998). Grubb and Hupp (1968) recognise that people develop perceptions, attitudes, feelings, and evaluations of themselves as objects classified as their self. Therefore, throughout their lives all consumers possess a self-image. According to Graeff (1996), this self-concept is developed over time, based on how one thinks of one's self, as well as how other people think of the person and react to them. Furthermore, the self-concept can be viewed as the sum total of an individual's ideas, thoughts and feelings about themselves in relation to other objects (Onkvisit \& Shaw, 1987, 1994). An alignment between a consumer's self-image and the perceived image of a product is referred to in the literature as 'self congruity' (M. Sirgy, 1982). Marketers should consider the self-concept and self congruity when promoting products to individual consumers, as congruity results in self-enhancement regarding the product (Grubb \& Hupp, 1968). The literature, therefore, suggests that the self-image of a consumer is reinforced by associations with the product in question. 
Self-connection is described as reflecting the degree to which a brand delivers on important identity concerns, tasks, or themes, thereby expressing a significant aspect of the consumer's self (Fournier, 1998). Consequently, it is implied that although congruence between the self and product image is of importance, congruity between the self and brand image may be more relevant. It is acknowledged that brands have a symbolic image beyond the physical attributes and characteristics of a product or service (Graeff, 1996). As such, the notion of a consumer's self-image and image congruity is extended to include alignment with the perceived image of a brand. Brands take on a multitude of meaning to consumers (Stern, 2006). Additionally, different brands are associated with various signals. The literature reveals that a brand's image is regarded as a consumer's perception of such brand associations (Faircloth, et al., 2001). Accordingly, brand image is defined as perceptions about a brand as reflected by the brand associations held in consumer memory (Keller, 1993). In developing theory regarding self and brand image congruity, Aaker (1997) suggests that congruence between a consumer's personality and brand personality is important. Five dimensions of brand personality are identified. These are sincerity, excitement, competence, sophistication, and ruggedness (Aaker, 1997). Consumers align elements of their own perceived personality with that of the brand; thus forming a connection with the brand. While there are other dimensions of brand image, such as organisational association and product quality (Keller, 1998), personality comprises part of the overall image of a consumer or brand (Aaker, 1997). In research involving case study analysis Fournier (1998) cites literature by Kleine, et al (1995), noting that brand-self connections occur regarding a consumer's past, current, and future self. It is recognised that brands symbolised as similar to the self concept will maintain or enhance the self. A consumer's self-image will be supported by the brand and a perceived connection forged. Therefore, the consumer associates him or herself with and is emotionally connected to the brand (Kleine, Kleine, \& Allen, 1995). Consumers evaluate the alignment of a brand's image with their own self-image. The more aligned or congruent the self-image is with the perceived brand image, the more connected the consumer will feel towards the brand. A consumer's self concept is recognised as influencing consumer behaviour. Graeff (1996), for example, advises that the degree of congruence between a consumer's self-image and the perceived image of a brand influences consumer brand evaluations and purchase intention. Relevant to the current research, connection between self and brand personality is also expected to affect the development and maintenance of customer relationships from a consumer perspective.

Self and brand personality connection is, therefore, acknowledged as an important component of a consumer's emotional connection with a brand. Aaker (1999) recognises that the self is malleable and, therefore, varies according to the context in which a person is operating. Therefore, preference for a brand, based on personality connection, will vary across usage situations (Aaker, 1999). Aaker (1999) uses the analogy of a corporate 
businessman who does not perceive himself during the week as rugged, tough, and outdoorsy. However he leaves for a weekend trip on his Harley-Davidson motorcycle, a brand perceived as such. There is an apparent incongruity between the self-image of the businessman during the week and the Harley-Davidson brand. Self-connection with a brand is determined according to the extent to which a consumer aligns their self-image with that of a brand. However, consumers may be unwilling or unable to articulate their self-image for a specific product or service category. It is recognised that sometimes consumers express who they wish to be, strive to be, or believe they should be, rather than who they consistently are across situations (Aaker, 1999). As such, the manner in which a consumer portrays themselves, or their expressive-self (Ataman \& Ulengin, 2003), may differ from their actualself. Accordingly, congruity between the perceived personality of a brand and a consumer's ideal brand personality may be a better determinant of a consumer's connection with a brand. Ideal brand personality is a product or service category specific measure of a consumer's self-image. It reveals how the consumer would like a brand in a product or service category to be ideally characterised. It is recognised that ideal attributes can be used to compare brands (Chapman, 1993; Green, Wind, \& Claycamp, 1975). Alignment of a consumer's ideal brand personality with the perceived personality of a brand is, therefore, used in the present research to determine the consumer's connection with the brand.

A consumer forms an emotional connection with a brand throughout the development and maintenance of a customer relationship. This connection is conceptualised as being salient to a relationship. Over time consumers perceive certain associations with brands, creating a brand image for the consumer (Faircloth, et al., 2001; Keller, 1993). Similarly, consumers develop a set of knowledge and beliefs about themselves, referred to as their self-image (Graeff, 1996). This self-image represents how the consumer sees themselves in reference to their surroundings. Brands perceived as similar to a consumer's self-image are recognised as maintaining or enhancing the self (Dolich, 1969). If a consumer's self-image is supported by a brand they will associate themselves and perceive a connection with the brand.

Although alignment between a brand's image and the self is acknowledged as part of a consumer's brand connection, it does not fully capture the construct of Brand Personality Connection. Consumers may be unwilling or unable to articulate their self-image for a specific product or service category (Aaker, 1999). Therefore, congruity between the perceived image of a brand and a consumer's ideal brand image is used to determine this construct. Personality comprises a significant part of a consumer's overall self or brand image (Aaker, 1997). The central construct of Brand Personality Connection, therefore, captures the extent to which a consumer perceives that a brand's personality aligns with their ideal brand personality for a product or service category. It is expected that the more a consumer's ideal brand personality for a product or service category is aligned with the perceived personality of a brand, the more connected the consumer will feel towards the brand. Perceived alignment 
will alter due to changes in a consumer's ideal brand personality or the perceived personality of a brand. Although a brand may attempt to influence perceived brand personality through communication, connection with a brand is ultimately determined by the consumer. The conceptual model illustrates that the construct of Brand Personality Connection is influenced by the various forms of communication that a consumer engages in regarding a brand. In turn, Brand Personality Connection directly influences the quality of a customer relationship.

Brand Personality Connection was operationalised using items that reflected perceived brand personality. Research respondents were asked to characterise a specific brand and then their ideal brand for the category. Respondent answers regarding perceived brand personality and ideal brand personality within a category were compared to determine connection with a given brand. The items used to determine brand personality were based on the brand personality dimensions identified by Aaker (1997). These brand personality dimensions included competent, exciting, rugged, sincere, and sophisticated.

\subsubsection{Brand Advertising}

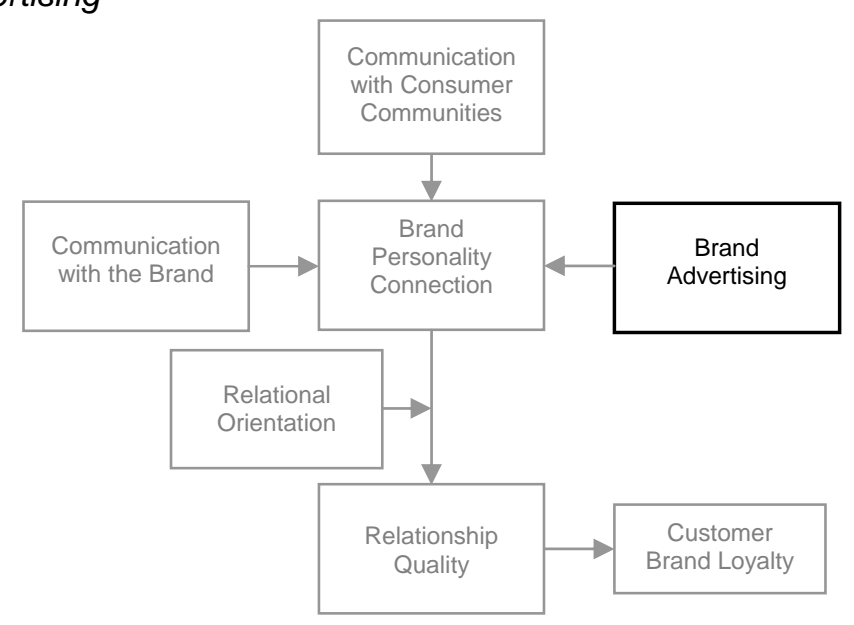

Feedback is recognised as a requirement in a process of two-way communication (Duncan \& Moriarty, 1998). Therefore, an absence of capacity for immediate interactivity or direct response signifies communication that is essentially one-way. Although, given its nature, consumers cannot immediately respond to advertising sent from a brand they are communication receivers. Accordingly, while they are considered more passive participants, consumers are co-producers of value in the process of advertising. Brands send advertising to consumers. This is usually planned communication comprising thoughts, ideas, or information that a brand intentionally encodes into a message. Advertising may or may not be intended to initiate and maintain a customer relationship. The present research suggests that a consumer's evaluation of such communication influences their perceived connection with a brand. 
The construct of Brand Advertising captures a consumer's attitude towards the advertising received from a brand. A consumer will form an attitude towards such communication after having experienced it. The construct, therefore, reflects a consumer's experience regarding advertising received from a brand. As a feature identifying one seller's goods or services as distinct from those of others a brand cannot literally send or receive communication (American Marketing Association, 2007). Representatives of the brand, such as brand communication decision makers and customer service representatives do this. However, given that consumers can perceive relationships with brands, communication with brand representatives is thought of as being sent and received by the brand in the context of this research. A consumer's positive or negative evaluation of a brand's advertising will affect their sense of connection with the brand.

It is recognised that an attitude represents a summary evaluation of a psychological object (Ajzen, 2001). Therefore, consumer attitudes result from an evaluation of an issue or object in question. In the context of attitude towards a brand the psychological object to be evaluated is a brand. Attitudes are formed either through the consideration of information that is believed to be central to a particular attitudinal position or via positive and negative cues associated with an issue or object (Petty, Cacioppo, \& Schumann, 1983). Furthermore, attitudes are formed through both cognitive and affective evaluation (Ajzen, 2001; Zajonc \& Markus, 1982). Consequently, a consumer's brand attitude is measured in multiple attribute dimensions which determine the overall degree of favourability towards a brand. A consumer's attitude towards the advertising received from a brand is determined in the same manner.

In the present research a consumer's evaluation regarding Brand Advertising is determined through the multiple semantic-differential attribute dimensions identified by Batra and Stayman (1990). Advertising sent from a brand and received by a consumer is usually planned and comprises thoughts, ideas, or information that a brand intentionally encodes into a message. Research respondents were asked to indicate on the scales provided how they would describe a brand's general advertising. This evaluation was made by respondents based on prior exposure to the brand's advertising and they were not shown new advertising stimuli. It was, therefore, expected that respondents would have been exposed to differing levels of brand advertising. 


\subsubsection{Communication with the Brand}

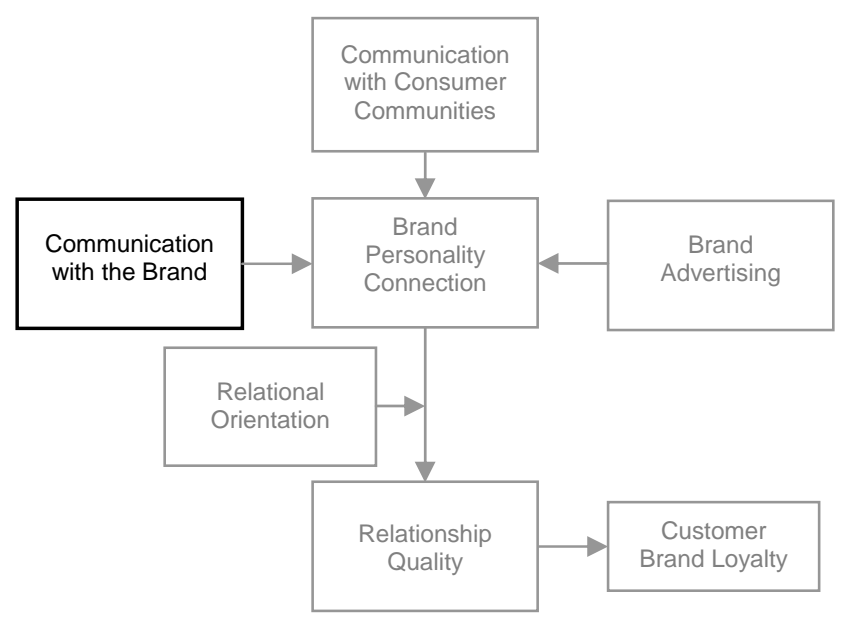

Consumers actively participate in communication regarding a brand by responding to or initiating such communication. This communication response and initiation is referred to as interactive communication. It is recognised within the literature that customer relationships are fostered through communication that is interactive (Ballantyne, 2004; Duncan \& Moriarty, 1998; Gronroos, 2004; Yadav \& Varadarajan, 2005). An interactive process of communication involves the two-way flow of messages between parties. A communication recipient's set of reactions to receiving a message is regarded as their message response (Belch \& Belch, 2004). It has, therefore, been suggested that interaction begins when an action generates a response (Ballantyne, 2004). In the context of the development and maintenance of a customer relationship through communication, response takes the form of a consumer response to communication sent regarding a brand. In a process of interactive communication consumers not only receive communication regarding a brand, but also create and send their own communication. Thus, the consumer becomes the communication source; deliberately encoding thoughts, ideas, and information into a message that is sent to another party. Communication sourced from a consumer concerning a brand can conceivably be either positive or negative in nature, and to varying degrees.

Further to communication response, consumers initiate two-way communication regarding a brand. They do this by sending communication concerning a brand which requires its own response. A consumer may derive value (Ravald \& Gronroos, 1996) from being able to control the initiation of communication. As such, customer relationships can be developed and maintained through two-way communication that is initiated by the consumer. A consumer, however, must be willing and able to initiate the sending of communication between themselves and others for this to occur. Such communication sending and receiving can build cumulatively as consumers engage in reciprocal communication response regarding a brand. This is referred to as a process of communication dialogue between parties (Ballantyne, 2004; Gronroos, 2004). Dialogue builds upon itself as one party sends a message to the other and subsequently receives a response. The initial communication source then sends a further 
message and receives another response. Parties, therefore, engage in dialogue with each other by receiving and sending reciprocal communication. From a consumer perspective dialogue involves both receiving communication from and sending reciprocal communication to others over time. The time taken between sending and receiving corresponding communication is regarded as the temporal proximity of dialogue (Yadav \& Varadarajan, 2005). Should the temporal proximity of communication sent and received be close then it is acknowledged that the dialogue is occurring in real-time (Hoffman \& Novak, 1996). Without consumer participation neither party could acquire value through communication. In this way, consumers can be considered active co-producers of value (Prahalad \& Ramaswamy, 2004; Sheth \& Parvatiyar, 1995; Veloutsou, et al., 2002) in the communication process with a brand.

Interactive communication is mediated by Internet based, as well as non-Internet based media channels. In fact, the facilitation of interactive communication is regarded as one of the most powerful and distinctive capabilities of media that is connected to the Internet (Hoffman \& Novak, 1996). An interactive communication process requires that consumers can respond to or initiate communication. As a form of one-way communication, advertising sent from a brand is not open to direct consumer response or initiation. Consequently, one-way advertising is for the most part mediated by non-Internet based media only. A consumer can, however, engage in interactive communication with a brand or consumer community via both media that is connected to the Internet and media that is not. The literature suggests that Internet based media facilitate the development and maintenance of customer relationships (Arnott \& Bridgewater, 2002; Artis, et al., 2001; Srirojanant \& Thirkell, 1998). Such media may even be better at facilitating customer relationships than non-Internet based media (Brady, et al., 2002; Gilbert, et al., 1999; Wang, et al., 2000; Zineldin, 2000).

Similarly, consumer communities exist in both virtual and real worlds. Communication mediated by Internet based media is acknowledged as being ideally suited to the facilitation of consumer communities (Szmigin, et al., 2005). In the present research Internet based media is conceptualised as including all media enabled through the common protocol of the Internet, such as the world wide web and e-mail. Mass communications tools not connected to the Internet, such as magazines, newspapers, radio, and television are recognised as lacking interactivity (Hoffman \& Novak, 1996; Shih, 1998; Stewart \& Pavlou, 2002). Accordingly, nonInternet based media comprise face-to-face, paper based, and non-Internet connected telephone communications. A summary of interactive Internet based and non-Internet based media is provided in appendix $A$.

Consumers and brands engage in interactive communication; receiving communication from as well as sending communication to each other. The independent construct of Communication with the Brand adopts a consumer perspective regarding interactive communication. It, therefore, determines the interactive communication that a consumer 
perceives they engage in with a brand. This interactive process of communication by which brands and consumers are both message originators and message recipients is also referred to as bidirectional communication (Andersen, 2001; Yadav \& Varadarajan, 2005). The bidirectionality of communication refers to the degree to which communication between parties is a two-way process (Fisher, Maltz, \& Jaworski, 1997; Mohr, et al., 1996; Mohr \& Nevin, 1990). Brands may facilitate two-way communication through the provision of a channel by which consumers are able to send messages. However, the ability to engage in two-way communication with a brand will not necessarily ensure consumers do so. A consumer will not respond to or initiate communication with a brand if they do not want to develop or maintain some form of relationship. This may or may not be conscious and deliberate behaviour. It is expected that the perceived frequency of interactive communication that a consumer engages in with a brand, as well as the extent to which this communication is positive or negative in nature, will affect the consumer's connection with the brand. The construct of Communication with the Brand, accordingly, captures the perceived frequency and nature of interactive communication that a consumer engages in with a brand. As such, it reflects a consumer's communication experience with a brand. The conceptual model guiding this research suggests that a consumer's perceived communication with a brand directly influences their connection with the brand.

Communication with the Brand captures the perceived frequency and nature of interactive communication that a consumer engages in with a brand. Measurement of this construct, therefore, reflects interactive communication between a consumer and a brand. Research respondents were asked to indicate how often they engage in communication regarding a specific brand through various channels, as well as the extent to which such communication is positive or negative. Items used to capture this construct referred to interactive communication facilitated by both Internet based and non-Internet based media, as well as overall interactive communication with a brand. 


\subsubsection{Communication with Consumer Communities}

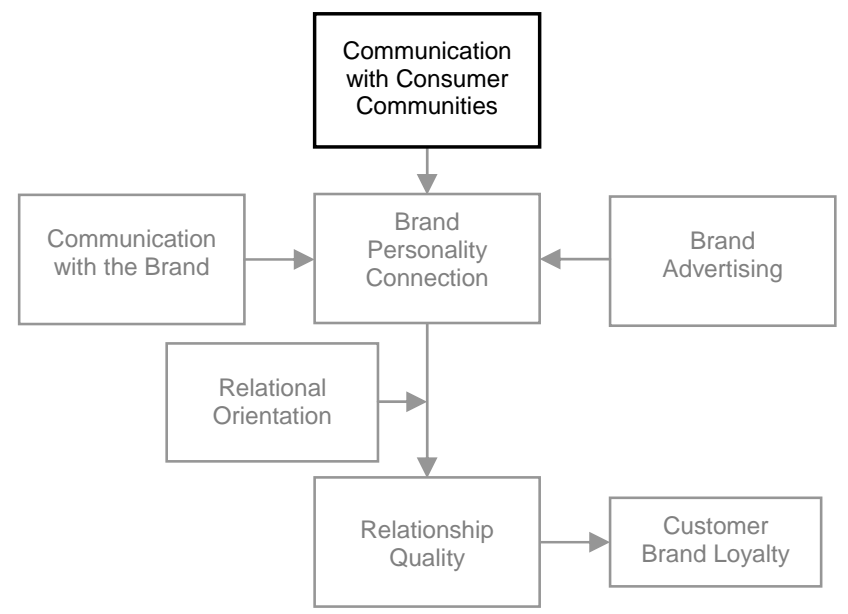

Further to interactive communication regarding a brand occurring between consumers and brands, such communication also takes place amongst consumer communities (Achrol \& Kotler, 1999). The construct of Communication with Consumer Communities captures the perceived frequency and nature of interactive communication that a consumer engages in with consumer communities, regarding a brand. It, therefore, measures the consumer's communication experience with consumer communities regarding the brand. Consumers receive, reply to, and initiate communication concerning a brand with parties other than those representing the brand. Community members are brought together through a common interest in a brand and the value that they acquire from interacting with other members (McAlexander, et al., 2002). Those in a consumer community, therefore, engage in interactive communication regarding a brand; sending communication to and receiving communication from others within the community. Consumer communities exist so that consumers can share their brand experiences (Bagozzi \& Dholakia, 2006; Cova \& Cova, 2002). Interaction within a consumer community focuses upon communication regarding a brand that occurs amongst parties other than those directly representing the brand. Accordingly, consumer communities are comprised of consumers, as well as third party organisations such as brand review and comparison services. Third party organisations are included as they do not directly represent the brand; however, interactive communication regarding a brand with such organisations is expected to affect the development, maintenance and nature of a customer relationship.

It is recognised that consumers can receive, reply to, and initiate negative communication regarding a brand within a consumer community. Communication of this nature is sent and received in anti-brand communities, for example (Maclaran \& Catterall, 2002). Consumers, therefore, engage in both positive and negative interactive communication regarding a brand with other consumers and third party organisations within consumer communities. In this way community members share their collective brand experience. The independent construct of Communication with Consumer Communities is similar to that of Communication with the 
Brand. Both constructs capture a consumer's interactive communication regarding a brand, however, the two constructs differ in that they measure such communication with different parties. Consumer communities are noted as enhancing customer relationships (Szmigin, et al., 2005). Furthermore, it is recognised that consumers feel an emotional connection with groups that they belong to (Algesheimer, et al., 2005). Accordingly, as with interactive communication sent and received between consumers and brands, it is expected that interactive communication regarding a brand sent and received amongst consumer communities will affect a consumer's connection with the brand.

The construct of Communication with Consumer Communities captures the perceived frequency and nature of interactive communication that a consumer engages in with consumer communities, regarding a brand. Consumer communities exist so that consumers can share their brand experiences. Interaction within a consumer community comprises communication amongst parties other than those directly representing the brand. Accordingly, measurement of this construct focuses upon a consumer's interactive communication regarding a brand with friends and family. Like Communication with the Brand, items used to capture this construct referred to interactive communication with consumer communities facilitated by Internet based and non-Internet based media, as well as overall interactive communication.

\subsubsection{Relationship Quality}

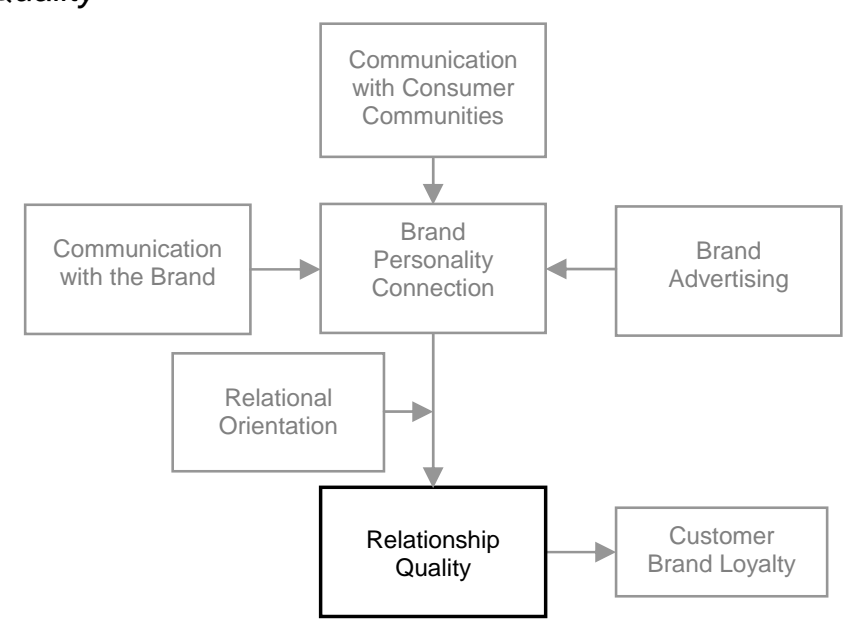

The construct of Relationship Quality captures the quality of a customer relationship between a consumer and a brand. Relationship Quality is directly influenced by a consumer's connection with a brand and indirectly influenced by the communication that a consumer engages in regarding the brand. Relationship Quality is recognised as a higher-order construct (Crosby, et al., 1990; Dorsch, et al., 1998; Dwyer \& Oh, 1987) which reflects a consumer's evaluative judgement regarding the excellence of a relationship. Extant literature examining the quality of customer relationships between consumers and brands identifies 
Relationship Quality as including the dimensions of commitment, interdependence, intimacy, love and passion, partner quality, satisfaction, self-connection, and trust.

The dimensions of commitment, partner quality, and self-connection were not included in the present research, to ensure conceptual distinction amongst the examined constructs. The dimension of commitment reflects a desire to continue a relationship with a brand, in addition to making an effort with the intention of developing and maintaining the relationship (De Wulf, et al., 2001; Dwyer, et al., 1987; Morgan \& Hunt, 1994). Commitment is multi-dimensional, including an affective bond (Dwyer, et al., 1987; Kressmann, et al., 2006) and a behavioural intention to support relationship longevity (Fournier, 1998). This is similar to loyalty, which captures an affective expression of preference as well as a behavioural commitment to repurchase (Gupta \& Zeithaml, 2006; Oliver, 1999; Zeithaml, Berry, \& Parasuraman, 1996). The literature, accordingly, recognises commitment and loyalty as conceptually similar constructs (Fournier, 1998). Customer Brand Loyalty is acknowledged as an important performance indicator (Chaudhuri \& Holbrook, 2001) and a salient construct within the conceptual model. For this reason the relationship quality dimension of commitment was removed in the current study to prevent overlapping with the brand loyalty construct.

Equally, the dimension of partner quality is conceptually similar to the relationship quality dimension of trust. Partner quality is determined according to judgements regarding a brand's dependability, reliability, and predictability, adherence to rules, trust in that which the brand delivers, and comfort in the brand's accountability (Fournier, 1998). It is noted that trust is determined according to judgements regarding confidence in a brand's reliability and integrity (De Wulf, et al., 2001; Dorsch, et al., 1998; Morgan \& Hunt, 1994). Some authors suggest that cognitive evaluations of relationship trust are sufficient determinants of the construct (De Wulf, et al., 2001; Morgan \& Hunt, 1994; Sirdeshmukh, et al., 2002). Therefore, both partner quality and relationship trust between a consumer and a brand can be determined by the consumer's cognitive evaluation regarding the perceived reliability of a brand. Of the two constructs, trust is more established in the literature and was therefore retained as a dimension of relationship quality within the present research.

Furthermore, the relationship quality dimension of self-connection is conceptually similar to the research construct of Brand Personality Connection. Both concepts examine a consumer's perceived alignment with the image of a brand. Within the extant literature, the dimension of self-connection with a brand is determined by a consumer's perceived alignment between their self-image and the image of a brand (Aaker, et al., 2004; Fournier, 1998). In fact, the research construct of Brand Personality Connection is based on this relationship quality dimension. The present research looks to focus on this aspect of a relationship, specifically examining the process by which consumers form relationships with brands. This variable is, therefore, treated as a separate and central construct. 
In this study the construct of Relationship Quality comprises five separately identifiable and distinct dimensions, including interdependence, intimacy, love and passion, satisfaction, and trust. Relationship interdependence occurs when there is mutual dependency between a consumer and brand (Kressmann, et al., 2006). Strong brand relationships are recognised as comprising a high level of interdependence between parties (Fournier, 1998; Thorbjornsen, et al., 2002). Accordingly, the consumer depends on the brand and the brand depends on the consumer. This is exhibited by the consumer frequently interacting with the brand and interacting at an intense level (Fournier, 1998). From a consumer perspective interdependence exists when the brand is depended on. Interdependence is, therefore, determined according to the level of personal importance if not necessity which a consumer associates with a brand.

The dimension of relationship intimacy is reflected in knowledge or understanding regarding a relationship partner (Aaker, et al., 2004; Fournier, 1998; Kressmann, et al., 2006; Thorbjornsen, et al., 2002). Consumers develop elaborate knowledge structures around certain brands and feel a closeness towards them (Fournier, 1998; Thorbjornsen, et al., 2002). This occurs when they perceive that they understand the brand and that the brand understands them in return (Aaker, et al., 2004). There are, therefore, two elements to relationship intimacy. In the present research, intimacy is determined by a consumer's level of perceived knowledge concerning a brand, as well as the perceived extent of consumer understanding exhibited by the brand.

Relationship love and passion concerns a consumer's degree of affection towards a brand. Like their relationships with other people, consumers exhibit varying feelings of love towards brands, ranging from warmth to obsessive dependency (Fournier, 1998). It is, accordingly, recognised that consumers may feel a sense of love or passion towards brands with which they have a relationship (Fournier, 1998; Kressmann, et al., 2006; Thorbjornsen, et al., 2002). In the present research, this relationship quality dimension is determined by the extent to which a consumer feels passionate about a brand.

Relationship satisfaction results from an overall appraisal of a cumulative relationship (De Wulf, et al., 2001). Perceived value is an important aspect of relationship satisfaction (Dorsch, et al., 1998). It is the value that an individual consumer perceives that they are receiving from being involved in ongoing relational exchange with a brand that determines their level of relationship satisfaction. Perceived value is established according to the perceived benefits that the consumer obtains in relation to the perceived sacrifice that they must make when engaging in exchange with the brand (Gronroos, 2004). The dimension of relationship satisfaction captures a consumer's assessment of the value that they perceive they obtain 
from being involved in a relationship and is determined by the extent to which a consumer feels satisfied by a brand.

Finally, as previously discussed, relationship trust is a cognitive evaluation regarding confidence in an exchange partner's reliability and integrity (De Wulf, et al., 2001; Morgan \& Hunt, 1994). The literature suggests that cognitive evaluations of relationship trust are necessary and sufficient determinants of the construct (De Wulf, et al., 2001; Morgan \& Hunt, 1994; Sirdeshmukh, et al., 2002). Therefore, relationship trust between a consumer and a brand can be determined by the consumer's evaluation regarding confidence in the brand's reliability and integrity. The trust dimension of relationship quality captures the extent to which a consumer believes that a brand is reliable and possesses integrity. In the present research, this dimension is determined by asking individuals their level of trust in a brand.

The items used to measure this construct were based on scales provided by a number of authors (Aaker, et al., 2004; De Wulf, et al., 2001; Kressmann, et al., 2006; Thorbjornsen, et al., 2002). Items in the form of statements regarding a specific brand were used to measure the construct of Relationship Quality, with each item reflecting a dimension of the construct.

\subsubsection{Relational Orientation}

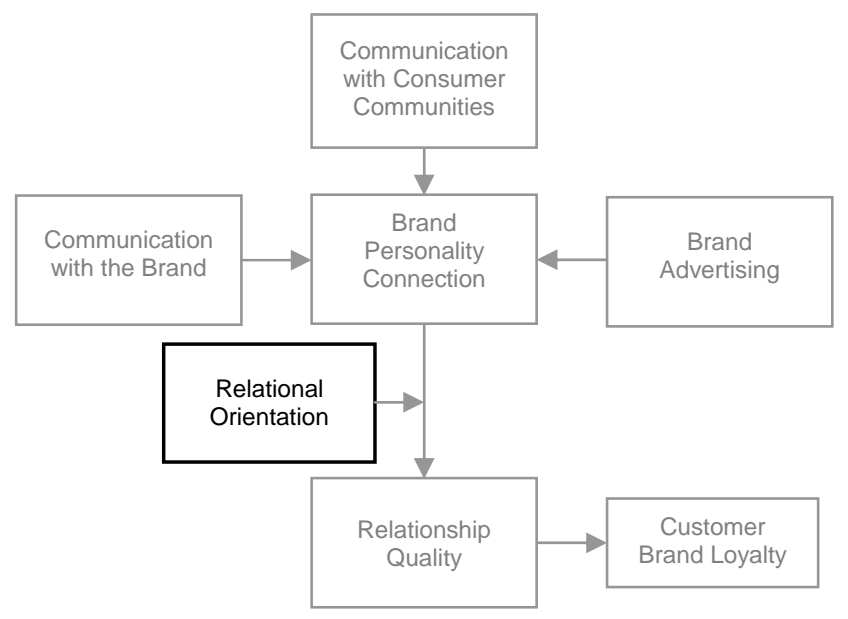

The construct of Relational Orientation captures a consumer's favourability towards being involved in customer relationships with brands in a product or service category. Relational Orientation addresses a consumer perspective regarding their overall involvement in the development and maintenance of customer relationships with product or service category brands. Due to the mutual nature of a relationship both brands and consumers must be willing to engage in ongoing relational exchange in order for a customer relationship to transpire. It is recognised that consumers vary regarding their involvement in customer relationships (Day, 2000) and, therefore, possess varying degrees of individual favourability towards relational 
exchange (Garbarino \& Johnson, 1999; V Liljander \& Roos, 2002). The extent to which a consumer favours being involved in relationships with brands in a product or service category will vary according to the individual consumer. It is possible that some consumers favour engaging in a relatively low level of relational exchange with brands in a category, or are averse to being involved in customer relationships. Such consumers do not favour being involved in customer relationships and, according to the marketing strategy continuum (Gronroos, 1994), will favour engaging in more transaction focussed exchange with brands. A consumer's favourability towards being involved in customer relationships with brands in a product or service category may be positive to varying levels, or negative if they ordinarily favour transactional exchange with brands.

The extent to which a consumer favours being involved in relationships with brands in a product or service category is established through the concept of perceived value. Value is regarded as an important part of relationship marketing. This is based on the premise that relationships are forged through the mutual exchange of value between parties over time (Ravald \& Gronroos, 1996). The value that a consumer perceives they are obtaining from being involved in a customer relationship is the perceived benefit that a consumer receives relative to the perceived sacrifice that they must make when engaging in relational exchange (Day, 1990; Gronroos, 2004). A consumer will favour being involved in customer relationships if they believe they obtain value in doing so. The construct of Relational Orientation is determined by an evaluative judgement made by the consumer regarding the value that they receive from being involved in relationships with brands in a product or service category.

The literature indicates that consumers evaluate the quality of relationships with brands according to dimensions of interdependence, intimacy, love and passion, satisfaction, and trust. In the present research a consumer's overall evaluation concerning brand relationships in a product or service category is determined according to the same dimensions. A consumer will favour relationships with brands in a product or service category if they receive feelings of interdependence, intimacy, love and passion, satisfaction, and trust from being involved in such relationships. Relational Orientation is, therefore, defined at both an individual and product category level. It is expected that a consumer's favourability towards being involved in customer relationships will vary not only according to the individual, but also the product category in question. While determined by the same dimensions, it is noted that Relational Orientation measures a consumer's generalised sentiment towards being involved in customer relationships; compared to Relationship Quality which measures brand-specific sentiment.

The construct of Relational Orientation reflects the value that a consumer perceives they acquire from involvement in relationships with brands in a product or service category and derives from an evaluation regarding engaging in such behaviour. Consumers evaluate the 
quality of their relationships with brands according to dimensions of interdependence, intimacy, love and passion, satisfaction, and trust. A consumer's Relational Orientation is measured through a new scale capturing these dimensions.

\subsubsection{Customer Brand Loyalty}

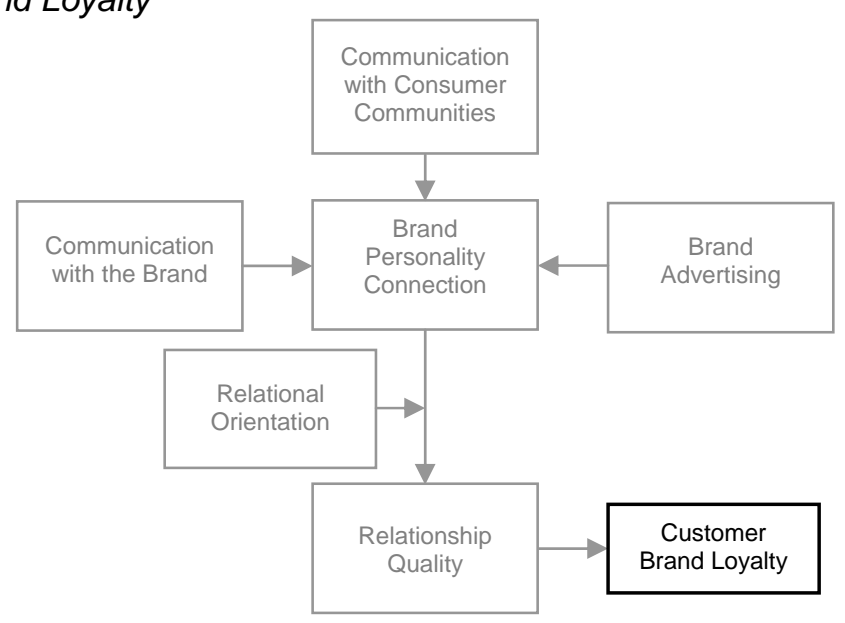

Although the present research focuses on a consumer perspective regarding the development and maintenance of customer relationships with brands, it is important to acknowledge the outcomes of a relationship for a brand. Like consumers, brands will participate in customer relationships if they obtain value from doing so. The performance outcomes of a relationship for the brand, therefore, justify their involvement in a relationship with a consumer. It is accepted that brands cannot literally assess their involvement in a relationship. This is done by those that control the brand. Consumers, however, consider brands to be active relationship partners (Aggarwal, 2004; Fournier, 1998). Therefore, the present research refers to performance outcomes of a customer relationship for the brand. The construct of Customer Brand Loyalty reflects one possible performance outcome for a brand of being involved in a customer relationship. Other measures of brand performance include market share (Buzzell \& Wiersema, 1981; McKee, Varadarajan, \& Pride, 1989) and profitability (Dekimpe \& Hanssens, 1999; Narver \& Slater, 1990). Customer Brand Loyalty was used as the dependant variable because it is an accepted measure of brand performance (Chaudhuri \& Holbrook, 2001; Dick \& Basu, 1994) that, like a relationship, develops over time (Gupta \& Zeithaml, 2006; Oliver, 1999). Loyalty is recognised as a basis for developing sustainable competitive advantage (Dick \& Basu, 1994), allowing brands to charge premium prices and experience greater market share (Chaudhuri \& Holbrook, 2001). As indicated in the conceptual model, the effect of Relationship Quality upon the performance of a brand is examined. It is expected that the quality of a relationship between a consumer and a brand will directly influence Customer Brand Loyalty for the brand. 
Customer Brand Loyalty is conceptualised as an important performance outcome of being involved in a customer relationship for a brand. It is identified as an asset which contributes towards brand equity (Leone, Rao, Keller, Luo, McAlister, \& Srivastava, 2006). Loyalty is recognised as having both attitudinal and behavioural indicators (Jacoby, Chestnut, \& Fisher, 1978) and is defined as "a deeply held commitment to rebuy or repatronise a preferred product/service consistently in the future, thereby causing repetitive same-brand or same brand-set purchasing, despite situational influences and marketing efforts having the potential to cause switching behaviour" (Oliver, 1999, p. 36). Repeated exchange is fundamental to a relationship. Repetitive brand purchasing is a form of repeated exchange salient to a brand, as brands receive value from consumer purchases. The Zeithaml, et al (1996) scale to measure Brand Loyalty has been used by a number of authors (Bell, Auh, \& Smalley, 2005; Sirdeshmukh, et al., 2002) and reflects an intention on behalf of the customer to perform behaviour that signals a motivation to maintain a relationship, including engaging in positive word of mouth and repeat purchasing (Gupta \& Zeithaml, 2006). In the present research Customer Brand Loyalty is determined according to the extent to which a consumer says positive things about the brand, recommends the brand to someone who seeks advice, encourages friends and relatives to do business with the brand, considers the brand their first choice, and intends to do business with the brand in the next few years (Zeithaml, et al., 1996). The construct of Customer Brand Loyalty, therefore, comprises attitudinal as well as behavioural indices of loyalty and captures a consumer's level of loyalty regarding a brand.

With operational definition given to the constructs of the conceptual model, in Figure $3 \mathrm{~b}$ below, the following section discusses the scales used to measure each construct. Section 4.1 therefore provides an explanation of the techniques adopted to develop the construct measures, including detail regarding the types of scales and items used. 
Figure 3b. Conceptual Model with Construct Definitions

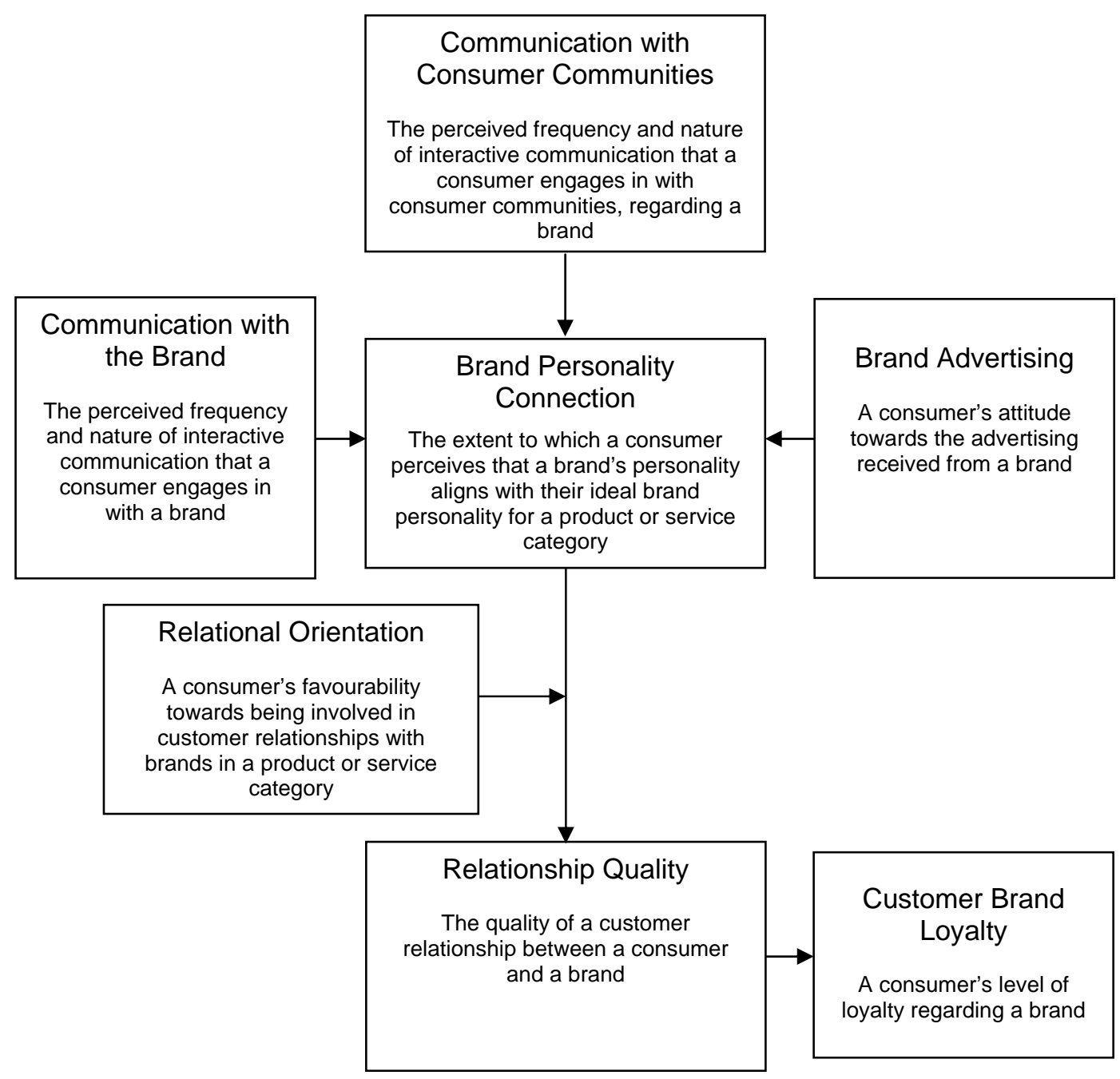




\subsection{Hypotheses and Full Conceptual Model}

With the complete conceptual model identified and research constructs defined, specific research hypotheses are now discussed. Overall, the hypotheses covered in this section are based on the expected relationships amongst constructs. The subsequent research methodology is guided by these hypotheses, as is analysis and testing of data. Research hypotheses one, two, and three are concerned with confirming the linkage between the communication that a consumer engages in regarding a brand and the construct of Brand Personality Connection. Three forms of communication that a consumer can engage in concerning a brand, acknowledged as critical in a relationship (Duncan \& Moriarty, 1998), are considered. These include advertising sourced from the brand, interactive communication with the brand, as well as interactive communication with consumer communities.

Advertising sent from a brand and received by a consumer may or may not be intended to develop and maintain a customer relationship. However, it is hypothesised that advertising influences a consumer's relationship with a brand. Consumers are noted as co-producers of value in the process of communication (Gruen, et al., 2000; Sheth \& Parvatiyar, 1995). Although they cannot directly respond to advertising sent from a brand, consumer participation as communication receivers is necessary. Consequently, consumer evaluation of advertising is expected to influence their perceived brand connection. In the present study, a consumer's evaluation of advertising regarding a brand is determined by their attitude towards the brand's advertising. Advertising being a key type of one-way communication sent from a brand. The literature indicates that attitudes are formed through cognitive and affective evaluation (Ajzen, 2001; Zajonc \& Markus, 1982). Given the affective aspect of this evaluation, it is reasonable to expect that a consumer's attitude towards a brand's advertising will influence their connection with that brand. Research hypothesis one is based on this likely relationship.

H1. A consumer's attitude towards the advertising received from a brand positively influences the consumer's connection with the brand.

Similarly, interactive communication, which occurs between consumers and brands as well as within consumer communities, is recognised as significant in the development and maintenance of relationships (Ballantyne, 2004; Gronroos, 2004). Interactive communication requires communication response or initiation beyond just the receiving of one-way messages. Individuals form relationships with other parties by participating in interactive communication (Fisher, et al., 1997; Mohr, et al., 1996; Mohr \& Nevin, 1990). The time taken between sending and receiving corresponding messages is an important part of this communication and therefore influences relationship formation (Hoffman \& Novak, 1996; Yadav \& Varadarajan, 2005). Consequently, it is predicted that consumers develop and maintain at 
least some form of relationship with brands when they engage in interactive communication with them. This may or may not be conscious and deliberate behaviour on behalf of the consumer, but can occur with differing frequency and be positive or negative in nature to varying degrees. A connection is made between a consumer and a brand when the brand reflects significant aspects of a consumer's self (Thorbjornsen, et al., 2002), determined by an alignment of the consumer's self image and that of the brand (Dolich, 1969; M. Sirgy, Grewal, Mangleburg, Park, Chon, Claiborne, Johar, \& Berkman, 1997). It is expected that the more a consumer engages in positive communication regarding a brand, the more positively they will see the brand. Therefore, they will perceive the brand reflecting aspects of their self. Research hypothesis two reflects this relationship between a consumer's interactive communication with a brand and their perceived connection with the brand.

$\mathrm{H} 2$. The perceived frequency and nature of interactive communication that a consumer engages in with a brand positively influences the consumer's connection with the brand.

Interactive communication regarding a brand is also recognised as occurring amongst consumer communities (Achrol \& Kotler, 1999). Community members are brought together through common interest (McAlexander, et al., 2002) and interact with each other, sharing brand experiences (Bagozzi \& Dholakia, 2006; Cova \& Cova, 2002). Again, this type of interactive communication varies in frequency and can be positive or negative in nature (Maclaran \& Catterall, 2002). It is recognised that consumer communities can enhance customer relationships, as consumers perceive a connection with the groups that they belong to (Algesheimer, et al., 2005; Szmigin, et al., 2005). Hypothesis three reflects the expectation that a consumer's interactive communication with consumer communities, regarding a brand, will influence their connection with the brand.

H3. The perceived frequency and nature of interactive communication that a consumer engages in with consumer communities regarding a brand positively influences the consumer's connection with the brand.

Brand image congruity enhances the self and, subsequently, influences consumer behaviour (Dolich, 1969; Graeff, 1996). In the present research, an alignment between the perceived personality of a brand and a consumer's ideal brand personality is used as a category specific measure of the connection with a brand. Brand Personality Connection is expected to affect overall Relationship Quality between a consumer and a brand. Therefore, the extent to which a consumer perceives that the personality of a brand aligns with their ideal brand personality is conceptualised as directly influencing the quality of a customer relationship. Relationship Quality is determined through several dimensions including interdependence, intimacy, love and passion, satisfaction, and trust (Aaker, et al., 2004; De Wulf, et al., 2001; Fournier, 1998; Garbarino \& Johnson, 1999; Kressmann, et al., 2006). A consumer that perceives a brand as 
ideal will make positive evaluations about that brand (Graeff, 1996). Relationship Quality is acknowledged as an evaluative judgement regarding the excellence of a relationship (Zeithaml, 1988). It is, therefore, expected that the more a consumer perceives their personality is aligned with that of a brand, the more positive will be their evaluation of the brand relationship. Research hypothesis four addresses this linkage between the constructs of Brand Personality Connection and Relationship Quality.

H4. Brand Personality Connection positively influences the level of Relationship Quality.

Furthermore, consumers favour being involved in customer relationships with brands to varying levels (Garbarino \& Johnson, 1999). Such overall favourability towards being involved in customer relationships with brands in a product or service category is conceptualised as Relational Orientation. It is expected that the linkage between a consumer's connection with a brand and the quality of a customer relationship is moderated by the consumer's level of favourability towards being involved in customer relationships with brands in a product or service category. Other influences of Relational Orientation could be examined; such as a direct link between Relational Orientation and Brand Personality Connection or Relational Orientation as a moderating variable between the various forms of communication consumers engage in and Brand Personality Connection. However, theory suggests that Relational Orientation impacts the manner in which consumers evaluate relationships (Garbarino \& Johnson, 1999). In the present research such an evaluation is conceptualised as Relationship Quality. Research hypothesis five, therefore, concerns the moderating influence of a consumer's relational orientation.

H5. The association between Brand Personality Connection and Relationship Quality is positively moderated by a consumer's Relational Orientation.

A secondary objective of the research is to examine the consequences of customer relationships for the owners of a brand. The consequences of a customer relationship for the owners of a brand are important, as such outcomes help justify a brand's involvement in a relationship. Customer Brand Loyalty, noted as a salient performance outcome of a customer relationship for a brand owner (Chaudhuri \& Holbrook, 2001; Dick \& Basu, 1994) is examined in the present research. Customer Brand Loyalty addresses a consumer's level of loyalty regarding a brand. Research hypothesis six concerns the linkage between the quality of a customer relationship and the consequences of such a relationship for a brand owner.

H6. Relationship Quality positively influences Customer Brand Loyalty.

In developing a measurement instrument it is important that not only the proposed linkages between constructs of the conceptual model are upheld, but also that the intended measures 
of the research constructs are valid and reliable. The validity of a construct considers the degree of correspondence between an unobservable construct and the intended measure (Peter, 1981). Construct reliability determines whether the measurement instrument produces consistent results by examining the extent to which the construct measures are free from error (Peter, 1979). As such the present research also examines the validity and reliability of the construct measures.

Figure 3c. Conceptual Model with Construct Definitions and Hypotheses

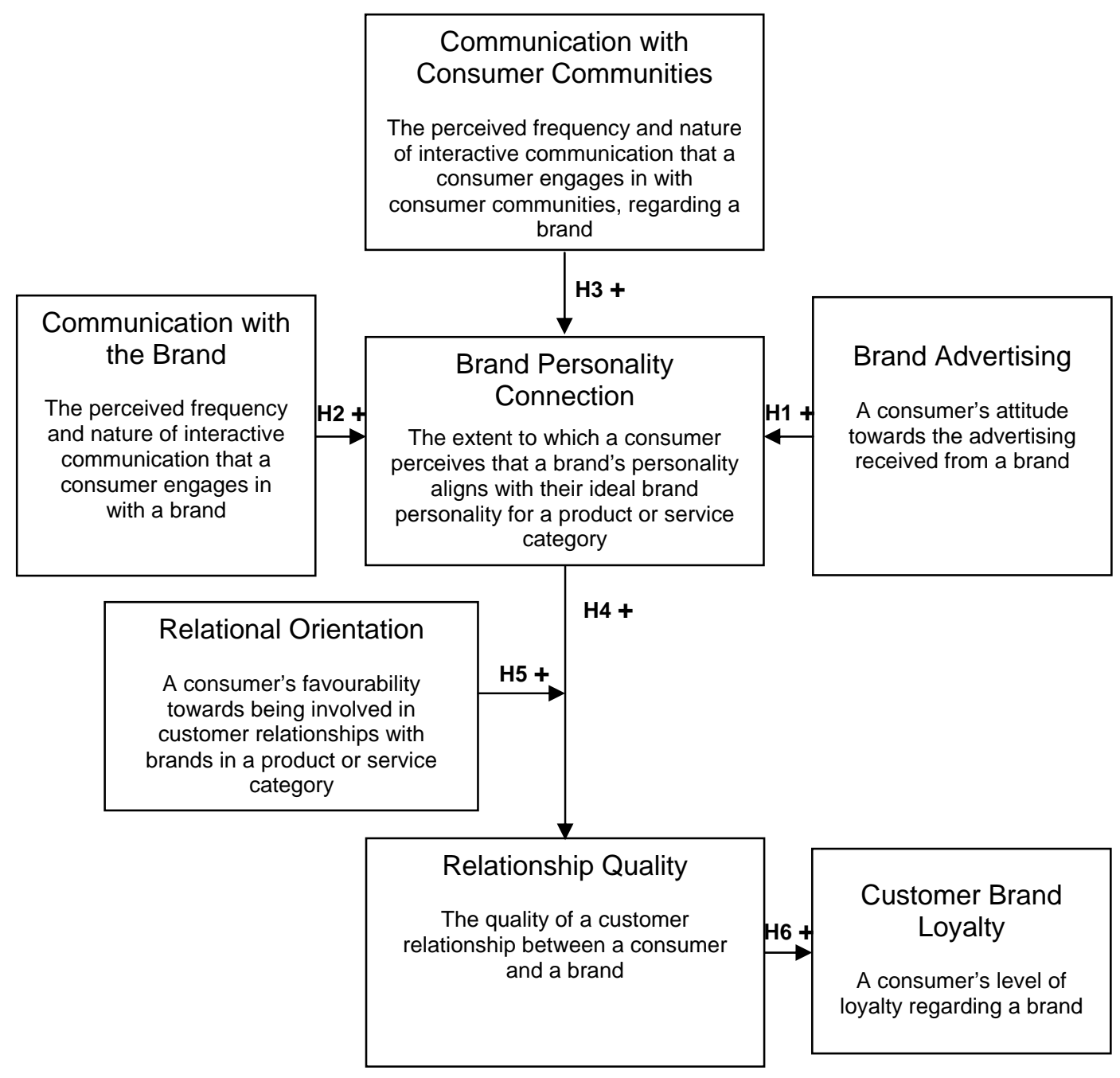




\subsection{Research Methodology}

The research examined the process by which customer relationships are formed from a consumer perspective. Its primary objective is to investigate how consumers participate in the development and maintenance of a customer relationship through communication. Consequently, insight from individual consumers concerning their communication and relationships with certain brands has been sought. The research was conducted in a New Zealand context. New Zealand is a developed country and responses from New Zealand consumers were expected to reflect those of consumers residing in other developed nations. The brands which potential respondents were asked to consider their communication and relationship with operate in the New Zealand commercial airline industry. More specifically, these are brands offering personal air travel to New Zealand residents. The New Zealand commercial airline industry was utilised as the focal industry of this research for a number of reasons. Foremost, airlines offering personal air travel services strive to develop and maintain customer relationships with end consumers. This is important as consumers are more likely to reciprocate the relationship desired by the brand. Also, consumers residing in New Zealand are exposed to numerous forms of communication from commercial airline operators and can engage in interactive communication through Internet based, as well as non-Internet based, media with brands operating in this industry.

The research population is defined as all New Zealand resident adults. For the purposes of the research, adults are considered all individuals who are aged 18 years and older at the time of data collection. The population, therefore, comprised New Zealand residents aged 18 years and older. Residents aged less than 18 years were not included in the population. This is because measuring concepts such as consumer ideal self and future self is recognised as difficult with younger children, and that self-brand connections increase with age (Chaplin \& John, 2005). The central construct of Brand Personality Connection, for example, comprises elements of the self and perceived alignment with a brand's personality. Previous research regarding customer relationships with individual consumers has involved respondents aged 18 years or older (Aaker, et al., 2004; Fournier, 1998; V Liljander \& Roos, 2002). In addition respondents aged 18 years or older are more likely to pay for their own air travel, allowing brand loyalty to be measured.

New Zealand residents can travel by commercial airline both domestically within the country and internationally to and from other nations. Three major commercial airlines operate domestic flights in New Zealand. These airlines are Air New Zealand, Pacific Blue, and Qantas. Air New Zealand is considered New Zealand's national airline and flies to 26 domestic destinations (Air New Zealand, 2008). This airline dominates the country's commercial airline market, offering over 550 domestic flights each day (Air New Zealand, 2008) and carrying over 7.5 million domestic passengers during the 2007 financial year (Air 
New Zealand, 2007). Pacific Blue is part of parent company Virgin Airlines and is positioned within the New Zealand domestic airline market as a low cost airline. Virgin launched the Pacific Blue brand in January 2004 as a New Zealand based airline offering flights between New Zealand, Australia, and the Pacific Islands. The airline commenced New Zealand domestic flights in November 2007 (Virgin Blue, 2008) and offers 70 domestic flights per week between New Zealand's major cities, Auckland, Christchurch, and Wellington (Virgin Blue, 2007). Although recognised as Australia's national airline, Qantas services 230 domestic flights throughout New Zealand each week, flying between Auckland, Christchurch, Queenstown, Rotorua, and Wellington (Qantas Airlines, 2008). Internationally, New Zealand residents are given the opportunity to travel on some 29 airlines (Auckland Airport, 2008). However, Air New Zealand carries a significant number of passengers to and from the country, with over 4.5 million international passengers annually (Air New Zealand, 2007). Over two million of the passengers carried by Air New Zealand internationally each year are on transTasman flights between New Zealand and Australia (Air New Zealand, 2005). Air New Zealand is thought to have an approximate 40 per cent share of the trans-Tasman commercial airline market, with Qantas possessing an approximate 35 per cent market share, and Pacific Blue leading the remaining airlines with an approximate market share percentage in single digits (Sheeran, 2007).

The research, therefore, focuses upon consumer relationships with commercial airlines operating in New Zealand. Respondents were asked to complete the research questionnaire with reference to Air New Zealand, as well as one other commercial airline operating in New Zealand with which they had travelled. The questionnaire consisted of three parts: $A, B$, and C. Part A was answered regarding Air New Zealand, part B regarding an additional selfselected airline, and Part $C$ consisted of general questions. After completing part $A$ of the questionnaire in reference to Air New Zealand, respondents were asked to complete section $B$ in reference to the airline they most frequently travel with selected from a provided list. If respondents had not travelled with any of the airlines from the list provided they were directed to part $\mathrm{C}$ of the questionnaire. In this way, the research constructs were measured for each participant in reference to one or two brands.

All respondents were asked to answer part A of the research questionnaire in reference to Air New Zealand, due to the airline's significant domestic market share and position as the national carrier. Carrying 12 million domestic and international passengers a year, most of New Zealand's three million adult residents (Statistics New Zealand, 2006) would have had direct experience with the brand at some point. If not a service experience, it is probable that they would at least have a level of brand awareness. It was expected that most would have formed an attitude towards the brand. Therefore, there was a basis for measuring relationship based constructs relevant to a high proportion of the New Zealand adult population. 


\subsection{Construct Measurement}

This section complements earlier discussion regarding scale definition, providing specific detail on the scale items used to measure each construct. In accordance with recognised technique regarding the development of construct measures in marketing (Churchill, 1979), the research scales arise from an established conceptual basis. The scales and accompanying items intended to measure each construct are directly linked to construct definitions obtained from the literature. From these literature-based construct definitions a set of items were established which tap each of the dimensions of the construct at issue (Churchill, 1979). In instances where appropriate construct dimension measurement scales had been previously published, scale items were adapted for the purposes of the research. In other cases, where measurement scales did not exist, original scales were created. Several self-report scales were developed to measure constructs. Where previously published scale items were available, scale items were added, removed, or re-worded to suit the research context. Scale items did not exist, however, for all construct dimensions.

The scales intended to measure the constructs of Communication with the Brand, Communication with Consumer Communities, and Brand Personality Connection are recognised as formative. While the scales used to measure Brand Advertising, Relationship Quality, Relational Orientation, and Customer Brand Loyalty are reflective. Constructs with formative indicators are conceived as an explanatory combination of indicators, determined by a combination of variables (Bucic \& Gudergan, 2004; Diamantopoulos \& Winklhofer, 2001; Fornell \& Bookstein, 1982). Conversely reflective constructs are those viewed as possessing underling factors to something observed, such as an attitude (Diamantopoulos \& Winklhofer, 2001). The validity of reflective measures was established by using partial least square analysis. Formative measures were likewise tested through the examination of formative indicators; including content specification, indicator specification, indicator collinearity, and external validity. Scale validation is discussed further in section 5.4 .

\subsubsection{Brand Personality Connection}

To determine brand personality, Aaker (1997) used five-point Likert scales anchored by 'not at all descriptive' and 'extremely descriptive' and asked subjects to rate the extent to which personality traits described a brand. Aaker (1997) acknowledges that Likert scales were used rather than semantic-differential scales, as the study was intended to determine the extent to which a brand can be described by certain human characteristics. The present research seeks to measure a specific brand's perceived association with personality characteristics. Therefore, semantic-differential scales are used. This is consistent with recommendations 
regarding scales used to determine brand personality (Aaker, 1997), as well as self-concepts in general (Malhotra, 1981). To create semantic-differential scale items incompetent, conservative, refined, pretentious, and relaxed were selected as contrasting descriptors to the brand personality dimensions identified by Aaker (1997). The Brand Personality Connection scale, therefore, comprised five five-point items with semantic-differential anchors of ruggedrefined, competent-incompetent, exciting-conservative, sophisticated-relaxed, and sincerepretentious. Table $4 a$ shows the items used to measure Brand Personality Connection.

Table 4a. Brand Personality Connection Items

\begin{tabular}{|c|c|c|}
\hline Items & Construct & Source \\
\hline How you would characterise [insert brand]? & \multirow{6}{*}{$\begin{array}{l}\text { Brand } \\
\text { Personality } \\
\text { Connection } \\
\text { (formative) }\end{array}$} & \multirow{6}{*}{$\begin{array}{c}\text { (Aaker, 1997) } \\
\text { No reported } \\
\text { Cronbach's Alpha } \\
\text { value }\end{array}$} \\
\hline Rugged - Refined & & \\
\hline Competent - Incompetent & & \\
\hline Exciting - Conservative & & \\
\hline Sophisticated - Relaxed & & \\
\hline Sincere - Pretentious & & \\
\hline
\end{tabular}

\subsubsection{Brand Advertising}

Scale items used to measure the construct of Brand Advertising are based on the Batra and Stayman (1990) Attitude toward the Brand scale. An Attitude toward the Brand scale was used as the basis of measurement as the construct captures a consumer's attitude, specifically towards the advertising received from a brand. Consumer attitudes result from an evaluation of an issue or object in question. Batra and Stayman (1990) provide a ten item seven-point semantic-differential scale to measure Attitude toward the Brand and report a coefficient alpha value of 0.94 . Factor analysis concerning this original scale revealed that the ten items could be analysed as two factors, one factor reflecting hedonism and the other utilitarianism. However, results using two separate scales were not significantly different to those when using one scale (Batra \& Stayman, 1990). Half of the ten semantic-differential items used to measure a consumer's evaluation of Brand Advertising in the present study were selected at random to be reversed. This was done to avoid participant responses tending to the positive or negative for each item (Fisher, 1993). The semantic-differential scale items intended to measure the construct of Brand Advertising comprised good-bad, useful-useless, positive-negative, agreeable-disagreeable, like-dislike, high quality-low quality, pleasant-unpleasant, valuable-worthless, beneficial-not beneficial, and favourableunfavourable. Table $4 \mathrm{~b}$ shows the items used to measure Brand Advertising. 
Table 4b. Brand Advertising Items

\begin{tabular}{|c|c|c|}
\hline Items & Construct & Source \\
\hline $\begin{array}{l}\text { In general, how would you describe [insert brand] } \\
\text { advertising? }\end{array}$ & \multirow{11}{*}{$\begin{array}{l}\text { Brand Advertising } \\
\text { (reflective) }\end{array}$} & \multirow{11}{*}{$\begin{array}{c}\text { (Batra \& Stayman } \\
\text { 1990) } \\
\text { Cronbach's Alpha } \\
=0.94\end{array}$} \\
\hline Good - Bad & & \\
\hline Useful - Useless & & \\
\hline Positive - Negative & & \\
\hline Agreeable - Disagreeable & & \\
\hline Like - Dislike & & \\
\hline High Quality - Low Quality & & \\
\hline Pleasant - Unpleasant & & \\
\hline Valuable - Worthless & & \\
\hline Beneficial - Not Beneficial & & \\
\hline Favourable - Unfavourable & & \\
\hline
\end{tabular}

\subsubsection{Communication with the Brand and Consumer Communities}

Communication with the Brand and Communication with Consumer Communities are similar in conceptual definition in that they capture the perceived frequency and nature of interactive communication that a consumer engages in regarding a brand. As such, the two constructs are measured by similar scales. The constructs differ, however, in that they capture a consumer's interactive communication regarding a brand with different parties. Communication with the Brand and Communication with Consumer Communities are measured through several self-report scale items. Five-point scales comprising never, rarely, occasionally, frequently, and very frequently answer categories were used to determine the frequency of each of the four different types of communication; face-to-face, telephone, web site, and e-mail. This was based on scales found within the extant marketing literature (Bush, Rose, Gilbert, \& Ingram, 2001; Coviello, et al., 2002; Katsanis, 2006; Kivetz \& Simonson, 2002; Newell, Goldsmith, \& Banzhaf, 1998; Singh, 1993). The literature reports the use of five-point Likert scales in previous research concerning bidirectional communication between parties (Fisher, et al., 1997). Five-point Likert-type scales were also used to measure the frequency of communication in general, as well as the nature of each communication type; ranging from very negative to very positive.

Scale items intended to measure Communication with the Brand and Communication with Consumer Communities captured communication facilitated by both Internet based, as well as non-Internet based, media. Items concerning the world wide web and e-mail were used to capture communication facilitated by Internet based media, while items concerning face-toface and telephone communications were used to capture non-Internet based media. Tables $4 \mathrm{c}$ and $4 \mathrm{~d}$ show the items used to measure Communication with the Brand and Communication with Consumer Communities. 
Table 4c. Communication with the Brand Items

a

\begin{tabular}{|l|l|c|}
\hline Items & Construct & Source \\
\hline
\end{tabular}

Frequency (never - very frequently)

How often do you talk face-to-face with [insert brand]

staff members, including check-in staff and in-flight

crew?

b How often do you talk on the telephone with [insert brand]?

c How often do you visit the [insert brand] Website?

d How often do you communicate with [insert brand] through e-mail or online live chat?

e

In general, how often do you communicate with [insert brand]?

Nature (very negative - very positive)

a How would you generally rate this experience?

b How would you generally rate this experience?

c How would you generally rate this experience?

d How would you generally rate this experience?

e How would you rate your overall communication with [insert brand]?

Table 4d. Communication with Consumer Communities Items

a

Items

Frequency (never - very frequently)

family about [insert brand]?

b How often do you talk on the telephone with friends or family about [insert brand]?

c How often do you e-mail friends or family about [insert brand]?

d How often do you participate in online discussions about [insert brand]?

e How often do you engage overall in discussion with others about [insert brand]?

Nature (very negative - very positive)

a Is face-to-face discussion about [insert brand] generally positive, negative, or neutral?

b Is telephone discussion about [insert brand] generally positive, negative, or neutral?

c Is e-mail discussion about [insert brand] generally positive, negative, or neutral?

d Is online discussion about [insert brand] generally positive, negative, or neutral?

e Is overall discussion about [insert brand] positive, negative, or neutral?

\subsubsection{Relationship Quality}

The construct of Relationship Quality captures the quality of a customer relationship between a consumer and a brand, and comprises five dimensions (Aaker, et al., 2004; De Wulf, et al., 
2001; Kressmann, et al., 2006; Thorbjornsen, et al., 2002). These five dimensions of relationship quality include interdependence, intimacy, love and passion, satisfaction, and trust. Interdependence establishes a consumer's dependence upon their relationship with a brand. Intimacy reveals the extent to which a consumer perceives that they are knowledgeable regarding a brand, as well as the extent to which they feel that the brand knows them. Love and passion uncovers the extent to which a consumer feels deeply towards a brand. Satisfaction captures a consumer's assessment of the value that they perceive they obtain from being involved in a relationship with a brand over time. Relationship trust is determined by the extent to which a consumer believes that a brand is reliable and possesses integrity. Consequently, six items were used to measure this construct. Although multiple items are used by some authors to measure Relationship Quality dimensions (Aaker, et al., 2004), the majority of the items used in the present research were based on single item measures (Kressmann, et al., 2006; Thorbjornsen, et al., 2002). While the use of further items was considered, six items captured the definition of this construct. Five-point Likert scales ranging from strongly disagree to strongly agree were used as respondent answer categories. Similar Likert scales anchored by strongly disagree and strongly agree were used to measure dimensions of relationship quality within the marketing literature (Aaker, et al., 2004; De Wulf, et al., 2001; Garbarino \& Johnson, 1999). Table 4e shows the items used to measure Relationship Quality.

Table 4e. Relationship Quality Items

\begin{tabular}{|c|c|c|c|}
\hline & Items & Construct & Source \\
\hline a & [insert brand] plays an important role in my life. & \multirow{6}{*}{$\begin{array}{l}\text { Relationship } \\
\text { Quality } \\
\text { (reflective) }\end{array}$} & \multirow{6}{*}{$\begin{array}{c}\text { (Aaker, et al., } \\
\text { 2004; De Wulf, et } \\
\text { al., 2001; } \\
\text { Garbarino \& } \\
\text { Johnson, 1999) } \\
\\
\text { No Reported } \\
\text { Cronbach's Alpha } \\
\text { value }\end{array}$} \\
\hline o & I am knowledgeable about [insert brand]. & & \\
\hline 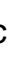 & [insert brand] understands my travel needs. & & \\
\hline$d$ & I am passionate about [insert brand]. & & \\
\hline & $\begin{array}{l}\text { I am satisfied by the efforts that [insert brand] makes } \\
\text { towards me. }\end{array}$ & & \\
\hline & I have trust in [insert brand]. & & \\
\hline
\end{tabular}

\subsubsection{Relational Orientation}

The construct of Relational Orientation captures a consumer's favourability towards being involved in a customer relationship with a brand in a product or service category. In the present research, Relational Orientation is established through the concept of perceived value. Relationships are forged through the mutual exchange of value between parties over time (Ravald \& Gronroos, 1996). A consumer will favour being involved in customer relationships if they believe that they obtain value in doing so. The value that a consumer perceives they are 
obtaining from being involved in customer relationships in a product or service category is the perceived benefit that a consumer receives relative to the perceived sacrifice that they must make when engaging in relational exchange with brands. Relational Orientation is determined according to the same five dimensions as Relationship Quality, and like Relationship Quality comprises six items. Relational Orientation measures a consumer's generalised sentiment towards being involved in customer relationships in a product or service category, while Relationship Quality measures brand-specific sentiment. Accordingly, respondents were asked to indicate the extent to which they agree or disagree with statements regarding category brands in general on a number of self-report five-point Likert scales. Table $4 \mathrm{f}$ shows the items used to measure Relational Orientation.

Table 4f. Relational Orientation Items

\begin{tabular}{|c|c|c|c|}
\hline & Items & Construct & Source \\
\hline$a$ & Certain airlines are important to me. & \multirow{6}{*}{$\begin{array}{l}\text { Relational } \\
\text { Orientation } \\
\text { (reflective) }\end{array}$} & \multirow{6}{*}{$\begin{array}{c}\text { (Aaker, et al., } \\
\text { 2004; De Wulf, et } \\
\text { al., 2001; } \\
\text { Garbarino \& } \\
\text { Johnson, 1999) } \\
\\
\text { No Reported } \\
\text { Cronbach's Alpha } \\
\text { value }\end{array}$} \\
\hline b & I know a lot about certain airlines. & & \\
\hline r & I like it when airlines know me well. & & \\
\hline & I am passionate about certain airlines. & & \\
\hline & There are certain airlines that particularly satisfy me. & & \\
\hline & I really trust certain airlines. & & \\
\hline
\end{tabular}

\subsubsection{Customer Brand Loyalty}

The items intended to determine the construct of Customer Brand Loyalty are based on a loyalty scale developed by Zeithaml, et al (1996). These authors use a five item seven-point likelihood scale anchored by 'not at all likely' and 'extremely likely' to determine loyalty toward a service. Cronbach's coefficient alpha values between 0.93 and 0.94 were reported for the loyalty scale. Upon examining the factors that comprise an individual's behavioural intention toward a service, Zeithaml, et al (1996) identify loyalty as a significant dimension. For the purposes of the present research, the wording of the items presented by these authors was used as a guide, being altered to reflect customer loyalty toward a brand. For consistency with other research scales, the Zeithaml, et al (1996) seven-point likelihood scale was anchored by 'extremely unlikely' and 'extremely likely' and reduced to comprise five-point items. Table $4 \mathrm{~g}$ shows the items used to measure Customer Brand Loyalty. 
Table 4g. Customer Brand Loyalty Items

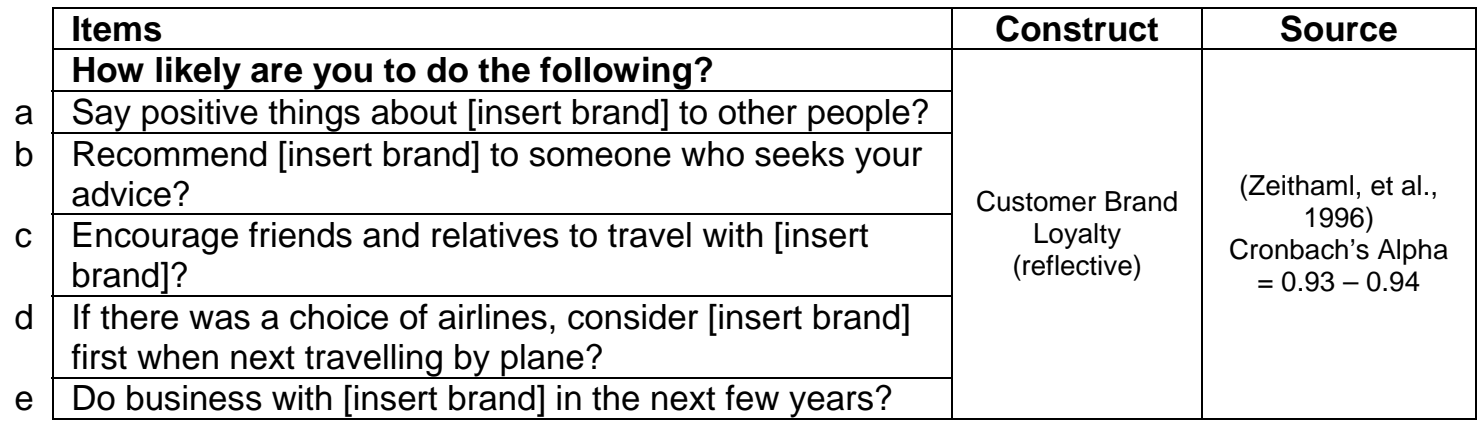

\subsection{Overview of Research Approach}

The conceptual model guiding this research, including construct definitions and proposed hypotheses, has been identified. Focus is now placed on the research methodology used to test the hypotheses. This research adopts a consumer perspective regarding the development and maintenance of customer relationships through communication. In doing so the influence of the communication that a consumer participates in regarding a brand upon the consumer's connection with the brand is identified. Furthermore, the research determines how a consumer's connection with a brand influences the quality of a customer relationship, as well as the manner in which relationship quality affects the performance of a brand. An instrument was developed, in the form of a self-report questionnaire, to measure the research constructs. Each research construct was measured using scales comprising a series of questions presented to individual consumers, in a particular service industry setting.

The research methodology was set-up in three phases:

1. Questionnaire design

2. Instrument development and refinement

3. Survey implementation data collection

The first phase comprised questionnaire design and was implemented to verify the scales selected to measure the research constructs through expert opinion. The development of an instrument by which to measure the research constructs is in itself an important contribution of the research, and particular attention was paid to reliability and validity concerns. Part of the research methodology, accordingly, concerned the refinement of the measurement instrument and the items selected to measure the research constructs. For some construct dimensions scale items had been published and were subsequently adapted to the context of the research. In other cases new scale items had to be created in accordance with established conceptual development. The opinions of methodological experts are regarded as 
valuable for construct attribute classification (Diamantopoulos, 2005). Therefore, input from academics was sought in order to verify and refine each of the construct measures.

Following the creation of scale items based upon the literature and input from methodological experts, the instrument was screened, pretested and applied to a representative sample of New Zealand consumers. A quantitative research methodology assisted in further refining the measurement instrument to ensure reliability (Peter, 1979), as well as determining the consumer behaviour of respondents. Accordingly, consumer participation in the development and maintenance of customer relationships through communication could be examined. The method of measurement was, therefore, by way of a questionnaire intended to measure the research constructs presented in the conceptual model. It was requested that individual consumers complete the research questionnaire regarding relationships between themselves and one or two specified airline brands. The questionnaire was initially screened by several consumers to ensure understanding and usability. A convenience sample was used to select potential respondents to be involved in this screening process. A pretest was then conducted involving a small representative sample of consumers. Such pretesting provides information regarding the questionnaire itself, specific instrument items, and data analysis (Hunt, Sparkman, \& Wilcox, 1982).

Finally data collection was performed utilising a larger research sample. The test units consisted of individual adult New Zealand consumers. Respondents were asked to complete a questionnaire regarding their relationship with well-known commercial airline brands operating in New Zealand. A database of adult New Zealand consumers was obtained for use as a sampling frame for the research. This database comprised the New Zealand electoral roll. The New Zealand commercial airline industry is ideally suited to this research as airlines strive to develop and maintain customer relationships with end consumers. The majority of New Zealand adult consumers are aware of commercial airline brands operating in New Zealand and, therefore, engage in some form of exchange with these brands. Furthermore, consumers can engage in interactive communication both through Internet based and nonInternet based media with brands operating in this industry. Consumers selected from the sampling frame were asked to complete the research questionnaire regarding their relationship with New Zealand's national airline, Air New Zealand, as well as another airline they had travelled with.

\subsection{Approach to Developing Measures}

An intended contribution of the present research was the creation of an instrument measuring the identified research constructs. Separately, branding and customer relationships are much researched areas within the marketing literature with a sound conceptual basis. Therefore, 
each research construct identified in the conceptual model has a theoretical grounding. The significance of the present research was the bringing together of multiple marketing fields of thought, the measurement of key variables, and the examination of linkages between them. The constructs comprising the conceptual model were identified as important to relationship marketing in a business-to-consumer context. Their measurement was central to understanding the process by which relationships are developed and maintained from a consumer perspective. A conclusive research design was adopted to test specific hypotheses and investigate the linkages between constructs (Malhotra, 1999). With such research the information required was clearly identified. The chosen research design is, accordingly, conclusive and the method of measurement was quantitative in nature.

Drawing on existing literature, the constructs of interest were initially defined within the specific context of the research. A research instrument, in the form of a questionnaire, was subsequently developed. The questionnaire was sent to individual consumers for completion and contained questions concerning their communication and relationship with specific brands operating in New Zealand. The research constructs were, therefore, measured through a number of self-report scales. As discussed earlier, the scales are based on established conceptual thought. The Relationship Quality dimensions of satisfaction and trust, for example, are conceptually distinct and quantifiable construct dimensions within the relationship marketing literature (De Wulf, et al., 2001; Garbarino \& Johnson, 1999). The scale items used to determine Relationship Quality satisfaction and trust were, therefore, modified from previous studies to suit the context of the current research. In contrast, the construct of Brand Personality Connection, although based on established conceptual foundations with respect to brand personality and congruence (Aaker, 1997; Malhotra, 1981), required the development of original scale items. As such, each scale item intended to measure a research construct or construct dimension has a robust theoretical basis. Once a number of questions and accompanying scales had been identified, academics with experience in scale development were asked to review the scale items, as well as the overall structure of the research questionnaire. This was done to verify each item (Diamantopoulos, 2005) and ensure the structure of the research instrument as a whole was appropriate. Subsequent to this verification by experts in scale generation the questionnaire was screened by a small group of respondents and administered, initially in a pretest and then to a larger sample. As recommended in the scale development literature (Churchill, 1979; Peter, 1979), further refinement of the scales followed final data collection.

\subsection{Sampling Frame}

Given the defined population of the research, the New Zealand electoral roll was used as a sampling frame from which a representative sample of adult New Zealand residents could be 
obtained. The 2006 census calculates New Zealand's usually resident population at 4,027,927 people. Of these approximately three million people are aged 18 years or older (Statistics New Zealand, 2006). According to electorate profile information published by New Zealand Parliament, New Zealand had a voting age population of 2,990,300 in 2005 (New Zealand Parliament, 2005). The New Zealand electoral roll is a list containing the names and mailing addresses of most New Zealand residents who are aged 18 years or older. Citizens and permanent residents are for the most part included on the electoral roll so that they can vote in New Zealand's general and local elections. A New Zealand citizen who is Maori has a choice to enrol on the General or Maori electoral roll. Therefore, in New Zealand those people eligible to vote may be listed on one of two electoral rolls.

With some restrictions, New Zealand citizens or permanent residents that have lived in New Zealand for one year or more without leaving the country and are aged 18 years or older are eligible to be on the electoral roll. Although all eligible New Zealanders are required by law to enrol to be registered on the Parliamentary Electoral Roll (Elections New Zealand, 2007), not everyone is enrolled. Of the voting age population, 95.2 per cent were enrolled on either the General or Maori electoral roll in 2005; equating to 2,847,396 New Zealanders (New Zealand Parliament, 2005). Despite being enrolled to vote, not all names and addresses are published in the electoral roll. Of those people enrolled to vote a number are listed on an unpublished electoral roll. An unpublished electoral roll exists to ensure the confidentiality of people who believe that their life could be endangered if their personal details were included on a public document. As such, a small under-registration of the specified research population was expected within the sampling frame.

According to the Electoral Act (1993), New Zealand citizens or permanent residents who are overseas may choose to enrol and be registered on the electoral roll. This may result in overregistration of the specified research population if New Zealand citizens are listed on the electoral roll, but do not reside in New Zealand. Although residents are encouraged to update their personal information, it is expected that some mailing address information contained within the sampling frame will have dated at the time of data collection. This is a result of residents moving address between the time when they enrolled to be included on the electoral roll and were sent a research questionnaire. Therefore, further sampling frame error is acknowledged due to the inaccuracy of a modest but unknown number of electoral roll mailing addresses.

An electronic copy of the New Zealand electoral roll was obtained from The Electoral Enrolment Centre for use as a sampling frame. This included both the General and Maori electoral rolls. The Electoral Enrolment Centre is a self-contained business unit of New Zealand Post, which is under contract to the Minister of Justice and has a team of Registrars of Electors responsible for compiling and maintaining electoral rolls (Elections New Zealand, 
2007). The electronic version of the New Zealand electoral roll was received on the 26 October 2007 and contained 2,849,055 individual entries. Each entry contained the enrolled elector's full name, mailing address, occupation, date of birth, and electorate in which they are registered.

\subsection{Research Sample}

A research sample was drawn from the sampling frame for both the pretest and subsequent larger collection of research data. As recommended in the literature (Hair, Bush, \& Ortinau, 2000), the research pretest comprised a small, representative sample of the defined population. A greater sample was then obtained for the main data collection phase. Approximately 300 completed responses were required as a baseline sample size to allow appropriate data analysis of the full set of research construct measures (Nunnally, 1978; Pallant, 2001; Tabachnick \& Fidell, 2000). Allowing for a minimum response rate of 20 per cent, 1500 questionnaires were sent to potential respondents. In addition, an initial 150 questionnaires were sent as part of the research pretest; although data obtained from these respondents did not form part of the main study database.

A total of 1650 entries were, therefore, drawn from the sampling frame to be sent questionnaires via mail. A probability sampling technique was used to select potential respondents from the sampling frame. This involved systematic random sampling using the SPSS 'Select Cases: Random Sample' function. Using this random sample function of SPSS, exactly 1650 cases were selected from the sampling frame. SPSS takes a defined random sample without replacement. Therefore, a case cannot be selected more than once. As a random sampling technique, each population element's probability of selection was known and equal (Malhotra, 1999). Population members were listed on the sampling frame by electorate and in alphabetical order. As such, their ordering was unrelated to the research variables of interest. 150 entries were in turn randomly selected from the sample of 1650 for use in the pretest. The remaining 1500 entries were used as the research sample for the main study. It is believed that this sampling technique contributed towards obtaining an unbiased and representative sample from the desired research population. It was also a practical sampling technique, given the size of the sampling frame at close to three million individual entries.

\subsection{Pretesting}

The value of pretesting research questionnaires is well documented (De Leeuw, Hox, \& Dillman, 2008; Dillman, 1978). Extensive questionnaire pretesting was conducted in this study, prior to full data collection. The research instrument was initially scrutinised by experts with 
experience in scale development, as well as a small sample of the research population. A dress rehearsal (De Leeuw, et al., 2008) of the data collection method was then conducted, to test the research instrument as a whole under intended survey conditions. The following section describes the questionnaire pretesting procedures in detail.

\subsubsection{Expert Evaluation}

It is recommended that individuals with experience in scale development help refine construct measures (Diamantopoulos, 2005; Zikmund, 1997). The opinions of methodological experts are regarded as valuable for construct attribute classification (Diamantopoulos, 2005). Input from marketing academics was, therefore, sought in order to verify the construct measures prior to data collection. Three academic staff members from the Victoria University of Wellington School of Marketing and International Business with experience in scale development contributed to this process. The research experts were asked to comment on the scale items intended to measure each construct, as well as the overall structure of the questionnaire. This assisted in ensuring that the attributes of each defined construct were captured by the scales. In addition, the wording of individual scale items and the appropriateness of the overall questionnaire structure was verified, or modified further on the basis of the provided feedback.

In accordance with recommended questionnaire development procedures, these academics were informed of the research purpose and asked to comment on the questionnaire as well as its questions (De Leeuw, et al., 2008; Dillman, 1978). The particular academics were asked to comment on the research instrument due to their respective expertise in marketing strategy, relationship marketing, and research methodologies. The three academics were each given a copy of the research instrument in June 2008. Feedback had been provided by the end of the first week of July 2008. One expert provided feedback written directly on a mock-up of the questionnaire. The other two, who were both overseas at the time, provided feedback via a written report and tracked changes. This expert input resulted in a number of changes to the research instrument. Amendments included the rewording of items and answer categories, reformatting of the questionnaire layout, addition of participant instructions, inclusion of further demographic questions, and revision regarding the presentation of some scales.

\subsubsection{Question Testing}

Following initial refinement of the questionnaire on the basis of expert opinion, the overall research instrument and individual questions were then screened for respondent 
understanding. This is referred to as the 'question testing stage' of questionnaire development (De Leeuw, et al., 2008). Literature regarding marketing scale development suggests that an initial developmental pretest be implemented in a manner that facilitates respondent feedback, regardless of how the questionnaire will ultimately be administered (Hunt, et al., 1982). A developmental pretest was, therefore, conducted and participant input used to help ensure respondent understanding of the survey as a whole, including individual questions and answer categories. A debriefing method of pretest was used for this purpose, in which respondents were asked to complete the research questionnaire in its entirety and then comment on any aspect of the instrument (De Leeuw, et al., 2008; Hunt, et al., 1982). Respondent comments concerned specific questions, as well as the overall format of the questionnaire. Question testing was conducted between August 26 and September 162008.

A convenience sample of 12 was used to screen the research instrument. This small sample was drawn independently of the overall population used to obtain the larger pretest and research samples. Such a sample size is consistent with recommended question testing procedure (De Leeuw, et al., 2008). The sample comprised postgraduate students completing degrees at Victoria University of Wellington, New Zealand, as well as non-university respondents. Specifically, the respondents included three Masters of Business and Administration (MBA) students, one Masters of Commerce and Administration (MCA) Student, and three PhD students. In addition, feedback was provided by five non-university respondents in various professional positions and with differing levels of educational attainment. Although all respondents were living in the Wellington region at the time that the research was conducted, the sample exhibited a range of demographic characteristics in line with the ultimate intended research population. It was, therefore, assumed that such respondents are not dissimilar to the greater research population in their assessment of research instrument question and answer categories. Such a heterogeneous sample is acknowledged as providing variation across responses and useful in questionnaire pretesting (Hunt, et al., 1982).

When possible, respondents were debriefed on an individual basis examining each question with the researcher to ensure understanding and that an adequate answer could be provided. The postgraduate students were advised that their participation in the research was voluntary and had no impact upon their course requirements. Upon receiving a copy of the questionnaire, potential respondents were informed of their role in the refinement process. MBA student respondents were asked to complete the research questionnaire and comment in writing on the questions and response categories. Ideally this screening process would have been conducted in a personal interview style, so that respondents could be observed during questionnaire completion to collect both verbal and non-verbal feedback (Dillman, 1978; Hunt, et al., 1982). However, as the students had limited time it was requested that they take the questionnaire away and return it upon completion. The research instrument 
contained four blank pages allowing respondents to provide written feedback. Personal interviews were conducted with the remaining question testing respondents, upon their completion of the questionnaire. The qualitative information, in the form of verbal and written participant opinion, was examined for common themes and patterns. Appropriate alterations were then made to help ensure participant understanding regarding the research instrument.

\subsubsection{Pretest}

The third and final stage of pretesting was pretest data collection. Such a data collection dress rehearsal is designed to examine the research instrument under intended survey conditions (De Leeuw, et al., 2008). It is recommended that pretests subsequent to questionnaire screening be conducted by the administration method used in the ultimate research (Hunt, et al., 1982). In accordance with this, as well as other suggested pretesting procedure (Hair, et al., 2000), the research instrument was mailed via postal service to a small, representative sample of respondents. Pretesting in this manner is recognised as providing information regarding the questionnaire itself, specific instrument items, and data analysis (Hunt, et al., 1982).

A total of 149 self-administered questionnaires were sent to potential respondents randomly selected from the research sampling frame. One was dropped because of an overseas address. Potential respondents were asked to complete the research questionnaire in its entirety and mail it back to the researcher in a pre-paid envelope. In contrast to the previous screening pretest, respondents were not given the opportunity to provide qualitative feedback regarding the survey. The 149 questionnaires were mailed to potential pretest respondents on September 26 2008. After one week a reminder card was mailed to the original pretest sample of 149. These initial reminder cards were posted on October 3 2008. Respondents who had already returned a completed questionnaire could not be identified due to the anonymity of the research. A second reminder card was mailed to the sample on October 17 2008, two weeks after the first reminder was posted. This is in accordance with recommended procedure regarding self-administered postal questionnaires and reminder cards (De Leeuw, et al., 2008).

Of the 149 pretest questionnaires posted to addresses throughout New Zealand, 44 usable responses were received by the researcher. Three respondents returned the questionnaire uncompleted. One of which returned the questionnaire blank with a message that they could not help with the research as they had "not ever travelled by plane, or had anything to do with any travel agents or Air New Zealand". Eight members of the pretest sample were considered non-reachable. Copies of the questionnaire sent to these individuals were returned to the researcher, noting that the intended respondent did not reside at the address. Three 
respondents requested additional copies of the research questionnaire by e-mail. However, no members of the sample were identified as ineligible to participate in the research. The data collection pretest, therefore, achieved a response rate of 31.2 per cent. Table $5 \mathrm{a}$, below, provides a summary of this result.

Table 5a. Data Collection Pretest Response Rate

\begin{tabular}{|c|c|c|c|}
\hline $\begin{array}{c}\text { Data Collection } \\
\text { Pretest Sample Size }\end{array}$ & Return Mail & Ineligible & Responses \\
\hline 149 & 8 & 0 & 44 \\
\hline
\end{tabular}

Response rate: $31.2 \%$

Descriptive statistics were examined for the data obtained in the data collection pretest. This analysis was performed to identify the demographic composition of respondents; including age, geographic residence, gender, personal income level, and airline travel behaviour. It also helped establish if respondents were able to successfully answer the survey questions and whether there was an expected range of answers to each question. The findings from this analysis, as well as discussion regarding the implications of these results for research involving a larger sample, can be found in appendix B. Overall, the pretest results indicated that the research scales possessed good levels of reliability and could be used with a larger sample. Although the main research questions did not alter from that of the pretest, data from the pretest was not included in the overall data analysis. This is because the purpose of the pretest was to get an overview of the research instrument under intended survey conditions, rather than collect data for the main analysis (De Leeuw, et al., 2008; Hunt, et al., 1982). The main research questionnaire was also designed to collect sufficient data for analysis, without requiring pretest data (Nunnally, 1978; Pallant, 2001; Tabachnick \& Fidell, 2000). A copy of the data collection pretest questionnaire can be found in appendix $\mathrm{C}$.

\subsection{Research Implementation}

As previously discussed, a random sample of 1500 entries was drawn from the New Zealand general electoral roll for the research. With the research population defined as all New Zealand resident adults, 24 of the entries were deleted from the sample as the potential respondents were reported on the database to be living outside of New Zealand. These 24 entries were not replaced, because it was believed the remaining sample would be sufficient to acquire the number of responses required for appropriate data analysis. At least 300 responses are recommended for factor and regression analysis (Nunnally, 1978; Tabachnick \& Fidell, 2000). The final research sample, therefore, comprised 1476 New Zealand residents. 
Each of the 1476 potential respondents was sent a research questionnaire by post on the week of November 17 2008. One week after this initial postal mail out, a reminder card was sent to the sample. Reminder cards were, accordingly, posted on the week of November 24 2008. The reminder asked potential respondents to complete and return the research instrument and informed them that they could contact the researcher should they require an additional copy. Potential respondents were also told that they could go to a designated website to view a printable copy of the questionnaire. Respondents who had already returned a completed questionnaire could not be identified due to the anonymity of the research. These individuals were thanked for their prior response in the reminder. A copy of the reminder card can be found in appendix $D$. Although recommended procedure regarding selfadministered postal questionnaires suggests that a second reminder card be mailed two weeks after the first (De Leeuw, et al., 2008), a second reminder was not mailed to the larger sample due to budget constraints.

The research questionnaire did, however, include a prize draw. Small token incentives are recognised as increasing mail survey response rates (De Leeuw, et al., 2008). Accordingly, entry into a prize draw to win petrol vouchers to the value of $\$ 100$ was offered to respondents. Respondents were asked to write their contact details on the back of the questionnaire to enter the prize draw. Although identifying details were required to enter the draw, research respondents were assured that no attempt would be made to link their name with responses to the questionnaire. A copy of the final questionnaire can be found in appendix $\mathrm{E}$. 


\subsection{Research Findings}

The main objective of this study was to investigate how consumers participate in the development and maintenance of a relationship with a brand through communication, in all of its forms. To this end, a sample of consumers was asked to reflect on their experiences with commercial airline brands. Consumers can engage with airlines in many ways; be it through staff interaction, advertising, or discussions with friends and family. It is expected that as they engage with brands, individuals form some type of perceived relationship. Airline brands are ideal for this purpose, as contact with such brands is highly experiential and such brands strive to form relationships with numerous consumers. Capturing elements of communication, the research sought to identify the process by which consumers forge relationships with brands. This provides insight concerning how consumers think about their connections with brands and the process by which relationships are developed and maintained. A related objective was to examine the consequences of customer relationships for the owners of a brand. Therefore, consumer relationships were examined to determine how perceived connections influence brand loyalty.

This chapter begins with an examination of the response rate and descriptive analysis. It then discusses data analysis as a whole, scale testing and refinement, and an assessment of the key relationships between constructs. Finally, the proposed hypotheses are tested. This results in a validation and refinement of the conceptual model and key insights into the scope of communication effects on the development and maintenance of consumer relationships with brands.

\section{$5.1 \quad$ Response Rate}

Of the 1476 questionnaires posted, 62 were returned to the researcher through the postal system as the intended respondent no longer resided at the address. Questionnaires sent to these residents were marked 'return to sender' by New Zealand Post. Potential research respondents with questionnaires returned in this manner were considered non-reachable. The research instrument included a filtering question on the front page asking respondents if they work for a commercial airline. This was done because it is believed employees of a commercial airline would exhibit a natural bias towards the airline for which they work. Three incomplete questionnaires were sent back to the researcher indicating that the potential participant works for an airline. An additional 10 incomplete questionnaires were returned to the researcher, as well as five e-mail messages received, noting that the potential participant was either deceased or no longer resident in New Zealand. These 18 people were, subsequently, noted as ineligible to participate in the research. 391 usable responses were collected from the sample, giving a response rate of just over 28 per cent. A survey response 
rate is determined according to the number of questionnaires returned to the researcher, in relation to the number of test units in the sample minus non-eligible and non-reachable units (Dillman, 1978). In the present research of the 1476 questionnaires sent, 80 consumers were non-eligible or non-reachable; leaving 1396 potential respondents. 391 returned questionnaires, in relation to 1396 potential respondents, resulted in a response rate of 28.01 per cent. Response rates between 50 and 60 per cent are reported in the literature (Baruch, 1999; Dillman, 1978). However, it is also recognised, that common response rates are less than 40 per cent (Kerlinger, 1986) and that smaller response rates may not always be published (Cook, Heath, \& Thompson, 2000). Therefore, while 28 per cent is not a particularly high response rate it does not raise any significant concerns. Table $5 b$, below, provides a summary of the response rate for the research sample.

Table 5b. Research Response Rate

\begin{tabular}{|c|c|c|c|}
\hline $\begin{array}{c}\text { Research Sample } \\
\text { Size }\end{array}$ & Return Mail & Ineligible & Responses \\
\hline 1476 & 62 & 18 & 391 \\
\hline
\end{tabular}

Response rate: $28.01 \%$

40 members of the research sample who were mailed questionnaires sent a message back to the researcher, via the postal system, with an explanation for non-participation. A further three incomplete questionnaires were sent back to the researcher, without explanation. Of the 40 potential respondents who provided an explanation for non-participation in the research, a reoccurring theme was that the individual felt that they did not have sufficient travel experience with airlines to contribute to the research. Although it is believed that these individuals may have made a valuable contribution to the research, they could not be contacted and informed of this due to the anonymity of the research instrument. Other potential respondents advised that they "don't do surveys" or felt that they did not have the time to be involved. A number of the reasons provided for non-participation can be found in appendix F. Non-response bias is discussed in section 5.2 .

Table 6 details the frequency at which usable responses to the research instrument were received by the researcher. Week one refers to the week starting November 172008 and ending November 23 2008, directly following the initial mail out of the research questionnaire. Week 14 occurs between February 162009 and February 22 2009, 14 weeks later. In accordance with recommended procedure, a reminder card was posted one week after the initial questionnaire on the week of November 242008 (De Leeuw, et al., 2008). The majority of questionnaire responses were, accordingly, received within the time it would have feasibly taken for the reminder to reach potential respondents and for responses to be returned by post. The frequency of responses shows that half of all usable responses were received within three weeks and over 96 per cent received at the end of five weeks. 
Table 6. Research Response Frequency

\begin{tabular}{|c|c|c|c|}
\hline Week Received & Frequency & Percentage & Cumulative Percentage \\
\hline 1 & 2 & 0.5 & 0.5 \\
\hline 2 & 110 & 28.1 & 28.6 \\
\hline 3 & 85 & 21.7 & 50.4 \\
\hline 4 & 61 & 15.6 & 66.0 \\
\hline 5 & 118 & 30.2 & 96.2 \\
\hline 6 & 9 & 2.3 & 98.5 \\
\hline 7 & 1 & 0.3 & 98.7 \\
\hline 9 & 3 & 0.8 & 99.5 \\
\hline 11 & 1 & 0.3 & 99.7 \\
\hline 14 & 1 & 0.3 & 100.0 \\
\hline Total & 391 & 100.0 & \\
\hline
\end{tabular}

Respondents were asked to complete the research questionnaire with reference to Air New Zealand as a base case, as well as one other commercial airline operating in New Zealand with which they had travelled. Of the 391 usable responses collected, 280 respondents answered questions relating to both Air New Zealand and one other airline brand. Consequently, up to 671 responses are reported for any scale item.

Overall, the research methodology resulted in a well-tested questionnaire, with appropriate modifications over four phases of development. These phases included expert opinion, questionnaire screening, a data collection pretest, and finally wider data collection. A sampling frame, representative of the adult population aged 18 years and above, was obtained from the New Zealand electoral roll. This resulted in the questionnaire being sent to representative sample of adult consumers. Furthermore, upon implementation the questionnaire produced a good response rate meaning that appropriate data analysis could be conducted. The following chapter discusses analysis of the data obtained and testing of the research hypotheses.

\subsection{Descriptive Analysis, Non-Response Considerations and Distribution}

Descriptive data analysis is employed to describe an observation, examine the normality of distribution amongst research respondents, and through comparison with known population parameters allow some consideration of possible non-response bias. Frequencies can be used to obtain descriptive statistics for categorical variables and, accordingly, identify the number of respondents that gave each response (Pallant, 2001). Normality acknowledges the extent to which the frequency of scores can be described as a symmetrical bell shaped curve, with the greatest frequency of scores in the middle and smaller frequencies to the extremes (Gravetter \& Wallnau, 2000). Normality of distribution comprises an assessment of skewness and kurtosis values. 
The skewness value of responses provides an indication concerning the symmetry of the distribution and kurtosis values present information regarding the peakedness (Sharma, Durvasula, \& Dillon, 1989) of the distribution. If the distribution of responses is perfectly normal a skewness and kurtosis value of zero will be obtained (Pallant, 2001). A significantly positive or negative skewness can result in scores tending towards either the higher or lower ends of research scales and a significantly positive or negative kurtosis value may cause an underestimate in the variance of scores. Ideally skewness and kurtosis values should be close to zero. A summary of the skewness and kurtosis values for data obtained in the research can be found in appendix G, as can an analysis of missing data. As shown in appendix G, only some Communication with the Brand and Communication with Consumer Communities items had skewness or kurtosis values that were not close to zero. It is acknowledged, however, that with larger research samples skewness and kurtosis values do not greatly affect the analysis of variance (Pallant, 2001; Tabachnick \& Fidell, 1996). The following descriptive analysis details missing data and the characteristics of individuals who responded to the research questionnaire; including age, residence, gender, income, and airline travel behaviour. The sampling characteristics are also compared where possible to known characteristics of the New Zealand adult population, as a check for possible nonresponse bias.

\subsubsection{Missing Data}

Appendix $G$ shows that the incidence of missing data reached a maximum 15.2 per cent of responses to any item. Brand Personality Connection items displayed the highest percentage of missing data, ranging between 10.9 and 15.2 per cent of responses. This construct was measured through a congruence index, created by taking the sum of the absolute difference between a consumer's perceived brand personality and their ideal brand personality for the product or service category. Two sets of data were accordingly required to measure Brand Personality Connection; a consumer's perceived brand personality as well as their ideal brand personality for the category. Any missing data in the perceived or ideal brand personality scales resulted in missing data in the Brand Personality Connection scale. Therefore, it is not surprising that this construct possessed the highest percentage of missing data.

As regards the remaining constructs, missing data concerning items measuring Brand Advertising ranged between 7.2 and 11.9 per cent. Missing data concerning Communication with the Brand items ranged between 1.2 and 3.9 per cent, Communication with Consumer Communities items ranged between 1.9 and 3.4 per cent, Customer Brand Loyalty items ranged between 2.1 and 2.4 per cent, Relational Orientation items ranged between 1.2 and 1.8 per cent, and Relationship Quality items ranged between 1.0 and 1.3 per cent. The 
incidence of missing data was, therefore, low enough to not be of concern (Tabachnick \& Fidell, 2000; Winkler \& McCarthy, 2005). During further analysis missing data was addressed using recognised techniques, such as listwise deletion and Expectation Maximisation values.

\subsubsection{Age Group}

Tables $7 \mathrm{a}$ and $7 \mathrm{~b}$, as well as Figure $7 \mathrm{c}$, show the age distribution of research respondents, in addition to the age of the New Zealand usually resident population aged 18 years and over. Statistics indicate that middle-aged New Zealanders have the highest level of income (Statistics New Zealand, 2008). Consumers from the 30 to 54 age bracket are, therefore, expected to travel more than other consumers and are likely respond to the research questionnaire. As with this expectation, research respondents identified themselves as belonging to age categories slightly higher than those of the general New Zealand population. Proportionally, fewer research respondents identified themselves as aged between 18 to 44 years and more as aged over 44 than the overall New Zealand population. The research reported approximately 31 per cent of respondents as aged between 18 and 44 years, while as a population approximately 51 per cent of New Zealanders aged 18 and above belong to this age group. Furthermore, over 45 per cent of respondents identified themselves as aged between 45 and 64 years and 22 per cent as aged over 64 years. Comparatively, 32 per cent of New Zealanders are aged between 45 and 64 years and only 17 per cent are aged over 64 years. This could indicate an element of non-response bias towards older respondents. It is also consistent however with the view as noted that, overall, older New Zealanders are comparatively more likely than younger New Zealanders to have experience with airline travel. On balance, it was concluded that the sample age distribution did not provide any evidence of significant non-response bias among particular age groupings; although older consumers may be over-represented.

Table 7a. Age of Research Respondents

\begin{tabular}{|c|c|c|}
\hline Age & Number & Percentage (\%) \\
\hline $18-24$ & 26 & 6.7 \\
\hline $25-34$ & 45 & 11.6 \\
\hline $35-44$ & 49 & 12.6 \\
\hline $45-54$ & 85 & 21.9 \\
\hline $55-64$ & 96 & 24.7 \\
\hline $65-74$ & 61 & 15.7 \\
\hline $75+$ & 26 & 6.7 \\
\hline Total & 388 & 100.0 \\
\hline Missing & 3 & \\
\hline
\end{tabular}


Table 7b. Age (Single Years) for the Census Usually Resident Population Count 2006

\begin{tabular}{|c|c|c|}
\hline Age & Number of Residents & Percentage of Population Aged 18+ (\%) \\
\hline $18-24$ & 385,074 & 13.0 \\
\hline $25-34$ & 519,000 & 17.5 \\
\hline $35-44$ & 615,252 & 20.7 \\
\hline $45-54$ & 546,153 & 18.4 \\
\hline $55-64$ & 413,181 & 13.9 \\
\hline $65-74$ & 265,485 & 8.9 \\
\hline $75+$ & 230,127 & 7.7 \\
\hline (Statistics New Zealand, 2006) \\
\hline
\end{tabular}

Figure 7c. Age of Research Respondents Compared to Population

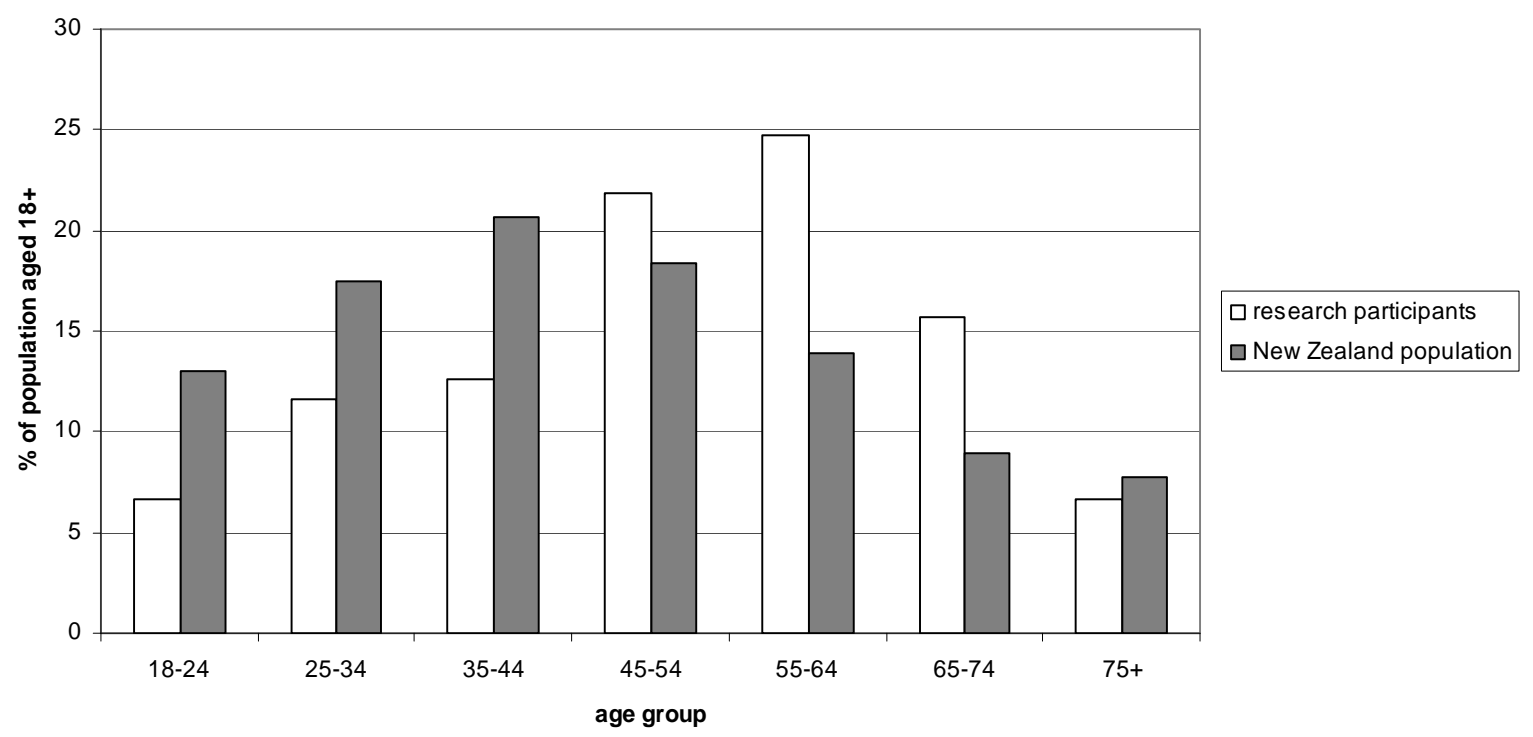

Respondents were separated into seven groups according to their self-identified age, ranging from 18-24 years of age to 75+. A one-way between-groups analysis of variance was performed to examine whether any differences in responses to the research constructs could be attributed to a consumer's age group. The significance value of the Levene Statistic for Communication with the Brand (experience) and Relational Orientation was below a 0.05 value, indicating that both these scales violate the assumption of homogeneity of variance required when conducting one-way analysis of variance. The ANOVA matrix revealed that there is a statistically significant difference at a 0.05 level in the Communication with the Brand (frequency) scale for the age groups. The eta squared value of this difference between groups was only 0.04. The Multiple Comparisons matrix suggests that 65-74 year olds differ from 25-34 year olds in their responses to the Communication with the Brand (frequency) scale, at a 0.05 level of significance. $75+$ year olds also differ in their Communication with the Brand (frequency) responses from 25-34, 35-44, 45-54, and 55-64 year olds, at a 0.05 level. Answers to the majority of items, however, did not differ significantly by age. 


\subsubsection{Residential Region}

Table 8a reveals that research respondents identified themselves as residing throughout New Zealand. Comparatively, Table $8 \mathrm{~b}$ presents the regional residence of the New Zealand usually resident population. Consistent with the general New Zealand population, the highest percentages of research respondents identified themselves as residing in Auckland, Canterbury, and Wellington. Approximately 53 per cent of research respondents identified themselves as residing in one of New Zealand's three main centres, compared to 56 per cent of New Zealand's usually resident population residing in Auckland, Canterbury, or Wellington. Similarly, about 69 per cent of research respondents identified themselves as residing in the North Island and 28 per cent in the South Island, with three per cent unknown; compared to 76 per cent in the North Island and 24 per cent in the South Island for the overall population. 2.6 per cent of research respondents identified themselves as residing outside of the 16 provided regions, whereas only 0.02 per cent resides outside the 16 regions according to usually resident population statistics. As shown in Table 9, over 72 per cent of research respondents identified themselves as residing in an urban area. In contrast, almost 28 per cent identified themselves as rural residents. Overall, this suggests that the sample has a good geographical spread, which closely resembles the known distribution of the New Zealand adult population. It also shows no evidence of non-response bias on the basis of geographic location. An independent-samples t-test was also performed to compare scores to the research scales among respondents from rural and urban locations. No statistically significant difference was identified at a 0.05 level between respondents from rural and urban locations, for any the construct measures. 
Table 8a. Regional Residence of Research Respondents

\begin{tabular}{|l|c|c|}
\hline \multicolumn{1}{|c|}{ Region } & Number & Percentage (\%) \\
\hline Auckland Region & 99 & 25.4 \\
\hline Canterbury Region & 58 & 14.9 \\
\hline Wellington Region & 51 & 13.1 \\
\hline Waikato Region & 31 & 7.9 \\
\hline Otago Region & 24 & 6.2 \\
\hline Bay of Plenty Region & 19 & 4.9 \\
\hline Hawke's Bay Region & 19 & 4.9 \\
\hline Manawatu-Wanganui Region & 18 & 4.6 \\
\hline Northland Region & 16 & 4.1 \\
\hline Southland Region & 10 & 2.6 \\
\hline Other & 10 & 2.6 \\
\hline Gisborne Region & 9 & 2.3 \\
\hline Taranaki Region & 9 & 2.3 \\
\hline Marlborough Region & 6 & 1.5 \\
\hline Nelson Region & 5 & 1.3 \\
\hline Tasman Region & 3 & 0.8 \\
\hline West Coast Region & 390 & 0.8 \\
\hline Total & 1 & 100.0 \\
\hline Missing & & \\
\hline
\end{tabular}

Table 8b. Regional Council for the Census Usually Resident Population Count 2006

\begin{tabular}{|l|c|c|}
\hline \multicolumn{1}{|c|}{ Regional Council } & Number of Residents & Percentage of Population (\%) \\
\hline Auckland Region & $1,303,068$ & 32.4 \\
\hline Canterbury Region & 521,832 & 13 \\
\hline Wellington Region & 448,959 & 11.2 \\
\hline Waikato Region & 382,716 & 9.5 \\
\hline Bay of Plenty Region & 257,379 & 6.4 \\
\hline Manawatu-Wanganui Region & 222,423 & 5.5 \\
\hline Otago Region & 193,800 & 4.8 \\
\hline Northland Region & 148,470 & 3.7 \\
\hline Hawke's Bay Region & 147,783 & 3.7 \\
\hline Taranaki Region & 104,124 & 2.6 \\
\hline Southland Region & 90,876 & 2.3 \\
\hline Tasman Region & 44,625 & 1.1 \\
\hline Gisborne Region & 44,499 & 1.1 \\
\hline Nelson Region & 42,888 & 1.1 \\
\hline Marlborough Region & 42,558 & 1.1 \\
\hline West Coast Region & 31,326 & 0.8 \\
\hline Area Outside Region & 618 & 0.02 \\
\hline (Statistics New Zealand, 2006) & & \\
\hline
\end{tabular}


Table 9. Urban/Rural Residence of Research Respondents

\begin{tabular}{|l|c|c|}
\hline Residence & Number & Percentage (\%) \\
\hline Rural & 106 & 27.7 \\
\hline Urban & 277 & 72.3 \\
\hline Total & 383 & 100.0 \\
\hline Missing & 8 & \\
\hline
\end{tabular}

\subsubsection{Gender}

Tables 10a and 10b identify the gender of research respondents, as well as that of the usually resident New Zealand population. As shown in Table 10a, almost 58 per cent of research respondents identified themselves as female and 42 per cent as male. In comparison, New Zealand's usually resident population is composed of 51 per cent females and 49 per cent males. Accordingly, the gender split of research respondents is reasonably representative of the overall New Zealand population, although skewed towards female respondents.

An independent-samples t-test was performed to compare scores to the research scales among male and female respondents. Like residential region, however, no statistically significant difference at a 0.05 level was identified between males and females for any the construct measures.

Table 10a. Gender of Research Respondents

\begin{tabular}{|l|c|c|}
\hline Gender & Number & Percentage (\%) \\
\hline Male & 164 & 42.3 \\
\hline Female & 224 & 57.7 \\
\hline Total & 388 & 100.0 \\
\hline Missing & 3 & \\
\hline
\end{tabular}

Table 10b. Usually Resident New Zealand Population Gender

\begin{tabular}{|l|c|c|}
\hline Gender & Number of Residents & Percentage of Population (\%) \\
\hline Male & $1,965,621$ & 48.8 \\
\hline Female & $2,062,326$ & 51.2 \\
\hline \multicolumn{2}{|l|}{ (Statistics New Zealand, 2006) } \\
\hline
\end{tabular}

\subsubsection{Personal Annual Income Level}

Table 11a reveals the personal annual income level identified by research respondents. As with the pretest, research respondents were skewed towards higher income earners than the usually resident New Zealand population. This is somewhat expected, however, as higher income earners are likely to travel more frequently by airline and subsequently feel that they can contribute to research of this nature. Census results include residents aged from 15 years, 
while the research sample included only residents aged 18 years or older. This noted, Table $11 \mathrm{~b}$ shows that almost 39 per cent of usually resident New Zealanders aged 15 years and over have an annual income of $\$ 20,000$ or less. In contrast, only 18 per cent of research respondents identified themselves as having an equivalent personal annual income. Almost half of the research respondents reported that their personal annual income exceeded $\$ 40,000$ and over 34 per cent reported that their personal annual income exceeded $\$ 50,000$. Comparatively, about 25 per cent of all New Zealand residents have an annual income over $\$ 40,000$ and 16 per cent report an annual income of over $\$ 50,000$.

Table 11a. Personal Income of Research Respondents

\begin{tabular}{|l|c|c|}
\hline \multicolumn{1}{|c|}{ Personal Annual Income } & Number of Residents & Percentage of Population (\%) \\
\hline$\$ 0-\$ 10,000$ & 27 & 7.3 \\
\hline$\$ 10,001-\$ 20,000$ & 41 & 11.0 \\
\hline$\$ 20,001-\$ 30,000$ & 60 & 16.1 \\
\hline$\$ 30,001-\$ 40,000$ & 59 & 15.9 \\
\hline$\$ 40,001-\$ 50,000$ & 56 & 15.1 \\
\hline$\$ 50,001-\$ 60,000$ & 37 & 9.9 \\
\hline$\$ 60,001-\$ 70,000$ & 31 & 8.3 \\
\hline$\$ 70,001+$ & 61 & 16.4 \\
\hline Total & 372 & 100.0 \\
\hline Missing & 19 & \\
\hline
\end{tabular}

Table 11b. Total Personal Income for the Census Usually Resident Population Count Aged 15 Years and Over

\begin{tabular}{|l|c|c|}
\hline \multicolumn{1}{|c|}{ Personal Annual Income } & Number of Residents & Percentage of Population (\%) \\
\hline Loss & 17,355 & 0.6 \\
\hline$\$ 0-\$ 10,000$ & 593,016 & 18.8 \\
\hline$\$ 10,001-\$ 20,000$ & 615,981 & 19.5 \\
\hline$\$ 20,001-\$ 30,000$ & 434,955 & 13.8 \\
\hline$\$ 30,001-\$ 40,000$ & 404,073 & 12.8 \\
\hline$\$ 40,001-\$ 50,000$ & 262,299 & 8.3 \\
\hline$\$ 50,001-\$ 70,000$ & 281,160 & 8.9 \\
\hline$\$ 70,001+$ & 230,643 & 7.3 \\
\hline Not Elsewhere Included & 320,892 & 10.2 \\
\hline Total & $3,160,374$ & 100.0 \\
\hline (Statistics New Zealand, 2006) & \\
\hline
\end{tabular}


Respondents were separated into eight groups according to their self-identified personal income. A one-way between-groups analysis of variance was performed to examine whether any differences in responses to the research constructs could be attributed to income. The significance value of the Levene Statistic for Communication with the Brand (frequency), Communication with Consumer Communities (experience), and Customer Brand Loyalty was below a 0.05 value, indicating that these scales violated the assumption of homogeneity of variance. The ANOVA matrix revealed that there is a statistically significant difference at a 0.05 level in the Communication with the Brand (frequency) and Relational Orientation scales for the personal annual income level groups. The eta squared value of the difference between groups, regarding both scales, is only 0.04 . The Multiple Comparisons matrix suggests that respondents with a personal annual income of $\$ 70,001+$ differed from those with an income of $\$ 0-\$ 10,000, \$ 10,001-\$ 20,000, \$ 20,001-\$ 30,000, \$ 30,001-\$ 40,000$, and $\$ 40,001-\$ 50,000$ in their responses to the Communication with the Brand (frequency) scale, at a 0.05 level. Respondents with a personal annual income of $\$ 0-\$ 10,000$ and $\$ 30,001-\$ 40,000$ differed from those with an income of $\$ 50,001-\$ 60,000$ and $\$ 70,001+$ in their responses to the Relational Orientation scale, at a 0.05 level. Like age, however, answers to the majority of items did not differ significantly by personal annual income level.

\subsubsection{Airline Travel}

It is possible that a consumer travelling primarily for business purposes may be bound by a contractual relationship between the organisation they work for and a commercial airline. They could, therefore, exhibit high levels of communication regarding a brand although they perceive a low personal relationship. To account for this, research respondents were asked whether they perceived their airline travel to be mostly for business purposes. Data analysis could then be performed to reveal whether there was a significant difference in the measurement of the research constructs between respondents who travel for business or personal reasons. As shown in Table 12, below, over 88 per cent of research respondents identified that they travel by airline mostly for personal reasons. The remaining 12 per cent of respondents identified that they travel primarily for business purposes.

An independent-samples t-test was performed to compare scores to the research scales, among respondents who identify themselves as travelling by airline mostly for personal and business purposes. A significant difference between the responses of personal and business travellers was identified at a 0.05 level for scale items intended to measure Communication with the Brand (frequency) and Relational Orientation. Responses to the Communication with the Brand (frequency) scale were significantly higher for business (mean: 9.27, standard deviation: 2.71) than personal (mean: 8.18, standard deviation: 2.54) travellers. Similarly, responses to the Relational Orientation scale were significantly higher for business (mean: 
21.82, standard deviation: 4.14) than personal (mean: 19.95, standard deviation: 3.87 ) travellers. The Eta squared value suggests that only 1.97 per cent of the variance in Communication with the Brand (frequency) and only 2.53 per cent of the variance in Relational Orientation is explained by a respondent's reason for travel. No significant difference in scores is identified for any of the other research scales. Because a significant difference is only shown in two constructs and the attributable variance is relatively low, data was not separated according to a respondent's primary reason for travel in further analysis.

Table 12. Primary Purpose for Travel of Research Respondents

\begin{tabular}{|l|c|c|}
\hline Purpose & Number & Percentage (\%) \\
\hline Business & 45 & 11.7 \\
\hline Personal & 340 & 88.3 \\
\hline Total & 385 & 100.0 \\
\hline Missing & 6 & \\
\hline
\end{tabular}

Research respondents were also asked whether Air New Zealand is the airline that they use most frequently. In addition, they were asked which of eight alternative airlines excluding Air New Zealand they most frequently use. Table 13 indicates that 70 per cent of research respondents who answered the question acknowledged Air New Zealand as the airline that they use most frequently. All 391 research respondents answered items concerning Air New Zealand. Almost 61 per cent answered items concerning an alternative airline. The remaining 39 per cent of respondents did not specify an alternative airline to Air New Zealand. As with the research pretest, the most frequently used alternative airline was Qantas. This was followed by Pacific Blue (Virgin), Singapore Airlines, and Emirates.

Table 13. Most Frequently Travelled Airline of Research Respondents

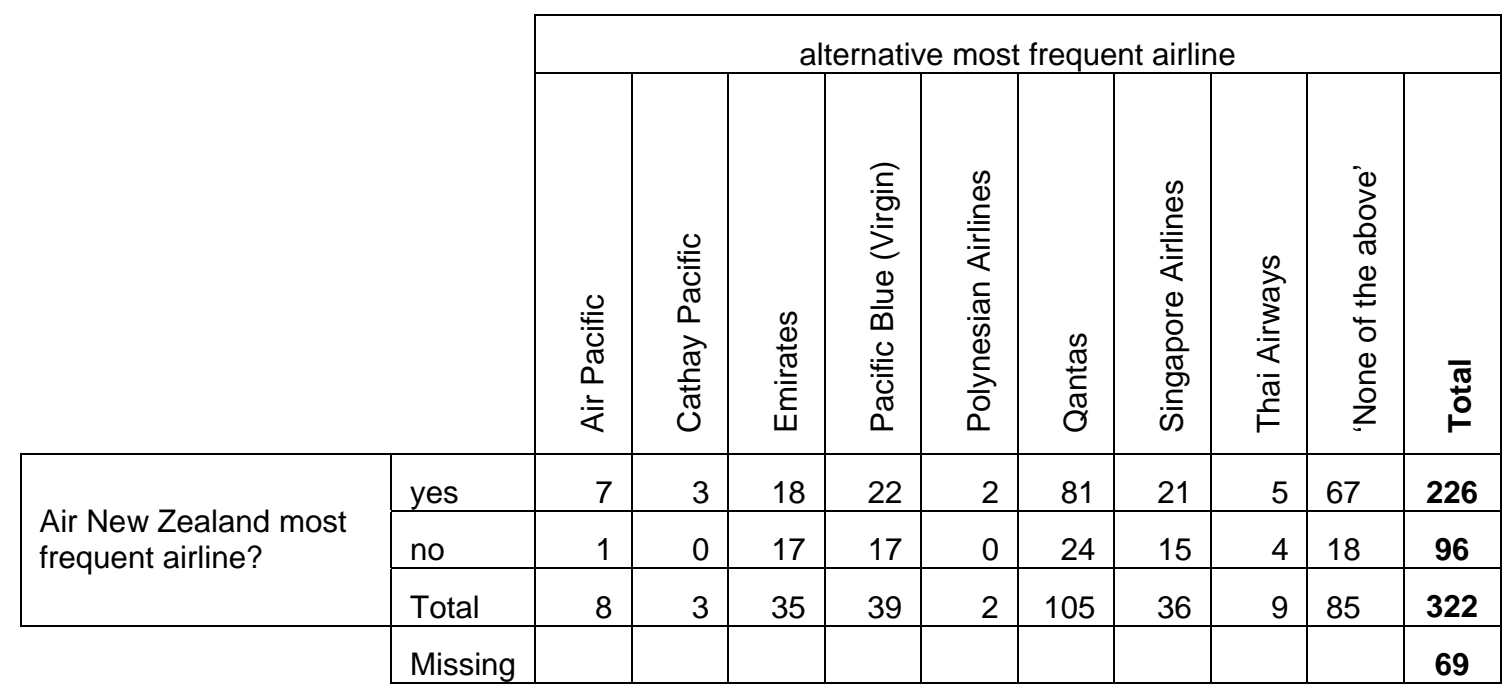

Consumers have the choice to be Air New Zealand Airpoints or Koru Club members. Depending on their Airpoints or Koru Club status, members are entitled to certain benefits 
when travelling with Air New Zealand. This includes priority service and access to airport lounges. It is possible that individuals that are part of an airline's membership programme form a relationship with the airline differently from non-members. Accordingly, research respondents were asked whether they are Air New Zealand Airpoints members and the status of their membership, as well as whether they are Air New Zealand Koru Club members. The results are shown in Tables 14a, 14b, and 15 below. Just over one third of research respondents that answered the question identified themselves as Air New Zealand Airpoints members. The majority of these respondents acknowledged their Airpoints membership status as standard. Furthermore, of the research respondents that answered the question regarding Air New Zealand Koru Club membership, less than three per cent indicated that they are members. It should be noted however that Gold and Gold Elite Air New Zealand Airpoints members automatically have access to some priority services and are not obliged to purchase a separate Koru Club membership. Hence, around 10 per cent of respondents have access to the Air New Zealand hospitality lounges.

Table 14a. Air New Zealand Airpoints Membership of Research Respondents

\begin{tabular}{|l|c|c|}
\hline Airpoints & Number & Percentage (\%) \\
\hline Yes & 128 & 34.0 \\
\hline No & 248 & 66.0 \\
\hline Total & 376 & 100.0 \\
\hline Missing & 15 & \\
\hline
\end{tabular}

Table 14b. Air New Zealand Airpoints Status of Research Respondents

\begin{tabular}{|l|c|c|}
\hline Status & Number & Percentage (\%) \\
\hline Standard & 99 & 79.2 \\
\hline Silver & 16 & 12.8 \\
\hline Gold & 7 & 5.6 \\
\hline Gold Elite & 3 & 2.4 \\
\hline Total & 125 & 100.0 \\
\hline
\end{tabular}

Table 15. Air New Zealand Koru Club Membership of Research Respondents

\begin{tabular}{|l|c|c|}
\hline Airpoints & Number & Percentage (\%) \\
\hline Yes & 10 & 2.7 \\
\hline No & 365 & 97.3 \\
\hline Total & 375 & 100.0 \\
\hline Missing & 16 & \\
\hline
\end{tabular}

\subsubsection{Customer Lifetime Value}

Out of interest regarding the potential profit received from consumers throughout a relationship, the customer lifetime value of research respondents was measured. Four 
questions were used to determine the value of a customer relationship to a brand over time. Research respondents were asked how often they make a domestic and international round trip with an airline throughout a year, as well as the average amount spent on each flight. Airline travel frequency was then multiplied by airline travel spend, to calculate total annual domestic and international spend. Of the 391 usable responses collected through the research, 280 respondents answered questions relating to both Air New Zealand and one other airline brand. Consequently, up to 671 responses are reported for each customer lifetime value item. Table 16 shows that, on average, research respondents take 1.5 domestic flights and 0.8 international flights on any one airline annually. In total, respondents' average annual spend is $\$ 445$ on domestic and $\$ 1005$ on international flights. Comparatively, it is estimated that 0.64 per cent of every $\$ 100$ spent by New Zealand households is spent on domestic air transport and 1.68 per cent is spent on international air transport (Statistics New Zealand, 2009). Average annual household expenditure in New Zealand is approximately $\$ 50,000$ (Statistics New Zealand, 2007). Therefore, as a population it is estimated that $\$ 320$ is spent on domestic air travel and $\$ 840$ is spent on international air travel by household each year. These comparative spend levels provide further reassurance about the representativeness of the sample data provided. Allowing for adult New Zealanders that may never travel by air, this suggests a level of spend by people who fly at least once a year as not markedly dissimilar from that among sample respondents. The possibility remains that respondents did travel somewhat more frequently than members of the travelling public overall. There was no evidence however of a marked difference in air travel, either domestically or internationally.

Table 16. Total Annual Airline Travel Spend of Research Respondents

\begin{tabular}{|l|c|c|c|c|c|c|}
\hline & $\begin{array}{c}\text { domestic } \\
\text { frequency }\end{array}$ & $\begin{array}{c}\text { domestic } \\
\text { spend (\$) }\end{array}$ & $\begin{array}{c}\text { international } \\
\text { frequency }\end{array}$ & $\begin{array}{c}\text { international } \\
\text { spend }(\$)\end{array}$ & $\begin{array}{c}\text { domestic } \\
\text { total }(\$)\end{array}$ & $\begin{array}{c}\text { International } \\
\text { total }(\$)\end{array}$ \\
\hline Valid & 653 & 632 & 654 & 639 & 632 & 639 \\
\hline Missing & 18 & 39 & 17 & 32 & 39 & 32 \\
\hline Mean & 1.49 & 208.96 & 0.817 & 1135.84 & 444.87 & 1005.10 \\
\hline Std. Deviation & 3.82 & 160.37 & 2.46 & 762.74 & 1430.95 & 2363.73 \\
\hline Skewness & 7.14 & 0.28 & 14.75 & 0.06 & 10.27 & 6.39 \\
\hline Kurtosis & 69.02 & -0.81 & 290.22 & -1.32 & 137.03 & 51.78 \\
\hline Minimum & 0.00 & 0.00 & 0.00 & 0.00 & .00 & .00 \\
\hline Maximum & 52.00 & 550.00 & 52.00 & 2200.00 & 23400.00 & 26400.00 \\
\hline
\end{tabular}

\subsection{Overview of Data Analysis}

A number of data analysis techniques were performed following data collection. The analyses detailed in this section reflect the objectives and hypotheses of the research, outlined earlier. An intended contribution of the research includes verification of the proposed conceptual model concerning the process by which consumers form relationships with brands, as well as the development of an instrument by which to measure the research constructs. Therefore, 
assessment of the proposed linkages between variables and of the measurement instrument is of significance. Assessment of the research instrument is discussed in sections 5.4 and 5.5, comprising analysis of scale validity and reliability. Further analysis, including that to examine the linkages between constructs, was tested by performing partial least square analysis in section 5.7 .

Scales were developed to measure the research constructs. Individual consumer responses to a paper and pen survey were then utilised to measure the variables presented in the conceptual model. New scales were developed for the constructs of Communication with the Brand, Communication with Consumer Communities, and Brand Personality Connection. For these new scales, validity was assessed using exploratory factor analysis (Bagozzi, Yi, \& Phillips, 1991; Churchill, 1979; Gerbing \& Anderson, 1988). Exploratory factor analysis was conducted to identify the structure of each construct, providing an assessment of the unidimensionality of the construct in question. Communication with the Brand, Communication with Consumer Communities, and Brand Personality Connection are also formative constructs. Therefore formative indicators were used to test the unidimensionality of the scales used to measure these constructs; including an examination of content specification, indicator specification, indicator collinearity, and external validity (Diamantopoulos \& Winklhofer, 2001). Although reflective, the constructs of Brand Advertising, Relationship Quality, Relational Orientation, and Customer Brand Loyalty were measured using scales based on existing literature. Confirmatory factor analysis was performed in section 5.7. This was done using partial least square analysis to assess convergent and discriminant validity (Bagozzi, et al., 1991). A summary of the measurement model is shown in Table 17, below.

Partial least square analysis, using SmartPLS (Ringle, Wende, \& Will, 2005), was also used to test the research hypotheses. The purpose of partial least square analysis is to maximise the explanation of variance in dependent constructs. This analysis allows regression regarding a number of dependent and independent variables to be conducted simultaneously. In the present research, an explanation of variance means that the degree of influence of different forms of communication upon a consumer's connection with a brand could be determined, as well as the influence of relationship quality upon customer brand loyalty. Essentially, the degree of influence of multiple independent variables upon dependent variables can be examined at once. Partial least square analysis is also suited to more complex conceptual models in which measurement scales are newly adapted, such as in the present research (Barclay \& Smith, 1997; Chin, Peterson, \& Brown, 2008). This is discussed further in section 5.7 . 
Table 17. Measurement Model Summary

\begin{tabular}{|c|c|c|}
\hline Construct & Item & $\begin{array}{l}\text { Partial least } \\
\text { square cross } \\
\text { loadings }\end{array}$ \\
\hline $\begin{array}{l}\text { Brand Advertising } \\
\text { (reflective) } \\
\text { Cronbach's Alpha: } 0.94\end{array}$ & $\begin{array}{l}\text { In general, how would you describe the brand's advertising? } \\
\text { - good/bad } \\
\text { - useful/useless } \\
\text { - positive/negative } \\
\text { - agreeable/disagreeable } \\
\text { - like/dislike } \\
\text { - high quality/low quality } \\
\text { - pleasant/unpleasant } \\
\text { - valuable/worthless } \\
\text { - beneficial/not beneficial } \\
\text { - favourable/unfavourable }\end{array}$ & $\begin{array}{l}0.852 \\
0.832 \\
0.787 \\
0.832 \\
0.806 \\
0.832 \\
0.795 \\
0.768 \\
0.761 \\
0.741\end{array}$ \\
\hline $\begin{array}{l}\text { Communication with } \\
\text { the Brand } \\
\text { (formative) }\end{array}$ & $\begin{array}{l}\text { - How often do you talk face-to-face with the brand's staff members, } \\
\text { including check-in staff and in-flight crew? How would you generally rate } \\
\text { this experience? } \\
\text { - How often do you talk on the telephone with the brand? How would you } \\
\text { generally rate this experience? } \\
\text { - How often do you visit the brand's Website? How would you generally } \\
\text { rate this experience? } \\
\text { live chat? How would you generally rate this experience? }\end{array}$ & $\begin{array}{l}0.540 \\
0.406 \\
0.037 \\
0.324\end{array}$ \\
\hline $\begin{array}{l}\text { Communication with } \\
\text { Consumer } \\
\text { Communities } \\
\text { (formative) }\end{array}$ & $\begin{array}{l}\text { - How often do you talk face-to-face with friends or family about the brand? } \\
\text { Is face-to-face discussion about the airline generally positive, negative, or } \\
\text { neutral? } \\
\text { - How often do you talk on the telephone with friends or family about the } \\
\text { brand? Is telephone discussion about the airline generally positive, } \\
\text { negative, or neutral? } \\
\text { - How often do you participate in online discussions about the brand? Is } \\
\text { online discussion about the airline generally positive, negative, or } \\
\text { neutral? } \\
\text { - How often do you e-mail friends or family about the brand? Is e-mail } \\
\text { discussion about the airline generally positive, negative, or neutral? }\end{array}$ & $\begin{array}{l}0.581 \\
0.317 \\
0.038 \\
0.294\end{array}$ \\
\hline $\begin{array}{l}\text { Relationship Quality } \\
\text { (reflective) } \\
\text { Cronbach's Alpha: } 0.84 \\
\mathrm{R}^{2}: 0.43\end{array}$ & $\begin{array}{l}\text { - The brand plays an important role in my life. } \\
\text { - I am knowledgeable about the brand. } \\
\text { - The brand understands my travel needs. } \\
\text { - I am passionate about the brand. } \\
\text { - I am satisfied by the efforts that the brand makes towards me. } \\
\text { - I have trust in the brand. }\end{array}$ & $\begin{array}{l}0.744 \\
0.604 \\
0.794 \\
0.786 \\
0.802 \\
0.739\end{array}$ \\
\hline $\begin{array}{l}\text { Relational Orientation } \\
\text { (reflective) } \\
\text { Cronbach's Alpha: } 0.87\end{array}$ & $\begin{array}{l}\text { - Certain airlines are important to me. } \\
\text { - I know a lot about certain airlines. } \\
\text { - I like it when airlines know me well. } \\
\text { - I am passionate about certain airlines. } \\
\text { - There are certain airlines that particularly satisfy me. } \\
\text { - I really trust certain airlines. }\end{array}$ & $\begin{array}{l}0.827 \\
0.751 \\
0.685 \\
0.820 \\
0.789 \\
0.812\end{array}$ \\
\hline $\begin{array}{l}\begin{array}{l}\text { Customer Brand } \\
\text { Loyalty } \\
\text { (reflective) }\end{array} \\
\text { Cronbach's Alpha: } 0.89 \\
\mathrm{R}^{2}: 0.49\end{array}$ & $\begin{array}{l}\text { How likely are you to do the following? } \\
\text { - Say positive things about the brand to other people? } \\
\text { - Recommend the brand to someone who seeks your advice? } \\
\text { - If there was a choice of airlines, consider the brand first when next } \\
\text { travelling by plane? } \\
\text { - Do business with the brand in the next few years? }\end{array}$ & $\begin{array}{l}0.851 \\
0.922 \\
0.912 \\
0.811 \\
0.646\end{array}$ \\
\hline $\begin{array}{l}\text { Brand Personality } \\
\text { Connection } \\
\text { (formative) } \\
\mathrm{R}^{2}: 0.21\end{array}$ & $\begin{array}{l}\text { Please indicate how you would characterise the brand I your ideal } \\
\text { airline. } \\
\text { - rugged/refined } \\
\text { - competent/incompetent } \\
\text { - exciting/conservative } \\
\text { - sophisticated/relaxed } \\
\text { - sincere/pretentious }\end{array}$ & $\begin{array}{l}0.179 \\
0.557 \\
0.025 \\
0.174 \\
0.513\end{array}$ \\
\hline
\end{tabular}




\subsection{Scale Validation}

The following sections report on the results of scale validation. Factor analysis was conducted to test each of the research constructs. The constructs of Brand Advertising, Relationship Quality, Relational Orientation, and Customer Brand Loyalty are reflective. As reflective scales, their items are assumed to share an underlying common dimension or construct (Fornell \& Bookstein, 1982). The items comprising these scales are expected to collectively reflect the construct of interest. However the scales used to measure Brand Advertising, Relationship Quality, Relational Orientation, and Customer Brand Loyalty were also based on existing scales. As such, confirmatory factor analysis was conducted for these scales using partial least squares. This analysis is discussed in section 5.7.

The scales intended to measure the constructs of Communication with the Brand, Communication with Consumer Communities, and Brand Personality Connection were defined as formative; given they are used to measure a construct that is an explanatory combination of its indicators (Bucic \& Gudergan, 2004; Fornell \& Bookstein, 1982). The measurement of formative constructs comprises a total weighted score across all the items; with each item representing an independent construct dimension. The scale items should cover the scope of the construct, depending on its definition (Diamantopoulos \& Winklhofer, 2001). An increase or decrease in the score of one item means a higher or lower score for the formative scale overall (Bucic \& Gudergan, 2004). In accordance with recommended procedure when testing formative scales, the validity of the scales used to measure Communication with the Brand, Communication with Consumer Communities, and Brand Personality Connection was determined by examining formative indicators; including content specification, indicator specification, indicator collinearity, and external validity (Diamantopoulos \& Winklhofer, 2001). This exploratory construct analysis was used as a preliminary test of scale construction (Stewart, 1981) and is reported in section 5.4.1. Confirmatory factor analysis is undertaken in subsequent chapters, to refine the research scales by assessing the unidimensionality of each scale simultaneously (Churchill, 1979; Gerbing \& Anderson, 1988).

\subsubsection{Exploratory Construct Analysis}

The research constructs of Communication with the Brand, Communication with Consumer Communities, and Brand Personality Connection were measured using new scales. They are also recognised as formative. The following section discusses exploratory construct analysis of these scales using formative indicators. 


\subsubsection{Communication with the Brand}

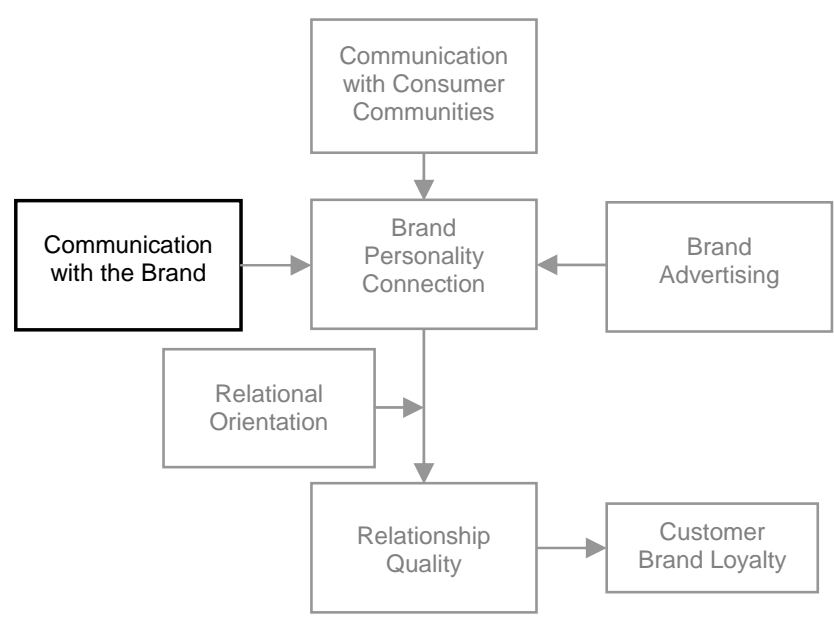

Communication with the Brand measures the frequency of a consumer's interactive communication with a brand, as well as the nature of the experience perceived when engaging in such communication. The scales used to measure this construct, therefore, captured communication frequency and experience. Communication with the Brand (total) was calculated by multiplying items measuring Communication with the Brand (frequency) by Communication with the Brand (experience). The scale intended to measure this construct is recognised as formative, given it is used to measure a construct that is an explanatory combination of its indicators (Bucic \& Gudergan, 2004; Fornell \& Bookstein, 1982). The validity of this scale is, therefore, determined using formative indicators. Four items were used in the scale measuring Communication with the Brand. The four scale items concerned four channels of communication that consumers can engage in with a brand. These included the perceived frequency and nature of a) face-to-face, b) non-Internet connected telephone, c) website, and d) e-mail or live-chat communication that a consumer engages in with a brand. In addition to items relating to these four channels of communication, respondents were asked to indicate the perceived frequency and nature of communication engaged in with a brand in general. This final scale item was used as a global item, summarising the essence of the construct that the scale is intended to measure and also providing an additional means of assessing the validity of the constructed scale.

Content specification assesses whether formative scale items capture that which they are intended to. In the present research, content specification is maintained through careful definition of the construct items. Indicator specification assesses whether formative scale items cover the scope of the construct as described under the content specification; although it is not unanimous whether a census of indicators is required (Diamantopoulos \& Winklhofer, 2001; Rossiter, 2002). Referring to the definition of Communication with the Brand, all effort was made to ensure the indicator specification of the items measuring this construct, with each item capturing a form of communication that consumers engage in with brands. Indicator collinearity is determined by the collinearity among scale items. It is recommended that 
excessive multi-collinearity should not exist among the individual formative scale items or it is difficult to identify the influence of each item (Diamantopoulos \& Winklhofer, 2001). Multicollinearity above a level of 0.80 is regarded as excessive (Leahy, 2000). Tables 18a, 18b, and 18c, below, show that although Communication with the Brand scale items are significantly correlated this is not excessive; with the maximum Pearson Correlation value among Communication with the Brand scale items being 0.50. While 391 usable research questionnaires were returned, the number of reported responses for any scale item ranges up to 671 . This is because over 70 per cent of the research sample responded to questions in reference to two brands.

Table 18a. Communication with the Brand (frequency) Indicator Collinearity

\begin{tabular}{|c|c|c|c|c|c|}
\hline & & $\begin{array}{c}\text { Communication with } \\
\text { the Brand (frequency) } \\
\text { face-to-face }\end{array}$ & $\begin{array}{c}\text { Communication with } \\
\text { the Brand (frequency) } \\
\text { telephone }\end{array}$ & $\begin{array}{c}\text { Communication with } \\
\text { the Brand (frequency) } \\
\text { web site }\end{array}$ & $\begin{array}{c}\text { Communication with } \\
\text { the Brand (frequency) } \\
\text { e-mail }\end{array}$ \\
\hline \multirow{3}{*}{$\begin{array}{l}\text { Communication with } \\
\text { the Brand (frequency) } \\
\text { face-to-face }\end{array}$} & $\begin{array}{l}\text { Pearson } \\
\text { Correlation }\end{array}$ & 1.000 & $.424^{\star *}$ & $.370^{\star *}$ & $.277^{\star *}$ \\
\hline & Sig. (2-tailed) & & .000 & .000 & .000 \\
\hline & $\mathrm{N}$ & 663 & 659 & 659 & 660 \\
\hline \multirow{3}{*}{$\begin{array}{c}\text { Communication with } \\
\text { the Brand (frequency) } \\
\text { telephone }\end{array}$} & $\begin{array}{l}\text { Pearson } \\
\text { Correlation }\end{array}$ & & 1.000 & $.255^{* *}$ & $.294^{* *}$ \\
\hline & Sig. (2-tailed) & & & .000 & .000 \\
\hline & $\mathrm{N}$ & & 663 & 660 & 662 \\
\hline \multirow{3}{*}{$\begin{array}{l}\text { Communication with } \\
\text { the Brand (frequency) } \\
\text { web site }\end{array}$} & $\begin{array}{l}\text { Pearson } \\
\text { Correlation }\end{array}$ & & & 1.000 & $.353^{* \star}$ \\
\hline & Sig. (2-tailed) & & & & .000 \\
\hline & $\mathrm{N}$ & & & 664 & 662 \\
\hline \multirow{3}{*}{$\begin{array}{c}\text { Communication with } \\
\text { the Brand (frequency) } \\
\text { e-mail }\end{array}$} & $\begin{array}{l}\text { Pearson } \\
\text { Correlation }\end{array}$ & & & & 1.000 \\
\hline & Sig. (2-tailed) & & & & \\
\hline & $\mathrm{N}$ & & & & 665 \\
\hline
\end{tabular}

Table 18b. Communication with the Brand (experience) Indicator Collinearity

\begin{tabular}{|c|c|c|c|c|c|}
\hline & & $\begin{array}{c}\text { Communication with } \\
\text { the Brand (experience) } \\
\text { face-to-face }\end{array}$ & $\begin{array}{c}\text { Communication with } \\
\text { the Brand (experience) } \\
\text { telephone }\end{array}$ & $\begin{array}{c}\text { Communication with } \\
\text { the Brand (experience) } \\
\text { web site }\end{array}$ & $\begin{array}{c}\text { Communication with } \\
\text { the Brand (experience) } \\
\text { e-mail }\end{array}$ \\
\hline \multirow{3}{*}{$\begin{array}{c}\text { Communication with } \\
\text { the Brand } \\
\text { (experience) } \\
\text { face-to-face }\end{array}$} & $\begin{array}{l}\text { Pearson } \\
\text { Correlation }\end{array}$ & 1.000 & $.486^{\star *}$ & $.360^{* *}$ & $.252^{\star \star}$ \\
\hline & Sig. (2-tailed) & & .000 & .000 & .000 \\
\hline & $\mathrm{N}$ & 646 & 636 & 641 & 641 \\
\hline \multirow{3}{*}{$\begin{array}{c}\text { Communication with } \\
\text { the Brand } \\
\text { (experience) } \\
\text { telephone }\end{array}$} & $\begin{array}{l}\text { Pearson } \\
\text { Correlation }\end{array}$ & & 1.000 & $.363^{* *}$ & $.300^{* *}$ \\
\hline & Sig. (2-tailed) & & & .000 & .000 \\
\hline & $\mathrm{N}$ & & 651 & 648 & 648 \\
\hline \multirow{3}{*}{$\begin{array}{c}\text { Communication with } \\
\text { the Brand } \\
\text { (experience) } \\
\text { web site }\end{array}$} & $\begin{array}{l}\text { Pearson } \\
\text { Correlation }\end{array}$ & & & 1.000 & $.322^{* *}$ \\
\hline & Sig. (2-tailed) & & & & .000 \\
\hline & $\mathrm{N}$ & & & 662 & 657 \\
\hline \multirow{3}{*}{$\begin{array}{c}\text { Communication with } \\
\text { the Brand } \\
\text { (experience) } \\
\text { e-mail }\end{array}$} & $\begin{array}{l}\text { Pearson } \\
\text { Correlation }\end{array}$ & & & & 1.000 \\
\hline & Sig. (2-tailed) & & & & \\
\hline & $\mathrm{N}$ & & & & 663 \\
\hline
\end{tabular}

**. Correlation is significant at the 0.01 level (2-tailed). 
Table 18c. Communication with the Brand (total) Indicator Collinearity

\begin{tabular}{|c|c|c|c|c|c|}
\hline & & $\begin{array}{l}\text { Communication with } \\
\text { the Brand (total) } \\
\text { face-to-face }\end{array}$ & $\begin{array}{l}\text { Communication with } \\
\text { the Brand (total) } \\
\text { telephone }\end{array}$ & $\begin{array}{l}\text { Communication with } \\
\text { the Brand (total) } \\
\text { web site }\end{array}$ & $\begin{array}{c}\text { Communication with } \\
\text { the Brand (total) } \\
\text { e-mail }\end{array}$ \\
\hline \multirow{3}{*}{$\begin{array}{l}\text { Communication with } \\
\text { the Brand (total) } \\
\text { face-to-face }\end{array}$} & $\begin{array}{l}\text { Pearson } \\
\text { Correlation }\end{array}$ & 1.000 & $.504^{\star *}$ & $.393^{* \star}$ & $.273^{* \star}$ \\
\hline & Sig. (2-tailed) & & .000 & .000 & .000 \\
\hline & $\mathrm{N}$ & 645 & 635 & 640 & 640 \\
\hline \multirow{3}{*}{$\begin{array}{l}\text { Communication with } \\
\text { the Brand (total) } \\
\text { telephone }\end{array}$} & $\begin{array}{l}\text { Pearson } \\
\text { Correlation }\end{array}$ & & 1.000 & $.339^{\star *}$ & $.302^{* *}$ \\
\hline & Sig. (2-tailed) & & & .000 & .000 \\
\hline & $\mathrm{N}$ & & 651 & 648 & 648 \\
\hline \multirow{3}{*}{$\begin{array}{l}\text { Communication with } \\
\text { the Brand (total) } \\
\text { web site }\end{array}$} & $\begin{array}{l}\text { Pearson } \\
\text { Correlation }\end{array}$ & & & 1.000 & $.315^{* *}$ \\
\hline & Sig. (2-tailed) & & & & .000 \\
\hline & $\mathrm{N}$ & & & 662 & 657 \\
\hline \multirow{3}{*}{$\begin{array}{c}\text { Communication with } \\
\text { the Brand (total) } \\
\text { e-mail }\end{array}$} & $\begin{array}{l}\text { Pearson } \\
\text { Correlation }\end{array}$ & & & & 1.000 \\
\hline & Sig. (2-tailed) & & & & \\
\hline & $\mathrm{N}$ & & & & 663 \\
\hline
\end{tabular}

External validity of formative scales can be determined by examining the correlation between individual scale items and a global item that summarizes the construct (Diamantopoulos \& Winklhofer, 2001). Such a global item is simply a composite measure of the construct in question. Respondents were asked how often they communicate with the brand in general and how they rate their overall communication with the brand. According to this procedure, individual scale items should be significantly correlated with the global item at a 0.05 level (Diamantopoulos \& Winklhofer, 2001). Tables 19a, 19b, and 19c indicate that data obtained via the four individual scale items of the Communication with the Brand scale correlate positively at a 0.01 level with a general measure of the construct. This is true for Communication with the Brand (frequency), Communication with the Brand (experience), and Communication with the Brand (total). Pearson Correlation values are shown to range between 0.37 and 0.66 .

Table 19a. Communication with the Brand (frequency) Individual Item Correlation Matrix

\begin{tabular}{|c|c|c|c|c|c|}
\hline & & $\begin{array}{l}\text { Communication } \\
\text { with the Brand } \\
\text { (frequency) } \\
\text { face to face }\end{array}$ & $\begin{array}{l}\text { Communication } \\
\text { with the Brand } \\
\text { (frequency) } \\
\text { telephone }\end{array}$ & $\begin{array}{l}\text { Communication } \\
\text { with the Brand } \\
\text { (frequency) } \\
\text { web site }\end{array}$ & $\begin{array}{c}\text { Communication } \\
\text { with the Brand } \\
\text { (frequency) } \\
\text { e-mail }\end{array}$ \\
\hline \multirow{3}{*}{$\begin{array}{l}\text { Communication with } \\
\text { the Brand (frequency) } \\
\text { global measure }\end{array}$} & $\begin{array}{l}\text { Pearson } \\
\text { Correlation }\end{array}$ & $.545^{* *}$ & $.569^{* *}$ & $.487^{* *}$ & $.385^{* *}$ \\
\hline & Sig. (2-tailed) & .000 & .000 & .000 & .000 \\
\hline & $\mathrm{N}$ & 660 & 660 & 661 & 662 \\
\hline
\end{tabular}

**. Correlation is significant at the 0.01 level (2-tailed).

Table 19b. Communication with the Brand (experience) Individual Item Correlation Matrix

\begin{tabular}{|c|l|r|r|r|r|}
\hline \multicolumn{2}{|c|}{} & $\begin{array}{c}\text { Communication } \\
\text { with the Brand } \\
\text { (experience) } \\
\text { face to face }\end{array}$ & $\begin{array}{c}\text { Communication } \\
\text { with the Brand } \\
\text { (experience) } \\
\text { telephone }\end{array}$ & $\begin{array}{c}\text { Communication } \\
\text { with the Brand } \\
\text { (experience) } \\
\text { web site }\end{array}$ & $\begin{array}{c}\text { Communication } \\
\text { with the Brand } \\
\text { (experience) } \\
\text { e-mail }\end{array}$ \\
\hline \multirow{2}{*}{$\begin{array}{c}\text { Communication with } \\
\text { the Brand } \\
\text { (experience) } \\
\text { global measure }\end{array}$} & $\begin{array}{l}\text { Pearson } \\
\text { Correlation }\end{array}$ & $\mathbf{. 5 6 5 ^ { * * }}$ &. $\mathbf{6 2 1 ^ { * * }}$ &. $\mathbf{. 3 9}^{* *}$ &. $\mathbf{3 7 1}^{* *}$ \\
\cline { 2 - 6 } & Sig. (2-tailed) & .000 & .000 & .000 & .000 \\
\cline { 2 - 6 } & $\mathrm{N}$ & 632 & 638 & 647 & 649 \\
\hline
\end{tabular}

**. Correlation is significant at the 0.01 level (2-tailed). 
Table 19c. Communication with the Brand (total) Individual Item Correlation Matrix

\begin{tabular}{|c|l|r|r|r|r|}
\hline \multicolumn{2}{|c|}{} & $\begin{array}{c}\text { Communication } \\
\text { with the Brand } \\
\text { (total) } \\
\text { face to face }\end{array}$ & $\begin{array}{c}\text { Communication } \\
\text { with the Brand } \\
\text { (total) } \\
\text { telephone }\end{array}$ & $\begin{array}{c}\text { Communication } \\
\text { with the Brand } \\
\text { (total) } \\
\text { web site }\end{array}$ & $\begin{array}{c}\text { Communication } \\
\text { with the Brand } \\
\text { (total) } \\
\text { e-mail }\end{array}$ \\
\hline \multirow{2}{*}{$\begin{array}{c}\text { Communication with } \\
\text { the Brand (total) } \\
\text { global measure }\end{array}$} & $\begin{array}{l}\text { Pearson } \\
\text { Correlation }\end{array}$ & $.591^{* *}$ & $.663^{* *}$ &. $\mathbf{4 1 4 *}$ & $.410^{* * *}$ \\
\cline { 2 - 6 } & Sig. (2-tailed) & .000 & .000 & .000 & .000 \\
\cline { 2 - 7 } & $\mathrm{N}$ & 630 & 637 & 646 & 648 \\
\hline
\end{tabular}

**. Correlation is significant at the 0.01 level (2-tailed).

To further test the correlation between individual Communication with the Brand scale items and the global item, scores obtained via scale items Communication with the Brand (face to face), Communication with the Brand (telephone), Communication with the Brand (web site), and Communication with the Brand (e-mail) were added together. As shown in Tables 20a, $20 \mathrm{~b}$, and $20 \mathrm{c}$, the sum of data obtained from the four scale items is also shown to correlate positively with general measures of Communication with the Brand frequency, experience, and overall respectively. Pearson Correlation values range between 0.67 and 0.70 . The scale items are, accordingly, both individually and collectively correlated with the global measure of the construct. It was concluded that the scale measuring Communication with the Brand exhibited good construct validity.

Table 20a. Communication with the Brand (frequency) Collective Item Correlation Matrix

\begin{tabular}{|c|l|r|}
\hline \multicolumn{2}{|c|}{} & \multicolumn{1}{c|}{$\begin{array}{c}\text { Communication with the Brand (frequency) } \\
\text { face to face + telephone + web site + e-mail }\end{array}$} \\
\hline \begin{tabular}{c} 
Communication with the $\begin{array}{c}\text { Brand (frequency) } \\
\text { global measure }\end{array}$ \\
\cline { 2 - 4 }
\end{tabular} & Pearson Correlation & .000 \\
\cline { 2 - 4 } & Sig. (2-tailed) & 653 \\
\hline
\end{tabular}

**. Correlation is significant at the 0.01 level (2-tailed).

Table 20b. Communication with the Brand (experience) Collective Item Correlation Matrix

\begin{tabular}{|c|c|c|}
\hline & & $\begin{array}{l}\text { Communication with the Brand (experience) } \\
\text { face to face }+ \text { telephone }+ \text { web site }+ \text { e-mail }\end{array}$ \\
\hline \multirow{3}{*}{$\begin{array}{l}\text { Communication with the } \\
\text { Brand (experience) } \\
\text { global measure }\end{array}$} & Pearson Correlation & $.684^{* \pi}$ \\
\hline & Sig. (2-tailed) & .000 \\
\hline & $\mathrm{N}$ & 618 \\
\hline
\end{tabular}

${ }^{\star \star}$. Correlation is significant at the 0.01 level (2-tailed).

Table 20c. Communication with the Brand (total) Collective Item Correlation Matrix

\begin{tabular}{|c|l|r|}
\hline \multicolumn{2}{|c|}{} & \multicolumn{1}{c|}{$\begin{array}{c}\text { Communication with the Brand (total) } \\
\text { face to face + telephone + web site + e-mail }\end{array}$} \\
\hline \begin{tabular}{c} 
Communication with the $\begin{array}{c}\text { Brand (total) } \\
\text { global measure }\end{array}$ \\
\cline { 2 - 4 }
\end{tabular} & Pearson Correlation & $.608^{* *}$ \\
\cline { 2 - 4 } & Sig. (2-tailed) & 616 \\
\cline { 2 - 4 }
\end{tabular}

**. Correlation is significant at the 0.01 level (2-tailed). 


\subsubsection{Communication with Consumer Communities}

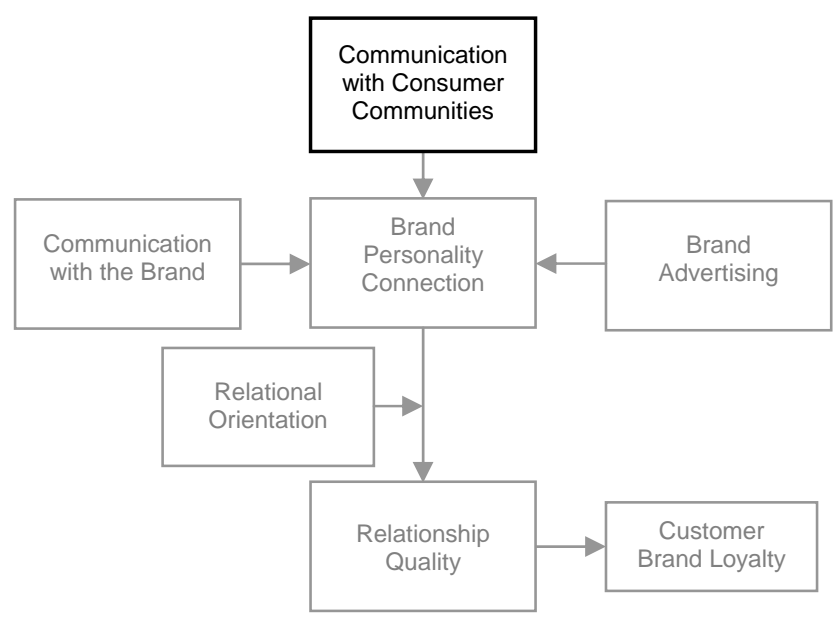

Communication with Consumer Communities determines the frequency and nature of a consumer's interactive communication with consumer communities, regarding a brand. As with Communication with the Brand, the scale used to measure this construct is formative and captures communication frequency as well as experience. Communication with Consumer Communities (total) was calculated by multiplying items measuring communication frequency by communication experience. Four items were used to measure this construct. These scale items concerned the perceived frequency and nature of a) face-to-face, b) non-Internet connected telephone, c) website, and d) e-mail communication that a consumer engages in with consumer communities regarding a brand. In addition to items relating to these four channels of communication, a global item was used to determine the perceived frequency and nature of communication that consumers engage in with consumer communities regarding a brand in general.

Every effort was made to ensure the content and indicator specification of items intended to measure Communication with Consumer Communities, with items capturing the different forms of communication that consumers engage in with consumer communities. Regarding indicator collinearity, Tables 21a, 21b, and 21c show that items measuring Communication with Consumer Communities are correlated at a level below 0.80; with Pearson Correlation values between 0.21 and 0.76 . Therefore, there were no issues with multi-colinearity. 
Table 21a. Communication with Consumer Communities (frequency) Indicator Collinearity

\begin{tabular}{|c|c|c|c|c|c|}
\hline & & $\begin{array}{l}\text { Communication with } \\
\text { Consumer Communities } \\
\text { (frequency) } \\
\text { face to face }\end{array}$ & $\begin{array}{l}\text { Communication with } \\
\text { Consumer Communities } \\
\text { (frequency) } \\
\text { telephone }\end{array}$ & $\begin{array}{c}\text { Communication with } \\
\text { Consumer Communities } \\
\text { (frequency) } \\
\text { web site }\end{array}$ & $\begin{array}{c}\text { Communication with } \\
\text { Consumer Communities } \\
\text { (frequency) } \\
\text { e-mail }\end{array}$ \\
\hline \multirow{3}{*}{$\begin{array}{l}\text { Communication with } \\
\text { Consumer } \\
\text { Communities } \\
\text { (frequency) } \\
\text { face to face }\end{array}$} & $\begin{array}{l}\text { Pearson } \\
\text { Correlation }\end{array}$ & 1.000 & $.693^{* *}$ & $.379^{\star *}$ & $.240^{\star \star}$ \\
\hline & Sig. (2-tailed) & & .000 & .000 & .000 \\
\hline & $\mathrm{N}$ & 665 & 663 & 661 & 661 \\
\hline \multirow{3}{*}{$\begin{array}{c}\text { Communication with } \\
\text { Consumer } \\
\text { Communities } \\
\text { (frequency) telephone }\end{array}$} & $\begin{array}{l}\text { Pearson } \\
\text { Correlation }\end{array}$ & & 1.000 & $.461^{* *}$ & $.365^{* *}$ \\
\hline & Sig. (2-tailed) & & & .000 & .000 \\
\hline & $\mathrm{N}$ & & 663 & 660 & 660 \\
\hline \multirow{3}{*}{$\begin{array}{c}\text { Communication with } \\
\text { Consumer } \\
\text { Communities } \\
\text { (frequency) } \\
\text { web site }\end{array}$} & $\begin{array}{l}\text { Pearson } \\
\text { Correlation } \\
\end{array}$ & & & 1.000 & $.488^{* \star}$ \\
\hline & Sig. (2-tailed) & & & & .000 \\
\hline & $\mathrm{N}$ & & & 661 & 658 \\
\hline \multirow{3}{*}{$\begin{array}{c}\text { Communication with } \\
\text { Consumer } \\
\text { Communities } \\
\text { (frequency) } \\
\text { e-mail }\end{array}$} & $\begin{array}{l}\text { Pearson } \\
\text { Correlation } \\
\end{array}$ & & & & 1.000 \\
\hline & Sig. (2-tailed) & & & & \\
\hline & & & & & 661 \\
\hline
\end{tabular}

**. Correlation is significant at the 0.01 level (2-tailed).

Table 21b. Communication with Consumer Communities (experience) Indicator Collinearity

\begin{tabular}{|c|c|c|c|c|c|}
\hline & & $\begin{array}{l}\text { Communication with } \\
\text { Consumer Communities } \\
\text { (experience) } \\
\text { face to face }\end{array}$ & $\begin{array}{l}\text { Communication with } \\
\text { Consumer Communities } \\
\text { (experience) } \\
\text { telephone }\end{array}$ & $\begin{array}{l}\text { Communication with } \\
\text { Consumer Communities } \\
\text { (experience) } \\
\text { web site }\end{array}$ & $\begin{array}{l}\text { Communication with } \\
\text { Consumer Communities } \\
\text { (experience) } \\
\text { e-mail }\end{array}$ \\
\hline \multirow{3}{*}{$\begin{array}{c}\text { Communication with } \\
\text { Consumer } \\
\text { Communities } \\
\text { (experience) } \\
\text { face to face } \\
\end{array}$} & $\begin{array}{l}\text { Pearson } \\
\text { Correlation } \\
\end{array}$ & 1.000 & $.727^{* *}$ & $.393^{* *}$ & $.212^{* *}$ \\
\hline & Sig. (2-tailed) & & .000 & .000 & .000 \\
\hline & $\mathrm{N}$ & 648 & 642 & 642 & 643 \\
\hline \multirow{3}{*}{$\begin{array}{l}\text { Communication with } \\
\text { Consumer } \\
\text { Communities } \\
\text { (experience) } \\
\text { telephone }\end{array}$} & $\begin{array}{l}\text { Pearson } \\
\text { Correlation } \\
\end{array}$ & & 1.000 & $.424^{* *}$ & $.280^{* *}$ \\
\hline & Sig. (2-tailed) & & & .000 & .000 \\
\hline & $\mathrm{N}$ & & 655 & 649 & 650 \\
\hline \multirow{3}{*}{$\begin{array}{c}\text { Communication with } \\
\text { Consumer } \\
\text { Communities } \\
\text { (experience) } \\
\text { web site }\end{array}$} & $\begin{array}{l}\text { Pearson } \\
\text { Correlation } \\
\end{array}$ & & & 1.000 & $.384^{* *}$ \\
\hline & Sig. (2-tailed) & & & & .000 \\
\hline & $\mathrm{N}$ & & & 658 & 654 \\
\hline \multirow{3}{*}{$\begin{array}{c}\text { Communication with } \\
\text { Consumer } \\
\text { Communities } \\
\text { (experience) } \\
\text { e-mail }\end{array}$} & $\begin{array}{l}\text { Pearson } \\
\text { Correlation }\end{array}$ & & & & 1.000 \\
\hline & Sig. (2-tailed) & & & & \\
\hline & $\mathrm{N}$ & & & & 659 \\
\hline
\end{tabular}

${ }^{\star \star}$. Correlation is significant at the 0.01 level (2-tailed).

Table 21c. Communication with Consumer Communities (total) Indicator Collinearity

\begin{tabular}{|c|c|c|c|c|c|}
\hline & & $\begin{array}{c}\text { Communication with } \\
\text { Consumer Communities } \\
\text { (total) } \\
\text { face to face }\end{array}$ & $\begin{array}{c}\text { Communication with } \\
\text { Consumer Communities } \\
\text { (total) } \\
\text { telephone } \\
\end{array}$ & $\begin{array}{l}\text { Communication with } \\
\text { Consumer Communities } \\
\text { (total) } \\
\text { web site } \\
\end{array}$ & $\begin{array}{c}\text { Communication with } \\
\text { Consumer Communities } \\
\text { (total) } \\
\text { e-mail } \\
\end{array}$ \\
\hline \multirow{3}{*}{$\begin{array}{l}\text { Communication with } \\
\text { Consumer } \\
\text { Communities (total) } \\
\text { face to face }\end{array}$} & $\begin{array}{l}\text { Pearson } \\
\text { Correlation }\end{array}$ & 1.000 & $.757^{\star *}$ & $.436^{\star *}$ & $.250^{* *}$ \\
\hline & Sig. (2-tailed) & & .000 & .000 & .000 \\
\hline & $\mathrm{N}$ & 648 & 642 & 641 & 642 \\
\hline \multirow{3}{*}{$\begin{array}{l}\text { Communication with } \\
\text { Consumer } \\
\text { Communities (total) } \\
\text { telephone }\end{array}$} & $\begin{array}{l}\text { Pearson } \\
\text { Correlation }\end{array}$ & & 1.000 & $.468^{* *}$ & $.362^{* *}$ \\
\hline & Sig. (2-tailed) & & & .000 & .000 \\
\hline & $\mathrm{N}$ & & 655 & 648 & 649 \\
\hline \multirow{3}{*}{$\begin{array}{l}\text { Communication with } \\
\text { Consumer } \\
\text { Communities (total) } \\
\text { web site }\end{array}$} & $\begin{array}{l}\text { Pearson } \\
\text { Correlation }\end{array}$ & & & 1.000 & $.484^{\star *}$ \\
\hline & Sig. (2-tailed) & & & & .000 \\
\hline & $\mathrm{N}$ & & & 657 & 652 \\
\hline \multirow{3}{*}{$\begin{array}{c}\text { Communication with } \\
\text { Consumer } \\
\text { Communities (total) } \\
\text { e-mail }\end{array}$} & $\begin{array}{l}\text { Pearson } \\
\text { Correlation }\end{array}$ & & & & 1.000 \\
\hline & Sig. (2-tailed) & & & & \\
\hline & $\mathrm{N}$ & & & & 658 \\
\hline
\end{tabular}

${ }^{* *}$. Correlation is significant at the 0.01 level (2-tailed). 
External validity of the Communication with Consumer Communities scale was determined by examining the correlation between individual scale items and a global item, intended to summarize the construct. Tables $22 \mathrm{a}, 22 \mathrm{~b}$, and $22 \mathrm{c}$ indicate that data obtained via the four Communication with Consumer Communities scale items correlate positively at a 0.01 level with a general measure of the construct. Pearson Correlation values are shown to range between 0.25 and 0.77 , suggesting that scale items Communication with Consumer Communities (web site) and Communication with Consumer Communities (e-mail) correlate at a lower level than scale items Communication with Consumer Communities (face to face) and Communication with Consumer Communities (telephone).

Table 22a. Communication with Consumer Communities (frequency) Individual Item Correlation Matrix

\begin{tabular}{|c|l|r|r|r|r|}
\hline \multicolumn{2}{|c|}{} & $\begin{array}{c}\text { Communication } \\
\text { with Consumer } \\
\text { Communities } \\
\text { (frequency) } \\
\text { face to face }\end{array}$ & $\begin{array}{c}\text { Communication } \\
\text { with Consumer } \\
\text { Communities } \\
\text { (frequency) } \\
\text { telephone }\end{array}$ & $\begin{array}{c}\text { Communication } \\
\text { with Consumer } \\
\text { Communities } \\
\text { (frequency) } \\
\text { web site }\end{array}$ & $\begin{array}{c}\text { Communication } \\
\text { with Consumer } \\
\text { Communities } \\
\text { (frequency) } \\
\text { e-mail }\end{array}$ \\
\hline $\begin{array}{c}\text { Communication with } \\
\text { Consumer } \\
\text { Communities } \\
\text { frequency) global } \\
\text { measure }\end{array}$ & $\begin{array}{l}\text { Pearson } \\
\text { Correlation }\end{array}$ & $\mathbf{. 7 0 1 *}$ & $.613^{* *}$ & $.358^{* *}$ & $.264^{* *}$ \\
\cline { 2 - 6 } & Sig. (2-tailed) & .000 & .000 & .000 & .000 \\
\cline { 2 - 7 } & $\mathrm{N}$ & 664 & 662 & 660 & 660 \\
\hline
\end{tabular}

**. Correlation is significant at the 0.01 level (2-tailed).

Table 22b. Communication with Consumer Communities (experience) Individual Item Correlation Matrix

\begin{tabular}{|c|l|r|r|r|r|}
\hline \multicolumn{2}{|c|}{} & $\begin{array}{c}\text { Communication } \\
\text { with Consumer } \\
\text { Communities } \\
\text { (experience) } \\
\text { face to face }\end{array}$ & $\begin{array}{c}\text { Communication } \\
\text { with Consumer } \\
\text { Communities } \\
\text { (experience) } \\
\text { telephone }\end{array}$ & $\begin{array}{c}\text { Communication } \\
\text { with Consumer } \\
\text { Communities } \\
\text { (experience) } \\
\text { web site }\end{array}$ & $\begin{array}{c}\text { Communication } \\
\text { with Consumer } \\
\text { Communities } \\
\text { (experience) } \\
\text { e-mail }\end{array}$ \\
\hline $\begin{array}{c}\text { Communication with } \\
\text { Consumer } \\
\begin{array}{c}\text { Communities } \\
\text { (experience) global } \\
\text { measure }\end{array}\end{array}$ & $\begin{array}{l}\text { Pearson } \\
\text { Correlation }\end{array}$ & $.770^{* *}$ & $.721^{* *}$ & $.424^{* *}$ & $.249^{* *}$ \\
\cline { 2 - 6 } & Sig. (2-tailed) & .000 & .000 & .000 & .000 \\
\hline
\end{tabular}

**. Correlation is significant at the 0.01 level (2-tailed).

Table 22c. Communication with Consumer Communities (total) Individual Item Correlation Matrix

\begin{tabular}{|c|l|r|r|r|r|}
\hline \multicolumn{2}{|c|}{} & $\begin{array}{c}\text { Communication } \\
\text { with Consumer } \\
\text { Communities } \\
\text { (total) } \\
\text { face to face }\end{array}$ & $\begin{array}{c}\text { Communication } \\
\text { with Consumer } \\
\text { Communities } \\
\text { (total) } \\
\text { telephone }\end{array}$ & $\begin{array}{c}\text { Communication } \\
\text { with Consumer } \\
\text { Communities } \\
\text { (total) } \\
\text { web site }\end{array}$ & $\begin{array}{c}\text { Communication } \\
\text { with Consumer } \\
\text { Communities } \\
\text { (total) } \\
\text { e-mail }\end{array}$ \\
\hline \multirow{2}{*}{$\begin{array}{c}\text { Communication with } \\
\text { Consumer } \\
\text { Communities (total) } \\
\text { global measure }\end{array}$} & $\begin{array}{l}\text { Pearson } \\
\text { Correlation }\end{array}$ & $.762^{* *}$ & $.724^{* *}$ & $.465^{* *}$ & $.310^{* *}$ \\
\cline { 2 - 6 } & Sig. (2-tailed) & .000 & .000 & .000 & .000 \\
\hline
\end{tabular}

**. Correlation is significant at the 0.01 level (2-tailed).

As shown in Tables 23a, 23b, and 23c, data obtained via the four individual items of the Communication with Consumer Communities scale also correlate positively at a 0.01 level 
with a global measure of the construct. Pearson Correlation values range between 0.67 and 0.79. The Communication with Consumer Communities scale items are, therefore, both individually and collectively correlated with the global measure of the construct. Like Communication with the Brand scale items, it is concluded that this scale possesses sufficient external validity.

Table 23a. Communication with Consumer Communities (frequency) Collective Item Correlation Matrix

\begin{tabular}{|c|c|c|}
\hline & $\begin{array}{l}\text { Communication with Consumer Communities (frequency) } \\
\text { face to face + telephone + web site + e-mail }\end{array}$ \\
\hline \multirow{3}{*}{$\begin{array}{l}\text { Communication with } \\
\text { Consumer Communities } \\
\text { (frequency) } \\
\text { global measure }\end{array}$} & Pearson Correlation & $.667^{\text {*t }}$ \\
\hline & Sig. (2-tailed) & .000 \\
\hline & $\mathrm{N}$ & 656 \\
\hline
\end{tabular}

**. Correlation is significant at the 0.01 level (2-tailed).

Table 23b. Communication with Consumer Communities (experience) Collective Item Correlation Matrix

\begin{tabular}{|c|c|c|}
\hline & & $\begin{array}{l}\text { Communication with Consumer Communities (experience } \\
\text { face to face }+ \text { telephone }+ \text { web site }+ \text { e-mail }\end{array}$ \\
\hline \multirow{3}{*}{$\begin{array}{c}\text { Communication with } \\
\text { Consumer Communities } \\
\text { (experience) } \\
\text { global measure }\end{array}$} & Pearson Correlation & $.783^{* \pi}$ \\
\hline & Sig. (2-tailed) & .000 \\
\hline & $\mathrm{N}$ & 620 \\
\hline
\end{tabular}

**. Correlation is significant at the 0.01 level (2-tailed).

Table 23c. Communication with Consumer Communities (total) Collective Item Correlation Matrix

\begin{tabular}{|c|c|c|}
\hline & & $\begin{array}{l}\text { Communication with Consumer Communities (total) } \\
\text { face to face }+ \text { telephone }+ \text { web site }+ \text { e-mail }\end{array}$ \\
\hline \multirow{3}{*}{$\begin{array}{c}\text { Communication with } \\
\text { Consumer Communities } \\
\text { (total) } \\
\text { global measure }\end{array}$} & Pearson Correlation & $.785^{\text {** }}$ \\
\hline & Sig. (2-tailed) & .000 \\
\hline & $\mathrm{N}$ & 618 \\
\hline
\end{tabular}

**. Correlation is significant at the 0.01 level (2-tailed).

\subsubsection{Brand Personality Connection}

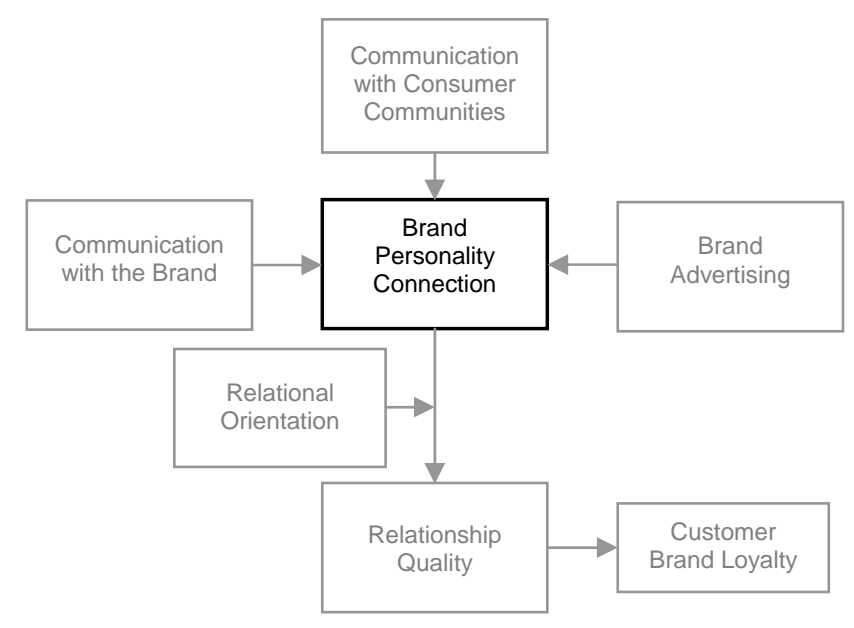


The Brand Personality Connection scale comprised five items. Each item concerned a brand personality dimension (Aaker, 1997), determining the extent to which the brand is perceived by a consumer as competent, exciting, rugged, sincere, and sophisticated. A congruence index was used to measure the construct, created by taking the sum of the absolute difference between a consumer's perceived brand personality and their ideal brand personality for the product or service category. Two sets of items were accordingly used to determine the consumer's perceived brand personality, as well as their ideal brand personality. The absolute difference between consumers' perceived brand personality and ideal brand personality was then calculated for each of the five brand personality dimensions. This data was used for analysis.

Care was again taken to ensure content and indicator specification for the construct of Brand Personality Connection, with each scale item capturing a dimension of brand personality. Table 24 shows that collinearity was present among the Brand Personality Connection scale items but not to an excessive level of 0.80 ; with Pearson Correlation values ranging between 0.26 and 0.55 .

Table 24. Brand Personality Connection Indicator Collinearity

\begin{tabular}{|c|c|c|c|c|c|c|}
\hline & & $\begin{array}{c}\text { Brand } \\
\text { Personality } \\
\text { Connection } \\
\text { (rugged) } \\
\text { absolute } \\
\text { difference }\end{array}$ & $\begin{array}{c}\text { Brand } \\
\text { Personality } \\
\text { Connection } \\
\text { (competent) } \\
\text { absolute } \\
\text { difference }\end{array}$ & $\begin{array}{c}\text { Brand } \\
\text { Personality } \\
\text { Connection } \\
\text { (exciting) } \\
\text { absolute } \\
\text { difference }\end{array}$ & $\begin{array}{c}\text { Brand } \\
\text { Personality } \\
\text { Connection } \\
\text { (sophisticated) } \\
\text { absolute } \\
\text { difference }\end{array}$ & $\begin{array}{c}\text { Brand } \\
\text { Personality } \\
\text { Connection } \\
\text { (sincere) } \\
\text { absolute } \\
\text { difference }\end{array}$ \\
\hline \multirow{3}{*}{$\begin{array}{l}\text { Brand Personality } \\
\text { Connection (rugged) } \\
\text { absolute difference }\end{array}$} & $\begin{array}{l}\text { Pearson } \\
\text { Correlation }\end{array}$ & 1.000 & $.367^{\star *}$ & $.322^{* *}$ & $.295^{\star *}$ & $.344^{* *}$ \\
\hline & Sig. (2-tailed) & & .000 & .000 & .000 & .000 \\
\hline & $\mathrm{N}$ & 569 & 569 & 567 & 566 & 568 \\
\hline \multirow{3}{*}{$\begin{array}{c}\text { Brand Personality } \\
\text { Connection } \\
\text { (competent) absolute } \\
\text { difference }\end{array}$} & $\begin{array}{l}\text { Pearson } \\
\text { Correlation }\end{array}$ & & 1.000 & $.300^{* *}$ & $.261^{\star *}$ & $.551^{\star *}$ \\
\hline & Sig. (2-tailed) & & & .000 & .000 & .000 \\
\hline & $\mathrm{N}$ & & 598 & 577 & 577 & 578 \\
\hline \multirow{3}{*}{$\begin{array}{l}\text { Brand Personality } \\
\text { Connection (exciting) } \\
\text { absolute difference }\end{array}$} & $\begin{array}{l}\text { Pearson } \\
\text { Correlation }\end{array}$ & & & 1.000 & $.379^{* *}$ & $.320^{* *}$ \\
\hline & Sig. (2-tailed) & & & & .000 & .000 \\
\hline & $\mathrm{N}$ & & & 581 & 576 & 577 \\
\hline \multirow{3}{*}{$\begin{array}{l}\text { Brand Personality } \\
\text { Connection } \\
\text { (sophisticated) } \\
\text { absolute difference }\end{array}$} & $\begin{array}{l}\text { Pearson } \\
\text { Correlation }\end{array}$ & & & & 1.000 & $.288^{* *}$ \\
\hline & Sig. (2-tailed) & & & & & .000 \\
\hline & $\mathrm{N}$ & & & & 587 & 576 \\
\hline \multirow{3}{*}{$\begin{array}{l}\text { Brand Personality } \\
\text { Connection (sincere) } \\
\text { absolute difference }\end{array}$} & $\begin{array}{l}\text { Pearson } \\
\text { Correlation }\end{array}$ & & & & & 1.000 \\
\hline & Sig. (2-tailed) & & & & & \\
\hline & $\mathrm{N}$ & & & & & 582 \\
\hline
\end{tabular}




\subsection{Measurement Evaluation}

Scale validity establishes the degree of correspondence between an unobservable construct and its intended measure (Peter, 1981). Two types of commonly assessed scale validity are content validity and construct validity. The extent to which a scale samples from the intended domain of content determines content validity (Pallant, 2001); while convergent validity, discriminant validity, and factor analytic investigation provide supportive evidence of construct validity (Peter, 1981). Convergent and discriminant validity identify whether the items used to measure each construct correlate as expected in a convergent or discriminant manner. Factor analysis concerns the dimensionality of a scale.

Reliability examines the extent to which construct measures are free from error (Peter, 1979). One method of establishing scale reliability is by assessing the internal consistency of the scale. A scale's internal consistency reveals the extent to which a scale's items are measuring the same underlying attribute (Pallant, 2001). In order to identify the internal consistency of the scales implemented in the research, Cronbach's coefficient alpha is calculated for each scale. Nunnally (1978) suggests that a minimum Cronbach's coefficient alpha value of 0.60 is required for new scales to be deemed reliable and 0.70 for existing scales.

\subsubsection{Scale Validity}

Communication with the Brand, Communication with Consumer Communities, and Brand Personality Connection are new scales. Therefore, exploratory factor analysis was initially used to test scale construction (Stewart, 1981). They are also recognised as formative constructs. As such, measures of internal consistency are not appropriate for these scales (Diamantopoulos \& Winklhofer, 2001). Instead the validity of the scales was determined by examining content specification, indicator specification, indicator collinearity, and external validity (Diamantopoulos \& Winklhofer, 2001); as discussed in detail in section 5.4. Brand Advertising, Relationship Quality, Relational Orientation, and Customer Brand Loyalty are based on existing scales. Therefore, exploratory analysis was unnecessary (Stewart, 1981). Confirmatory analysis for all scales is examined using partial least squares in section 5.7.

\subsubsection{Scale Reliability}

Communication with the Brand captures the perceived frequency and nature of interactive communication that a consumer engages in with a brand. Respondents were asked how frequently they communicate with a brand, as well as the extent to which the communication 
experience is perceived as positive, negative, or neutral in nature. Respondents' perceived frequency of communication was then multiplied by the perceived communication nature to provide overall communication with a brand. The scale consisted of four items concerning communication frequency, as well as four items regarding the nature of communication. The scale also comprised items relating to a respondent's communication with a brand facilitated by Internet based and non-Internet based media.

Communication with Consumer Communities captures the perceived frequency and nature of interactive communication that a consumer engages in with consumer communities, regarding a brand. In a manner similar to the measurement of Communication with the Brand, respondents were asked how frequently they communicate with consumer communities regarding a brand as well as the perceived nature of this communication. The scale also consisted of four items concerning communication frequency and four items regarding the nature of communication, with questions relating to communication facilitated by Internet based and non-Internet based media. Partial least square analysis, in section 5.7, indicates scale reliability.

The construct of Brand Personality Connection is also recognised as formative. This construct was measured through a congruence index, created by taking the sum of the absolute difference between the perceived brand personality of a consumer and their ideal brand personality for the category. The scales used to determine perceived and ideal brand personality comprised five items, based on five brand personality dimensions identified by Aaker (1997). A congruence index was used, as it is acknowledged that consumers may be unwilling or unable to articulate their self-image for a specific product or service category (Aaker, 1999). As shown in Figure 25 research respondents were asked to indicate their perceived and ideal brand personality on a scale of one to five for the brand personality dimension of rugged, for example. Absolute values were used to identify the difference between the perceived brand personality of a consumer and their ideal brand personality for the category. The resulting absolute values, ranging from 0 to 4 , were then reversed $(0=4$, $1=3,2=2,3=1,4=0$ ), so that higher values reflected a stronger connection with the brand. As discussed earlier in section 5.4.1, the Brand Personality Connection scale possessed acceptable validity. A discussion regarding partial least square analysis in section 5.7 also indicates scale reliability.

Figure 25. Brand Personality Connection (perceived and ideal brand personality scales) Perceived brand personality

Rugged

\begin{tabular}{|c|c|c|c|c|}
\hline 1 & 2 & 3 & 4 & 5 \\
\hline \multicolumn{5}{|c|}{ Ideal brand personality } \\
\hline 1 & 2 & 3 & 4 & 5 \\
\hline
\end{tabular}

Refined 


\subsection{Hypotheses Testing}

The primary objective of the present research was to investigate how consumers participate in the development and maintenance of a customer relationship through communication. It is recognised that consumers perceive brands as active relationship partners (Aggarwal, 2004; Fournier, 1998). Furthermore, communication is acknowledged as an essential element of a relationship (Duncan \& Moriarty, 1998). The communication that a consumer participates in with reference to a brand is, therefore, expected to affect their customer relationship with the brand. This research comprises an examination concerning the manner in which the type, frequency, nature, and channel of communication that a consumer perceives they participate in regarding a brand influence relationship quality. The communication that a consumer participates in regarding a brand is expected to affect the consumer's connection with the brand. This connection with a brand, as perceived by a consumer, is further anticipated to influence the quality of a customer relationship. The research also considers a consumer's general favourability towards being involved in customer relationships with brands in a product or service category.

A secondary research objective was to examine the consequences of customer relationships for the owners of a brand. This enhances the value of the research for brand owners. The quality of a customer relationship between a consumer and brand is predicted to ultimately impact upon the performance of a brand. In the present study brand performance is determined by customer brand loyalty. The research objectives, as well as the expected relationships between identified variables, are reflected in the research hypotheses presented in Table 26. The research hypotheses were tested using partial least square analysis; discussed in detail in section 5.7.

Table 26. Research Hypotheses

\begin{tabular}{|l|l|}
\hline H1 & $\begin{array}{l}\text { A consumer's attitude towards the advertising received from a brand positively } \\
\text { influences the consumer's connection with the brand. }\end{array}$ \\
\hline H2 & $\begin{array}{l}\text { The perceived frequency and nature of interactive communication that a consumer } \\
\text { engages in with a brand positively influences the consumer's connection with the brand. }\end{array}$ \\
\hline H3 & $\begin{array}{l}\text { The perceived frequency and nature of interactive communication that a consumer } \\
\text { engages in with consumer communities regarding a brand positively influences the } \\
\text { consumer's connection with the brand. }\end{array}$ \\
\hline H4 & Brand Personality Connection positively influences the level of Relationship Quality. \\
\hline H5 & $\begin{array}{l}\text { The association between Brand Personality Connection and Relationship Quality is } \\
\text { positively moderated by a consumer's Relational Orientation. }\end{array}$ \\
\hline H6 & Relationship Quality positively influences Customer Brand Loyalty. \\
\hline
\end{tabular}




\subsection{Partial Least Square Analysis}

Partial least square structural equation modelling analysis (PLS SEM) was performed using the research data, to provide a robust holistic analysis of the full research model. Covariancebased structural equation modelling (SEM), conducted using statistical analysis programmes such as AMOS, can be used to examine the variance explained by constructs within a conceptual model. Covariance-based SEM is not, however, reported in this study due to the nature of the research. The present research involves several constructs with newly adapted scales, consisting of a relatively large number of items. Although Covariance-based SEM allows several hypotheses to be tested simultaneously concerning relationships between a number of variables, it is a technique best used with relatively simple, well-defined frameworks, where measurement is established and models not overly complicated (Baumgartner \& Homburg, 1996). It is recognised that using structural equation modelling to fully capture complex measures, comprising multidimensional scales and many variables, can be problematic (McQuitty, 1999). As such, few reported structural equation models have a large number of latent variables (Chin, et al., 2008).

PLS SEM analysis is suited to conceptual models that are more complex, with higher numbers of indicators or latent variables, where the aim is to explain variance (Barclay \& Smith, 1997; Chin, et al., 2008; Fornell \& Bookstein, 1982; Hulland, Chow, \& Lam, 1996). Importantly, unlike structural equation modelling, partial least square analysis is capable of incorporating formative and reflective measurements (Diamantopoulos \& Winklhofer, 2001). This analysis can also be used when measurement scales are less well-established (Barclay \& Smith, 1997; Chin, et al., 2008). Furthermore, any construct with weak measures can be detrimental to structural equation modelling. Whereas PLS SEM analysis, acknowledged as a limited-information component-based least square alternative, is less impacted upon by construct measurement (Chin, et al., 2008). PLS SEM analysis is applicable when conceptual models comprise unobservable variables with measurement error (Fornell \& Bookstein, 1982), as with the present research, and is performed when measures can be grouped into construct blocks and path relationships specified (Chin, 1995). The primary aim of such analysis is to maximise the explanation of variance in dependent constructs (Hulland, et al., 1996), providing a holistic view of model performance as a whole.

PLS SEM data analysis was, accordingly, performed using the research data and SmartPLS programme (Ringle, et al., 2005). Prior to PLS SEM analysis being conducted, SPSS was used to replace all missing data with an Expectation Maximisation value for each scale item. This was done to minimise issues with analysis due to missing data within the data set; although the incidence of missing data was low, at a maximum of 15.2 per cent of responses to any item. Expectation Maximisation values were used to replace missing data because techniques such as casewise deletion result in the loss of useful information, while pairwise 
deletion or mean imputation create covariances based on different sample sizes and biased parameter estimates (Temme, Kreis, \& Hildebrandt, 2006). Expectation Maximisation is an approach to iterative computation of maximum-likelihood estimates (Dempster, Laird, \& Rubin, 1977; Esposito Vinzi, Chin, Henseler, \& Wang, 2008) that is suited to partial least squares (Temme, et al., 2006). The following section discusses the results from the partial least square analysis.

\subsubsection{Partial Least Square Analysis Results}

Three steps are recommended when interpreting partial least square output; a) examination of the measurement model, b) examination of the structural model, and c) final model selection. Firstly an assessment of the measurement model's reliability and validity is made. Then the nature of relationships between measures and constructs is determined. Thirdly, a model is selected; with path coefficients interpreted, model adequacy established, and measures reported on (Hulland, 1999). The following section outlines each of these steps in detail. Additional output from the PLS SEM analysis can be found in appendix I.

\subsubsection{Measurement Model}

It is recommended that researchers ensure construct measures are reliable and valid before attempting to draw conclusions about the relationships between constructs. With partial least square analysis, the reliability of scale items is determined by examining the value of the item loadings. To ensure scale reliability, the cross loadings matrix was examined for the model. This cross loadings matrix is shown in appendix I. Bearing in mind that any item removal must be considered from a theoretical basis (Hulland, 1999), the literature suggests that any items loading below 0.50 should be considered for removal (Nunnally, 1978). Ideally, loadings should be above 0.70 for their respective construct (Nunnally, 1978). However, values exceeding 0.60 are deemed acceptable, particularly for research involving new items or scales (Hulland, 1999; Hulland, et al., 1996). Items from reflective scales loading at a level of 0.60 or below on the cross loadings matrix were considered for removal prior to further analysis. Scales items from formative scales were not considered for removal (Diamantopoulos \& Winklhofer, 2001). As shown in appendix I, no reflective items loaded at a level of 0.60 or below. Therefore, no items were removed.

Convergent validity is indicated by partial least square average variance extracted (AVE) values. The AVE value, found in the first column of the AVE matrix, is noted as the meansquared loading for each construct (Fornell \& Bookstein, 1982). It is recommended that convergent validity is upheld if AVE values for each construct are over 0.50 (Barclay \& Smith, 
1997). Table 27a, below, reveals that the AVE values for all of the research constructs exceeded 0.50 .

Table 27a. AVE Matrix

\begin{tabular}{|l|c|c|c|c|}
\hline & AVE & R-Square & $\begin{array}{c}\text { Cronbach's } \\
\text { Alpha }\end{array}$ & Communality \\
\hline Relational Orientation & 0.61 & & 0.87 & 0.61 \\
\hline Relationship Quality & 0.56 & 0.43 & 0.84 & 0.56 \\
\hline Communication with the Brand & & & & 0.49 \\
\hline Communication with Consumer Communities & & & & 0.57 \\
\hline Brand Personality Connection & & & 0.21 & 0.97 \\
\hline Brand Personality Connection x Relational Orientation & 0.55 & & 0.59 \\
\hline Customer Brand Loyalty & 0.70 & 0.49 & 0.89 & 0.70 \\
\hline Brand Advertising & & & 0.94 & 0.64 \\
\hline
\end{tabular}

In addition, partial least square analysis can be used to determine the internal consistency of each scale used to measure the research constructs. Internal consistency is determined through values within the composite reliability column of the AVE matrix. Values should exceed 0.70 (Hulland, 1999) and ideally reach a 0.80 level (Barclay \& Smith, 1997). As shown in Table $27 \mathrm{a}$ above, this was the case with the research data. Composite reliability values were between 0.88 and 0.97 .

Following measures of convergent validity and internal consistency, correlation values between constructs within the latent variable correlations matrix are examined to ensure discriminant validity. Constructs should correlate with those that they are conceptually similar to, but not those with which they are conceptually different. Furthermore, measures should load higher on intended constructs than non-intended (Barclay \& Smith, 1997). Discriminant validity can also be identified by assessing construct AVE values as well as the correlation values, shown in the latent variable correlation matrix. A latent variable correlation matrix for the research data is shown in Table 27b below. If the root AVE values, determined by calculating the square root of each AVE value in the AVE matrix, are larger than the latent variable correlations they estimate then discriminant validity is regarded as adequate (Hulland, 1999). The root AVE values for the research data are between 0.74 and 0.83 . As shown in Table 27b, the highest path coefficient value is 0.73 . 
Table 27b. Latent Variable Correlation Matrix

\begin{tabular}{|c|c|c|c|c|c|}
\hline AVE & 0.61 & 0.56 & 0.55 & 0.70 & 0.64 \\
\hline & 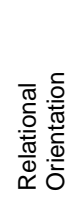 & 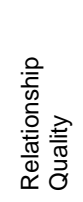 & 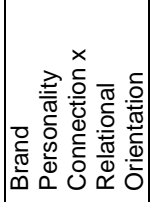 & 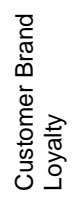 & 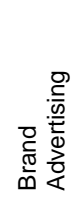 \\
\hline Relational Orientation & 0.78 & & & & \\
\hline Relationship Quality & 0.49 & 0.75 & & & \\
\hline $\begin{array}{l}\text { Brand Personality Connection } \times \text { Relational } \\
\text { Orientation }\end{array}$ & 0.73 & 0.64 & 0.74 & & \\
\hline Customer Brand Loyalty & 0.31 & 0.70 & 0.50 & 0.83 & \\
\hline Brand Advertising & 0.23 & 0.47 & 0.36 & 0.41 & 0.80 \\
\hline
\end{tabular}

\subsubsection{Structural Model}

Once reliability and validity of the measures are determined, the structural parameters of the model can be interpreted through partial least square analysis (Barclay \& Smith, 1997; Hulland, 1999). The nature of measure and construct relationships is established through the partial least square path diagram and path coefficients. Structurally, path coefficients should be significant at a 0.05 level and be in an expected direction (Barclay \& Smith, 1997). The significance of path coefficients is identified by the path coefficient t-statistic matrix and the explanatory value of a partial least square model is determined by examining the R-square values for the dependent constructs, found within the R-square matrix (Hulland, 1999). The path coefficients matrix is shown in Table $27 \mathrm{c}$.

The Average Variance Accounted for (AVA) value is determined by the mean $R^{2}$ of the structural model and indicates the predictive power of the structural model without regarding the measurement model (Fornell \& Bookstein, 1982). The AVA value for the present research model was 0.38 . The moderating effect of Relational Orientation upon Relationship Quality was determined using partial least square analysis, by multiplying the predictor variable by the moderator and examining the influence on the dependent variable (Chin, Marcolin, \& Newsted, 2003). In this case, multiplying Brand Personality Connection by Relational Orientation and examining the influence on Relationship Quality. 
Table 27c. Path Coefficients Matrix

\begin{tabular}{|c|c|c|c|c|c|c|c|c|}
\hline & 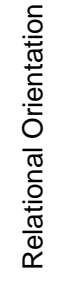 & 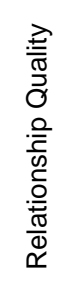 & 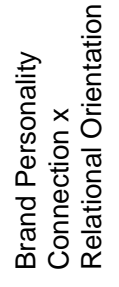 & 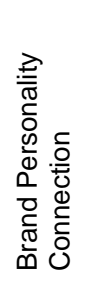 & 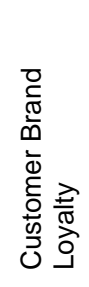 & 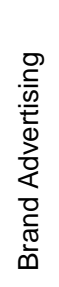 & 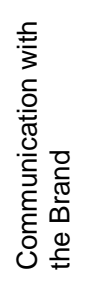 & 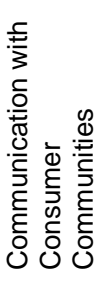 \\
\hline Relational Orientation & & 0.21 & & & & & & \\
\hline Relationship Quality & & & & & 0.70 & & & \\
\hline $\begin{array}{l}\text { Brand Personality Connection } x \\
\text { Relational Orientation }\end{array}$ & & 0.34 & & & & & & \\
\hline Brand Personality Connection & & 0.23 & & & & & & \\
\hline \multicolumn{9}{|l|}{ Customer Brand Loyalty } \\
\hline Brand Advertising & & & & 0.21 & & & & \\
\hline Communication with the Brand & & & & 0.11 & & & & \\
\hline $\begin{array}{l}\text { Communication with Consumer } \\
\text { Communities }\end{array}$ & & & & 0.25 & & & & \\
\hline
\end{tabular}

The partial least square path coefficients t-statistics matrix, shown in Table 27d below, identifies the results from this analysis. The path coefficients t-statistics matrix in Table 27d indicates that all the research hypotheses are upheld, except $\mathrm{H} 2$. As recommended, the majority of these relationships are significant to at least a 0.05 level (Barclay \& Smith, 1997).

Table 27d. Path Coefficients T-Statistics Matrix

\begin{tabular}{|c|c|c|c|c|}
\hline & $\begin{array}{c}\text { Path } \\
\text { Coefficients } \\
\end{array}$ & $\begin{array}{l}\text { Standard Error } \\
\text { (STERR) }\end{array}$ & $\begin{array}{l}\text { T Statistics } \\
\text { (|O/STERR|) }\end{array}$ & $\begin{array}{l}\text { Sig. Level 2- } \\
\text { tailed }\end{array}$ \\
\hline $\begin{array}{l}\text { Brand Personality Connection x Relational Orientation -> } \\
\text { Relationship Quality }\end{array}$ & 0.34 & 0.17 & 1.99 & $p<0.05$ \\
\hline $\begin{array}{l}\text { Relationship Quality -> } \\
\text { Customer Brand Loyalty }\end{array}$ & 0.70 & 0.05 & 13.12 & $p<0.001$ \\
\hline $\begin{array}{l}\text { Communication with Consumer Communities -> } \\
\text { Brand Personality Connection }\end{array}$ & 0.25 & 0.10 & 2.44 & $p<0.05$ \\
\hline $\begin{array}{l}\text { Brand Personality Connection -> } \\
\text { Relationship Quality }\end{array}$ & 0.23 & 0.13 & 1.80 & $p<0.10$ \\
\hline
\end{tabular}

The partial least square R-square and Q-square matrix is shown in Table 27e, below. This matrix indicates that 21 per cent of the variance in Brand Personality Connection is attributable to the communication a consumer engages in regarding a brand and 49 per cent of the variance in Customer Brand Loyalty is attributable to Relationship Quality. Notably, 43 per cent of the variance in Relationship Quality is attributable to Brand Personality Connection and Relational Orientation. The R-square and Q-square matrix shows little difference in communality and redundancy Q-square values for omission distances of seven and 17 . This 
further indicates model adequacy. A partial least square path diagram is shown in appendix I.

This identifies all of the path coefficients between items and constructs.

Table 27e. R-Square and Q-Square Matrix

\begin{tabular}{|l|c|c|c|c|c|}
\hline & \multirow{2}{*}{ R-Square } & \multicolumn{2}{|c|}{ Omission distance = 7 } & \multicolumn{2}{c|}{ Omission distance = 17 } \\
\cline { 3 - 6 } & & $\begin{array}{c}\text { Communality Q- } \\
\text { square (cross- } \\
\text { validation) }\end{array}$ & $\begin{array}{c}\text { Redundancy Q- } \\
\text { square (cross- } \\
\text { validation) }\end{array}$ & $\begin{array}{c}\text { Communality Q- } \\
\text { square (cross- } \\
\text { validation) }\end{array}$ & $\begin{array}{c}\text { Redundancy Q- } \\
\text { square (cross- } \\
\text { validation) }\end{array}$ \\
\hline Relational Orientation & & 0.46 & 0.46 & 0.46 & 0.46 \\
\hline Relationship Quality & 0.43 & 0.39 & 0.24 & 0.39 & 0.23 \\
\hline $\begin{array}{l}\text { Communication with } \\
\text { the Brand }\end{array}$ & & 0.20 & 0.20 & 0.21 & 0.21 \\
\hline $\begin{array}{l}\text { Communication with } \\
\text { Consumer } \\
\text { Communities }\end{array}$ & & 0.30 & 0.30 & 0.33 & 0.33 \\
\hline $\begin{array}{l}\text { Brand Personality } \\
\text { Connection }\end{array}$ & 0.21 & 0.00 & 0.06 & 0.20 & 0.08 \\
\hline $\begin{array}{l}\text { Brand Personality } \\
\text { Connection x Relational } \\
\text { Orientation }\end{array}$ & & 0.47 & 0.47 & 0.52 & 0.52 \\
\hline $\begin{array}{l}\text { Customer Brand } \\
\text { Loyalty }\end{array}$ & 0.49 & 0.55 & 0.32 & 0.55 & 0.34 \\
\hline Brand Advertising & & 0.57 & 0.57 & 0.56 & 0.56 \\
\hline
\end{tabular}

\subsubsection{Final Model Selection}

Although $\mathrm{R}^{2}$ values indicate how well PLS has met its objective (Cohen, Cohen, Teresi, Marchi, \& Velez, 1990), a Goodness of Fit (GoF) value can also be calculated as a global fit index for validating the overall PLS model (Tenenhaus, Vinzi, Chatelin, \& Lauro, 2005). A PLS GoF is the geometric mean of the average communality and the average $R^{2}$ values (Tenenhaus, et al., 2005). The GoF for the present research is identified below.

$$
\begin{aligned}
\text { GoF } & =\sqrt{\overline{\text { communality }} \times \overline{\mathrm{R}^{2}}}=\sqrt{0.56 \times 0.377} \\
& =0.459
\end{aligned}
$$

On the whole, partial least square analysis revealed that the construct measurements are valid and reliable. The partial least square analysis also showed support for five of the six research hypotheses. Notably, partial least square results did not suggest that the perceived frequency and nature of interactive communication that a consumer engages in with a brand strongly influences the consumer's connection with the brand. As such, hypothesis $\mathrm{H} 2$ is not supported. As shown in Figure $27 \mathrm{f}$, below, the final selected partial least square model comprises six research constructs. This includes Brand Advertising, Communication with Consumer Communities, Brand Personality Connection, Relational Orientation, Relationship Quality, and Customer Brand Loyalty. These constructs are included in the final model as analysis revealed the relationships between them were significant. Overall the conceptual 
model's explanatory value holds up well, according to the partial least square analysis. These findings are discussed in detail throughout the final chapter of this thesis.

Figure 27f. Final Selected Partial Least Square Model with Path Coefficients and Summary of Support for Hypotheses

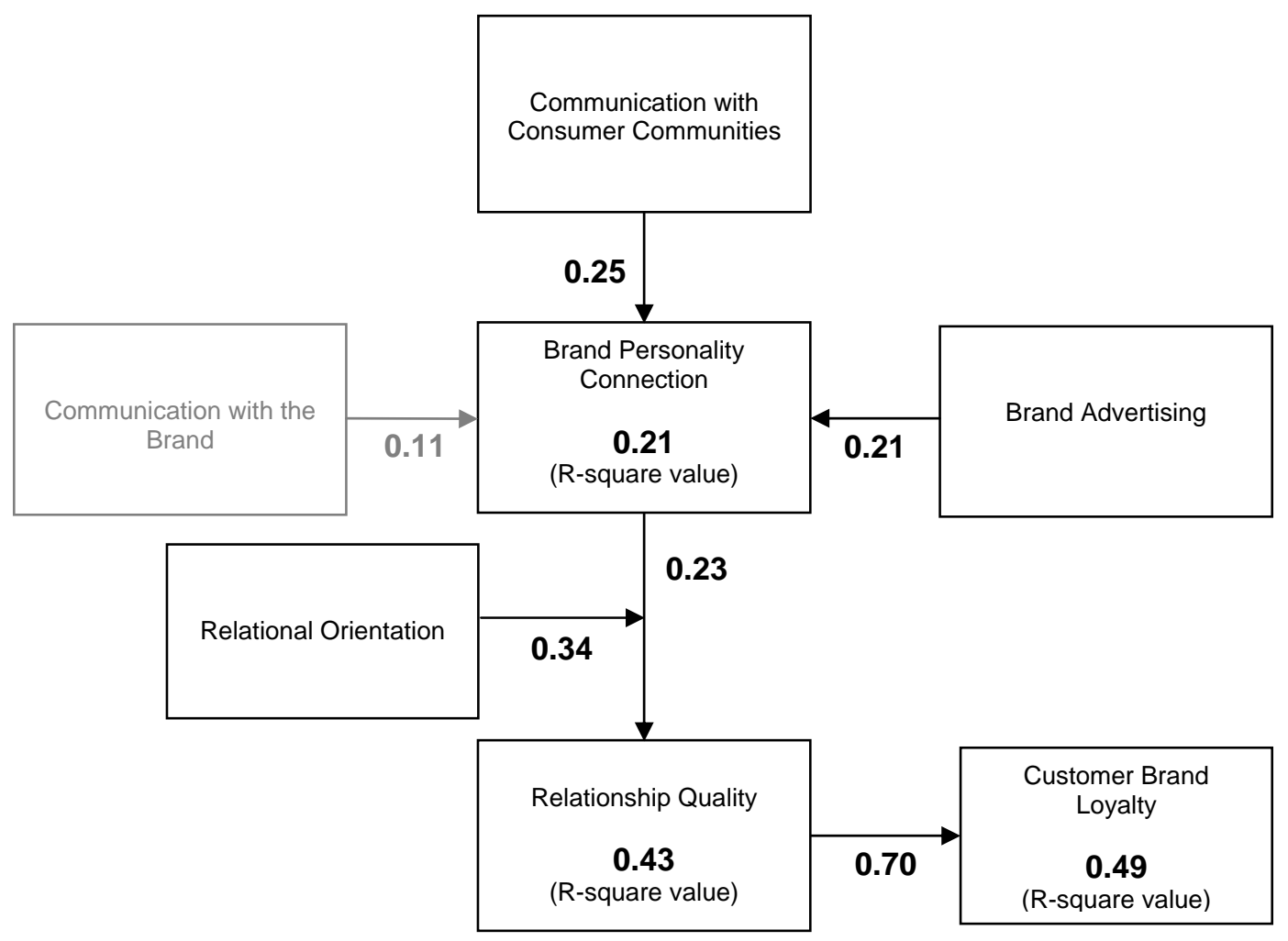

\begin{tabular}{|l|l|l|}
\hline Hypothesis & Support \\
\hline H1 & $\begin{array}{l}\text { A consumer's attitude towards the advertising received from a } \\
\text { brand positively influences the consumer's connection with } \\
\text { the brand. }\end{array}$ & Supported \\
\hline $\begin{array}{l}\text { The perceived frequency and nature of interactive } \\
\text { communication that a consumer engages in with a brand } \\
\text { positively influences the consumer's connection with the } \\
\text { brand. }\end{array}$ & Not supported \\
\hline H3 & $\begin{array}{l}\text { The perceived frequency and nature of interactive } \\
\text { communication that a consumer engages in with consumer } \\
\text { communities regarding a brand positively influences the } \\
\text { consumer's connection with the brand. }\end{array}$ & Supported \\
\hline H4 & $\begin{array}{l}\text { Brand Personality Connection positively influences the level } \\
\text { of Relationship Quality. }\end{array}$ & Supported \\
\hline H5 & $\begin{array}{l}\text { The association between Brand Personality Connection and } \\
\text { Relationship Quality is positively moderated by a consumer's } \\
\text { Relational Orientation. }\end{array}$ & Supported \\
\hline H6 & $\begin{array}{l}\text { Relationship Quality positively influences Customer Brand } \\
\text { Loyalty. }\end{array}$ & Supported \\
\hline
\end{tabular}




\subsection{Discussion of Findings}

The results of this study raise a number of key points for discussion concerning the examination of customer relationships from a consumer perspective. This section reflects on the research findings and suggests how they can be interpreted to understand how consumers participate in the development and maintenance of customer relationships through communication, as well as the consequences of relationships for brand owners. Discussion includes an overall assessment of the conceptual model and an evaluation of the construct measures. Through this, research contributions are identified and limitations of the current thesis are suggested. Future research streams are also considered and finally a statement regarding the central conclusions that can be drawn from the research is presented. Results show that advertising and communication with consumer communities influence a consumer's connection with a brand. They also show that brand connection influences relationship quality, a consumer's perceived relationship with a brand impacts brand loyalty, and that relational orientation is an important part of how brand relationships are formed. These findings are discussed in detail throughout the next section.

\subsection{Conceptual Model and Measurement}

The underlying objectives of the research were to investigate how consumers participate in the development and maintenance of a customer relationship through communication, in all of its forms, and examine the consequences of customer relationships for the owners of brands. A key part in achieving this was the presentation of a conceptual model helping to explain how consumers form relationships with brands. Overall, results show that this model held up well. Construct evaluation revealed the scales used in the research were consistent with the conceptual definitions upon which they were based. Analysis of the scale items generally supported this conclusion. All scales and associated items identified to measure the constructs presented were based on existing literature. Previously published scale items were available for some constructs and these were adapted to the context of the research. For other constructs, existing scales were further refined and developed in accordance with conceptual development. In general, the scales intended to measure the constructs within the model demonstrated acceptable reliability and validity.

An important part of the process by which relationships are developed and maintained is communication (Duncan \& Moriarty, 1998); with interactive communication regarded as particularly important to the formation of relationships (Gronroos, 2004; Yadav \& Varadarajan, 2005). Three types of communication regarding a brand were examined in this research; Communication with the Brand, Communication with Consumer Communities, and Brand Advertising. Communication with other consumers and advertising were shown to influence a 
consumer's connection with a brand. Interactive communication with the brand, however, was not.

In accordance with the literature regarding consumers and their relationships with brands (Fournier, 1998), the research also revealed that a consumer's connection with a brand is central to the process by which they form brand relationships. Such connection with a brand had not previously been explicitly used to explore the process by which relationships are developed and maintained, from a consumer perspective. Results indicate that Brand Personality Connection is influenced by two forms of communication that a consumer engages in regarding a brand; advertising and communication with consumer communities. In turn, this connection with a brand is shown to directly influence Relationship Quality. This provides a method by which marketers can assess a consumer's connection with their brands, as well as avenues for future research in the area. As such, the research goes some way in helping to understand this salient aspect of a brand relationship from a consumer perspective. Furthermore, the quality of a customer relationship between a consumer and brand was measured from the consumer perspective. The nature of a relationship implies participation by both a brand and consumer. Accordingly, an examination of the process by which consumers form relationships with brands requires a measure of consumer determined Relationship Quality. This research provides such a measure.

Overall, some key elements in the process by which consumers form relationships with brands are identified. It is shown that Communication with Consumer Communities has the greatest influence on a consumer's brand connection, followed by Brand Advertising. It is also shown that Brand Personality Connection and Relational Orientation influence Relationship Quality, and that a consumer's perceived relationship with a brand significantly impacts their level of loyalty. Section 6.2 below discusses the connections between these constructs, summarising the main elements of the conceptual model and the various interrelationships among its component parts.

\subsection{Relationships among Constructs}

Several variables were identified concerning the process by which brand relationships manifest and are nurtured. As discussed in section 6.1, research results revealed that a central part of this process is the connection that a consumer makes with a brand. The findings help to explain a consumer's connection with a brand, including the antecedents and consequences of such a connection. In accordance with literature that suggests communication is critical in the formation of a relationship (Duncan \& Moriarty, 1998), it is shown that a consumer's connection with a brand is influenced by communication regarding a brand in its various forms. This includes Communication with the Brand, Communication with 
Consumer Communities, and Brand Advertising. The communication that a consumer engages in regarding a brand and the influence this has upon their connection with the brand were examined. Partial least square analysis revealed that Communication with Consumer Communities and Brand Advertising contribute towards the variance in a consumer's connection with a brand. Notably, however, Communication with the Brand does not. From this, it is concluded that a brand's advertising and communication with consumer communities regarding a brand positively influence a consumer's brand connection. Although one-way in nature (Duncan \& Moriarty, 1998), advertising is shown to influence brand connection from a consumer perspective. Therefore, brand advertising does influence a relationship. Similarly, support is shown for the facilitation of consumer communities with the goal of forging customer relationships. This has implications concerning the management of social networks based on a common brand interest (McAlexander, et al., 2002).

The interactive communication that a consumer engages in with a brand directly is not shown to influence a consumer's connection with the brand. Interactive communication is an important aspect of a customer relationship, as it permits the sharing of knowledge between parties (Ballantyne, 2004; Duncan \& Moriarty, 1998; Yadav \& Varadarajan, 2005). The nonsignificant link between Communication with the Brand and Brand Personality Connection could be due to this construct being measured from a consumer perspective. Interactive communication from the brand is a form of planned brand communication (Duncan \& Moriarty, 1998; Gronroos, 2004). It may be that consumers do not see this as communication intended to commit to a genuine mutually beneficial relationship on behalf of the brand (Morgan \& Hunt, 1994). As such, communication with the brand will not positively influence the consumer's perceived connection with the brand. According to these results, marketers should strive to facilitate communication regarding their brands among consumers and engage in one-way advertising, with the goal of forging relationships. While still part of an overall communications mix, relationships are not shown to be influenced by direct interactive communication between consumers and brands.

Brand Personality Connection was also shown to significantly influence Relationship Quality. This reiterates the importance of a consumer's connection with a brand in the process by which they form relationships. Brand Personality Connection was determined according to the extent to which consumers characterised the brand as being ideal in its product or service category. A connection is formed when a brand delivers on significant aspects of a consumer's identity (Aaker, et al., 2004; Fournier, 1998). The fact that Brand Personality Connection influences the quality of a customer relationship implies that marketers should be concerned about whether their brand is perceived as ideal by consumers. This has a number of implications for marketers regarding the manner in which consumers form relationships with brands. Marketers must not only consider how their brand is perceived by consumers, but also what consumers consider ideal. An alignment of the two can then be sought, in an 
attempt to develop and maintain a relationship. A marketer may strive to achieve a certain position in the mind of the consumer, but if this position is not close to the consumer's ideal for the product or service category they will not perceive a connection. The research shows that communication will have at least some bearing on this connection with a brand. Therefore, an assessment of how consumers are able to communicate regarding a brand should be made. Brand Advertising and Communication with Consumer Communities are recognised as having a significant influence on Brand Personality Connection. As such, communication of this type should be managed. The influence of Communication with Consumer Communities is of particular relevance. This indicates that word of mouth communications among consumers has an important role in the formation of brand relationships. As consumers are increasingly able to interact in social networks (Bagozzi \& Dholakia, 2006; Cova \& Cova, 2002), in both online and physical environments, this is of growing interest to marketers.

Consumers vary in the extent to which they favour being involved in customer relationships with brands, depending on their Relational Orientation (Garbarino \& Johnson, 1999). In the present research, Relational Orientation is determined by a consumer's favourability towards being involved in customer relationships with brands in a product or service category. Results indicate that a consumer's Relational Orientation has a positive moderating effect on the association between Brand Personality Connection and Relationship Quality. It is, therefore, concluded that Relational Orientation is an important part of the process by which relationships are developed and maintained between consumers and brands. Accordingly, brand owners should attempt to take into account how important relationships are to the consumer in their efforts to forge a relationship. Essentially, some consumers are more disposed than others towards wanting to develop and maintain relationships within the product or service category of interest.

Furthermore the research shows that there are positive outcomes for brand owners, should they develop a relationship with consumers. Research results suggest that Relationship Quality positively influences Customer Brand Loyalty. This is a significant finding, as it implies that the research is of financial importance to brand owners (Keller \& Lehmann, 2006; Marketing Science Institute, 2007). Loyalty is regarded as a key consequence for a brand of being involved in a customer relationship, recognised as a basis for competitive advantage and increased market share (Chaudhuri \& Holbrook, 2001; Dick \& Basu, 1994). It is, therefore, worthwhile for brand owners to examine factors such as how consumers participate in communication regarding their brand, the extent to which consumers perceive a connection with their brand, and consumer determined relationship quality if they are to forge relationships. 


\subsection{Theoretical and Methodological Contributions}

This research contains a number of implications for marketing theory. Bringing together three important areas of literature, implications arise for relationship marketing, customer relationship management, and branding theory. Combining these fields, brands are treated as possessing human-like characteristics in a process of anthropomorphisation (Aggarwal, 2004; Patterson \& O'Malley, 2006). Consumers subsequently perceive relationships with brands, as they do with other people (Fournier, 1998). A contribution of this research is further examining the management of customer brand relationships. The objectives set out for this study were to investigate how consumers participate in the development and maintenance of a customer relationship through communication, as well as examine the consequences of customer relationships for brand owners. In doing so, the process by which consumers choose to participate in customer relationships with brands is explored. Specific research questions concern how the communication that a consumer participates in regarding a brand influences their connection with the brand, how this connection with a brand influences relationship quality, and how subsequent relationship quality influences the performance of a brand.

The construct of Brand Personality Connection was shown to be influenced by the perceived communication that a consumer engages in regarding a brand. Three types of communication that consumers engage in regarding a brand are identified. This includes Brand Advertising, Communication with the Brand, and Communication with Consumer Communities. These constructs capture elements of both one-way and interactive communication that a consumer may engage in regarding a brand. Although these three types of communication were never intended to exhaustively capture a consumer's participation in a relationship with a brand, they capture important aspects of this behaviour. Brand Advertising and Communication with Consumer Communities were found to markedly impact upon relationship formation. It is, therefore, confirmed that consumers participate in relationships with brands through communication. A central premise of this thesis was the importance of communication, in all its forms, in relationship development and maintenance. On the whole, this was strongly upheld.

Interactive communication directly between a consumer and a brand was shown not to have an influence on a relationship. These findings are consistent with theory concerning consumer communities (McAlexander, et al., 2002; Szmigin, et al., 2005), but somewhat contrary to theory that implies relationships are best developed through interactive rather than one-way communication (Duncan \& Moriarty, 1998; Gronroos, 2004). While Communication with the Brand was not shown to make the main contribution towards a consumer's connection with a brand, it should be born in mind that this is still an emerging and in some ways fledgling aspect of marketing activity and engagement. Communication through Internet based media, for example, is continuing to advance. A brand's online presence, although capable of 
facilitating interactive communication, may not necessarily be perceived by consumers as interactive. In some respects interactive communication is still in its infancy. It therefore is likely to have a growing, if not yet dominant, influence. It is expected that Communication with the Brand will have an increasingly significant impact upon relationships, as the facilitation of interactive communication evolves.

Existing literature suggests that consumers form an emotional connection with brands to varying degrees (Fournier, 1998; Graeff, 1996), described as the extent to which a brand expresses a significant aspect of the consumer's self (Thorbjornsen, et al., 2002). However, a scale by which to explicitly measure this connection between a consumer and a brand had not been previously identified. Using bi-polar scales adapted from established brand personality literature (Aaker, 1997) and considering measures of self-congruity (Aaker, et al., 2004; M. Sirgy, 1982), Brand Personality Connection was determined through a congruence index in the current research. This congruence index was created by taking the sum of the absolute difference between a consumer's perceived brand personality and their ideal brand personality for the category. Brand Personality Connection captures the extent to which a consumer perceives that a brand's personality aligns with their ideal brand personality for a product or service category. A congruence index comprising a consumer's ideal brand personality addresses the issue that consumers may be unwilling or unable to articulate their self-image for a specific category (Aaker, 1999). Accordingly, the research identifies a reliable and valid measure of consumer perceived personality connection with a brand.

A reliable and valid measure of Relationship Quality from a consumer perspective is also provided. This measure draws on previous research regarding the quality of a relationship (Aaker, et al., 2004; De Wulf, et al., 2001; Fournier, 1998; Garbarino \& Johnson, 1999; Kressmann, et al., 2006; Thorbjornsen, et al., 2002), adopting a consumer perspective concerning the construct. From a consumer viewpoint, Relationship Quality between themselves and a brand comprises elements of interdependence, intimacy, love and passion, satisfaction, and trust. This is an important contribution, as existing literature has been advanced to reveal how the quality of a customer relationship is constructed from a consumer perspective; providing a consumer-driven measure of relationship quality. This measure of Relationship Quality is shown to be influenced by Brand Personality Connection and, in turn, directly influence a consumer's level of brand loyalty.

Furthermore, a measure of a consumer's Relational Orientation is introduced. Discussed in the literature at a conceptual level (Garbarino \& Johnson, 1999), this construct is operationalised and a measure of a consumer's favourability towards being involved in customer relationships with brands in a product or service category is identified. The construct of Relational Orientation is shown to be theoretically significant in the formation of customer relationships between consumers and brands. Support was identified to suggest this 
construct positively moderates the association between Brand Personality Connection and Relationship Quality. Like Relationship Quality, Relational Orientation is found to capture elements of a consumer's perceived interdependence, intimacy, love and passion, satisfaction, and trust towards brands in a product or service category. While determined by the same dimensions, the scales measuring these constructs possess discriminant validity. Relational Orientation measures a consumer's generalised sentiment towards being involved in customer relationships, while Relationship Quality measures brand-specific sentiment. This presents a number of considerations. Specifically, a consumer's favourability towards being involved in customer relationships with brands in a product or service category is shown to be an important component in the process by which consumers forge relationships with brands. Future theory regarding consumer relationships should, therefore, consider a consumer's relational orientation. Consumers are likely to be more or less willing to develop and maintain a relationship with a brand according to the product or service category.

\subsection{Managerial Considerations}

In addition to theoretical and methodological considerations, the present research provides a number of guidelines for practitioners in high experience service industries such as air travel endeavouring to form relationships with consumers. It is recognised that consumers are increasingly in control of marketing processes and acknowledged as co-producers of value in relationships (Gruen, et al., 2000; Sheth \& Parvatiyar, 1995). Consumers consequently choose the manner in which they forge relationships, including with whom and how they communicate. In exploring the process by which consumers choose to participate in relationships, this research ultimately examines the consequences of forming relationships with end consumers for brand owners. As such, the findings are relevant for marketing practitioners.

The literature recommends that consumers perceive brands as relationship partners (Aggarwal, 2004; Fournier, 1998). An initial point of note stemming from this research is that if practitioners aspire to develop or maintain relationships with consumers, they should strive to have consumers form an emotional connection with their brand. Such a connection is shown to directly influence the quality of a customer relationship, as determined by the consumer. The current research identifies that a consumer's connection with a brand is in part influenced by the communication they engage in regarding the brand. Significantly, it is revealed that communication amongst consumer communities, as well as one-way communication in the form of advertising, can be more influential than interactive communication directly between a consumer and brand in building a brand connection. Therefore, marketing practitioners in the airline industry should consider activities that facilitate brand communities and using broadcast advertising to forge relationships. 
This has implications for airline brand managers regarding communication among social networks. Consumers engage with each other in social networks, sharing their collective brand experience (Bagozzi \& Dholakia, 2006; Cova \& Cova, 2002). Word of mouth effects concerning a brand are particularly relevant to marketers seeking to forge consumer relationships. Attention should, therefore, be given to the management of such communications. The Internet is an emerging force as a facilitator of consumer communities. Successful maintenance of online communities is likely to be beneficial to a brand, while unplanned negative communication equally detrimental (Maclaran \& Catterall, 2002). In addition to more traditional personal communication, consumers discuss brands with each other through e-mail and social networking websites (Fox, 2009). Airline brands that experience negative communications through online social networks should be wary of the impact upon relationships with consumers. Consumer communities, particularly those facilitated online, are likely to have an increasing influence upon brand relationships as technology evolves.

Airline marketing managers should also be aware that consumers vary in their favourability towards being involved in relationships with brands in a product or service category. Depending on their relational orientation, consumers may or may not favour forming a relationship with their airline. This is important for marketers, as efforts to develop and maintain a relationship with certain consumers may be ineffective due to their category specific relational orientation. Conversely, relationships are likely to be easier to forge with other consumers disposed to favour relationships. Additionally, the quality of a customer relationship between a consumer and a brand is shown to directly influence a consumer's level of loyalty regarding the brand. As a basis for competitive advantage and increased market share (Chaudhuri \& Holbrook, 2001; Dick \& Basu, 1994), marketing managers should want to maximise customer brand loyalty. The present research indicates that the higher a consumer perceives the quality of a customer relationship between themselves and an airline brand, the higher their level of brand loyalty. This makes the research relevant to airline brand owners. Those in control of airline brands can justify efforts to develop and maintain relationships with consumers if it results in improved performance. According to the final conceptual model, a consumer's brand loyalty is directly influenced by the quality of a relationship. In short airline brand managers need a full appreciation of the many and varied ways in which consumers engage in and with communications, as this can ultimately impact the performance of their brand. 


\subsection{Research Limitations}

There are several research limitations that should be acknowledged. The following paragraphs identify these limitations and discuss their implications for the research findings. One limitation is that airlines were used as the reference brands for this study. Commercial airlines operating in New Zealand were used as these brands strive to develop and maintain relationships with end consumers, most New Zealand adults participate in some form of exchange with these brands, and consumers can engage in communication both through Internet based and non-Internet based media with brands operating in this industry. The research could be extended to include additional brands across other industries. In this case, only commercial airline brands operating in New Zealand were examined. A subsequent limitation is that the brands examined in this research can be regarded as highly experiential, in that they require a relatively high level of contact between the consumer and brand. As stated, brands operating in the airline industry were selected for the varying channels through which a consumer can communicate with the brand. This range of communication lends itself to an examination of services' marketing. It could, therefore, be argued that the research is of limited application to non-service brands, although the conceptual development was based on both product and services literature. It is recommended that although communication regarding a brand may occur to a lesser extent in a non-service situation, the research constructs remain applicable across products and services. Communication with brands operating in the consumer goods industry, for example, is still likely to occur, albeit to a lesser extent than with brands operating within high contact services industries. The constructs of Brand Personality Connection, Relationship Quality, and Relational Orientation may well still apply to varying degrees when considering consumer goods. This is particularly the case where products, such as durables, are complemented and extended through post purchase service channels.

A further limitation is recognised in the demographic profile of research respondents, compared to that of the normally resident New Zealand population. Research respondents identified themselves as generally older than the New Zealand population and reported a higher personal annual income level. Descriptive analysis reveals that more research respondents identified themselves as aged over 44, than the New Zealand census population. Approximately 22 per cent of respondents also identified themselves as aged over 64 years, compared to only 12 per cent of the census population. There is a possibility that older consumers behave differently compared to the overall population, in regards to forming relationships with brands. As such, the study results may not be entirely representative of the total population. Given that older consumers travel more, however, the greater representation of older consumers is not seen as a major limitation. 


\subsection{Future Research}

Reflecting on the results of this study, several interesting directions for future research can be identified. These research directions build upon the present study, incorporating the constructs that have been established and their respective measures. Considering the conceptual model as a whole, the identified constructs could be measured in the context of brands operating in industries other than those with high consumer contact. The fact that the present study was conducted in regards to high experience service brands is acknowledged as one of the research limitations. Additional research using product brands would confirm the applicability of the research findings to multiple product and service categories. Less experiential brands, such as those used to market fast moving consumer goods, are anticipated to provide an interesting area for further research. The research could also be replicated to include consumers residing in geographic locations other than New Zealand. This would help establish the generalisability of results across nations.

A key research finding is that Brand Advertising and Communication with Consumer Communities significantly influence a consumer's connection with a brand. Accordingly, future studies could further investigate these constructs. How best to facilitate communication amongst consumer communities with the intention of forging a brand relationship and whether certain types of advertising are more effective in creating a connection between a consumer and brand are examples of possible research streams. Consumer interaction with social media could be explored further. This is likely to be an increasingly important aspect of Communication with Consumer Communities. Social networks present an opportunity to strengthen brand relationships, but are also fraught with concern as much of the communication in a social network is unplanned from a brand owner perspective. Further factors influencing Brand Personality Connection could also be uncovered. The operational definition and measurement of this construct can be used to extend its antecedents beyond communication regarding a brand. A consumer's overall attitude towards the brand or other measures of brand experience could be examined, for example.

The construct of Relational Orientation is shown to be significant to both brand and relationship marketing theory. It captures a consumer's favourability towards being involved in customer relationships with brands in a product or service category. In the present research a consumer's relational orientation is identified as moderating the link between Brand Personality Connection and Relationship Quality. This suggests that the context in which relationships are made with brands is of importance to consumers and that individuals favour relationships with brands in some product and service categories over others. Future research could investigate the antecedents of a consumer's relational orientation. This examination would help to uncover the determinants of a consumer's favourability towards being involved in customer relationships with brands in a product or service category. Such 
factors as the perceived importance of the product or service category to the consumer and experience with products or services from the category of interest are worth investigation. The extent of a consumer's relational orientation is also a useful consideration. The consistency of a consumer's favourability towards being involved in customer relationships with brands across categories is of significance, as well as the durability of relational orientation. It would be interesting to establish whether a consumer's relational orientation alters or remains relatively unchanged over time. This would provide guidance regarding how a consumer's relational orientation can be influenced. Research could also examine whether consumers with a given demographic or psychographic profile are more likely to favour relationships with brands in certain categories. Marketing practitioners could subsequently be given guidance to more effectively segment their target markets, focussing relationship marketing efforts on consumers that favour category relationships.

\subsection{Conclusions}

Building on existing literature in the area (Aaker, et al., 2004; Fournier, 1998), this study provides further understanding regarding the formation of customer relationships between consumers and brands from a consumer perspective. It examines how consumers choose to engage in the co-creation of customer relationships with brands, as well as the consequences of such relationships for brand owners. Focus is placed on relationship marketing within a branding domain, examining the antecedents and consequences of customer relationships between end consumers and brands. In doing so the research brings together theory regarding relationship marketing, customer relationship management, and branding. A consumer perspective towards participating in the development and maintenance of customer relationships with brands through communication is explicitly examined. Overall this study indicates that numerous factors impact upon the process by which consumers forge relationships with brands, including the communication consumers choose to engage in regarding a brand, and their favourability towards being involved in customer relationships with brands in a product or service category. Furthermore, the development and maintenance of customer relationships from a consumer view-point is found to have direct implications for the performance of a brand.

As co-producers of value (Prahalad \& Ramaswamy, 2004; Sheth \& Parvatiyar, 1995; Veloutsou, et al., 2002), consumers control how they participate in relationships and make a brand connection. Being a critical element in a relationship (Duncan \& Moriarty, 1998), consumers choose how they communicate with brands. The research results show that the perceived communication that a consumer engages in regarding a brand influences their brand connection. This includes the type, frequency, nature, and channel of communication that a consumer engages in regarding a brand. In particular, brand advertising and 
communication with consumer communities concerning the brand are influential in the process by which brand relationships are formed. Interactive communication directly between the consumer and brand was not found to influence connection with a brand. These findings are consistent with theory concerning consumer communities (McAlexander, et al., 2002; Szmigin, et al., 2005), supporting the notion that marketers need to consider connected customers who communicate amongst themselves as well as with brands (Marketing Science Institute, 2007). The research results stress the importance of striving to control unplanned messages regarding brands, sent and received among consumers. This highlights the influence of social networks in relationships. It has been suggested that the management of interaction between parties is at the core of relationship marketing (Gronroos, 2004). Research results indicate that marketers should concentrate on managing interaction regarding their brands amongst consumer communities, as this significantly affects connection with a brand. A consumer community can be maintained by a brand, a third party organisation, or by independent consumers. It is advised that marketers attempt to ensure communication amongst consumer communities regarding their brands is as the brand desires. Social networks and word of mouth communication among consumers are likely to be increasingly relevant to marketers seeking to forge relationships. Particularly as online networks become richer and more accessible to consumers.

Furthermore, it is shown that a consumer's connection with a brand positively influences consumer perceived relationship quality. Brand personality connection is, therefore, identified as an important part of the process by which relationships are formed. Extending theory regarding the quality of relationships (De Wulf, et al., 2001; Morgan \& Hunt, 1994), a measure of relationship quality from a consumer point of view was identified. Discussed conceptually in the literature (Garbarino \& Johnson, 1999), a consumer's relational orientation was also operationalised and measured. This comprised a measure of a consumer's favourability towards being involved in customer relationships with brands in a product or service category. Literature suggests that organisations can benefit from changes in their approach to forming relationships, depending on their target consumers' favourability towards having a relationship (Coviello, et al., 2002; Garbarino \& Johnson, 1999; Pels, et al., 2000). However, a measure of consumer relational orientation had not been provided; nor had its influence on relationship quality. Research results reveal that the association between brand personality connection and relationship quality is positively moderated by a consumer's relational orientation. By determining relational orientation, marketers can identify whether consumers favour engaging in a relatively high or low level of relational exchange with certain product or service categories. As such, relational orientation is acknowledged as an important consideration in the development and maintenance of customer relationships.

Finally, a positive association is identified between the quality of a customer relationship between a consumer and a brand, as determined by the consumer, and customer brand 
loyalty. Loyalty is recognised as impacting upon organisational performance (Chaudhuri \& Holbrook, 2001; Dick \& Basu, 1994). The research results, therefore, confirm that developing and maintaining relationships with end consumers has a positive impact upon the performance of a brand. Consumer participation in relationships is, accordingly, emphasised for those that control brands. Overall, this research makes a contribution in the provision of measures regarding the process by which consumers form relationships with brands. The research shows that consumers participate in the development and maintenance of a customer relationship through communication, particularly in the form of advertising and communication with consumer communities. It is also shown that customer relationships have consequences for brand owners, by impacting customer brand loyalty. In doing so it identifies the manner in which customer relationships are developed and maintained from a consumer perspective, as well as the benefits for brand owners of relationships. 
Appendix A: Internet Based and Non-Internet Based Media

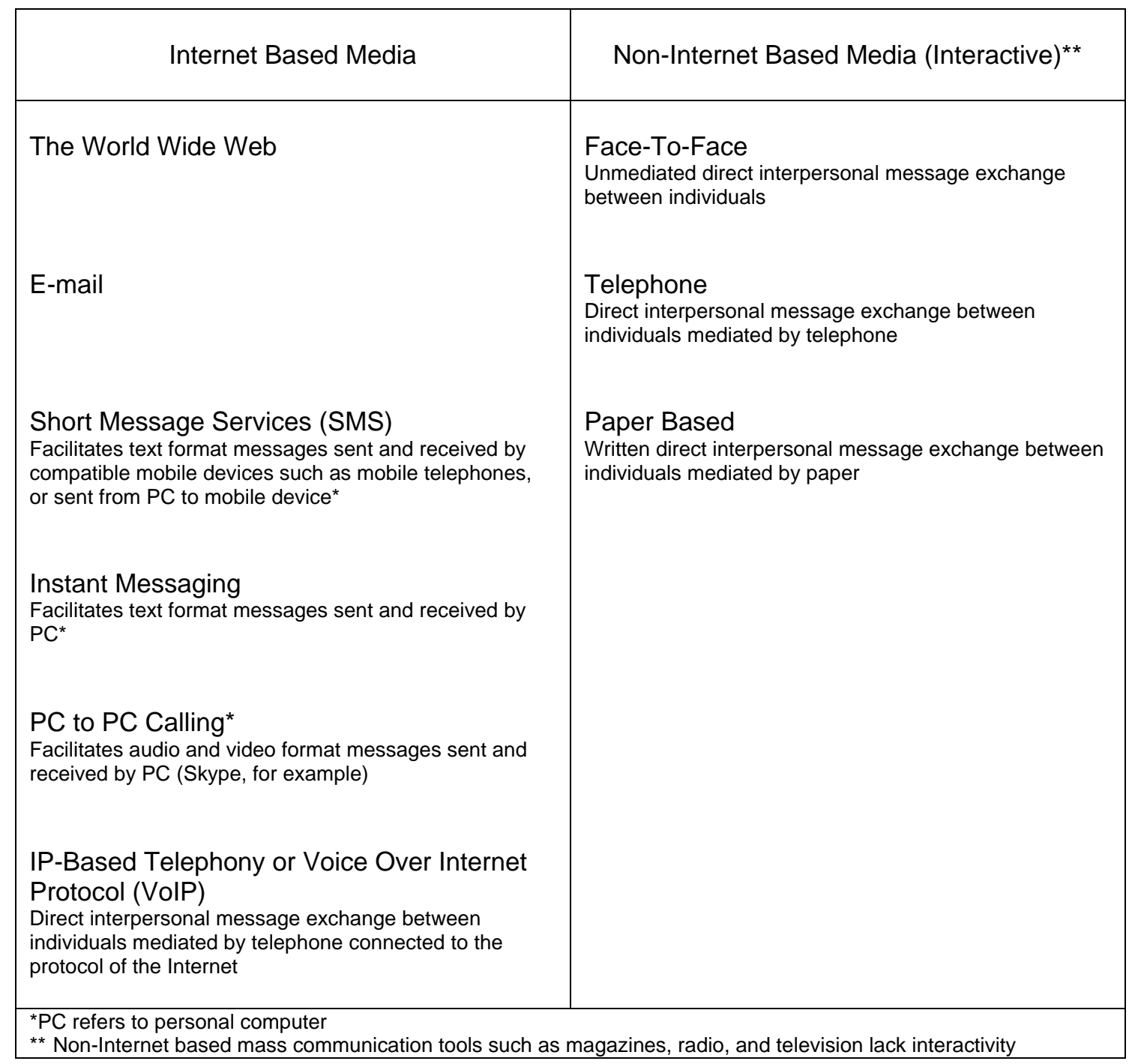


Appendix B: Pretest Data Analysis

Age

Table 28, below, shows that pretest respondents identified themselves as belonging to a range of age groups and only two respondents did not complete this question. As a population, over nine per cent of New Zealand residents are 18-24 years old and approximately 14 per cent are between 45 and 64 years of age (Statistics New Zealand, 2006). Although respondents identifying themselves as being 45-64 years of age were overrepresented as a percentage of the population in the pretest, this implies high involvement of consumers expected to be regular airline travellers.

Table 28. Pretest Age

\begin{tabular}{|c|c|c|}
\hline Age & Number & Percentage (\%) \\
\hline $18-24$ & 0 & 0 \\
\hline $25-34$ & 6 & 14.3 \\
\hline $35-44$ & 1 & 2.4 \\
\hline $45-54$ & 15 & 35.7 \\
\hline $55-64$ & 15 & 35.7 \\
\hline $65-74$ & 4 & 9.5 \\
\hline $75+$ & 1 & 2.4 \\
\hline Total & 42 & 100.0 \\
\hline Missing & 2 & \\
\hline
\end{tabular}

\section{Residential Region}

Similarly, Table 29 below reveals that pretest respondents reside geographically throughout New Zealand. The highest percentages of pretest respondents are shown to reside in Auckland, Canterbury, and Wellington. This is consistent with national population figures that indicate over 50 per cent of New Zealanders reside in these main centres (Statistics New Zealand, 2006). According to Table 30, approximately 73 per cent of pretest respondents identified themselves as residing in an urban area. The remaining 27 per cent identified themselves as rural residents. Only two respondents missed the question regarding their residential region, with three respondents missing the question concerning whether they consider their residence to be urban or rural. These results suggest a good geographic representation. 
Table 29. Pretest Residential Region

\begin{tabular}{|l|c|c|}
\hline Residential Region & Frequency & Percentage (\%) \\
\hline Northland & 1 & 2.4 \\
\hline Auckland & 9 & 21.4 \\
\hline Waikato & 2 & 4.8 \\
\hline Bay of Plenty & 3 & 7.1 \\
\hline Hawke's Bay & 3 & 7.1 \\
\hline Taranaki & 2 & 4.8 \\
\hline Manawatu-Wanganui & 4 & 9.5 \\
\hline Wellington & 5 & 11.9 \\
\hline Canterbury & 5 & 11.9 \\
\hline Otago & 3 & 7.1 \\
\hline Southland & 2 & 4.8 \\
\hline Nelson & 1 & 2.4 \\
\hline Marlborough & 1 & 2.4 \\
\hline Other & 1 & 2.4 \\
\hline Total & 42 & 100.0 \\
\hline Missing & 2 & \\
\hline
\end{tabular}

Table 30. Pretest Urban/Rural Residence

\begin{tabular}{|l|c|c|}
\hline Residence & Number & Percentage (\%) \\
\hline Rural & 11 & 26.8 \\
\hline Urban & 30 & 73.2 \\
\hline Total & 41 & 100.0 \\
\hline Missing & 3 & \\
\hline
\end{tabular}

\section{Gender}

New Zealand's usually resident population comprises 49 per cent males and 51 per cent females (Statistics New Zealand, 2006). As shown in Table 31, below, over 71 per cent of pretest respondents identified themselves as being female. The gender representation of respondents in the research pretest was, therefore, skewed towards females.

Table 31. Pretest Gender

\begin{tabular}{|l|c|c|}
\hline Gender & Number & Percentage (\%) \\
\hline Male & 12 & 28.6 \\
\hline Female & 30 & 71.4 \\
\hline Total & 42 & 100.0 \\
\hline Missing & 2 & \\
\hline
\end{tabular}




\section{Income}

Table 32 reveals a spread across the personal annual income categories that pretest respondents identified themselves as belonging to. In addition, only four respondents missed this question. The respondents did appear to be skewed towards higher income earners. According to census results, almost 39 per cent of usually resident New Zealanders aged 15 years and over have an annual income of $\$ 20,000$ or less, with 24.5 per cent having an annual income of over $\$ 40,000$ (Statistics New Zealand, 2006). Only 10 per cent of pretest respondents identified themselves as having a personal annual income of $\$ 20,000$ or less and 65 per cent reported that their personal annual income exceeded $\$ 40,000$. This recognised, however, there was no concern regarding respondents answering the question.

Table 32. Pretest Personal Income

\begin{tabular}{|l|c|c|}
\hline Personal Annual Income & Number of Residents & Percentage of Population (\%) \\
\hline$\$ 0-\$ 10,000$ & 2 & 5.0 \\
\hline$\$ 10,001-\$ 20,000$ & 2 & 5.0 \\
\hline$\$ 20,001-\$ 30,000$ & 2 & 5.0 \\
\hline$\$ 30,001-\$ 40,000$ & 8 & 20.0 \\
\hline$\$ 40,001-\$ 50,000$ & 9 & 22.5 \\
\hline$\$ 50,001-\$ 60,000$ & 7 & 17.5 \\
\hline$\$ 60,001-\$ 70,000$ & 4 & 10.0 \\
\hline$\$ 70,001+$ & 6 & 15.0 \\
\hline Total & 40 & 100.0 \\
\hline Missing & 4 & \\
\hline
\end{tabular}

\section{Airline Travel}

Pretest respondents were asked whether Air New Zealand is the airline that they use most frequently. They were also asked which of eight alternative airlines they used most frequently, excluding Air New Zealand. The primary reasons for this was to establish the extent to which Air New Zealand was the airline respondents use most often, as well as to measure the research constructs in relation to an alternative airline respondents have experience with. Table 33a, below, shows that 61 per cent of pretest respondents who answered the question acknowledged Air New Zealand as the airline that they use most frequently. Overall the most frequently used alternative airline was Qantas, with 39 per cent of respondents identifying this airline as that which they use most frequently excluding Air New Zealand. 29 per cent of respondents identified the alternative airline that they use most frequently as 'none of the above'. This indicates that these respondents had no experience with the eight alternative airlines. According to Table 33b, 19 per cent of pretest respondents travel by airline for business purposes, with the remaining 81 per cent travelling for personal reasons. As less 
than seven per cent of pretest respondents missed either of these items, it is concluded that these questions were successfully answered by respondents.

Table 33a. Pretest Most Frequently Travelled Airline

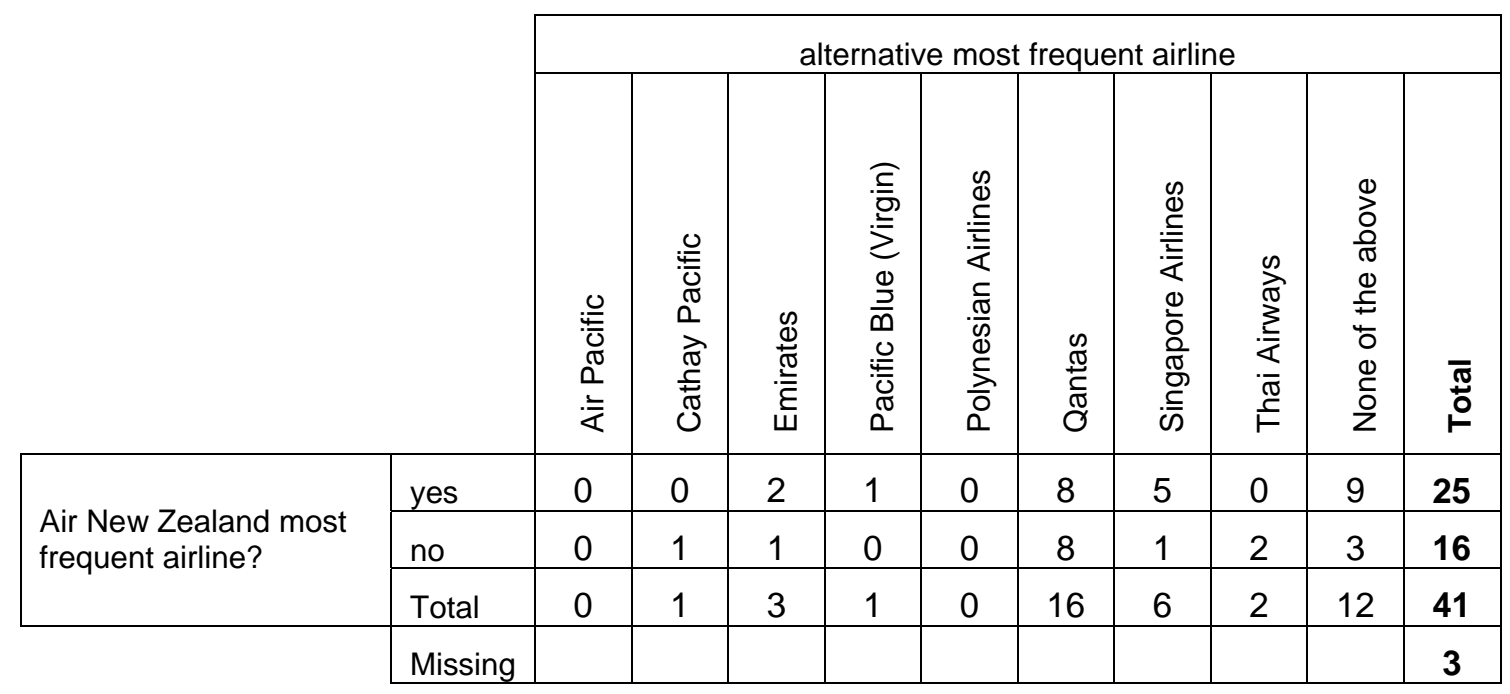

Table 33b. Pretest Primary Purpose of Travel

\begin{tabular}{|l|c|c|}
\hline Purpose & Number & Percentage (\%) \\
\hline Business & 8 & 19.0 \\
\hline Personal & 34 & 81.0 \\
\hline Total & 42 & 100.0 \\
\hline Missing & 2 & \\
\hline
\end{tabular}

Following descriptive analysis, the data collection pretest construct measures were examined. This was performed to again determine if respondents were able to successfully answer the survey questions, as well as whether there was an expected range of answers to each item. Although only employing a small sample, the pretest data was used to calculate the Cronbach's coefficient alpha of each scale. This identified the scales' internal consistency, revealing the extent to which each scale's items measure the same underlying attribute. A minimum Cronbach's coefficient alpha value of 0.70 is recommended for a scale to be regarded as reliable (Nunnally, 1978). The alpha if deleted value of each scale item was used to indicate whether an item could be removed to increase overall scale reliability. The following section examines the data range obtained, as well as the reliability of the scales intended to measure the pretest research constructs. Considerations arising from these results, for research involving a larger sample, are also discussed. Although 44 individuals participated in the pretest data collection, 31 respondents answered questions relating to Air New Zealand as well as one other airline brand. Accordingly, this data analysis reports up to 75 responses to each scale item. 


\section{Brand Personality Connection}

The scale intended to measure the construct of Brand Personality Connection comprised five items, based on the five brand personality dimensions identified by Aaker (1997). These brand personality dimensions determined the extent to which a brand is perceived by a consumer as competent, exciting, rugged, sincere, and sophisticated. Brand Personality Connection was determined through a congruence index, created by taking the sum of the absolute difference between a consumer's perceived brand personality and their ideal brand personality for the category. Therefore, two scales were used to determine both the perceived brand personality of the consumer and their ideal brand personality. The data range obtained for the two scales intended to determine Brand Personality Connection are displayed in Tables $34 \mathrm{a}$ and $34 \mathrm{~b}$ below. Pretest respondents selected a range of answers regarding the perceived personality of a brand, as well as their ideal brand personality for the category. In addition, no more than eight per cent of items from either scale were missed by respondents. The scale intended to measure this construct is recognised as formative, given it is used to measure a construct that is an explanatory combination of its indicators (Bucic \& Gudergan, 2004; Fornell \& Bookstein, 1982).

Table 34a. Brand Personality Connection Data Range

\begin{tabular}{|l|r|r|r|r|r|}
\hline & $\begin{array}{c}\text { Brand Personality } \\
\text { Connection } \\
\text { (rugged) }\end{array}$ & $\begin{array}{l}\text { Brand Personality } \\
\text { Connection } \\
\text { (competent) }\end{array}$ & $\begin{array}{l}\text { Brand Personality } \\
\text { Connection } \\
\text { (exciting) }\end{array}$ & $\begin{array}{c}\text { Brand Personality } \\
\text { Connection } \\
\text { (sophisticated) }\end{array}$ & $\begin{array}{c}\text { Brand Personality } \\
\text { Connection } \\
\text { (sincere) }\end{array}$ \\
\hline Valid & 69 & 70 & 70 & 70 & 70 \\
\hline Missing & 6 & 5 & 5 & 5 & 5 \\
\hline Minimum & 1.00 & 1.00 & 2.00 & 1.00 & 1.00 \\
\hline Maximum & 4.00 & 4.00 & 5.00 & 5.00 & 4.00 \\
\hline
\end{tabular}

Table 34b. Brand Personality Connection (Ideal) Data Range

\begin{tabular}{|l|r|r|r|r|r|}
\hline & $\begin{array}{c}\text { Brand Personality } \\
\text { Connection } \\
\text { (ideal) rugged }\end{array}$ & $\begin{array}{c}\text { Brand Personality } \\
\text { Connection } \\
\text { (ideal) } \\
\text { competent }\end{array}$ & $\begin{array}{l}\text { Brand Personality } \\
\text { Connection } \\
\text { (ideal) } \\
\text { exciting }\end{array}$ & $\begin{array}{l}\text { Brand Personality } \\
\text { Connection } \\
\text { (ideal) } \\
\text { sophisticated }\end{array}$ & $\begin{array}{c}\text { Brand Personality } \\
\text { Connection } \\
\text { (ideal) } \\
\text { sincere }\end{array}$ \\
\hline Valid & 41 & 41 & 41 & 41 & 31 \\
\hline Missing & 3 & 3 & 3 & 3 & 3 \\
\hline Minimum & 1.00 & 1.00 & 1.00 & 1.00 & 1.00 \\
\hline Maximum & 4.00 & 4.00 & 5.00 & 5.00 & 4.00 \\
\hline
\end{tabular}

\section{Brand Advertising}

Table 35a shows a range of pretest responses to items intended to measure Brand Advertising. Although up to 18.7 per cent of respondents missed some scale items, respondents appeared to successfully complete the scale. A Cronbach's coefficient alpha value of 0.865 was calculated for the Brand Advertising scale, exceeding the recommended minimum requirement of 0.70 (Nunnally, 1978). As displayed in Table 35b, this Cronbach's coefficient alpha value would be improved to 0.880 by deleting Brand Advertising (beneficial). All items were retained for further research, given that the purpose of the pretest was to get 
an overview of the research instrument under intended survey conditions (De Leeuw, et al., 2008; Hunt, et al., 1982).

Table 35a. Brand Advertising Data Range

\begin{tabular}{|c|c|c|c|c|c|c|c|c|c|c|}
\hline & 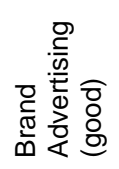 & 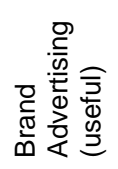 & 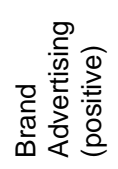 & 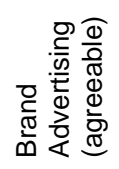 & 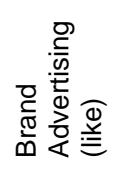 & 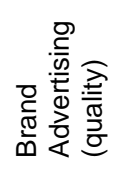 & 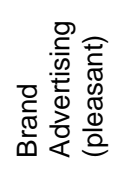 & 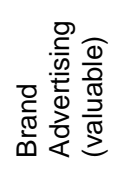 & 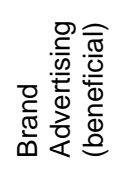 & 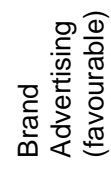 \\
\hline Valid & 65 & 68 & 64 & 62 & 63 & 62 & 62 & 61 & 61 & 61 \\
\hline Missing & 10 & 7 & 11 & 13 & 12 & 13 & 13 & 14 & 14 & 14 \\
\hline Minimum & 2.00 & 2.00 & 2.00 & 2.00 & 2.00 & 2.00 & 2.00 & 2.00 & 1.00 & 3.00 \\
\hline Maximum & 7.00 & 7.00 & 7.00 & 7.00 & 7.00 & 7.00 & 7.00 & 7.00 & 7.00 & 7.00 \\
\hline
\end{tabular}

Table 35b. Brand Advertising Cronbach's Coefficient Alpha

\begin{tabular}{|l|c|c|c|c|}
\hline & $\begin{array}{c}\text { Scale Mean if } \\
\text { Item Deleted }\end{array}$ & $\begin{array}{c}\text { Scale Variance } \\
\text { if Item Deleted }\end{array}$ & $\begin{array}{c}\text { Corrected Item- } \\
\text { Total } \\
\text { correlation }\end{array}$ & $\begin{array}{c}\text { Cronbach's } \\
\text { Alpha if Item } \\
\text { Deleted }\end{array}$ \\
\hline Brand Advertising (good) & 42.1864 & 37.878 & .699 & .841 \\
\hline Brand Advertising (useful) & 42.5932 & 39.073 & .646 & .846 \\
\hline Brand Advertising (positive) & 42.0678 & 37.202 & .828 & .832 \\
\hline Brand Advertising (agreeable) & 42.1186 & 39.451 & .621 & .849 \\
\hline Brand Advertising (like) & 42.3220 & 38.946 & .588 & .851 \\
\hline Brand Advertising (quality) & 41.9492 & 39.635 & .550 & .854 \\
\hline Brand Advertising (pleasant) & 42.2542 & 39.296 & .484 & .862 \\
\hline Brand Advertising (valuable) & 42.7288 & 39.201 & .578 & .852 \\
\hline Brand Advertising (beneficial) & 42.4407 & 44.630 & .199 & .880 \\
\hline Brand Advertising (favourable) & 42.1864 & 40.603 & .653 & .848 \\
\hline
\end{tabular}

\section{Communication with the Brand}

Pretest respondents were asked both how frequently they communicate with a brand of airline, as well as the extent to which the communication experience is generally positive, negative, or neutral in nature. In order to measure the construct of Communication with the Brand the perceived communication frequency of each respondent was multiplied by the perceived nature of their communication experience. The scale intended to determine Communication with the Brand consisted of four items concerning communication frequency, as well as four items regarding the nature of the communication experience. Once perceived communication frequency had been multiplied by the perceived nature of the experience, scores reflecting four scale items were identified. Two scale items concerned a respondent's communication with a brand facilitated by Internet based media, while the other two scale items concerned a respondent's communication with a brand facilitated by non-Internet based media. Table 36 shows that the majority of pretest respondents completed the scales intended to determine the frequency and nature of communication with the brand. The scale intended to measure Communication with the Brand is formative. Therefore, no Cronbach's coefficient alpha value is reported. 
Table 36. Communication with the Brand Valid Data

\begin{tabular}{|l|c|c|c|c|}
\hline & $\begin{array}{c}\text { Communication with the } \\
\text { Brand (total) face to face }\end{array}$ & $\begin{array}{c}\text { Communication with the } \\
\text { Brand (total) telephone }\end{array}$ & $\begin{array}{c}\text { Communication with the } \\
\text { Brand (total) web site }\end{array}$ & $\begin{array}{c}\text { Communication with the } \\
\text { Brand (total) e-mail }\end{array}$ \\
\hline Valid & 68 & 69 & 69 & 72 \\
\hline Missing & 7 & 6 & 6 & 3 \\
\hline
\end{tabular}

\section{Communication with Consumer Communities}

The scale items intended to determine the construct of Communication with Consumer Communities were similar to those used to measure Communication with the Brand. Pretest respondents were, therefore, asked questions regarding the frequency and nature of communication regarding a brand that they participate in with consumer communities. Subsequently, the perceived communication frequency of each respondent was multiplied by the perceived nature of their communication experience. Like Communication with the Brand, the scale intended to determine Communication with Consumer Communities comprised of four items regarding communication frequency and four items regarding the nature of the communication experience. The scale items were split evenly between those that concerned communication facilitated by Internet based media and communication facilitated by nonInternet based media. Table 37 shows that 96 per cent of pretest respondents completed the scales. Like Communication with the Brand, the scale used to measure Communication with Consumer Communities is formative and no Cronbach's coefficient alpha value is reported.

Table 37. Communication with Consumer Communities Valid Data

\begin{tabular}{|l|c|c|c|c|}
\hline & $\begin{array}{c}\text { Communication with } \\
\text { Consumer Communities } \\
\text { (total) face to face }\end{array}$ & $\begin{array}{c}\text { Communication with } \\
\text { Consumer Communities } \\
\text { (total) telephone }\end{array}$ & $\begin{array}{c}\text { Communication with } \\
\text { consumer Communities } \\
\text { (total) web site }\end{array}$ & $\begin{array}{c}\text { Communication with } \\
\text { Consumer Communities } \\
\text { (total) e-mail }\end{array}$ \\
\hline Valid & 72 & 72 & 72 & 72 \\
\hline Missing & 3 & 3 & 3 & 3 \\
\hline
\end{tabular}

\section{Relationship Quality}

Table 38a illustrates that less than three per cent of pretest respondents missed any Relationship Quality scale items. In addition, a Cronbach's coefficient alpha value of 0.790 was calculated for this scale, exceeding the recommended minimum requirement. This Cronbach's coefficient alpha value would not be improved by deleting any of the scale items, as shown in Table 38b. 
Table 38a. Relationship Quality Data Range

\begin{tabular}{|l|r|r|r|r|r|r|}
\hline & $\begin{array}{c}\text { Relationship } \\
\text { Quality } \\
\text { (interdependence) }\end{array}$ & $\begin{array}{c}\text { Relationship } \\
\text { Quality } \\
\text { (intimacy1) }\end{array}$ & $\begin{array}{c}\text { Relationship } \\
\text { Quality } \\
\text { (intimacy2) }\end{array}$ & $\begin{array}{c}\text { Relationship } \\
\text { Quality (love } \\
\text { and passion) }\end{array}$ & $\begin{array}{c}\text { Relationship } \\
\text { Quality } \\
\text { (satisfaction) }\end{array}$ & $\begin{array}{c}\text { Relationship } \\
\text { Quality (trust) }\end{array}$ \\
\hline Valid & 73 & 73 & 73 & 73 & 73 & 73 \\
\hline Missing & 2 & 2 & 2 & 2 & 2 & 2 \\
\hline Minimum & 1.00 & 1.00 & 1.00 & 1.00 & 1.00 & 1.00 \\
\hline Maximum & 5.00 & 5.00 & 5.00 & 4.00 & 5.00 & 5.00 \\
\hline
\end{tabular}

Table 38b. Relationship Quality Cronbach's Coefficient Alpha

\begin{tabular}{|l|c|c|c|c|}
\hline & $\begin{array}{c}\text { Scale Mean if } \\
\text { Item Deleted }\end{array}$ & $\begin{array}{c}\text { Scale Variance if } \\
\text { Item Deleted }\end{array}$ & $\begin{array}{c}\text { Corrected Item- } \\
\text { Total Correlation }\end{array}$ & $\begin{array}{c}\text { Cronbach's } \\
\text { Alpha if Item } \\
\text { Deleted }\end{array}$ \\
\hline Relationship Quality (interdependence) & 15.4521 & 8.557 & .470 & .777 \\
\hline Relationship Quality (intimacy1) & 14.8356 & 7.973 & .543 & .760 \\
\hline Relationship Quality (intimacy2) & 14.7808 & 8.118 & .667 & .730 \\
\hline Relationship Quality (love and passion) & 15.2603 & 7.945 & .651 & .731 \\
\hline Relationship Quality (satisfaction) & 14.6027 & 8.937 & .471 & .774 \\
\hline Relationship Quality (trust) & 14.3836 & 9.156 & .470 & .775 \\
\hline
\end{tabular}

\section{Relational Orientation}

According to Table 39a, few pretest respondents missed questions concerning the construct of Relational Orientation. A Cronbach's coefficient alpha value of 0.889 was calculated for the Relational Orientation scale. As displayed in Table 39b, this Cronbach's coefficient alpha value could be improved to 0.893 by deleting Relational Orientation (intimacy1). Given the Cronbach's coefficient alpha value including all items exceeded the recommended minimum requirement and the purpose of the pretest, to get an overview of the research instrument under intended survey conditions (De Leeuw, et al., 2008; Hunt, et al., 1982), all items were retained for research involving a larger sample.

Table 39a. Relational Orientation Data Range

\begin{tabular}{|c|c|c|c|c|c|c|}
\hline & 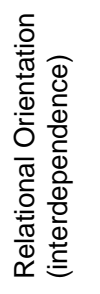 & 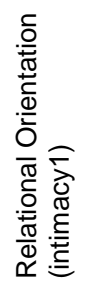 & 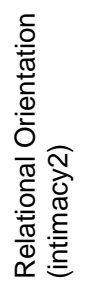 & 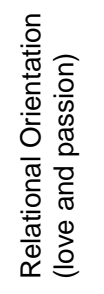 & 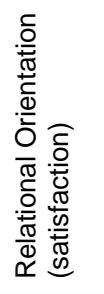 & 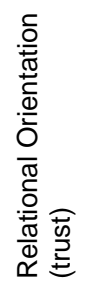 \\
\hline Valid & 42 & 42 & 42 & 42 & 41 & 40 \\
\hline Missing & 2 & 2 & 2 & 2 & 3 & 4 \\
\hline Minimum & 2.00 & 2.00 & 2.00 & 2.00 & 2.00 & 2.00 \\
\hline Maximum & 5.00 & 5.00 & 4.00 & 5.00 & 5.00 & 5.00 \\
\hline
\end{tabular}


Table 39b. Relational Orientation Cronbach's Coefficient Alpha

\begin{tabular}{|l|c|c|c|c|}
\hline & $\begin{array}{c}\text { Scale Mean } \\
\text { if Item } \\
\text { Deleted }\end{array}$ & $\begin{array}{c}\text { Scale } \\
\text { Variance if } \\
\text { Item Deleted }\end{array}$ & $\begin{array}{c}\text { Corrected } \\
\text { Item-Total } \\
\text { Correlation }\end{array}$ & $\begin{array}{c}\text { Cronbach's } \\
\text { Alpha if Item } \\
\text { Deleted }\end{array}$ \\
\hline Relational Orientation (interdependence) & 16.3250 & 10.122 & .769 & .860 \\
\hline Relational Orientation (initmacy1) & 16.6250 & 10.651 & .570 & .893 \\
\hline Relational Orientation (intimcay2) & 16.5750 & 10.712 & .671 & .876 \\
\hline Relational Orientation (love and passion) & 16.7250 & 9.999 & .773 & .859 \\
\hline Relational Orientation (satisfaction) & 16.2750 & 10.461 & .685 & .874 \\
\hline Relational Orientation (trust) & 16.2250 & 10.025 & .788 & .857 \\
\hline
\end{tabular}

\section{Customer Brand Loyalty}

Table 40a reveals that less than four per cent of pretest respondents missed any scale item intended to measure Customer Brand Loyalty. A Cronbach's coefficient alpha value of 0.907 was calculated for this scale, exceeding the recommended minimum requirement. As shown in Table 40b, this Cronbach's coefficient alpha value could be improved to 0.908 by deleting Customer Brand Loyalty (do business). The Cronbach's coefficient alpha value including all items exceeded the recommended minimum requirement. As the purpose of the pretest is to get an overview of the research instrument under intended survey conditions (De Leeuw, et al., 2008; Hunt, et al., 1982), all items were retained for further research.

Table 40a. Customer Brand Loyalty Data Range

\begin{tabular}{|c|c|c|c|c|c|}
\hline & 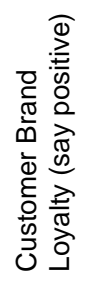 & 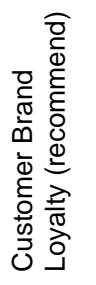 & 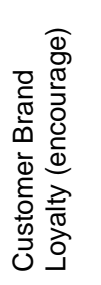 & 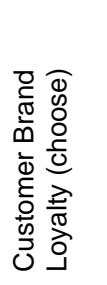 & 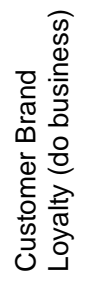 \\
\hline Valid & 73 & 72 & 73 & 73 & 72 \\
\hline Missing & 2 & 3 & 2 & 2 & 3 \\
\hline Minimum & 1.00 & 1.00 & 1.00 & 1.00 & 1.00 \\
\hline Maximum & 5.00 & 5.00 & 5.00 & 5.00 & 5.00 \\
\hline
\end{tabular}

Table 40b. Customer Brand Loyalty Cronbach's Coefficient Alpha

\begin{tabular}{|l|c|c|c|c|}
\hline & $\begin{array}{c}\text { Scale Mean } \\
\text { if Item } \\
\text { Deleted }\end{array}$ & $\begin{array}{c}\text { Scale } \\
\text { Variance if } \\
\text { Item Deleted }\end{array}$ & $\begin{array}{c}\text { Corrected } \\
\text { Item-Total } \\
\text { Correlation }\end{array}$ & $\begin{array}{c}\text { Cronbach's } \\
\text { Alpha if Item } \\
\text { Deleted }\end{array}$ \\
\hline Customer Brand Loyalty (say positive) & 14.1127 & 10.501 & .766 & .886 \\
\hline Customer Brand Loyalty (recommend) & 14.0282 & 10.285 & .789 & .881 \\
\hline Customer Brand Loyalty (encourage) & 14.1268 & 10.027 & .830 & .872 \\
\hline Customer Brand Loyalty (choose) & 14.1127 & 9.530 & .794 & .880 \\
\hline Customer Brand Loyalty (do business) & 13.7606 & 10.728 & .658 & .908 \\
\hline
\end{tabular}




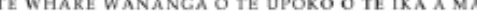 59菌: VICTORIA}

am a graduate student working towards a PhD at Victoria University of Wellington. As part of $m y$ thesis research I am carrying out a survey examining perceptions of commercial airlines.

Your name has been selected from the electoral roll, in an effort to include a good cross-section of New Zealanders for my study. I hope that you will be able to help me. Please be assured that all of your answers are anonymous - please do not write down your name or any other identifying information.

This questionnaire concerns your experiences with commercial airlines, and should take about 15 minutes to complete. It would be extremely helpful if you would provide your response to each of the questions, so that I can get a

Thank you very much for your help. Your involvement in this research is highly valued and much appreciated.

When complete, please fold the questionnaire in half, place in the envelope provided, and freepost to me Victoria University of Wellington by October 312008.

If you work for a commercial airline please tick this box $\square$ and return the questionnaire uncompleted.

Thank you for your time.

\section{Part A}

Section 1

1a. How often do you typically travel on a round trip domestic flight with any commercial airline? please tick one

$\begin{array}{llllll}2-3 \text { times Once a Several Twice Once Every 2-3 Less than } & \text { every 2-3 }\end{array}$

Daily Weekly a month month times a year a year a year years years

1b. How often do you typically travel on a round trip international flight with any commercial airline? please tick one

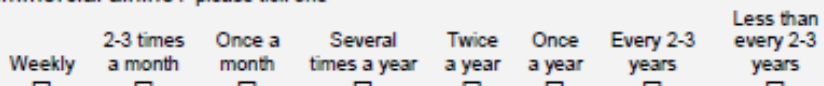

W

Sections 2 to 8 of the questionnaire concern Air New Zealand.

Section 2

This section concerns the television, radio, and print advertising of Air New Zealand,

Please indicate your response by ticking the appropriate space on each scale. Example 1. If you feel rather happy about something, your response might be:

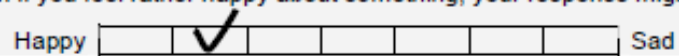

2. In general, how would you describe Air New Zealand advertising?

2a. Good \begin{tabular}{|l|l|l|l|l|l|l|}
\hline & & & & & & \\
\hline
\end{tabular}

$2 b$.

2d. Disagreeable

Dislike

Low Quality

2g. Pleasant

Valuable

2i. Not Beneficial

2j. Unfavourable

\begin{tabular}{|l|l|l|l|l|l|l|}
\hline & & & & & & \\
\hline & & & & & & \\
\hline
\end{tabular}

Page 2 
Section 3

section concerns your own communication with Air New Zealand. Please indicate your reaponse by circling the appropriate answer.

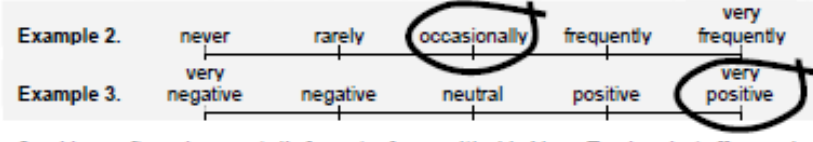

3a. How often do you talk face-to-face with Air New Zealand staff members, including check-in staff and in-flight crew?

$$
\text { never rarely occasionally frequenty frequenty }
$$

How would you generally rate this experience?

$$
\text { negative negative neutral positive positive }
$$

3b. How often do you talk on the telephone with Air New Zealand?

$$
\begin{aligned}
& \text { never rarely occasionally frequenty trequenty } \\
& \text { If never please go to question } 3 \mathrm{c} \text { below. }
\end{aligned}
$$

How would you generally ring

$$
\begin{gathered}
\begin{array}{c}
\text { very } \\
\text { negative negative neutral positive postive }
\end{array} \\
\text { ind }
\end{gathered}
$$

3c. How often do you visit the Air New Zealand Website?

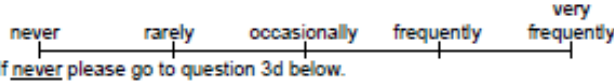

How would you generally rate this experience?

$$
\begin{gathered}
\begin{array}{c}
\text { very } \\
\text { negative negative neutral positive positive }
\end{array} \\
\text { perl }
\end{gathered}
$$

3d. How often do you communicate with Air New Zealand through e-mail or online live chat?

$$
\text { never rarely occasionally frequenty frequenty }
$$

How would you generally rate this experience?

$$
\begin{gathered}
\begin{array}{c}
\text { very } \\
\text { negative negative neutral positive positive }
\end{array} \\
\text { peral }
\end{gathered}
$$

3e. In general, how often do you communicate with Air New Zealand?

$$
\text { never rarely occasionally frequenty trequenty }
$$

How would you rate your overall communication with Air New Zealand?

$$
\begin{gathered}
\text { very } \\
\text { negative negative neutral positive positive }
\end{gathered}
$$

Page 3
Section 4

This section concerns your communication with other people regarding Air New Zealand.

4a. How often do you talk face-to-face with friends or family about Air New Zealand?

$$
\begin{aligned}
& \text { never rarely occasionally frequenty frequentily } \\
& \text { If never please go to question } 4 \mathrm{~b} \text { below. }
\end{aligned}
$$

Is face-to-face discussion about the airline generally positive, negative, or neutral?

$$
\begin{gathered}
\text { very } \\
\text { negative negative neutral positive positive }
\end{gathered}
$$

4b. How often do you talk on the telephone with friends or family about Air New Zealand?

$$
\begin{aligned}
& \text { never rarely occasionally frequenty frequently } \\
& \text { If never please go to question } 4 \mathrm{c} \text { below. }
\end{aligned}
$$

telephone discussion about the

neutral?

$$
\begin{gathered}
\text { very } \\
\text { negative negative neutral postive positive }
\end{gathered}
$$

4c. How often do you e-mail friends or family about Air New Zealand?

$$
\text { never rarely occasionally trequenty frequentiy }
$$

Is e-mail discussion about the airline generally positive, negative, or neutral?

$$
\begin{gathered}
\text { very } \\
\text { negative negative neutral positive positive }
\end{gathered}
$$

4d. How often do you participate in online discussions / live chat about Air New Zealand?

$$
\begin{array}{lll}
\text { never rarely occasionally frequenty } & \begin{array}{c}
\text { very } \\
\text { frequentily }
\end{array} \\
\text { If never please go to question } 4 \mathrm{e} \mathrm{below.} & &
\end{array}
$$

Is online discussion about the airline generally positive, negative, or neutral?

$$
\begin{gathered}
\text { very } \\
\text { negative negative neutral positive positive }
\end{gathered}
$$

4e. How often do you engage overall in discussion with others about Air New Zealand?

never rarely occasionally trequenty frequenty If never please go to section 5 of the questionnaire on the next page. Is overall discussion about the airline positive, negative, or neutral? very
negative negative neutral positive

Page 4 
Section 5

Please indicate on the scales provided the extent to which you agree/disagree with the following statements about Air New Zealand.
Example 5.
strongly
disagree
neutral
agree strongly

5a. Air New Zealand plays an important role in my life.

strongly
disagree disagree neutral agree strongly
agree

5b. I am knowledgeable about Air New Zealand.

$$
\begin{gathered}
\text { strongly } \\
\text { disagree disagree neutral agree }
\end{gathered}
$$

5c. Air New Zealand understands my travel needs.

$$
\begin{gathered}
\text { strongly } \\
\text { disagree disagree neutral agree }
\end{gathered}
$$

5d. I am passionate about Air New Zealand.

$$
\begin{gathered}
\text { strongly } \\
\text { disagree disagree neutral agree }
\end{gathered} \begin{gathered}
\text { strongly } \\
\text { agree }
\end{gathered}
$$

5e. I am satisfied by the efforts that Air New Zealand makes towards me.

$$
\begin{gathered}
\text { strongly } \\
\text { disagree disagree neutral agree }
\end{gathered}
$$

5f. I have trust in Air New Zealand.

strongly
disagree disagree neutral agree

Section 6

How likely are you to do the following? Please indicate your response by circling the appropriate answer.

Example 6. If you are somewhat unlikely to do something, your response will be:

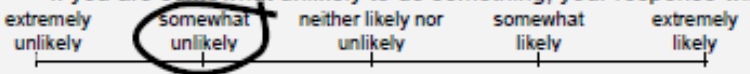

6a. Say positive things about Air New Zealand to other people?

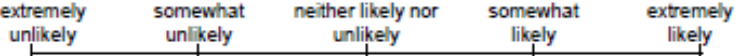

6b. Recommend Air New Zealand to someone who seeks your advice? $\begin{array}{ccccc}\begin{array}{c}\text { extremely } \\ \text { unlikely }\end{array} & \begin{array}{c}\text { somewhat } \\ \text { unlikely }\end{array} & \begin{array}{c}\text { neither likely nor } \\ \text { unlikely }\end{array} & \begin{array}{c}\text { somewhat } \\ \text { likely }\end{array} & \begin{array}{c}\text { extremely } \\ \text { likely }\end{array}\end{array}$

6c. Encourage friends and relatives to travel with Air New Zealand?

\begin{tabular}{|c|c|c|c|c|}
\hline $\begin{array}{l}\text { extremely } \\
\text { unlikely }\end{array}$ & $\begin{array}{l}\text { somewhat } \\
\text { unlikely }\end{array}$ & $\begin{array}{c}\text { neither likely nor } \\
\text { unlikely }\end{array}$ & $\begin{array}{l}\text { somewhat } \\
\text { likely }\end{array}$ & $\begin{array}{c}\text { extremely } \\
\text { likely }\end{array}$ \\
\hline
\end{tabular}
$\begin{array}{ccccc}\begin{array}{c}\text { extremely } \\ \text { unlikely }\end{array} & \begin{array}{c}\text { somewhat } \\ \text { unlikely }\end{array} & \begin{array}{c}\text { neither likely nor } \\ \text { unlikely }\end{array} & \begin{array}{c}\text { somewhat } \\ \text { likely }\end{array} & \begin{array}{c}\text { extremely } \\ \text { likely }\end{array}\end{array}$

6d. If there was a choice of airlines, consider Air New Zealand first when next travelling by plane?

6e. Do business with Air New Zealand in the next few years? $\begin{array}{ccccc}\begin{array}{c}\text { extremely } \\ \text { unlikely }\end{array} & \begin{array}{c}\text { somewhat } \\ \text { unlikely }\end{array} & \begin{array}{c}\text { neither likely nor } \\ \text { unlikely }\end{array} & \begin{array}{c}\text { somewhat } \\ \text { likely }\end{array} & \begin{array}{c}\text { extremely } \\ \text { likely }\end{array}\end{array}$

Section 7

Please indicate how you would characterise Air New Zealand.

Example 7. If you would characterise Air New Zealand as more rational and less Emotional your response might be:

7. Rugged \begin{tabular}{|l|l|l|l|l|}
\hline & & & & \\
\hline
\end{tabular}

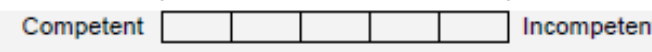

Exciting

Sophisticated

Sincere Relaxed

7 e.

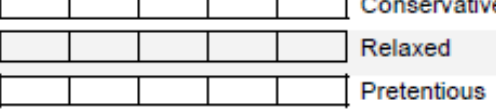

Page 6 
Section 8

8a. How often do you make a domestic round trip with Air New Zealand?

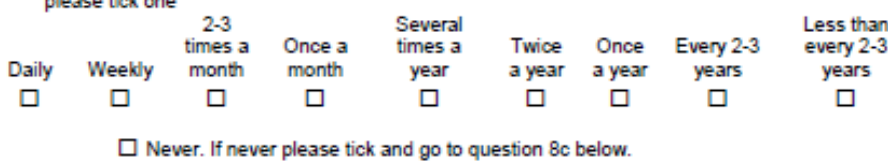
$\square$ Never. If never please tick and go to question $8 \mathrm{c}$ below.

8b. On average, how much is spent on each domestic flight that you take with Air New Zealand (a round trip counts as one flight)? please tick one $\$ 0-\$ 99$
¿

$$
\$ 400-\$ 49
$$$$
\text { 500-\$599 \$600+ }
$$

8c. How often do you make an international round trip with Air New Zealand? please tick one

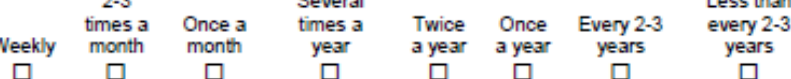

$$
\begin{aligned}
& \text { Never. If never please tick and go to question } 8 \text { e below. }
\end{aligned}
$$

8d. On average, how much is spent on each international flight that you take with

\begin{tabular}{|c|c|c|c|c|}
\hline$\$ 0-\$ 399$ & $\$ 400-\$ 799$ & $\begin{array}{l}\$ 800- \\
\$ 1199\end{array}$ & $\begin{array}{l}\$ 1200- \\
\$ 1599\end{array}$ & $\begin{array}{l}\$ 1600- \\
\$ 1999\end{array}$ \\
\hline 口 & $\square$ & $\square$ & $\square$ & ㅁ \\
\hline
\end{tabular}
Air New Zealand (a round trip counts as one flight)? please tick one

8e. Are you an Air New Zealand Airpoints member? $\quad$ Yes $\quad$ No

If yes, what is your Air New Zealand Airpoints status? please tick one $\begin{array}{cccc}\text { Standard } & \text { Silver } & \text { Gold } & \text { Gold Elite } \\ \square & \square & \square & \square\end{array}$

8f. Are you an Air New Zealand Koru Club member? Yes No

\section{Part B}

9. Is Air New Zealand the airline that you use most frequently? $\square$ Yes

10. Apart from Air New Zealand, of the airlines listed below which one do you use most frequently? please tick one
$\square$ Air Pacific

$$
\begin{array}{ll}
\square \text { Cathay Pacific } & \text { Q Emirates } \\
\square \text { Polynesian Airlines } & \square \text { Qantas }
\end{array}
$$
Pacific Blue (Virgin)
None of the above.

If none of the above, please go to Part $\mathrm{C}$ on page 14 of the questionnaire.

All questions in this part (pages 8 to 13 ) relate to the airline that you have ticked in question 10 above.

Section 11

This section concerns the television, radio, and print advertising of the airline that you have ticked in question 10.

Please indicate your response by ticking the appropriate space on each scale. Example 11. If you feel rather sad about something, your response might be:

$$
\text { Happy } \begin{array}{|l|l|l|l|l|l|l|}
\hline & & & & & \boldsymbol{V} & \\
\end{array}
$$

11. In general, how would you describe the airline's advertising?

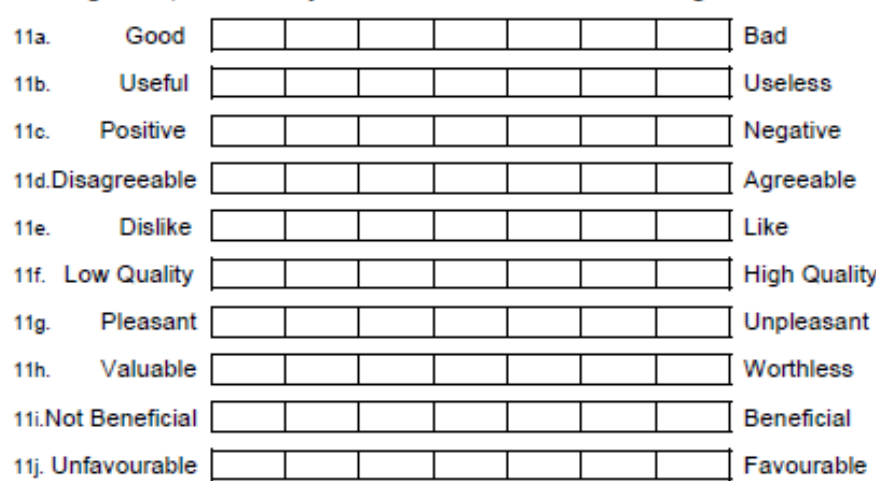

11j. Unfavourable

Page 8 
Section 12

This section concerns your own communication with the airline ticked in question 10. Please indicate your response by circling the appropriate answer.

12a. How often do you talk face-to-face with airline staff members, including checkin staff and in-flight crew?

$$
\begin{array}{lll}
\text { never rarely occasionally frequently frequently } \\
\text { If never please go to question } 12 \mathrm{~b} \text { below. }
\end{array}
$$$$
\text { If never please go to question } 12 \mathrm{~b} \text { below. }
$$

How would you generally rate this experience?

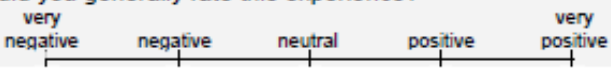

12b. How often do you talk on the telephone with the airline?

$$
\begin{aligned}
& \text { never rarely occasionally frequently } \\
& \text { If } \begin{array}{l}
\text { vequently } \\
\text { If never please go to question } 12 \mathrm{c} \text { below. }
\end{array} \\
& \text { ould you generally rate this experience? } \\
& \text { very } \\
& \text { negative negative neutral positive postive }
\end{aligned}
$$

12c. How often do you visit the airline's website?

$$
\begin{aligned}
& \text { never rarely occasionally frequently frequently } \\
& \text { If never please go to question 12d below. }
\end{aligned}
$$

How would you generally rate this experience?

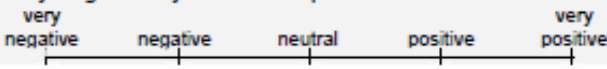

12d. How often do you communicate with the airline through e-mail or online live chat?

$$
\begin{gathered}
\text { never rarely occasionally frequently frequently } \\
\text { If never please go to question } 12 \mathrm{e} \text { below. }
\end{gathered}
$$

If never please go to question $12 \mathrm{e}$ below.

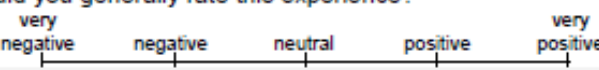

12e. In general, how often do you communicate with the airline?

$$
\text { never rarely occasionally frequently frequently }
$$

If never please go to section 13 of the questionnaire on the next page
How would you rate your overall communication with the airline?

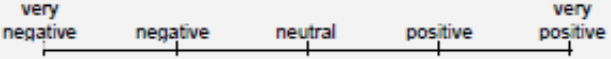

Page 9
Section 13

This section concerns your communication with other people regarding the airline ticked in question 10. Please indicate your response by circling the appropriate answer.

13a. How often do you talk face-to-face with friends or family about the airline?

$$
\text { never rarely occasionally frequently frequently }
$$

face-to-face discussion about the airline generally positive, negative, or

$$
\stackrel{\substack{\text { very } \\ \text { negative negative neutral positive positive }}}{\longleftarrow}
$$

13b. How often do you talk on the telephone with friends or family about the airline?

$$
\begin{aligned}
& \text { never rarely occasionally frequently frequently } \\
& \text { If never please go to question 13c below. }
\end{aligned}
$$

Is telephone discussion about the airline generally positive, negative, or

$$
\begin{gathered}
\text { very } \\
\text { negative negative neutral positive positive }
\end{gathered}
$$

13c. How often do you e-mail friends or family about the airline?

$$
\begin{aligned}
& \text { never rarely occasionaly frequently frequently } \\
& \text { never please go to question } 13 \mathrm{~d} \text { below. }
\end{aligned}
$$

13d. How often do you participate in online discussions / live chat about the airline?

$$
\begin{array}{llll}
\text { never rarely occasionally frequently frequently } \\
\text { If never please go to question } 13 \mathrm{e} \text { below. }
\end{array}
$$

Is online discussion about the airline generally positive, negative, or neutral?

$$
\begin{gathered}
\text { very negative negative neutral positive positive } \\
\text { netrat }
\end{gathered}
$$

13e. How often do you engage overall in discussion with others about the airline?

$$
\text { never rarely occasionally trequently frequently }
$$

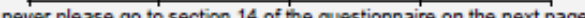

Is overall discussion about the airline positive, negative, or neutral?

$$
\begin{gathered}
\text { very } \\
\text { negative negative neutral positive positive }
\end{gathered}
$$

Page 10 


\section{Section 14}

Please indicate on the scales provided the extent to which you agree/disagree with the following statements about the airline ticked in question 10.

Example 14. Strongly disagree disagree neutral

14a. The airline plays an important role in my life.

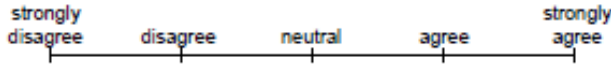

14b. I am knowledgeable about the airline.

$$
\begin{gathered}
\begin{array}{c}
\text { strongly } \\
\text { disagree disagree neutral agree }
\end{array} \\
\begin{array}{c}
\text { strongly } \\
\text { agree }
\end{array}
\end{gathered}
$$

14c. The airline understands my travel needs.

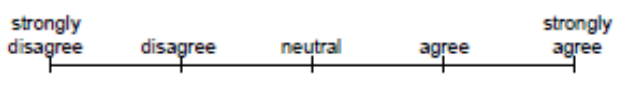

14d. I am passionate about the airline.

$$
\begin{aligned}
& \text { strongly } \\
& \text { disagree disagree neutral agree }
\end{aligned}
$$

14e. I am satisfied by the efforts that the airline makes towards me.

$$
\begin{aligned}
& \text { strongly } \\
& \text { disagree disagree neutral agree strongly }
\end{aligned}
$$

14f. I have trust in the airline.

strongly
disagree disagree neutral agree

Section 15

All statements concern the airline ticked in question 10.

How likely are you to do the following? Please indicate your response by circling the appropriate answer.

Example 15. If you are somewhat likely to do something vour response will be:

$$
\begin{gathered}
\text { extremely somewhat } \\
\text { unlikely neitherly likely nor } \\
\text { unlikely }
\end{gathered}
$$

15a. Say positive things about the airline to other people?

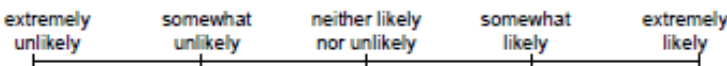

15b. Recommend the airline to someone who seeks your advice?

$$
\begin{array}{ccccc}
\begin{array}{c}
\text { extremely } \\
\text { unlikely }
\end{array} & \begin{array}{c}
\text { somewhat } \\
\text { un/lkely }
\end{array} & \begin{array}{c}
\text { neither likely } \\
\text { nor unlikely }
\end{array} & \begin{array}{c}
\text { somewhat } \\
\text { likely }
\end{array} & \begin{array}{c}
\text { extremely } \\
\text { likely }
\end{array} \\
\hline
\end{array}
$$

15c. Encourage friends and relatives to travel with the airline?

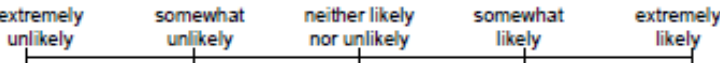

15d. If there was a choice of airlines, consider the airline first when next travelling by plane?

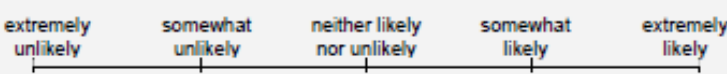

15e. Do business with the airline in the next few years?

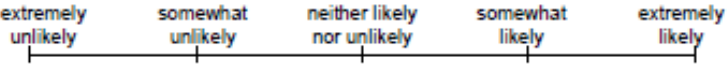

Page 12 
Section 16

Please indicate how you would characterise the airline ticked in question 10.

Example 16. If you would characterise the airline as more emotional and less rational, your responsegmight be:

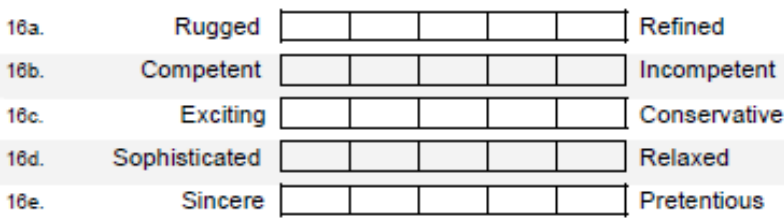

Section 17

All questions concern the airline ticked in question 10.

17a. How often do you make a domestic round trip with the airline? please tick on

$\begin{array}{ccccccc}2-3 \text { times } & \text { Once a Several Twice Once Every 2-3 } & \text { Less than } \\ \text { every } 2-3\end{array}$

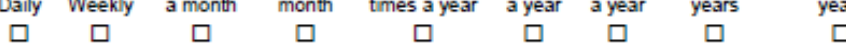

$\square$ Never. If never please tick and go to question $17 \mathrm{c}$ below.

17b. On average, how much is spent on each domestic flight that you take with the airline (a round trip counts as one flight)? please tick one

\$0-\$99 $\$ 100-\$ 199 \quad \$ 200-\$ 399 \quad \$ 400-\$ 499 \quad \$ 500-\$ 599 \quad \$ 600+$

c. How often do you make an international round trip with the airline?

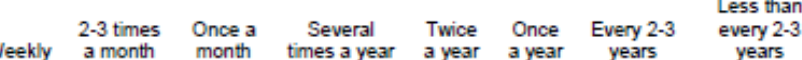
Weekly a month month times a year a year a year years years

$\square$ Never. If never please tick and go to section 18 of the questionnaire on the next page

$17 \mathrm{~d}$. On average, how much is spent on each international flight that you take with the airline (a round trip counts as one flight)? please tick one
\$0-\$399 \$400-\$799
$\$ 800$
$\$ 1200$
$\$ 1600-$
$\$ 2000+$

Page 13

\section{Part C}

All questions in Part $\mathrm{C}$ concern airlines in general.

Section 18

Please indicate on the scales provided the extent to which you agree/disagree with the following statements about airlines in general.

Example 18. $\begin{gathered}\text { strongly } \\ \text { disagree disagree neutral agree }\end{gathered}$

18a. Certain airlines are important to me.

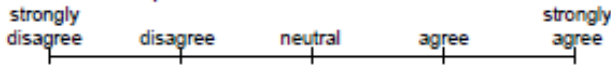

18b. I know a lot about certain airlines.

$$
\begin{gathered}
\text { strangly } \\
\text { disagree disagree neutral agree }
\end{gathered}
$$

18c. I like it when airlines know me well.

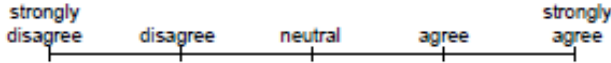

8d. I am passionate about certain airlines.

$$
\begin{aligned}
& \begin{array}{c}
\text { strongly } \\
\text { disagree disagree neutral agree }
\end{array} \\
& \begin{array}{c}
\text { strongly } \\
\text { agree }
\end{array}
\end{aligned}
$$

$18 \mathrm{e}$. There are certain airlines that particularly satisfy me.

$$
\begin{gathered}
\text { strongly } \\
\text { disagree disagree neutral agree }
\end{gathered}
$$

18f. I really trust certain airline

$$
\begin{aligned}
& \begin{array}{l}
\text { strongly } \\
\text { disagree disagree }
\end{array} \text { neutral agree } \\
& \text { strongly } \\
& \text { agree }
\end{aligned}
$$

Section 19

Most of us have ideas about our ideal airline. Please indicate on the following scales how your ideal airline would be characterised.

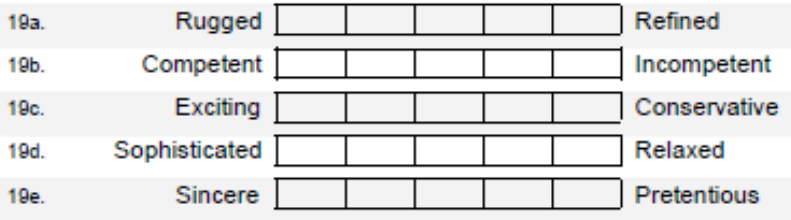

Page 14 


\section{Section 20}

20a. In general, is your airline travel mostly for business purposes?

$$
\begin{array}{cc}
\text { Yes } & \text { No } \\
\square & \square
\end{array}
$$

20b. Please indicate your age group. please tick one

$\begin{array}{ccccccc}18-24 & 25-34 & 35-44 & 45-54 & 55-64 & 65-74 & 75+ \\ \square & \square & \square & \square & \square & \square & \square\end{array}$

20c. Please indicate the region where you live. please tick one

\begin{tabular}{|c|c|}
\hline $\begin{array}{l}\square \text { Northland } \\
\square \text { Waikato } \\
\square \text { Gisborne } \\
\square \text { Taranaki } \\
\square \text { Wellington } \\
\square \text { Canterbury } \\
\square \text { Southland } \\
\square \text { Nelson } \\
\square \text { Other }\end{array}$ & $\begin{array}{l}\text { 口 Auckland } \\
\text { Q Bay of Plenty } \\
\text { Q Hawke's Bay } \\
\text { Q Manawatu-Wanganui } \\
\text { Q West Coast } \\
\text { Q Otago } \\
\text { 口 Tasman } \\
\text { Q Marlborough }\end{array}$ \\
\hline
\end{tabular}

20d. Do you live in a rural or urban area? Rural Urben

20e. Please indicate whether you are:

Male Female

20f. Please indicate your personal annual income level. please tick one

\$0- $\quad \$ 10,001-\quad \$ 20,001-\quad \$ 30,001-\$ 40,001-\quad \$ 50,001-\$ 60,001-\quad \$ 70,001+$ $\begin{array}{cccccccc}\$ 10,000 & \$ 20,000 & \$ 30,000 & \$ 40,000 & \$ 50,000 & \$ 60,000 & \$ 70,000 & \$ 70,001+ \\ \square & \square & \square & \square & \square & \square & \square & \square\end{array}$

\section{Thank you for your participation. It is much appreciated.}

Please return to:

School of Marketing and International Business

Victoria University of Wellington

PO Box 600

Phone: (04) 4638655

Page 15

\section{篦8 VICTORIA}

Information sheet for research regarding 'The Development and Maistenance of Customer Perspective

\section{Researcher: Nicholas Thompson School of Marketing and International Business Victoria University of Wellington}

Victoria University ethics approval has been obtained for this research. The research also adheres to the Market Research Society of New Zealand Code of Practice. Responses collected will form the basis of the research project. All data will be reported in an aggregated manner, with material collected kept confidential in locked or password protected files and access restricted to the investigator. Only my supervisors, Professors Peter Thirkel and Ashish Sinha, will view the completed questionnaires in addition to myself. Questionnaires will be destroyed at the conclusion of the research. A thesis will be submitted for marking to the School of Marketing and International Business and be deposited in the University Library. It is proposed that one or more articles concerning the research .

If you have any questions or require further information about the project, or would like to receive a summary of results once the research has been completed, please Wellington, PO Box 600, Wellington. 
I am a graduate student working towards a PhD at Victoria University of Wellington. A week ago you were sent a questionnaire regarding well known brands operating in New Zealand. Your name has been selected from the electoral roll, in an effort to include a good cross-section of New Zealanders.

This is a follow-up reminder to please complete and return the questionnaire. Thank you, if you have already done so.

It should take about 15 minutes to complete. Your response is much appreciated and will greatly help with the study. If you would like to be sent an additional copy of the questionnaire, please e-mail me at nick.thompson@vuw.ac.nz.

Alternatively, a printable copy is available at newmedia.vuw.ac.nz/survey.doc

Thank you again for your help.

Nick Thompson

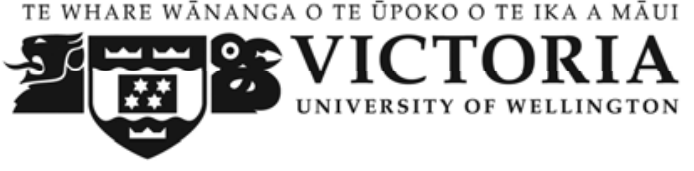




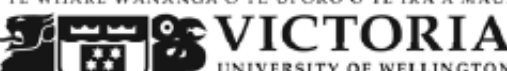

am a graduate student working towards a PhD at Victoria University of Wellington. As part of my thesis research I am (n)

Your name has been selected from the electoral roll, in an effort to include a good cross-section of New Zealanders for my study. I hope that you will be able to help me. Please be assured that all of your answers are anonymous - please do not write down your name or any other identifying information.

This questionnaire concerns your experiences with commercial airlines, and should take about 15 minutes to complete. It would be extremely helpful if you would provide your response to each of the questions, so that I can get a complete picture of what people think.

Thank you very much for your help. Your involvement in this research is highly valued and much appreciated.

When complete, please post to me at:

\section{Nicholas Thompson}

School of Marketing and International Business

Victoria University of Wellington

Box 600

Wellington 6140

If you work for a commercial airline please tick this box $\square$ and return the questionnaire uncompleted.

Thank you for your time.

Page 1

\section{Part A}

Section 1

1a. How often do you typically travel on a round trip domestic flight with any commercial airline? please tick one

Daily Weekly $\begin{gathered}2-3 \text { times } \\ \text { a month }\end{gathered}$ Monthly times a year a year ance $\begin{gathered}\text { Every } 2-3 \\ \text { years }\end{gathered}$

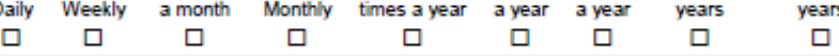

1b. How often do you typically travel on a round trip international flight with any commercial airline? please tick one

Weekly $\begin{gathered}2-3 \text { times } \\ \text { a month }\end{gathered}$ Monthly times a year a year a year $\begin{gathered}\text { Every } 2-3 \\ \text { years }\end{gathered} \begin{gathered}\text { Less than } \\ \text { every } 2-3 \\ \text { years }\end{gathered}$

प

Sections 2 to 8 of the questionnaire concern Air New Zealand.

Section 2

This section concerns the television, radio, and print advertising of Air New Zealand.

Please indicate your response by ticking the appropriate space, as follows: Example 1. If you feel rather happy about something, your response might be:

Happy \begin{tabular}{l|l|l|l|l|l|l|}
\hline & $\boldsymbol{V}$ & & & & & \\
\hline
\end{tabular}

2a. In general, how would you describe Air New Zealand advertising? Good \begin{tabular}{l|l|l|l|l|l|l|l}
\hline & & & & & & \\
\hline
\end{tabular}

Useful \begin{tabular}{|l|l|l|l|l|l|l|}
\hline & & & & & & \\
\hline
\end{tabular}

Positive \begin{tabular}{|l|l|l|l|l|l|l|}
\hline & & & & & & \\
\hline
\end{tabular}

Disagreeable \begin{tabular}{|l|l|l|l|l|l|l|}
\hline & & & & & & \\
\hline
\end{tabular}

Dislike \begin{tabular}{|l|l|l|l|l|l|l|}
\hline & & & & & & \\
\hline
\end{tabular}

Low Quality \begin{tabular}{l|l|l|l|l|l|l|}
\hline & & & & & & \\
\end{tabular}

Pleasant \begin{tabular}{|l|l|l|l|l|l|l|}
\hline & & & & & & \\
\hline
\end{tabular}

Valuable \begin{tabular}{l|l|l|l|l|l|l|l|}
\hline & & & & & & \\
Worthless
\end{tabular}

Not Beneficial \begin{tabular}{|l|l|l|l|l|l|l|}
\hline & & & & & & \\
\hline
\end{tabular}

Unfavourable \begin{tabular}{|l|l|l|l|l|l|l|}
\hline & & & & & & \\
\hline
\end{tabular}

Page 2 
Section 3

This section concerns your own communication with Air New Zealand. Please indicate your response by circling the appropriate answer.

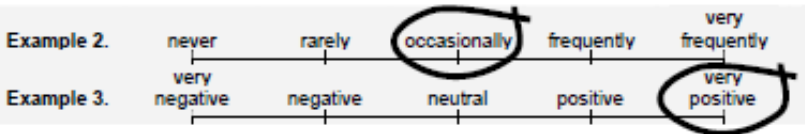

3a. How often do you talk face-to-face with Air New Zealand staff members, including check-in staff and in-flight crew?

$$
\begin{aligned}
& \text { never rarely occasionally frequenty frequenty } \\
& \text { If never please go to question } 3 \mathrm{~b} \text { below. }
\end{aligned}
$$

How would you generally rate this experience?

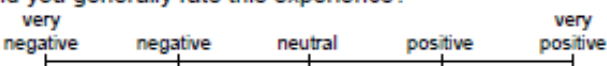

3b. How often do you talk on the telephone with Air New Zealand?

$$
\text { never rarely occassionally frequenty frequenty }
$$

If never please go to question $3 \mathrm{c}$ below.
How would you generally rate this experience?

$$
\text { negative negative neutral positive positive }
$$

3c. How often do you visit the Air New Zealand Website?

$$
\text { never rarely occasionally frequenty trequenty }
$$

If never please go to question $3 \mathrm{~d}$ below.
How would you generally rate this experience?

$$
\begin{gathered}
\text { very } \\
\text { negative negative neutral positive postive }
\end{gathered}
$$

3d. How often do you communicate with Air New Zealand through e-mail or online live chat?

$$
\begin{aligned}
& \text { never rarely occasionally frequenty frequenty } \\
& \text { If never please go to question } 3 \mathrm{e} \text { below. }
\end{aligned}
$$

How would you generally ate this experience?

$$
\begin{gathered}
\text { very } \\
\text { negative negative neutral positive postive }
\end{gathered}
$$

3e. In general, how often do you communicate with Air New Zealand?

$$
\text { never rarely occasionally frequenty frequenty }
$$$$
\text { never please go to section } 4 \text { of the questionnaire on the next page. }
$$

How would you rate your overall communication with Air New Zealand? very positive positive

Page 3

\section{Section 4}

This section concerns your communication with other people regarding Air New Zealand.

4a. How often do you talk face-to-face with friends or family about Air New Zealand?

$$
\begin{aligned}
& \text { never rarely occasionally frequently frequently } \\
& \text { If never please go to question } 4 \mathrm{~b} \text { below. }
\end{aligned}
$$

If never please go to question $4 \mathrm{~b}$ below. Is face-to-f

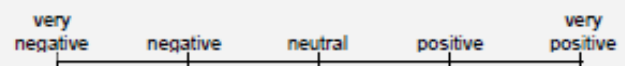

4b. How often do you talk on the telephone with friends or family about Air New Zealand?

$$
\begin{aligned}
& \text { never rarely occasionally frequently frequently } \\
& \text { If never please go to question } 4 \mathrm{c} \text { below. }
\end{aligned}
$$

Is telephone discussion about the airline generally positive, negative, or

$$
\begin{gathered}
\text { very } \\
\text { negative negative neutral positive positive }
\end{gathered}
$$

4c. How often do you participate in online discussions about Air New Zealand?

$$
\begin{aligned}
& \text { never rarely occasionally frequently frequently } \\
& \text { If never please go to question } 4 \mathrm{~d} \text { below. }
\end{aligned}
$$

If never please go to question $4 \mathrm{~d}$ below.

Is online discussion about the airline generally positive, negative, or neutral?

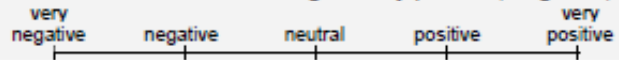

4d. How often do you e-mail friends or family about Air New Zealand?

$$
\begin{aligned}
& \text { never rarely occasionally frequently frequently } \\
& \text { If never please go to question } 4 \mathrm{e} \text { below. }
\end{aligned}
$$

Is e-mail discussion about the airline generally positive, negative, or neutral?

$$
\begin{gathered}
\text { very } \\
\text { negative negative neutral positive }
\end{gathered}
$$

4e. How often do you engage overall in discussion with others about Air New Zealand?

$$
\text { never rarely occasionally frequently frequently }
$$
If never please go to section 5 of the questionnaire on the next page.

Is overall discussion about the airline positive, negative, or neutral?

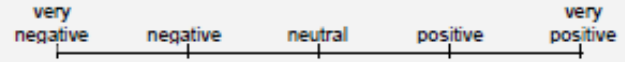

Page 4 
Section 5

Please indicate on the scales provided the extent to which you agree/disagree with the following statements about Air New Zealand.

Example 5. disagree disagree neutral agree $\begin{gathered}\text { strongly } \\ \text { agree }\end{gathered}$

5a. Air New Zealand plays an important role in my life.

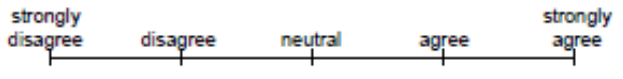

5b. I am knowledgeable about Air New Zealand.

$$
\begin{gathered}
\text { strongly } \\
\text { disagree disagree neutral agree }
\end{gathered}
$$

5c. Air New Zealand understands my travel needs.

$$
\begin{gathered}
\text { strongly } \\
\text { disagree disagree neutral agree }
\end{gathered}
$$

5d. I am passionate about Air New Zealand.

$$
\begin{gathered}
\text { strongly } \\
\text { disagree disagree neutral agree }
\end{gathered}
$$

5e. I am satisfied by the efforts that Air New Zealand makes towards me.

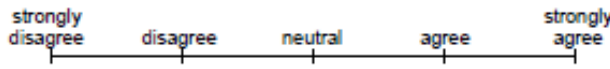

5f. I have trust in Air New Zealand.

strongly
disagree disagree neutral agree

Section 6

How likely are you to do the following? Please indicate your response by circling the appropriate answer.

Example 6. If you are somewhat unlikely to do something, your response will be:

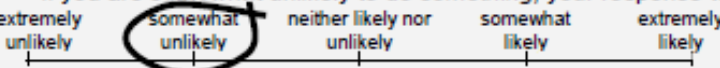

6a. Say positive things about Air New Zealand to other people? extremely somewhat
unlikely

6b. Recommend Air New Zealand to someone who seeks your advice?

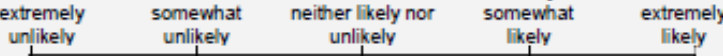

6c. Encourage friends and relatives to travel with Air New Zealand?

\begin{tabular}{|c|c|c|c|}
\hline $\begin{array}{l}\text { extremely } \\
\text { unlikely }\end{array}$ & $\begin{array}{l}\text { somewhat } \\
\text { unlikely }\end{array}$ & $\begin{array}{l}\text { neither likely nor } \\
\text { unlikely }\end{array}$ & $\begin{array}{c}\text { somewhat } \\
\text { Fikely }\end{array}$ \\
\hline
\end{tabular}

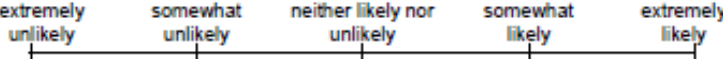

6d. If there was a choice of airlines, consider Air New Zealand first when next travelling by plane?

6e. Do business with Air New Zealand in the next few years?

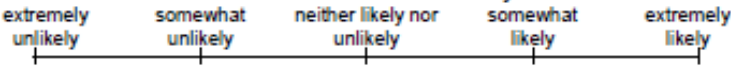

Section 7

Please indicate how you would characterise Air New Zealand.

Example 7. If you would characterise Air New Zealand as more rational and less emotional, your response might be:

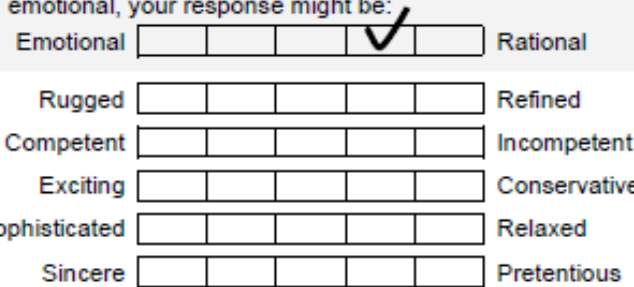

Page 6 


\section{Section 8}

8a. How often do you make a domestic round trip with Air New Zealand?

$\begin{array}{cccccccc}\text { Daily } & \text { Weekly } & \begin{array}{c}2-3 \\ \text { times a } \\ \text { month }\end{array} & \text { Monthly } & \begin{array}{c}\text { Several } \\ \text { timesa } \\ \text { year }\end{array} & \begin{array}{c}\text { Twice } \\ \text { a year }\end{array} \text { ance } & \text { Every 2-3 } & \text { Less than } \\ \text { yevers } & \text { every 2-3 } \\ \text { years }\end{array}$ $\square$ Never. If never please tick and go to question $8 \mathrm{c}$ below.

8 b. On average, how much is spent on each domestic flight that you take with Air New Zealand (a round trip counts as one flight)? please tick one
\$0-\$99
$100-\$ 199$
$\$ 200-\$ 299$
$\square$
$\$ 300-\$ 399 \quad \$ 400-\$ 499$
$\$ 500+$

. How often do you make an international round trip with Air New Zealand?

How often do

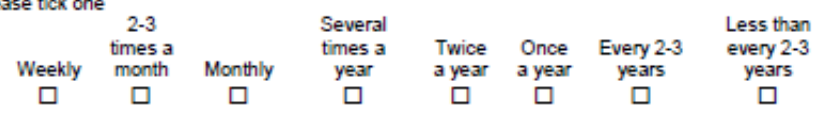

$\square$ Never. If never please tick and go to section 9 of the questionnaire on the next page.

8d. On average, how much is spent on each international flight that you take with Air New Zealand (a round trip counts as one flight)? please tick one

$\$ 0-\$ 399 \quad \$ 400-\$ 799 \quad \$ 800-\quad \$ 1200-\quad \$ 1600-\$ 2000+$

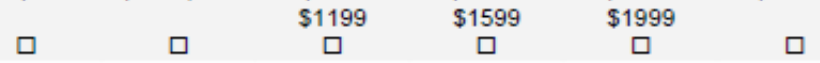

8e. Are you an Air New Zealand Airpoints member? Yes No

If yes, what is your Air New Zealand Airpoints status? please tick one Standard Silver Gold Gold Elite

$\begin{array}{ccccc}\square & \square & \square & \square\end{array}$

8f. Are you an Air New Zealand Koru Club member? Yes

\section{Part B}

9. Is Air New Zealand the airline that you use most frequently?

10. Apart from Air New Zealand, of the airlines listed below which do you use most frequently? please tick one

$\square$ Air Pacific $\square$ Cathay Pacific $\square$ Emirates

$\square$ Pacific Blue (Virgin) $\square$ Polynesian Airlines $\square$ Qantas

$\square$ Singapore Airlines $\square$ Thai Airways

None of the above.

If none of the above, please go to part $\mathrm{C}$ on page 14 of the questionnaire.

All questions in this part (pages 8 to 13) relate to the airline that you have ticked in question 10 above.

Section 11

This section concerns the television, radio, and print advertising of the airline that you have ticked in question 10.

Please indicate your response by ticking the appropriate space, as follows: Example 11. If you feel rather sad about something, your response might be:
Happy

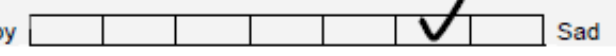

11a. In general, how would you describe the airline's advertising?

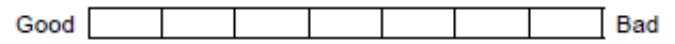

Useful \begin{tabular}{l|l|l|l|l|l|l|}
\hline & & & & & & \\
\hline
\end{tabular}

Positive \begin{tabular}{|l|l|l|l|l|l|l|l}
\hline & & & & & & \\
\hline
\end{tabular}

Disagreeable \begin{tabular}{|l|l|l|l|l|l|l|}
\hline & & & & & & \\
\hline
\end{tabular}

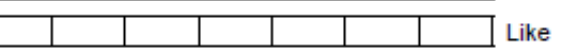

Low Quality \begin{tabular}{|l|l|l|l|l|l|l|}
\hline & & & & & & \\
\hline
\end{tabular}

Pleasant \begin{tabular}{|l|l|l|l|l|l|l|}
\hline & & & & & & \\
\hline
\end{tabular}

Valuable \begin{tabular}{|l|l|l|l|l|l|l|}
\hline & & & & & & \\
\hline
\end{tabular}

Not Beneficial \begin{tabular}{l|l|l|l|l|l|l|}
\hline & & & & & & \\
\hline
\end{tabular}

Unfavourable \begin{tabular}{|l|l|l|l|l|l|l|}
\hline & & & & & & \\
\cline { 2 - 4 }
\end{tabular}

Page 8 
Section 12

This section concerns your own communication with the airline ticked in

question 10. Please indicate your response by circling the appropriate answer.

12a. How often do you talk face-to-face with airline staff members, including checkin staff and in-flight crew?

$$
\begin{gathered}
\text { never rarely } \\
\text { If never please go to question } 12 \text { below. } \\
\text { How would you generally rate this experience? } \\
\text { very } \\
\text { neqative negative neutral cositive }
\end{gathered}
$$

12b. How often do you talk on the telephone with the airline?

$$
\text { never rarely occasionally frequently frequently }
$$$$
\text { If never please go to question } 12 \mathrm{c} \text { below. }
$$

How would you generally rate this experience?

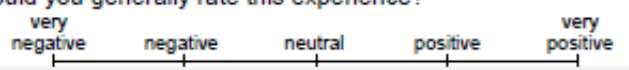

12c. How often do you visit the airline's website?

$$
\begin{aligned}
& \text { never rarely occasionally frequently frequently } \\
& \text { If never please go to question } 12 \mathrm{~d} \text { below. } \\
& \begin{array}{c}
\text { very } \\
\text { negative negative neutral positive cory }
\end{array}
\end{aligned}
$$

12d. How often do you communicate with the airline through e-mail or online live chat?

$$
\begin{aligned}
& \begin{array}{c}
\text { never rarely occasionally frequenty frequentiy } \\
\text { If never please go to question } 12 \mathrm{e} \text { below. }
\end{array} \\
& \text { If never please go to question } 12 \mathrm{e} \mathrm{below.} \\
& \text { How would you generally rate this experience? } \\
& \begin{array}{c}
\text { very } \\
\text { negative negative neutral positive positive }
\end{array}
\end{aligned}
$$

12e. In general, how often do you communicate with the airline?

$$
\text { never rarely occasionally frequently frequentiy }
$$

in never please go to section 13 of the questionnaire on the next page.

How would you rate your overall communication with the airline?

very
negative neqative neutral positive

Section 13

This section concerns your communication with other people regarding the airline ticked in question 10. Please indicate your response by circling the

$$
\text { appropriate answer. }
$$

13a. How often do you talk face-to-face with friends or family about the airline?

$$
\text { never rarely occasionally frequently frequently }
$$

Is face-to-face discussion about the airline generally positive, negative, or neutral?

$$
\text { negative negative neutral positive positive }
$$

13b. How often do you talk on the telephone with friends or family about the airline?

$$
\begin{aligned}
& \text { never rarely occasionally frequently frequently } \\
& \text { If never please go to question } 13 \mathrm{c} \text { below. }
\end{aligned}
$$

Is telephone discussion about the airline generally positive, negative, or neutral?

$$
\text { negative negative neutral positive positive }
$$

13c. How often do you participate in online discussions about the airline?

$$
\text { never rarely occasionaly trequently frequently }
$$

If never please go to question $13 \mathrm{~d}$ below.
e discussion about the airline generally positive, negative, or neutral?

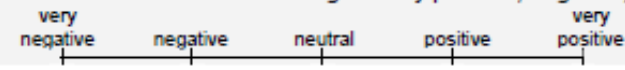

13d. How often do you e-mail friends or family about the airline?

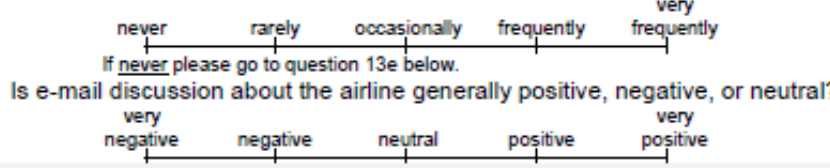

13e. How often do you engage overall in discussion with others about the airline?

$$
\text { never rarely occasionally trequently trequently }
$$

never please go to section 14 of the questionnaire on the next page.

Is overall discussion about the airline positive, negative, or neutral?

very
negative negative neutral positive

Page 10 
Section 14

Please indicate on the scales provided the extent to which you agree/disagree with the following statements about the airline ticked in question 10.

Example 14. Strongly disagree disagree neutral agree

14a. The airline plays an important role in my life.

$$
\begin{aligned}
& \begin{array}{c}
\text { strongly } \\
\text { disagree disagree neutral agree }
\end{array} \text { agree } \\
& \text { agraly }
\end{aligned}
$$

14b. I am knowledgeable about the airline.

$$
\begin{aligned}
& \begin{array}{l}
\text { strongly } \\
\text { disagree disagree neutral agree }
\end{array} \\
& \text { strongly } \\
& \text { agree }
\end{aligned}
$$

14c. The airline understands my travel needs.

$$
\begin{gathered}
\text { strongly } \\
\text { disagree disagree neutral agree }
\end{gathered}
$$

14d. I am passionate about the airline.

$$
\begin{gathered}
\text { strongly } \\
\text { disagree }
\end{gathered} \text { disagree neutral agree } \begin{gathered}
\text { strongly } \\
\text { agree }
\end{gathered}
$$

14e. I am satisfied by the efforts that the airline makes towards me.

$$
\begin{gathered}
\text { strongly } \\
\text { disagree disagree neutral agree strongly } \\
\text { agree }
\end{gathered}
$$

14f. I have trust in the airline.

strongly
disagree disagree neutral agree

Section 15

All statements concern the airline ticked in question 10.

How likely are you to do the following? Please indicate your response by circling the appropriate answer.

Example 15. If you are somewhat likely to do something vour response will be: extremely
unlikely $\begin{gathered}\text { somewhat } \\ \text { unlikely }\end{gathered}$

15a. Say positive things about the airline to other people?

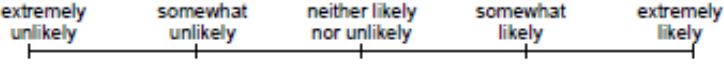

15b. Recommend the airline to someone who seeks your advice?

\begin{tabular}{ccccc}
$\begin{array}{c}\text { extremely } \\
\text { unlikely }\end{array}$ & $\begin{array}{c}\text { somewhat } \\
\text { unlikely }\end{array}$ & $\begin{array}{c}\text { neither likely } \\
\text { nor unlikely }\end{array}$ & $\begin{array}{c}\text { somewhat } \\
\text { likely }\end{array}$ & $\begin{array}{c}\text { extremely } \\
\text { likely }\end{array}$ \\
\hline
\end{tabular}

15c. Encourage friends and relatives to travel with the airline?

\begin{tabular}{ccccc}
$\begin{array}{c}\text { extremely } \\
\text { nulikely }\end{array}$ & $\begin{array}{c}\text { somewhat } \\
\text { unlikely }\end{array}$ & $\begin{array}{c}\text { neither likely } \\
\text { nor unlikely }\end{array}$ & $\begin{array}{c}\text { somewhat } \\
\text { likely }\end{array}$ & $\begin{array}{c}\text { extremely } \\
\text { inely }\end{array}$ \\
\hline
\end{tabular}

\begin{tabular}{|c|c|c|c|}
\hline $\begin{array}{l}\text { extremely } \\
\text { unlikely }\end{array}$ & $\begin{array}{l}\text { somewhat } \\
\text { unlikely }\end{array}$ & $\begin{array}{l}\text { neither likely } \\
\text { nor unlikely }\end{array}$ & $\begin{array}{l}\text { somewhat } \\
\text { likely }\end{array}$ \\
\hline
\end{tabular}

15d. If there was a choice of airlines, consider the airline first when next travelling by plane?

$\begin{array}{ccccc}\text { extremely } & \begin{array}{c}\text { somewhat } \\ \text { unlikely }\end{array} & \begin{array}{c}\text { neither likely } \\ \text { nor unlikely }\end{array} & \begin{array}{c}\text { somewhat } \\ \text { likely }\end{array} & \begin{array}{c}\text { extremely } \\ \text { Ikely }\end{array}\end{array}$

$15 \mathrm{e}$. Do business with the airline in the next few years? 
Section 16

Please indicate how you would characterise the airline ticked in question 10.

Example 16. If you would characterise the airline as more emotional and less rational, your responsegmight be:

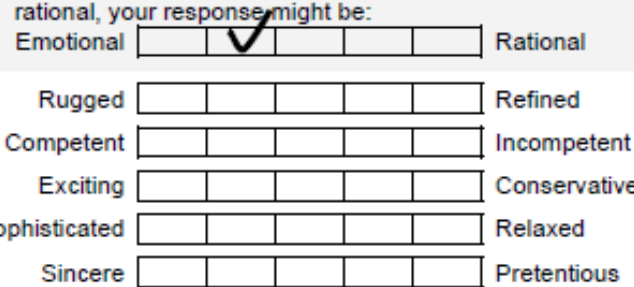

Section 17

All questions concern the airline ticked in question 10.

17a. How often do you make a domestic round trip with the airline? please tick one

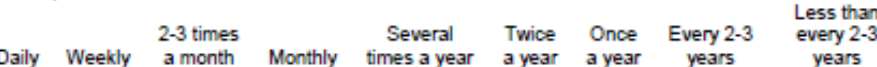

Daily Weekly a month Monthly times a year a year a year years years

$\square$ Never. If never please tick and go to question $17 \mathrm{c} \mathrm{below}$

17b. On average, how much is spent on each domestic flight that you take with the airline (a round trip counts as one flight)? please tick one

$\begin{array}{cccccc}\$ 0-\$ 99 & \$ 100-\$ 199 & \$ 200-\$ 299 & \$ 300-\$ 399 & \$ 400-\$ 499 & \$ 500+ \\ \square & \square & \square & \square & \square & \square\end{array}$

c. How often do you make an international round trip with the airline? please tick one

$$
\begin{aligned}
& \begin{array}{lllll}
2-3 \text { times Several Twice Once Every 2-3 Less than } & \text { every 2-3 }
\end{array}
\end{aligned}
$$

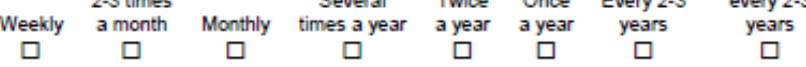

$\square$ Never. If never please tick and go to section 18 of the questionnaire on the next page.

$17 \mathrm{~d}$. On average, how much is spent on each international flight that you take with the airline (a round trip counts as one flight)? please tick one

$\begin{array}{llllll}\$ 0-\$ 399 & \$ 400-\$ 799 & \$ 800- & \$ 1200- & \$ 1600- & \$ 2000+\end{array}$

$\square$

$\square$

$\$ 1999$
$\square$

$\square$

Page 13

\begin{tabular}{|l|}
\hline Part C \\
\hline All questions in Part $\mathrm{C}$ concern airlines in general. \\
\hline
\end{tabular}

Section 18

Please indicate on the scales provided the extent to which you agree/disagree with the following statements about airlines in general.

Example 18. Strongly disagree disagree neytral agree

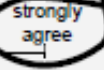

18a. Certain airlines are important to me. strongly
disagree disagree neutral agree strongly

18b. I know a lot about certain airlines.

$$
\begin{aligned}
& \text { strongly } \\
& \text { disagree disagree neutral agree }
\end{aligned}
$$

$18 \mathrm{c}$. I like it when airlines know me well.

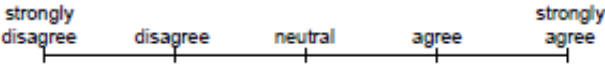

18d. I am passionate about certain airlines. strongly
disagree disagree neutral agree strongly
agree

$18 \mathrm{e}$. There are certain airlines that particularly satisfy me. strongly disagree neutral agree
disagree

18f. I really trust certain airlines.

strongly
disagree disagree neutral agree

Section 19

Most of us have ideas about our ideal airline. Please indicate on the following scales how your ideal airline would be characterised.

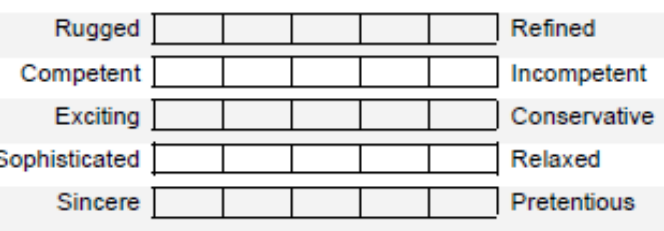

Page 14 
Section 20

20a. Please indicate your age group. please tick one

$\begin{array}{ccccccc}18-24 & 25-34 & 35-44 & 45-54 & 55-64 & 65-74 & 75+ \\ \square & \square & \square & \square & \square & \square & \square\end{array}$

20b. Please indicate the region where you live. please tick one

$\begin{array}{ll}\square \text { Northland } & \square \text { Auckland } \\ \square \text { Waikato } & \square \text { Bay of Plenty } \\ \square \text { Gisborne } & \square \text { Hawke's Bay } \\ \square \text { Taranaki } & \square \text { Manawatu-Wanga } \\ \square \text { Wellington } & \square \text { West Coast } \\ \square \text { Canterbury } & \square \text { Otago } \\ \square \text { Southland } & \square \text { Tasman } \\ \square \text { Nelson } & \square \text { Marlborough } \\ \square \text { Other } & \end{array}$

$20 \mathrm{c}$. Do you live in a rural or urban area?

Rural Urban

20d. Please indicate whether you are:

Male Female

$20 \mathrm{e}$. Please indicate your personal annual income level. please tick one \$o- $\quad \$ 10,001-\$ 20,001-\$ 30,001-\$ 40,001-\$ 50,001-\quad \$ 60,001-\quad \$ 70,001+$ $\$ 10,000 \quad \$ 20,000 \quad \$ 30,000 \quad \$ 40,000 \quad \$ 50,000 \quad \$ 60,000 \quad \$ 70,000 \quad \$ 70,001+$

\section{Thank you for your participation. It is much appreciated.}

Please return to:

Nicholas Thompson

School of Marketing and International Business

Victoria University of Wellington

PO Box 600

Phone: (04) 4638655 or 0211003343

e-mail: nick.thompson@vuw.ac.nz

Page 15

\section{0}

Information sheet for research regarding 'The Development and Maintenance of Customer gh Communication: A

Researcher: Nicholas Thompson

$$
\begin{aligned}
& \text { Nicholas Thompson } \\
& \text { School of Marketiting and Intermational Business } \\
& \text { Victoria University of Wellington }
\end{aligned}
$$

Victoria University ethics approval has been obtained for this research. The research also adheres to the Marke Respon solly coll form the basis of the research project. All data will be reported in an aggregated manner, with material collected kept confidential in locked or password protected files and access restricted to the investigator. Only my supervisors, Professors Peter Thirkell and Ashish Sinha, will view the completed questionnaires in addition to myself. Questionnaires will be destroyed at the conclusion of the research. A thesis will be submitted for marking to the School of Marketing and International Business and be deposited in the University Library. It is proposed that one or more anticles concerning the research will be submitted for publication in scholarly journals.

If you have any questions or require further information about the project, or would like to receive a summary of results once the research has been completed, please Wellington, PO Box 600 , Wellington.

If you would like to enter the prize draw for a $\$ 100$ petrol voucher please write your name and address link your name with your responses to the questionnaire.

Address:

Page 16 


\section{Appendix F: Reasons Provided for Non-Participation}

- "We have only been on one plane flight in the last four years".

- "Unable to help. Limited experience of Air New Zealand"

- "Sorry, but I can't help. Have not been on a plane for about thirty years, and I hate flying".

- "Sorry, I don't travel. Don't fly".

- "I am not a traveller". "Many of the questions asked I have no interest in"

- "I have flown only once in the last 27 years".

- "I only flew once approx in 1970's and never wanted to fly again".

- "I don't do surveys etc".

- "I class myself as unqualified to answer the questions as to air-line travel".

- "Sorry, I feel I am in no position to answer this Questionnaire, as it would be 20 years or so, since I was an airline passenger".

- "As we never travel anywhere by air we feel we aren't really qualified to answer your questions".

- "I am so sorry I just didn't have the time to sit and read through your questionnaire".

- "I'm sorry I can't fill in this questionnaire".

- "I am returning this form to you unused because I have not been on a plane in over 40 years".

- "I do not travel by plane".

- "I have only been on an airplane once since 1990, so no experience or opinions".

- "Never flown in my life".

- "I am not a suitable person to respond to this as I have not flown with Air New Zealand or any other airline for 30 years".

- "The last time I used a plane was in 1997 and I went with Air New Zealand. I haven't been in a plane since".

- "I am unable to contribute to your questionnaire".

- "Sorry I would be no help in your research I haven't used any airline in the past 17 years".

- "Have only ever travelled once and that was in 1987".

- "I have not flown for 15 years so feel this does not apply to me".

- "Sorry I was unable to complete your questionnaire, as I have no experience whatsoever of airlines".

- "I have never used Air New Zealand and don't intend to. Friends of mine used to go Air New Zealand but they told me they will not use them again".

- "Sorry. Don't do surveys".

- "Received it but it's not applicable to me". 
Appendix G: Skewness, Kurtosis, and Missing Data

Age (skewness and kurtosis)

\begin{tabular}{|c|c|c|c|c|c|c|c|}
\hline \multirow{2}{*}{} & $\mathrm{N}$ & Mean & Std. Deviation & \multicolumn{2}{|c|}{ Skewness } & \multicolumn{2}{c|}{ Kurtosis } \\
\cline { 2 - 8 } & Statistic & Statistic & Statistic & Statistic & Std. Error & Statistic & Std. Error \\
\hline \multirow{2}{*}{ age } & 388 & 4.2036 & 1.62420 & -.274 & .124 & -.698 & .247 \\
\hline
\end{tabular}

Income (skewness and kurtosis)

\begin{tabular}{|c|c|c|c|c|c|c|c|}
\hline \multirow{2}{*}{} & $\mathrm{N}$ & Mean & Std. Deviation & \multicolumn{2}{|c|}{ Skewness } & \multicolumn{2}{c|}{ Kurtosis } \\
\cline { 2 - 8 } & Statistic & Statistic & Statistic & Statistic & Std. Error & Statistic & Std. Error \\
\hline \multirow{2}{*}{ income } & 372 & 4.6559 & 2.18174 & .103 & .126 & -1.089 & .252 \\
\hline
\end{tabular}

Brand Personality Connection, congruence index (skewness and kurtosis)

\begin{tabular}{|l|c|c|c|c|c|c|c|}
\hline & $\mathrm{N}$ & Mean & Std. Deviation & \multicolumn{2}{|c|}{ Skewness } & \multicolumn{2}{c|}{ Kurtosis } \\
\cline { 2 - 8 } & Statistic & Statistic & Statistic & Statistic & Std. Error & Statistic & Std. Error \\
\hline $\begin{array}{l}\text { Brand Personality Connection } \\
\text { (rugged) }\end{array}$ & 569 & 3.3234 & .73698 & -.859 & .102 & .240 & .204 \\
\hline $\begin{array}{l}\text { Brand Personality Connection } \\
\text { (competent) }\end{array}$ & 598 & 3.1689 & .82663 & -.876 & .100 & .600 & .200 \\
\hline $\begin{array}{l}\text { Brand Personality Connection } \\
\text { (exciting) }\end{array}$ & 581 & 3.1721 & .89903 & -1.031 & .101 & .708 & .202 \\
\hline $\begin{array}{l}\text { Brand Personality Connection } \\
\text { (sophisticated) }\end{array}$ & 587 & 3.1772 & .87589 & -1.056 & .101 & 1.075 & .201 \\
\hline $\begin{array}{l}\text { Brand Personality Connection } \\
\text { (sincere) }\end{array}$ & 582 & 3.0430 & .87017 & -.618 & .101 & .032 & .202 \\
\hline
\end{tabular}

Brand Advertising (skewness and kurtosis)

\begin{tabular}{|c|c|c|c|c|c|c|c|}
\hline & $\mathrm{N}$ & Mean & Std. Deviation & \multicolumn{2}{|c|}{ Skewness } & \multicolumn{2}{|c|}{ Kurtosis } \\
\hline & Statistic & Statistic & Statistic & Statistic & Std. Error & Statistic & Std. Error \\
\hline Brand Advertising (good) & 623 & 5.2616 & 1.25672 & -.381 & .098 & -.395 & .195 \\
\hline Brand Advertising (useful) & 603 & 4.8259 & 1.22862 & -.161 & .100 & -.019 & .199 \\
\hline Brand Advertising (positive) & 598 & 5.2391 & 1.10943 & -.343 & .100 & .149 & .200 \\
\hline Brand Advertising (agreeable) & 592 & 5.1199 & 1.14328 & -.148 & .100 & -.425 & .201 \\
\hline Brand Advertising (like) & 594 & 5.0909 & 1.18812 & -.201 & .100 & -.320 & .200 \\
\hline Brand Advertising (quality) & 594 & 5.1380 & 1.18071 & -.251 & .100 & -.237 & .200 \\
\hline Brand Advertising (pleasant) & 594 & 5.1768 & 1.24586 & -.401 & .100 & -.293 & .200 \\
\hline Brand Advertising (valuable) & 593 & 4.6965 & 1.23393 & .095 & .100 & -.150 & .200 \\
\hline Brand Advertising (beneficial) & 593 & 4.7386 & 1.26977 & -.175 & .100 & .148 & .200 \\
\hline Brand Advertising (favourable) & 591 & 5.0338 & 1.16686 & .018 & .101 & -.495 & .201 \\
\hline
\end{tabular}


Communication with the Brand, frequency (skewness and kurtosis)

\begin{tabular}{|l|c|c|c|c|c|c|c|}
\hline & $\mathrm{N}$ & Mean & Std. Deviation & \multicolumn{2}{|c|}{ Skewness } & \multicolumn{2}{c|}{ Kurtosis } \\
\cline { 2 - 8 } & Statistic & Statistic & Statistic & Statistic & Std. Error & Statistic & Std. Error \\
\hline $\begin{array}{l}\text { Communication with the Brand (frequency) } \\
\text { face to face }\end{array}$ & 663 & 2.5897 & .89511 & .179 & .095 & -.054 & .190 \\
\hline $\begin{array}{l}\text { Communication with the Brand (frequency) } \\
\text { telephone }\end{array}$ & 663 & 1.8416 & .83029 & .637 & .095 & -.267 & .190 \\
\hline $\begin{array}{l}\text { Communication with the Brand (frequency) } \\
\text { web site }\end{array}$ & 664 & 2.4111 & 1.19372 & .249 & .095 & -1.023 & .189 \\
\hline $\begin{array}{l}\text { Communication with the Brand (frequency) } \\
\text { e-mail }\end{array}$ & 665 & 1.4271 & .73500 & 1.600 & .095 & 1.583 & .189 \\
\hline
\end{tabular}

Communication with the Brand, experience (skewness and kurtosis)

\begin{tabular}{|l|c|c|c|c|c|c|c|}
\hline \multirow{2}{*}{} & $\mathrm{N}$ & Mean & Std. Deviation & \multicolumn{2}{|c|}{ Skewness } & \multicolumn{2}{c|}{ Kurtosis } \\
\cline { 2 - 8 } & Statistic & Statistic & Statistic & Statistic & Std. Error & Statistic & Std. Error \\
\hline $\begin{array}{l}\text { Communication with the Brand (experience) } \\
\text { face to face }\end{array}$ & 646 & .7183 & .64306 & -.118 & .096 & .136 & .192 \\
\hline $\begin{array}{l}\text { Communication with the Brand (experience) } \\
\text { telephone }\end{array}$ & 651 & .3610 & .58726 & .759 & .096 & .626 & .191 \\
\hline $\begin{array}{l}\text { Communication with the Brand (experience) } \\
\text { web site }\end{array}$ & 662 & .4411 & .62379 & .468 & .095 & .139 & .190 \\
\hline $\begin{array}{l}\text { Communication with the Brand (experience) } \\
\text { e-mail }\end{array}$ & 663 & .1342 & .40587 & 1.257 & .095 & 6.828 & .190 \\
\hline
\end{tabular}

Communication with the Brand, frequency $\mathrm{x}$ experience (skewness and kurtosis)

\begin{tabular}{|l|c|c|c|c|c|c|c|}
\hline \multirow{2}{*}{} & $\mathrm{N}$ & Mean & Std. Deviation & \multicolumn{2}{|c|}{ Skewness } & \multicolumn{2}{c|}{ Kurtosis } \\
\cline { 2 - 8 } & Statistic & Statistic & Statistic & Statistic & Std. Error & Statistic & Std. Error \\
\hline $\begin{array}{l}\text { Communication with the Brand (total) } \\
\text { face to face }\end{array}$ & 648 & 1.2886 & 2.02650 & .181 & .096 & 1.844 & .192 \\
\hline $\begin{array}{l}\text { Communication with the Brand (total) } \\
\text { telephone }\end{array}$ & 651 & .9078 & 1.59830 & 1.251 & .096 & 3.406 & .191 \\
\hline $\begin{array}{l}\text { Communication with the Brand (total) } \\
\text { web site }\end{array}$ & 662 & 1.5091 & 2.32185 & 1.214 & .095 & 2.656 & .190 \\
\hline $\begin{array}{l}\text { Communication with the Brand (total) } \\
\text { telephone }\end{array}$ & 663 & .3484 & 1.11602 & 1.028 & .095 & 10.854 & .190 \\
\hline
\end{tabular}

Communication with Consumer Communities, frequency (skewness and kurtosis)

\begin{tabular}{|c|c|c|c|c|c|c|c|}
\hline & $\mathrm{N}$ & Mean & Std. Deviation & \multicolumn{2}{|c|}{ Skewness } & \multicolumn{2}{|c|}{ Kurtosis } \\
\hline & Statistic & Statistic & Statistic & Statistic & Std. Error & Statistic & Std. Error \\
\hline $\begin{array}{l}\text { Communication with Consumer Communities } \\
\text { (frequency) face to face }\end{array}$ & 665 & 2.4707 & .84639 & .115 & .095 & -.160 & .189 \\
\hline $\begin{array}{l}\text { Communication with Consumer Communities } \\
\text { (frequency) telephone }\end{array}$ & 663 & 1.9985 & .89392 & .563 & .095 & -.257 & .190 \\
\hline $\begin{array}{l}\text { Communication with Consumer Communities } \\
\text { (frequency) web site }\end{array}$ & 661 & 1.4312 & .71997 & 1.635 & .095 & 2.131 & .190 \\
\hline $\begin{array}{l}\text { Communication with Consumer Communities } \\
\text { (frequency) e-mail }\end{array}$ & 661 & 1.1604 & .50000 & 3.646 & .095 & 14.887 & .190 \\
\hline
\end{tabular}


Communication with Consumer Communities, experience (skewness and kurtosis)

\begin{tabular}{|c|c|c|c|c|c|c|c|}
\hline & $\mathrm{N}$ & Mean & Std. Deviation & \multicolumn{2}{|c|}{ Skewness } & \multicolumn{2}{|c|}{ Kurtosis } \\
\hline & Statistic & Statistic & Statistic & Statistic & Std. Error & Statistic & Std. Error \\
\hline $\begin{array}{l}\text { Communication with Consumer Communities } \\
\text { (experience) face to face }\end{array}$ & 648 & .4398 & .66446 & .016 & .096 & .171 & .192 \\
\hline $\begin{array}{l}\text { Communication with Consumer Communities } \\
\text { (experience) telephone }\end{array}$ & 655 & .3191 & .59085 & .529 & .095 & .910 & .191 \\
\hline $\begin{array}{l}\text { Communication with Consumer Communities } \\
\text { (experience) web site }\end{array}$ & 658 & .1459 & .39785 & 1.756 & .095 & 5.210 & .190 \\
\hline $\begin{array}{l}\text { Communication with Consumer Communities } \\
\text { (experience) e-mail }\end{array}$ & 659 & .0379 & .24048 & 2.919 & .095 & 29.377 & .190 \\
\hline
\end{tabular}

Communication with Consumer Communities, frequency $\mathrm{x}$ experience (skewness and kurtosis)

\begin{tabular}{|c|c|c|c|c|c|c|c|}
\hline & $\mathrm{N}$ & Mean & Std. Deviation & \multicolumn{2}{|c|}{ Skewness } & \multicolumn{2}{|c|}{ Kurtosis } \\
\hline & Statistic & Statistic & Statistic & Statistic & Std. Error & Statistic & Std. Error \\
\hline $\begin{array}{l}\text { Communication with Consumer Communities } \\
\text { (total) face to face }\end{array}$ & 648 & 1.2886 & 2.02650 & .181 & .096 & 1.844 & .192 \\
\hline $\begin{array}{l}\text { Communication with Consumer Communities } \\
\text { (total) telephone }\end{array}$ & 655 & .8626 & 1.66803 & .484 & .095 & 3.671 & .191 \\
\hline $\begin{array}{l}\text { Communication with Consumer Communities } \\
\text { (total) web site }\end{array}$ & 657 & .3501 & 1.07740 & .604 & .095 & 17.579 & .190 \\
\hline $\begin{array}{l}\text { Communication with Consumer Communities } \\
\text { (total) e-mail }\end{array}$ & 658 & .0912 & .70498 & -1.463 & .095 & 79.781 & .190 \\
\hline
\end{tabular}

Relationship Quality (skewness and kurtosis)

\begin{tabular}{|l|c|c|c|c|c|c|c|}
\hline & $\mathrm{N}$ & Mean & Std. Deviation & \multicolumn{2}{|c|}{ Skewness } & \multicolumn{2}{c|}{ Kurtosis } \\
\cline { 2 - 8 } & Statistic & Statistic & Statistic & Statistic & Std. Error & Statistic & Std. Error \\
\hline $\begin{array}{l}\text { Relationship Quality } \\
\text { (interdependence) }\end{array}$ & 664 & 2.5723 & .96900 & .064 & .095 & -.595 & .189 \\
\hline $\begin{array}{l}\text { Relationship Quality } \\
\text { (intimacy1) }\end{array}$ & 664 & 3.1145 & .86955 & -.375 & .095 & -.189 & .189 \\
\hline $\begin{array}{l}\text { Relationship Quality } \\
\text { (intimacy2) }\end{array}$ & 664 & 3.2681 & .74733 & -.546 & .095 & .716 & .189 \\
\hline $\begin{array}{l}\text { Relationship Quality } \\
\text { (love and passion) }\end{array}$ & 664 & 2.8133 & .90319 & -.166 & .095 & .019 & .189 \\
\hline $\begin{array}{l}\text { Relationship Quality } \\
\text { (satisfaction) }\end{array}$ & 663 & 3.3756 & .80546 & -.696 & .095 & .778 & .190 \\
\hline $\begin{array}{l}\text { Relationship Quality } \\
\text { (trust) }\end{array}$ & 662 & 3.6435 & .74398 & -.600 & .095 & .815 & .190 \\
\hline
\end{tabular}

Relational Orientation (skewness and kurtosis)

\begin{tabular}{|l|c|c|c|c|c|c|c|}
\hline & $\mathrm{N}$ & Mean & Std. Deviation & \multicolumn{2}{|c|}{ Skewness } & \multicolumn{2}{c|}{ Kurtosis } \\
\cline { 2 - 8 } & Statistic & Statistic & Statistic & Statistic & Std. Error & Statistic & Std. Error \\
\hline $\begin{array}{l}\text { Relational Orientation } \\
\text { (interdependence) }\end{array}$ & 383 & 3.4308 & .90652 & -.471 & .125 & .190 & .249 \\
\hline $\begin{array}{l}\text { Relational Orientation } \\
\text { (intimacy1) }\end{array}$ & 384 & 3.0130 & .93515 & -.296 & .125 & -.182 & .248 \\
\hline $\begin{array}{l}\text { Relational Orientation } \\
\text { (intimacy2) }\end{array}$ & 385 & 3.2883 & .78892 & -.112 & .124 & .782 & .248 \\
\hline $\begin{array}{l}\text { Relational Orientation } \\
\text { (love and passion) }\end{array}$ & 386 & 3.0389 & .92641 & -.294 & .124 & -.037 & .248 \\
\hline $\begin{array}{l}\text { Relational Orientation } \\
\text { (satisfaction) }\end{array}$ & 386 & 3.5984 & .77083 & -.607 & .124 & .987 & .248 \\
\hline $\begin{array}{l}\text { Relational Orientation } \\
\text { (trust) }\end{array}$ & 383 & 3.6110 & .79763 & -.585 & .125 & .787 & .249 \\
\hline
\end{tabular}


Customer Brand Loyalty (skewness and kurtosis)

\begin{tabular}{|l|c|c|c|c|c|c|c|}
\hline & $\mathrm{N}$ & Mean & Std. Deviation & \multicolumn{2}{|c|}{ Skewness } & \multicolumn{2}{c|}{ Kurtosis } \\
\cline { 2 - 8 } & Statistic & Statistic & Statistic & Statistic & Std. Error & Statistic & Std. Error \\
\hline $\begin{array}{l}\text { Customer Brand Loyalty } \\
\text { (say positive) }\end{array}$ & 655 & 3.5725 & .95327 & -.681 & .095 & .206 & .191 \\
\hline $\begin{array}{l}\text { Customer Brand Loyalty } \\
\text { (recommend) }\end{array}$ & 655 & 3.6611 & .91267 & -.707 & .095 & .457 & .191 \\
\hline $\begin{array}{l}\text { Customer Brand Loyalty } \\
\text { (encourage) }\end{array}$ & 657 & 3.5388 & .93644 & -.459 & .095 & .155 & .190 \\
\hline $\begin{array}{l}\text { Customer Brand Loyalty } \\
\text { (choose) }\end{array}$ & 657 & 3.6134 & 1.06052 & -.557 & .095 & -.324 & .190 \\
\hline $\begin{array}{l}\text { Customer Brand Loyalty } \\
\text { (do business) }\end{array}$ & 656 & 3.6845 & 1.10908 & -.855 & .095 & .149 & .191 \\
\hline
\end{tabular}


Missing Data Analysis

\begin{tabular}{|c|c|c|c|c|c|c|c|}
\hline & \multirow[b]{2}{*}{$\mathrm{N}$} & \multirow[b]{2}{*}{ Mean } & \multirow{2}{*}{$\begin{array}{l}\text { Std. } \\
\text { Deviation }\end{array}$} & \multicolumn{2}{|c|}{ Missing } & \multicolumn{2}{|c|}{$\begin{array}{c}\text { No. of } \\
\text { Extremes }^{b}\end{array}$} \\
\hline & & & & Count & Percent & Low & High \\
\hline Brand Advertising (good) & 623 & 5.2616 & 1.25672 & 48 & 7.2 & 2 & 0 \\
\hline Brand Advertising (useful) & 603 & 4.8259 & 1.22862 & 68 & 10.1 & 5 & 0 \\
\hline Brand Advertising (positive) & 598 & 5.2391 & 1.10943 & 73 & 10.9 & 3 & 0 \\
\hline Brand Advertising (agreeable) & 592 & 5.1199 & 1.14328 & 79 & 11.8 & 1 & 0 \\
\hline Brand Advertising (like) & 594 & 5.0909 & 1.18812 & 77 & 11.5 & 1 & 0 \\
\hline Brand Advertising (quality) & 594 & 5.1380 & 1.18071 & 77 & 11.5 & 2 & 0 \\
\hline Brand Advertising (pleasant) & 594 & 5.1768 & 1.24586 & 77 & 11.5 & 1 & 0 \\
\hline Brand Advertising (valuable) & 593 & 4.6965 & 1.23393 & 78 & 11.6 & 3 & 0 \\
\hline Brand Advertising (beneficial) & 593 & 4.7386 & 1.26977 & 78 & 11.6 & 9 & 0 \\
\hline Brand Advertising (favourable) & 591 & 5.0338 & 1.16686 & 80 & 11.9 & 1 & 0 \\
\hline Relationship Quality (interdependence) & 664 & 2.5723 & .96900 & 7 & 1.0 & 0 & 10 \\
\hline Relationship Quality (intimacy1) & 664 & 3.1145 & .86955 & 7 & 1.0 & 27 & 0 \\
\hline Relationship Quality (intimacy2) & 664 & 3.2681 & .74733 & 7 & 1.0 & 16 & 0 \\
\hline Relationship Quality (love and passion) & 664 & 2.8133 & .90319 & 7 & 1.0 & 0 & 17 \\
\hline Relationship Quality (satisfaction) & 663 & 3.3756 & .80546 & 8 & 1.2 & 20 & 0 \\
\hline Relationship Quality (trust) & 662 & 3.6435 & .74398 & 9 & 1.3 & 6 & 0 \\
\hline Relational Orientation (interdependence) & 661 & 3.4660 & .88974 & 10 & 1.5 & 19 & 0 \\
\hline Relational Orientation (intimacy1) & 661 & 3.0681 & .92108 & 10 & 1.5 & 39 & 0 \\
\hline Relational Orientation (intimacy2) & 662 & 3.2991 & .78832 & 9 & 1.3 & 15 & 0 \\
\hline Relational Orientation (love and passion) & 663 & 3.0618 & .91848 & 8 & 1.2 & 41 & 0 \\
\hline Relational Orientation (satisfaction) & 663 & 3.6591 & .74250 & 8 & 1.2 & 7 & 0 \\
\hline Relational Orientation (trust) & 659 & 3.6525 & .78107 & 12 & 1.8 & 8 & 0 \\
\hline Communication with the Brand (total) face to face & 645 & 2.1302 & 2.07059 & 26 & 3.9 & 1 & 20 \\
\hline Communication with the Brand (total) telephone & 651 & .9078 & 1.59830 & 20 & 3.0 & 8 & 16 \\
\hline Communication with the Brand (total) web site & 662 & 1.5091 & 2.32185 & 9 & 1.3 & 1 & 22 \\
\hline Communication with the Brand (total) e-mail & 663 & .3484 & 1.11602 & 8 & 1.2 & . & . \\
\hline $\begin{array}{l}\text { Communication with Consumer Communities (total) } \\
\text { face to face }\end{array}$ & 648 & 1.2886 & 2.02650 & 23 & 3.4 & 1 & 5 \\
\hline $\begin{array}{l}\text { Communication with Consumer Communities (total) } \\
\text { telephone }\end{array}$ & 655 & .8626 & 1.66803 & 16 & 2.4 & 11 & 12 \\
\hline $\begin{array}{l}\text { Communication with Consumer Communities (total) } \\
\text { web site }\end{array}$ & 657 & .3501 & 1.07740 & 14 & 2.1 & . & . \\
\hline $\begin{array}{l}\text { Communication with Consumer Communities (total) } \\
\text { e-mail }\end{array}$ & 658 & .0912 & .70498 & 13 & 1.9 & & . \\
\hline $\begin{array}{l}\text { Brand Personality Connection (rugged) absolute } \\
\text { difference }\end{array}$ & 569 & 3.3234 & .73698 & 102 & 15.2 & 10 & 0 \\
\hline $\begin{array}{l}\text { Brand Personality Connection (competent) absolute } \\
\text { difference }\end{array}$ & 598 & 3.1689 & .82663 & 73 & 10.9 & 22 & 0 \\
\hline $\begin{array}{l}\text { Brand Personality Connection (exciting) absolute } \\
\text { difference }\end{array}$ & 581 & 3.1721 & .89903 & 90 & 13.4 & 33 & 0 \\
\hline $\begin{array}{l}\text { Brand Personality Connection (sophisticated) absolute } \\
\text { difference }\end{array}$ & 587 & 3.1772 & .87589 & 84 & 12.5 & 25 & 0 \\
\hline $\begin{array}{l}\text { Brand Personality Connection (sincere) absolute } \\
\text { difference }\end{array}$ & 582 & 3.0430 & .87017 & 89 & 13.3 & 0 & 0 \\
\hline Customer Brand Loyalty (say positive) & 655 & 3.5725 & .95327 & 16 & 2.4 & 21 & 0 \\
\hline Customer Brand Loyalty (recommend) & 655 & 3.6611 & .91267 & 16 & 2.4 & 16 & 0 \\
\hline Customer Brand Loyalty (encourage) & 657 & 3.5388 & .93644 & 14 & 2.1 & 20 & 0 \\
\hline Customer Brand Loyalty (choose) & 657 & 3.6134 & 1.06052 & 14 & 2.1 & 24 & 0 \\
\hline Customer Brand Loyalty (do business) & 656 & 3.6845 & 1.10908 & 15 & 2.2 & 42 & 0 \\
\hline
\end{tabular}

a. . indicates that the inter-quartile range (IQR) is zero.

b. Number of cases outside the range (Q1 - 1.5*IQR, Q3 + 1.5*IQR). 
Appendix H: All Items Correlation Matrix

All Items Correlation Matrix (Part A)

\begin{tabular}{|c|c|c|c|c|c|c|c|c|c|c|c|c|c|c|c|c|c|c|c|c|}
\hline \multirow[b]{2}{*}{ 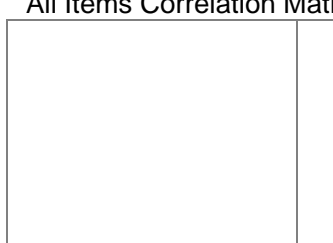 } & & & & & & & & & & & & & & & & & & & & \\
\hline & 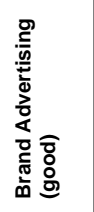 & 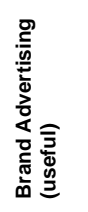 & 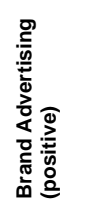 & 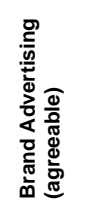 & 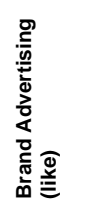 & 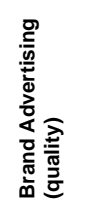 & 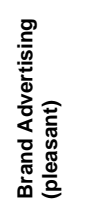 & 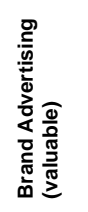 & 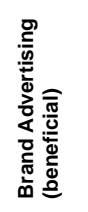 & 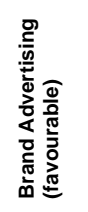 & 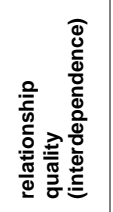 & 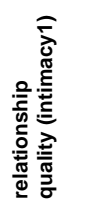 & 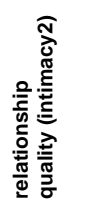 & 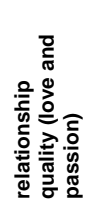 & 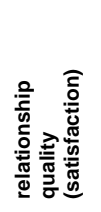 & 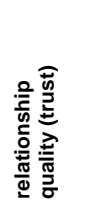 & 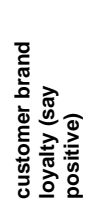 & 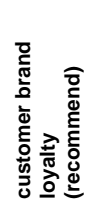 & 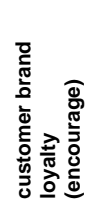 & 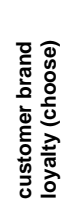 \\
\hline Ivertising (good) & 1.00 & 0.70 & 0.79 & 0.57 & 0.60 & 0.62 & 0.62 & 0.53 & 0.44 & 0.59 & 0.32 & 0.12 & 0.22 & 0.30 & 0.30 & 0.36 & 0.34 & 0.38 & 0.37 & 0.28 \\
\hline $\begin{array}{l}\text { Brand Advertising } \\
\text { (useful) }\end{array}$ & 0.70 & 1.00 & 0.71 & 0.48 & 0.48 & 0.45 & 0.53 & 0.73 & 0.61 & 0.56 & 0.33 & 0.18 & 0.30 & 0.32 & 0.33 & 0.30 & 0.31 & 0.32 & 0.35 & 0.19 \\
\hline $\begin{array}{l}\text { Brand Advertising } \\
\text { (positive) }\end{array}$ & 0.79 & 0.71 & 1.00 & 0.57 & 0.56 & 0.61 & 0.61 & 0.55 & 0.47 & 0.60 & 0.31 & 0.15 & 0.25 & 0.27 & 0.33 & 0.35 & 0.28 & 0.31 & 0.31 & 0.22 \\
\hline $\begin{array}{l}\text { Brand Advertising } \\
\text { (agreeable) }\end{array}$ & 0.57 & 0.48 & 0.57 & 1.00 & 0.74 & 0.65 & 0.53 & 0.46 & 0.49 & 0.67 & 0.24 & 0.10 & 0.24 & 0.22 & 0.27 & 0.37 & 0.25 & 0.27 & 0.27 & 0.23 \\
\hline Brand Advertising (like) & 0.60 & 0.48 & 0.56 & 0.74 & 1.00 & 0.69 & 0.59 & 0.48 & 0.57 & 0.70 & 0.26 & 0.10 & 0.24 & 0.27 & 0.29 & 0.40 & 0.26 & 0.30 & 0.28 & 0.25 \\
\hline $\begin{array}{l}\text { Brand Advertising } \\
\text { (quality) }\end{array}$ & 0.62 & 0.45 & 0.61 & 0.65 & 0.69 & 1.00 & 0.51 & 0.43 & 0.53 & 0.64 & 0.28 & 0.13 & 0.25 & 0.23 & 0.33 & 0.39 & 0.30 & 0.33 & 0.30 & 0.29 \\
\hline $\begin{array}{l}\text { Brand Advertising } \\
\text { (pleasant) }\end{array}$ & 0.62 & 0.53 & 0.61 & 0.53 & 0.59 & 0.51 & 1.00 & 0.61 & 0.40 & 0.56 & 0.26 & 0.10 & 0.22 & 0.23 & 0.27 & 0.34 & 0.28 & 0.29 & 0.28 & 0.16 \\
\hline $\begin{array}{l}\text { Brand Advertising } \\
\text { (valuable) }\end{array}$ & 0.53 & 0.73 & 0.55 & 0.46 & 0.48 & 0.43 & 0.61 & 1.00 & 0.65 & 0.61 & 0.28 & 0.17 & 0.30 & 0.27 & 0.32 & 0.29 & 0.33 & 0.33 & 0.35 & 0.20 \\
\hline $\begin{array}{l}\text { Brand Advertising } \\
\text { (beneficial) }\end{array}$ & 0.44 & 0.61 & 0.47 & 0.49 & 0.57 & 0.53 & 0.40 & 0.65 & 1.00 & 0.71 & 0.30 & 0.17 & 0.33 & 0.32 & 0.34 & 0.35 & 0.31 & 0.31 & 0.30 & 0.23 \\
\hline $\begin{array}{l}\text { Brand Advertising } \\
\text { (favourable) }\end{array}$ & 0.59 & 0.56 & 0.60 & 0.67 & 0.70 & 0.64 & 0.56 & 0.61 & 0.71 & 1.00 & 0.33 & 0.17 & 0.34 & 0.34 & 0.36 & 0.40 & 0.34 & 0.33 & 0.33 & 0.27 \\
\hline $\begin{array}{l}\text { relationship quality } \\
\text { (interdependence) }\end{array}$ & 0.32 & 0.33 & 0.31 & 0.24 & 0.26 & 0.28 & 0.26 & 0.28 & 0.30 & 0.33 & 1.00 & 0.50 & 0.45 & 0.59 & 0.45 & 0.36 & 0.46 & 0.46 & 0.45 & 0.43 \\
\hline $\begin{array}{l}\text { relationship quality } \\
\text { (intimacy1) }\end{array}$ & 0.12 & 0.18 & 0.15 & 0.10 & 0.10 & 0.13 & 0.10 & 0.17 & 0.17 & 0.17 & 0.50 & 1.00 & 0.39 & 0.44 & 0.28 & 0.27 & 0.29 & 0.31 & 0.30 & 0.23 \\
\hline $\begin{array}{l}\text { relationship quality } \\
\text { (intimacy2) }\end{array}$ & 0.22 & 0.30 & 0.25 & 0.24 & 0.24 & 0.25 & 0.22 & 0.30 & 0.33 & 0.34 & 0.45 & 0.39 & 1.00 & 0.49 & 0.68 & 0.51 & 0.49 & 0.47 & 0.48 & 0.39 \\
\hline $\begin{array}{l}\text { relationship quality (love } \\
\text { and passion) }\end{array}$ & 0.30 & 0.32 & 0.27 & 0.22 & 0.27 & 0.23 & 0.23 & 0.27 & 0.32 & 0.34 & 0.59 & 0.44 & 0.49 & 1.00 & 0.49 & 0.47 & 0.49 & 0.49 & 0.51 & 0.47 \\
\hline $\begin{array}{l}\text { relationship quality } \\
\text { (satisfaction) }\end{array}$ & 0.30 & 0.33 & 0.33 & 0.27 & 0.29 & 0.33 & 0.27 & 0.32 & 0.34 & 0.36 & 0.45 & 0.28 & 0.68 & 0.49 & 1.00 & 0.61 & 0.51 & 0.50 & 0.50 & 0.43 \\
\hline $\begin{array}{l}\text { relationship quality } \\
\text { (trust) }\end{array}$ & 0.36 & 0.30 & 0.35 & 0.37 & 0.40 & 0.39 & 0.34 & 0.29 & 0.35 & 0.40 & 0.36 & 0.27 & 0.51 & 0.47 & 0.61 & 1.00 & 0.52 & 0.52 & 0.52 & 0.49 \\
\hline $\begin{array}{l}\text { customer brand loyalty } \\
\text { (say positive) }\end{array}$ & 0.34 & 0.31 & 0.28 & 0.25 & 0.26 & 0.30 & 0.28 & 0.33 & 0.31 & 0.34 & 0.46 & 0.29 & 0.49 & 0.49 & 0.51 & 0.52 & 1.00 & 0.77 & 0.71 & 0.54 \\
\hline $\begin{array}{l}\text { customer brand loyalty } \\
\text { (recommend) }\end{array}$ & 0.38 & 0.32 & 0.31 & 0.27 & 0.30 & 0.33 & 0.29 & 0.33 & 0.31 & 0.33 & 0.46 & 0.31 & 0.47 & 0.49 & 0.50 & 0.52 & 0.77 & 1.00 & 0.85 & 0.65 \\
\hline $\begin{array}{l}\text { customer brand loyalty } \\
\text { (encourage) }\end{array}$ & 0.37 & 0.35 & 0.31 & 0.27 & 0.28 & 0.30 & 0.28 & 0.35 & 0.30 & 0.33 & 0.45 & 0.30 & 0.48 & 0.51 & 0.50 & 0.52 & 0.71 & 0.85 & 1.00 & 0.69 \\
\hline $\begin{array}{l}\text { customer brand loyalty } \\
\text { (choose) }\end{array}$ & 0.28 & 0.19 & 0.22 & 0.23 & 0.25 & 0.29 & 0.16 & 0.20 & 0.23 & 0.27 & 0.43 & 0.23 & 0.39 & 0.47 & 0.43 & 0.49 & 0.54 & 0.65 & 0.69 & 1.00 \\
\hline
\end{tabular}


All Items Correlation Matrix (Part B)

\begin{tabular}{|c|c|c|c|c|c|c|c|c|c|c|c|c|c|c|c|c|c|c|c|c|}
\hline & 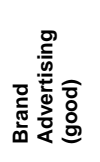 & 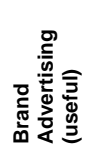 & 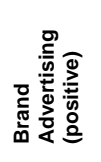 & 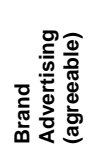 & 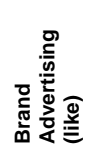 & 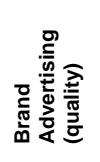 & 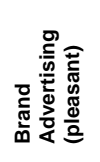 & 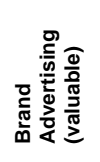 & 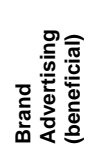 & 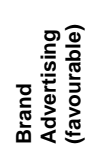 & 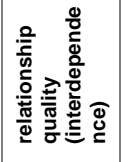 & 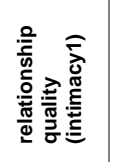 & 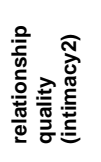 & 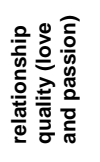 & 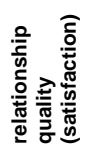 & 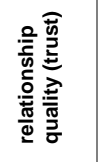 & 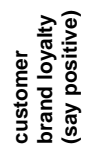 & 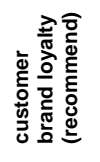 & 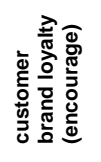 & 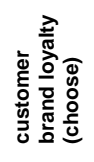 \\
\hline $\begin{array}{l}\text { customer brand loyalty } \\
\text { (do business) }\end{array}$ & 0.16 & 0.10 & 0.13 & 0.17 & 0.12 & 0.19 & 0.10 & 0.10 & 0.19 & 0.20 & 0.35 & 0.30 & 0.29 & 0.27 & 0.34 & 0.33 & 0.44 & 0.48 & 0.46 & 0.47 \\
\hline $\begin{array}{l}\text { relational orientation } \\
\text { (interdependence) }\end{array}$ & 0.13 & 0.19 & 0.13 & 0.16 & 0.16 & 0.19 & 0.16 & 0.24 & 0.19 & 0.18 & 0.36 & 0.35 & 0.27 & 0.36 & 0.20 & 0.20 & 0.27 & 0.23 & 0.22 & 0.10 \\
\hline $\begin{array}{l}\text { relational orientation } \\
\text { (intimacy1) }\end{array}$ & 0.07 & 0.15 & 0.13 & 0.12 & 0.08 & 0.15 & 0.08 & 0.16 & 0.15 & 0.13 & 0.33 & 0.58 & 0.22 & 0.28 & 0.16 & 0.11 & 0.24 & 0.23 & 0.21 & 0.11 \\
\hline $\begin{array}{l}\text { relational orientation } \\
\text { (intimacy2) }\end{array}$ & 0.05 & 0.08 & 0.10 & 0.05 & 0.04 & 0.14 & 0.04 & 0.09 & 0.13 & 0.07 & 0.24 & 0.24 & 0.27 & 0.27 & 0.22 & 0.13 & 0.22 & 0.19 & 0.21 & 0.10 \\
\hline $\begin{array}{l}\text { relational orientation } \\
\text { (love and passion) }\end{array}$ & 0.15 & 0.17 & 0.15 & 0.11 & 0.15 & 0.11 & 0.15 & 0.19 & 0.18 & 0.17 & 0.40 & 0.42 & 0.24 & 0.52 & 0.19 & 0.19 & 0.28 & 0.24 & 0.24 & 0.13 \\
\hline $\begin{array}{l}\text { relational orientation } \\
\text { (satisfaction) }\end{array}$ & 0.06 & 0.11 & 0.11 & 0.10 & 0.09 & 0.16 & 0.09 & 0.18 & 0.15 & 0.14 & 0.27 & 0.36 & 0.25 & 0.29 & 0.24 & 0.13 & 0.27 & 0.25 & 0.25 & 0.08 \\
\hline $\begin{array}{l}\text { relational orientation } \\
\text { (trust) }\end{array}$ & 0.16 & 0.17 & 0.15 & 0.18 & 0.18 & 0.19 & 0.16 & 0.23 & 0.22 & 0.22 & 0.25 & 0.35 & 0.29 & 0.30 & 0.31 & 0.35 & 0.33 & 0.29 & 0.25 & 0.10 \\
\hline $\begin{array}{l}\text { communication with the } \\
\text { brand (face-to-face) }\end{array}$ & 0.34 & 0.30 & 0.38 & 0.29 & 0.30 & 0.32 & 0.29 & 0.26 & 0.27 & 0.26 & 0.35 & 0.33 & 0.38 & 0.36 & 0.43 & 0.37 & 0.40 & 0.38 & 0.40 & 0.30 \\
\hline $\begin{array}{l}\text { communication with the } \\
\text { brand (telephone) }\end{array}$ & 0.29 & 0.25 & 0.26 & 0.17 & 0.23 & 0.25 & 0.20 & 0.24 & 0.24 & 0.27 & 0.39 & 0.29 & 0.36 & 0.34 & 0.39 & 0.33 & 0.32 & 0.34 & 0.34 & 0.31 \\
\hline $\begin{array}{l}\text { communication with the } \\
\text { brand (web site) }\end{array}$ & 0.24 & 0.22 & 0.27 & 0.19 & 0.22 & 0.22 & 0.19 & 0.21 & 0.23 & 0.22 & 0.25 & 0.27 & 0.25 & 0.17 & 0.24 & 0.19 & 0.25 & 0.25 & 0.23 & 0.19 \\
\hline $\begin{array}{l}\text { communication with the } \\
\text { brand (e-mail) }\end{array}$ & 0.24 & 0.26 & 0.22 & 0.14 & 0.16 & 0.15 & 19 & 0.27 & .22 & 0.17 & 0.25 & 0.15 & 0.20 & 0.18 & 0.20 & 0.19 & 0.22 & 0.24 & 0.26 & 0.20 \\
\hline $\begin{array}{l}\text { communication with } \\
\text { consumer communities } \\
\text { (face to face) }\end{array}$ & 0.33 & 30 & 32 & 24 & 31 & .31 & 24 & 0.28 & 32 & 0.33 & .36 & 0.24 & .37 & 0.39 & 0.46 & 0.42 & 0.55 & 0.52 & 0.49 & 0.42 \\
\hline $\begin{array}{l}\text { communication with } \\
\text { consumer communities } \\
\text { (telephone) }\end{array}$ & 0.33 & 34 & 32 & 24 & 29 & .31 & 27 & 0.30 & 32 & 0.30 & .37 & 0.22 & .37 & 0.39 & 0.45 & 0.43 & 0.49 & 0.47 & 0.45 & 0.42 \\
\hline $\begin{array}{l}\text { communication with } \\
\text { consumer communities } \\
\text { (web site) }\end{array}$ & 0.23 & 23 & 21 & 13 & 15 & .17 & 20 & 0.22 & 22 & 0.21 & 0.28 & 0.13 & 0.23 & 0.22 & 0.27 & 0.22 & 0.31 & 0.30 & 0.29 & 0.24 \\
\hline $\begin{array}{l}\text { communication with } \\
\text { consumer communities } \\
\text { (e-mail) }\end{array}$ & 0.21 & 0.20 & 0.19 & 0.08 & 0.07 & 0.07 & 0.18 & 0.19 & 0.12 & 0.11 & 0.21 & 0.09 & 0.19 & 0.20 & 0.23 & 0.21 & 0.20 & 0.19 & 0.21 & 0.19 \\
\hline $\begin{array}{l}\text { Brand Pe } \\
\text { Connecti }\end{array}$ & 0.19 & 0.12 & 0.15 & 0.18 & 0.19 & 0.15 & 0.16 & 0.17 & 0.07 & 0.16 & 0.14 & 0.03 & 0.18 & 0.16 & 0.25 & 0.24 & 0.18 & 0.25 & 0.22 & 0.26 \\
\hline $\begin{array}{l}\text { Brand P } \\
\text { Connect }\end{array}$ & 0.23 & 0.17 & 0.21 & 0.30 & 0.26 & 0.25 & 0.23 & 0.20 & 0.19 & 0.25 & 0.27 & 0.09 & 0.31 & 0.27 & 0.36 & 0.41 & 0.28 & 0.32 & 0.31 & 0.31 \\
\hline $\begin{array}{l}\text { Brand P } \\
\text { Connect }\end{array}$ & 0.07 & 0.06 & 0.06 & 0.03 & 0.06 & 0.05 & 0.04 & 0.04 & 0.10 & 0.07 & 0.13 & -0.03 & 0.16 & 0.09 & 0.21 & 0.15 & 0.11 & 0.18 & 0.16 & 0.16 \\
\hline $\begin{array}{l}\text { Brand Personality } \\
\text { Connection } \\
\text { (sophisticated) }\end{array}$ & 0.03 & 0.05 & -0.01 & 0.05 & 0.04 & 0.01 & 0.03 & 0.02 & 0.01 & 0.01 & 0.01 & -0.01 & 0.14 & 0.06 & 0.15 & 0.14 & 0.06 & 0.10 & 0.05 & 0.08 \\
\hline $\begin{array}{l}\text { Brand Personality } \\
\text { Connection (sincere) }\end{array}$ & 0.22 & 0.18 & 0.21 & 0.21 & 0.23 & 0.19 & 0.20 & 0.19 & 0.19 & 0.24 & 0.24 & 0.06 & 0.34 & 0.31 & 0.35 & 0.40 & 0.29 & 0.35 & 0.35 & 0.33 \\
\hline
\end{tabular}


All Items Correlation Matrix (Part C)

\begin{tabular}{|c|c|c|c|c|c|c|c|c|c|c|c|c|c|c|c|c|c|c|c|c|}
\hline & 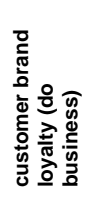 & 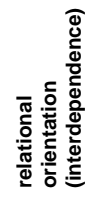 & 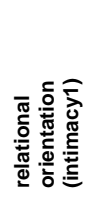 & 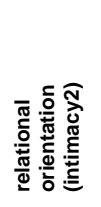 & 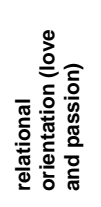 & 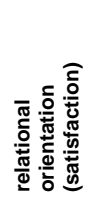 & 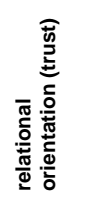 & 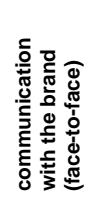 & 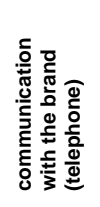 & 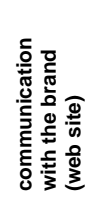 & 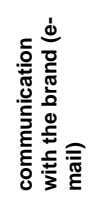 & 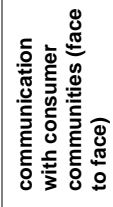 & 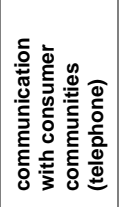 & 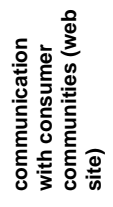 & 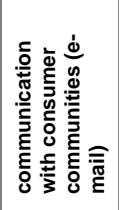 & 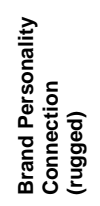 & 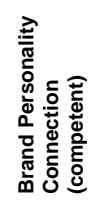 & 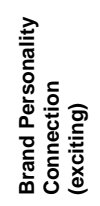 & 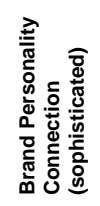 & 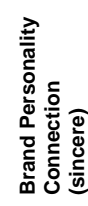 \\
\hline Brand Advertising (good) & 0.16 & 0.13 & 0.07 & 0.05 & 0.15 & 0.06 & 0.16 & 0.34 & 0.29 & 0.24 & 0.24 & 0.33 & 0.33 & 0.23 & 0.21 & 0.19 & 0.23 & 0.07 & 0.03 & 0.22 \\
\hline $\begin{array}{l}\text { Brand Advertising } \\
\text { (useful) }\end{array}$ & 0.10 & 0.19 & 0.15 & 0.08 & 0.17 & 0.11 & 0.17 & 0.30 & 0.25 & 0.22 & 0.26 & 0.30 & 0.34 & 0.23 & 0.20 & 0.12 & 0.17 & 0.06 & 0.05 & 0.18 \\
\hline $\begin{array}{l}\text { Brand Advertising } \\
\text { (positive) }\end{array}$ & 0.13 & 0.13 & 0.13 & 0.10 & 0.15 & 0.11 & 0.15 & 0.38 & 0.26 & 0.27 & 0.22 & 0.32 & 0.32 & 0.21 & 0.19 & 0.15 & 0.21 & 0.06 & -0.01 & 0.21 \\
\hline $\begin{array}{l}\text { Brand Advertising } \\
\text { (agreeable) }\end{array}$ & 0.17 & 0.16 & 0.12 & 0.05 & 0.11 & 0.10 & 0.18 & 0.29 & 0.17 & 0.19 & 0.14 & 0.24 & 0.24 & 0.13 & 0.08 & 0.18 & 0.30 & 0.03 & 0.05 & 0.21 \\
\hline Brand Advertising (like) & 0.12 & 0.16 & 0.08 & 0.04 & 0.15 & 0.09 & 0.18 & 0.30 & 0.23 & 0.22 & 0.16 & 0.31 & 0.29 & 0.15 & 0.07 & 0.19 & 0.26 & 0.06 & 0.04 & 0.23 \\
\hline $\begin{array}{l}\text { Brand Advertising } \\
\text { (quality) }\end{array}$ & 0.19 & 0.19 & 0.15 & 0.14 & 0.11 & 0.16 & 0.19 & 0.32 & 0.25 & 0.22 & 0.15 & 0.31 & 0.31 & 0.17 & 0.07 & 0.15 & 0.25 & 0.05 & 0.01 & 0.19 \\
\hline $\begin{array}{l}\text { Brand Advertising } \\
\text { (pleasant) }\end{array}$ & 0.10 & 0.16 & 0.08 & 0.04 & 0.15 & 0.09 & 0.16 & 0.29 & 0.20 & 0.19 & 0.19 & 0.24 & 0.27 & 0.20 & 0.18 & 0.16 & 0.23 & 0.04 & 0.03 & 0.20 \\
\hline $\begin{array}{l}\text { Brand Advertising } \\
\text { (valuable) }\end{array}$ & 0.10 & 0.24 & 0.16 & 0.09 & 0.19 & 0.18 & 0.23 & 0.26 & 0.24 & 0.21 & 0.27 & 0.28 & 0.30 & 0.22 & 0.19 & 0.17 & 0.20 & 0.04 & 0.02 & 0.19 \\
\hline $\begin{array}{l}\text { Brand Advertising } \\
\text { (beneficial) }\end{array}$ & 0.19 & 0.19 & 0.15 & 0.13 & 0.18 & 0.15 & 0.22 & 0.27 & 0.24 & 0.23 & 0.22 & 0.32 & 0.32 & 0.22 & 0.12 & 0.07 & 0.19 & 0.10 & 0.01 & 0.19 \\
\hline $\begin{array}{l}\text { Brand Advertising } \\
\text { (favourable) }\end{array}$ & 0.20 & 0.18 & 0.13 & 0.07 & 0.17 & 0.14 & 0.22 & 0.26 & 0.27 & 0.22 & 0.17 & 0.33 & 0.30 & 0.21 & 0.11 & 0.16 & 0.25 & 0.07 & 0.01 & 0.24 \\
\hline $\begin{array}{l}\text { relationship quality } \\
\text { (interdependence) }\end{array}$ & 0.35 & 0.36 & 0.33 & 0.24 & 0.40 & 0.27 & 0.25 & 0.35 & 0.39 & 0.25 & 0.25 & 0.36 & 0.37 & 0.28 & 0.21 & 0.14 & 0.27 & 0.13 & 0.01 & 0.24 \\
\hline $\begin{array}{l}\text { relationship quality } \\
\text { (intimacy1) }\end{array}$ & 0.30 & 0.35 & 0.58 & 0.24 & 0.42 & 0.36 & 0.35 & 0.33 & 0.29 & 0.27 & 0.15 & 0.24 & 0.22 & 0.13 & 0.09 & 0.03 & 0.09 & -0.03 & -0.01 & 0.06 \\
\hline $\begin{array}{l}\text { relationship quality } \\
\text { (intimacy2) }\end{array}$ & 0.29 & 0.27 & 0.22 & 0.27 & 0.24 & 0.25 & 0.29 & 0.38 & 0.36 & 0.25 & 0.20 & 0.37 & 0.37 & 0.23 & 0.19 & 0.18 & 0.31 & 0.16 & 0.14 & 0.34 \\
\hline $\begin{array}{l}\text { relationship quality (love } \\
\text { and passion) }\end{array}$ & 0.27 & 0.36 & 0.28 & 0.27 & 0.52 & 0.29 & 0.30 & 0.36 & 0.34 & 0.17 & 0.18 & 0.39 & 0.39 & 0.22 & 0.20 & 0.16 & 0.27 & 0.09 & 0.06 & 0.31 \\
\hline $\begin{array}{l}\text { relationship quality } \\
\text { (satisfaction) }\end{array}$ & 0.34 & 0.20 & 0.16 & 0.22 & 0.19 & 0.24 & 0.31 & 0.43 & 0.39 & 0.24 & 0.20 & 0.46 & 0.45 & 0.27 & 0.23 & 0.25 & 0.36 & 0.21 & 0.15 & 0.35 \\
\hline $\begin{array}{l}\text { relationship quality } \\
\text { (trust) }\end{array}$ & 0.33 & 0.20 & 0.11 & 0.13 & 0.19 & 0.13 & 0.35 & 0.37 & 0.33 & 0.19 & 0.19 & 0.42 & 0.43 & 0.22 & 0.21 & 0.24 & 0.41 & 0.15 & 0.14 & 0.40 \\
\hline $\begin{array}{l}\begin{array}{l}\text { customer brand loyalty } \\
\text { (say positive) }\end{array} \\
\text { (a) }\end{array}$ & 0.44 & 0.27 & 0.24 & 0.22 & 0.28 & 0.27 & 0.33 & 0.40 & 0.32 & 0.25 & 0.22 & 0.55 & 0.49 & 0.31 & 0.20 & 0.18 & 0.28 & 0.11 & 0.06 & 0.29 \\
\hline $\begin{array}{l}\begin{array}{l}\text { customer brand loyalty } \\
\text { (recommend) }\end{array} \\
\text { (a) }\end{array}$ & 0.48 & 0.23 & 0.23 & 0.19 & 0.24 & 0.25 & 0.29 & 0.38 & 0.34 & 0.25 & 0.24 & 0.52 & 0.47 & 0.30 & 0.19 & 0.25 & 0.32 & 0.18 & 0.10 & 0.35 \\
\hline $\begin{array}{l}\text { customer brand loyalty } \\
\text { (encourage) }\end{array}$ & 0.46 & 0.22 & 0.21 & 0.21 & 0.24 & 0.25 & 0.25 & 0.40 & 0.34 & 0.23 & 0.26 & 0.49 & 0.45 & 0.29 & 0.21 & 0.22 & 0.31 & 0.16 & 0.05 & 0.35 \\
\hline $\begin{array}{l}\text { customer brand loyalty } \\
\text { (choose) }\end{array}$ & 0.47 & 0.10 & 0.11 & 0.10 & 0.13 & 0.08 & 0.10 & 0.30 & 0.31 & 0.19 & 0.20 & 0.42 & 0.42 & 0.24 & 0.19 & 0.26 & 0.31 & 0.16 & 0.08 & 0.33 \\
\hline
\end{tabular}


All Items Correlation Matrix (Part D)

\begin{tabular}{|c|c|c|c|c|c|c|c|c|c|c|c|c|c|c|c|c|c|c|c|c|}
\hline & 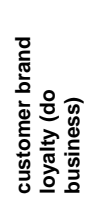 & 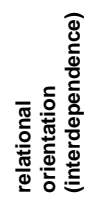 & 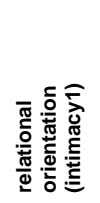 & 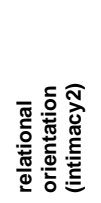 & 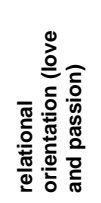 & 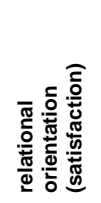 & 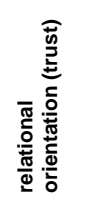 & 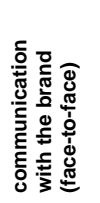 & 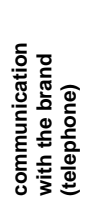 & 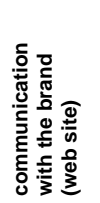 & 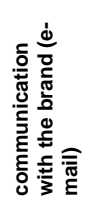 & 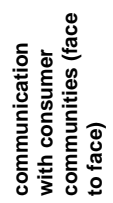 & 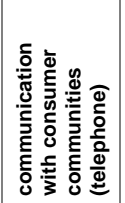 & 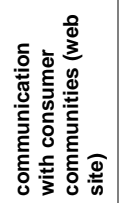 & 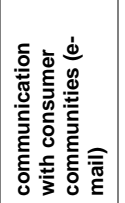 & 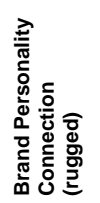 & 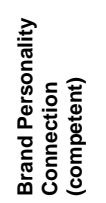 & 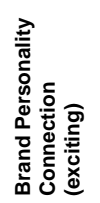 & 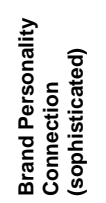 & 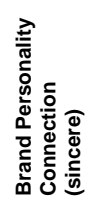 \\
\hline $\begin{array}{l}\text { customer brand loyalty } \\
\text { (do business) }\end{array}$ & 1.00 & 0.11 & 0.23 & 0.10 & 0.13 & 0.21 & 0.19 & 0.36 & 0.26 & 0.34 & 0.18 & 0.30 & 0.30 & 0.21 & 0.11 & 0.12 & 0.20 & 0.11 & 0.05 & 0.20 \\
\hline $\begin{array}{l}\text { relational orientation } \\
\text { (interdependence) }\end{array}$ & 0.11 & 1.00 & 0.55 & 0.49 & 0.61 & 0.62 & 0.58 & 0.21 & 0.20 & 0.16 & 0.15 & 0.23 & 0.20 & 0.14 & 0.05 & 0.01 & 0.11 & -0.02 & -0.11 & 0.08 \\
\hline $\begin{array}{l}\text { relational orientation } \\
\text { (intimacy1) }\end{array}$ & 0.23 & 0.55 & 1.00 & 0.41 & 0.57 & 0.47 & 0.53 & 0.21 & 0.23 & 0.21 & 0.12 & 0.22 & 0.24 & 0.14 & 0.04 & -0.10 & 0.05 & 0.00 & -0.07 & 0.03 \\
\hline $\begin{array}{l}\text { relational orientation } \\
\text { (intimacy2) }\end{array}$ & 0.10 & 0.49 & 0.41 & 1.00 & 0.49 & 0.47 & 0.45 & 0.18 & 0.11 & 0.10 & 0.09 & 0.16 & 0.11 & 0.10 & 0.06 & -0.06 & 0.05 & -0.08 & -0.13 & 0.02 \\
\hline $\begin{array}{l}\text { relational orientation } \\
\text { (Iove and passion) }\end{array}$ & 0.13 & 0.61 & 0.57 & 0.49 & 1.00 & 0.54 & 0.57 & 0.22 & 0.20 & 0.14 & 0.12 & 0.25 & 0.21 & 0.13 & 0.10 & -0.01 & 0.10 & -0.04 & -0.07 & 0.07 \\
\hline $\begin{array}{l}\text { relational orientation } \\
\text { (satisfaction) }\end{array}$ & 0.21 & 0.62 & 0.47 & 0.47 & 0.54 & 1.00 & 0.62 & 0.29 & 0.23 & 0.21 & 0.20 & 0.22 & 0.20 & 0.15 & 0.09 & 0.00 & 0.06 & -0.04 & -0.12 & 0.01 \\
\hline $\begin{array}{l}\text { relational orientation } \\
\text { (trust) }\end{array}$ & 0.19 & 0.58 & 0.53 & 0.45 & 0.57 & 0.62 & 1.00 & 0.23 & 0.22 & 0.23 & 0.11 & 0.30 & 0.25 & 0.18 & .03 & -0.03 & 0.10 & -0.01 & -0.05 & 0.09 \\
\hline $\begin{array}{l}\text { communication with the } \\
\text { brand (face-to-face) }\end{array}$ & 0.36 & 0.21 & 0.21 & 0.18 & 0.22 & 0.29 & 0.23 & 1.00 & 0.50 & 0.39 & 0.27 & 0.38 & 0.39 & 0.23 & 0.24 & 0.18 & 0.23 & 0.09 & 0.06 & 0.21 \\
\hline $\begin{array}{l}\text { communication with the } \\
\text { brand (telephone) }\end{array}$ & 0.26 & 0.20 & 0.23 & 0.11 & 0.20 & 0.23 & 0.22 & 0.50 & 1.00 & 0.34 & 0.30 & 0.32 & 0.41 & 0.26 & 0.26 & 0.10 & 0.19 & 0.09 & 0.03 & 0.23 \\
\hline $\begin{array}{l}\text { communication with the } \\
\text { brand (web site) }\end{array}$ & 0.34 & 0.16 & 0.21 & 0.10 & 0.14 & 0.21 & 0.23 & 0.39 & 0.34 & 1.00 & 0.32 & 0.25 & 0.27 & 0.33 & 0.19 & 0.16 & 0.12 & 0.08 & 0.02 & 0.12 \\
\hline $\begin{array}{l}\text { communication with the } \\
\text { brand (e-mail) }\end{array}$ & 0.18 & 0.15 & 0.12 & 0.09 & 12 & $0 . \angle 0$ & 0.11 & 0.27 & 0.30 & .32 & 1.00 & .24 & 0.31 & 0.35 & 0.40 & 0.07 & 0.19 & 0.05 & 0.08 & 0.16 \\
\hline $\begin{array}{l}\text { communication with } \\
\text { consumer communities } \\
\text { (face to face) }\end{array}$ & 0.30 & 0.23 & 22 & 16 & 25 & 22 & 0.30 & 38 & 0.32 & .25 & 0.24 & .00 & .76 & .44 & .25 & 0.20 & .34 & 0.18 & 0.08 & 0.28 \\
\hline $\begin{array}{l}\text { communication with } \\
\text { consumer communities } \\
\text { (telephone) }\end{array}$ & 0.30 & 0.20 & 24 & 11 & 1 & 20 & 0.25 & 39 & 0.41 & 27 & 0.31 & .76 & .00 & 0.47 & .36 & 0.16 & .31 & 0.17 & 0.06 & 0.27 \\
\hline $\begin{array}{l}\text { communication with } \\
\text { consumer communities } \\
\text { (web site) }\end{array}$ & 0.21 & 0.14 & 14 & 0.10 & .13 & 0.15 & 0.18 & 0.23 & 0.26 & 0.33 & 0.35 & 0.44 & 0.47 & 1.00 & 0.48 & 0.08 & 0.22 & 0.09 & 0.09 & 0.19 \\
\hline $\begin{array}{l}\text { communication with } \\
\text { consumer communities } \\
\text { (e-mail) }\end{array}$ & 0.11 & 0.05 & 0.04 & 0.06 & 0.10 & 0.09 & 0.03 & 0.24 & 0.26 & 0.19 & 0.46 & 0.25 & 0.36 & 0.48 & 1.00 & 0.09 & 0.19 & 0.05 & 0.04 & 0.21 \\
\hline $\begin{array}{l}\text { Brand Personality } \\
\text { Connection (rugged) }\end{array}$ & 0.12 & 0.01 & -0.10 & -0.06 & -0.01 & 0.00 & -0.03 & 0.18 & 0.10 & 0.16 & 0.07 & 0.20 & 0.16 & 0.08 & 0.09 & 1.00 & 0.37 & 0.32 & 0.30 & 0.34 \\
\hline $\begin{array}{l}\text { Brand } \mathrm{F} \\
\text { Connec }\end{array}$ & 0.20 & 0.11 & 0.05 & 0.05 & 0.10 & 0.06 & 0.10 & 0.23 & 0.19 & 0.12 & 0.19 & 0.34 & 0.31 & 0.22 & 0.19 & 0.37 & 1.00 & 0.30 & 0.26 & 0.55 \\
\hline $\begin{array}{l}\text { Brand P } \\
\text { Connec }\end{array}$ & 0.11 & -0.02 & 0.00 & -0.08 & -0.04 & -0.04 & -0.01 & 0.09 & 0.09 & 0.08 & 0.05 & 0.18 & 0.17 & 0.09 & 0.05 & 0.32 & 0.30 & 1.00 & 0.38 & 0.32 \\
\hline $\begin{array}{l}\text { Brand Personality } \\
\text { Connection } \\
\text { (sophisticated) }\end{array}$ & 0.05 & -0.11 & -0.07 & -0.13 & -0.07 & -0.12 & -0.05 & 0.06 & 0.03 & 0.02 & 0.08 & 0.08 & 0.06 & 0.09 & 0.04 & 0.30 & 0.26 & 0.38 & 1.00 & 0.29 \\
\hline $\begin{array}{l}\text { Brand Personality } \\
\text { Connection (sincere) }\end{array}$ & 0.20 & 0.08 & 0.03 & 0.02 & 0.07 & 0.01 & 0.09 & 0.21 & 0.23 & 0.12 & 0.16 & 0.28 & 0.27 & 0.19 & 0.21 & 0.34 & 0.55 & 0.32 & 0.29 & 1.00 \\
\hline
\end{tabular}




\section{Appendix I: Partial Least Square Output}

\section{SmartPLS Cross Loadings}

\begin{tabular}{|c|c|c|c|c|c|c|c|}
\hline$>$ Item was removed. & $\begin{array}{l}\text { Relational } \\
\text { Orientation }\end{array}$ & $\begin{array}{l}\text { Relationship } \\
\text { Quality }\end{array}$ & $\begin{array}{l}\text { Communication } \\
\text { with the Brand }\end{array}$ & $\begin{array}{c}\text { Communication } \\
\text { with Consumer } \\
\text { Communities }\end{array}$ & $\begin{array}{c}\text { Brand } \\
\text { Personality } \\
\text { Connection }\end{array}$ & $\begin{array}{l}\text { Customer Brand } \\
\text { Loyalty }\end{array}$ & Brand Advertising \\
\hline $\begin{array}{l}\text { Customer Brand Loyalty (say } \\
\text { positive) }\end{array}$ & 0.348490 & 0.633757 & 0.425640 & 0.547348 & 0.351529 & 0.851330 & 0.365362 \\
\hline $\begin{array}{l}\text { Customer Brand Loyalty } \\
\text { (recommend) }\end{array}$ & 0.309375 & 0.632893 & 0.427443 & 0.515882 & 0.422006 & 0.921930 & 0.395799 \\
\hline $\begin{array}{l}\text { Customer Brand Loyalty } \\
\text { (encourage) }\end{array}$ & 0.298471 & 0.633214 & 0.453885 & 0.499507 & 0.419267 & 0.911561 & 0.404197 \\
\hline Customer Brand Loyalty (choose) & 0.128248 & 0.569120 & 0.368385 & 0.443504 & 0.409268 & 0.810568 & 0.303809 \\
\hline $\begin{array}{l}\text { Customer Brand Loyalty (do } \\
\text { business) }\end{array}$ & 0.207662 & 0.425083 & 0.376139 & 0.304039 & 0.249460 & 0.646217 & 0.183448 \\
\hline $\begin{array}{l}\text { Communication with the Brand } \\
\text { (face to face) }\end{array}$ & 0.285678 & 0.500054 & 0.852478 & 0.416893 & 0.285345 & 0.441076 & 0.383782 \\
\hline $\begin{array}{l}\text { Communication with the Brand } \\
\text { (telephone) }\end{array}$ & 0.257221 & 0.475300 & 0.793834 & 0.396744 & 0.265714 & 0.386533 & 0.312527 \\
\hline $\begin{array}{l}\text { Communication with the Brand } \\
\text { (web site) }\end{array}$ & 0.229596 & 0.303244 & 0.494721 & 0.300948 & 0.165596 & 0.294509 & 0.255095 \\
\hline $\begin{array}{l}\text { Communication with the Brand (e- } \\
\text { mail) }\end{array}$ & 0.160223 & 0.266716 & 0.611945 & 0.387704 & 0.204831 & 0.262400 & 0.251637 \\
\hline $\begin{array}{l}\text { Communication with Consumer } \\
\text { Communities (face to face) }\end{array}$ & 0.304720 & 0.511734 & 0.414475 & 0.912522 & 0.358381 & 0.552675 & 0.371275 \\
\hline $\begin{array}{l}\text { Communication with Consumer } \\
\text { Communities (telephone) }\end{array}$ & 0.259295 & 0.500672 & 0.473327 & 0.882110 & 0.346437 & 0.520200 & 0.367835 \\
\hline $\begin{array}{l}\text { Communication with Consumer } \\
\text { Communities (web site) }\end{array}$ & 0.177909 & 0.305701 & 0.358608 & 0.581108 & 0.228221 & 0.324916 & 0.234068 \\
\hline $\begin{array}{l}\text { Communication with Consumer } \\
\text { Communities (e-mail) }\end{array}$ & 0.079244 & 0.262276 & 0.404630 & 0.572321 & 0.224771 & 0.219738 & 0.174988 \\
\hline $\begin{array}{l}\text { Brand Personality Connection } \\
\text { (rugged) }\end{array}$ & -0.027148 & 0.252614 & 0.191270 & 0.198835 & 0.538754 & 0.269454 & 0.214645 \\
\hline $\begin{array}{l}\text { Brand Personality Connection } \\
\text { (competent) }\end{array}$ & 0.126421 & 0.416616 & 0.289114 & 0.367614 & 0.881739 & 0.368870 & 0.307275 \\
\hline $\begin{array}{l}\text { Brand Personality Connection } \\
\text { (exciting) }\end{array}$ & -0.036658 & 0.175004 & 0.123019 & 0.185419 & 0.364623 & 0.184562 & 0.079775 \\
\hline $\begin{array}{l}\text { Brand Personality Connection } \\
\text { (sophisticated) }\end{array}$ & -0.118334 & 0.114600 & 0.055147 & 0.082071 & 0.194938 & 0.075750 & 0.020971 \\
\hline $\begin{array}{l}\text { Brand Personality Connection } \\
\text { (sincere) }\end{array}$ & 0.084824 & 0.423910 & 0.284924 & 0.316278 & 0.853421 & 0.398318 & 0.294581 \\
\hline Brand Advertising (favourable) & 0.235871 & 0.428986 & 0.337831 & 0.344926 & 0.244744 & 0.331125 & 0.741354 \\
\hline Brand Advertising (good) & 0.210167 & 0.457314 & 0.332079 & 0.326287 & 0.318518 & 0.365037 & 0.852210 \\
\hline Brand Advertising (useful) & 0.131456 & 0.367326 & 0.383283 & 0.355417 & 0.294260 & 0.368782 & 0.831807 \\
\hline Brand Advertising (positive) & 0.186358 & 0.399723 & 0.371163 & 0.347352 & 0.235540 & 0.331822 & 0.787014 \\
\hline Brand Advertising (agreeable) & 0.154985 & 0.369401 & 0.400168 & 0.338955 & 0.291188 & 0.318750 & 0.832190 \\
\hline Brand Advertising (like) & 0.155187 & 0.336828 & 0.283843 & 0.247978 & 0.323349 & 0.284083 & 0.805978 \\
\hline Brand Advertising (quality) & 0.160246 & 0.362943 & 0.326094 & 0.293089 & 0.315562 & 0.309131 & 0.831822 \\
\hline Brand Advertising (pleasant) & 0.208885 & 0.370629 & 0.336695 & 0.306706 & 0.299763 & 0.347843 & 0.795178 \\
\hline Brand Advertising (valuable) & 0.143464 & 0.325500 & 0.313324 & 0.287038 & 0.276019 & 0.278450 & 0.767598 \\
\hline Brand Advertising (beneficial) & 0.240997 & 0.374384 & 0.345812 & 0.325176 & 0.251928 & 0.326799 & 0.760856 \\
\hline $\begin{array}{l}\text { Relational Orientation } \\
\text { (interdependence) }\end{array}$ & 0.826893 & 0.393820 & 0.252071 & 0.222042 & 0.139962 & 0.230944 & 0.208752 \\
\hline Relational Orientation (intimacy1) & 0.750735 & 0.352036 & 0.245467 & 0.225154 & 0.049040 & 0.239172 & 0.138508 \\
\hline Relational Orientation (intimacy2) & 0.685029 & 0.303358 & 0.181653 & 0.153330 & 0.057995 & 0.204748 & 0.101572 \\
\hline $\begin{array}{l}\text { Relational Orientation (love and } \\
\text { passion) }\end{array}$ & 0.820099 & 0.437991 & 0.243496 & 0.249114 & 0.125889 & 0.255783 & 0.208459 \\
\hline $\begin{array}{l}\text { Relational Orientation } \\
\text { (satisfaction) }\end{array}$ & 0.789291 & 0.343992 & 0.325086 & 0.225836 & 0.077897 & 0.253347 & 0.142920 \\
\hline Relational Orientation (trust) & 0.812365 & 0.422727 & 0.252191 & 0.266181 & 0.132674 & 0.287024 & 0.229401 \\
\hline $\begin{array}{l}\text { Relationship Quality } \\
\text { (interdependence) }\end{array}$ & 0.401332 & 0.743988 & 0.446585 & 0.403086 & 0.327443 & 0.527551 & 0.372311 \\
\hline Relationship Quality (intimacy1) & 0.499128 & 0.604390 & 0.358452 & 0.247799 & 0.107996 & 0.346616 & 0.179628 \\
\hline Relationship Quality (intimacy2) & 0.335243 & 0.793607 & 0.432671 & 0.399195 & 0.381821 & 0.523782 & 0.324308 \\
\hline $\begin{array}{l}\text { Relationship Quality (love and } \\
\text { passion) }\end{array}$ & 0.446161 & 0.785899 & 0.399057 & 0.417949 & 0.354306 & 0.554281 & 0.361873 \\
\hline Relationship Quality (satisfaction) & 0.291195 & 0.802224 & 0.474022 & 0.486742 & 0.426257 & 0.564501 & 0.385313 \\
\hline Relationship Quality (trust) & 0.257068 & 0.739413 & 0.404971 & 0.453408 & 0.485470 & 0.590778 & 0.448398 \\
\hline
\end{tabular}


SmartPLS Inner Model T-Statistic

\begin{tabular}{|c|c|c|c|c|c|c|c|c|}
\hline & 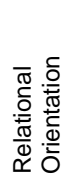 & 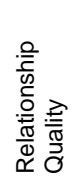 & 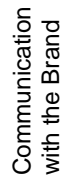 & 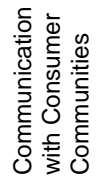 & 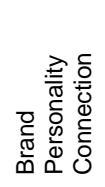 & 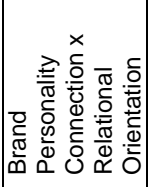 & 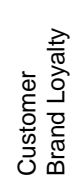 & 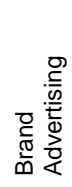 \\
\hline Relational Orientation & & 1.46 & & & & & & \\
\hline Relationship Quality & & & & & & & 13.12 & \\
\hline $\begin{array}{l}\text { Communication with the } \\
\text { Brand }\end{array}$ & & & & & 1.15 & & & \\
\hline $\begin{array}{l}\text { Communication with } \\
\text { Consumer Communities }\end{array}$ & & & & & 2.44 & & & \\
\hline $\begin{array}{l}\text { Brand Personality } \\
\text { Connection }\end{array}$ & & 1.80 & & & & & & \\
\hline $\begin{array}{l}\text { Brand Personality } \\
\text { Connection x Relational } \\
\text { Orientation }\end{array}$ & & 1.99 & & & & & & \\
\hline Customer Brand Loyalty & & & & & & & & \\
\hline Brand Advertising & & & & & & & & \\
\hline
\end{tabular}

\section{SmartPLS Total Effects}

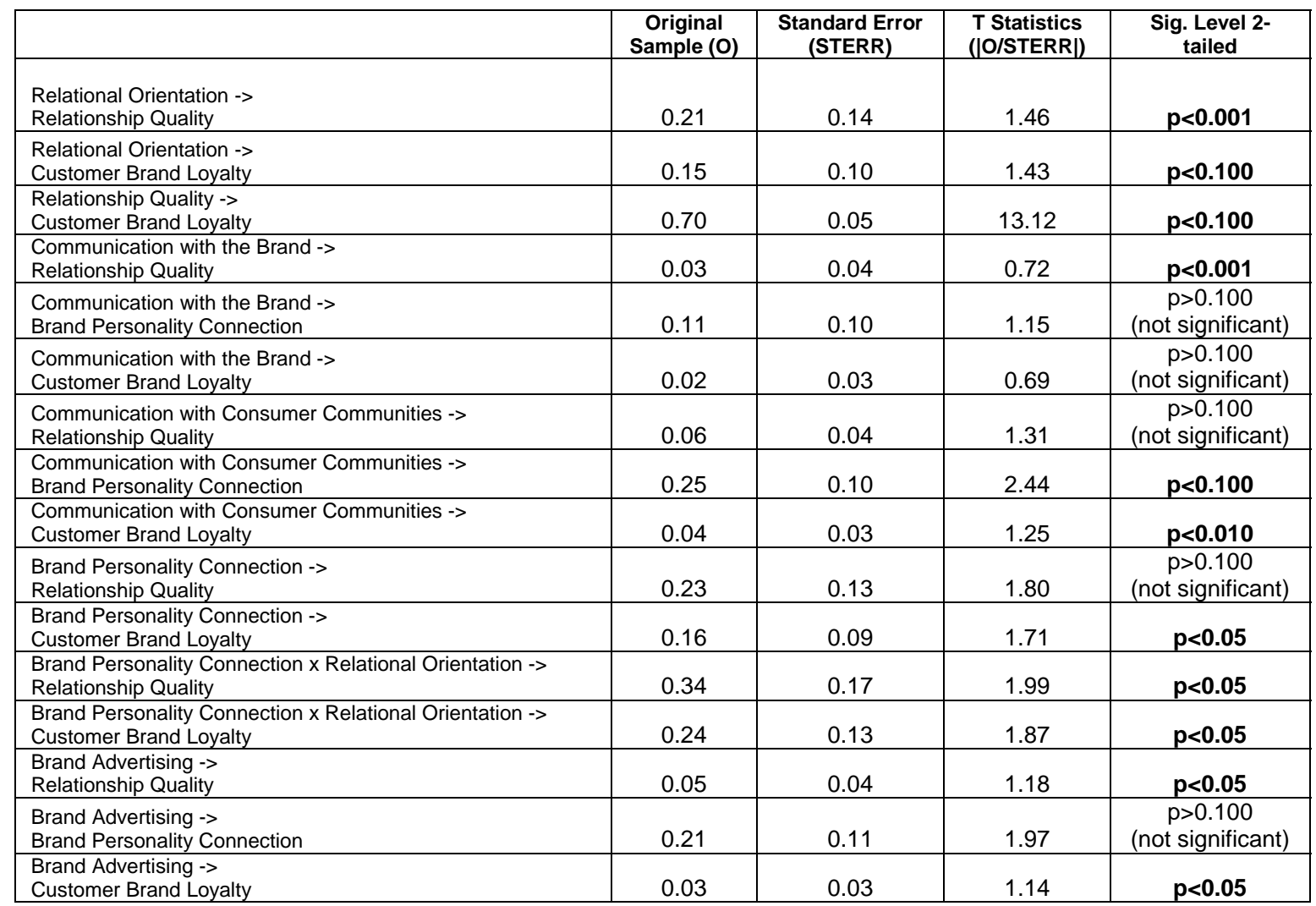




\section{SmartPLS Diagram}
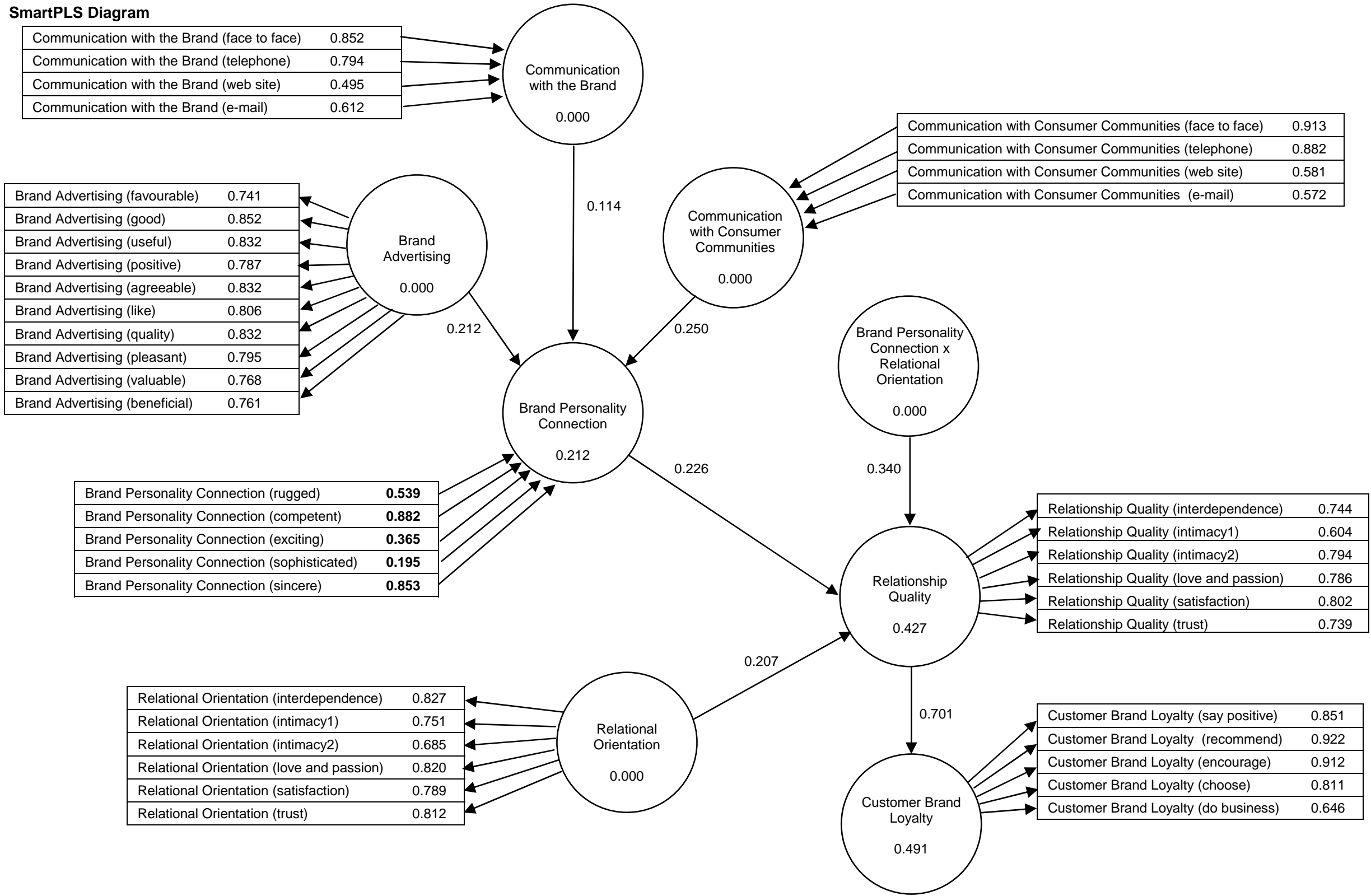


\section{Partial least square GoF calcualtion}

AVE Matrix

\begin{tabular}{|c|c|c|c|c|}
\hline & AVE & R-Square & $\begin{array}{c}\text { Cronbach's } \\
\text { Alpha }\end{array}$ & Communality \\
\hline Relational Orientation & 0.61 & & 0.87 & 0.61 \\
\hline Relationship Quality & 0.56 & 0.43 & 0.84 & 0.56 \\
\hline Communication with the Brand & & & & 0.49 \\
\hline Communication with Consumer Communities & & & & 0.57 \\
\hline Brand Personality Connection & & 0.21 & & 0.39 \\
\hline Brand Personality Connection $\times$ Relational Orientation & 0.55 & & 0.97 & 0.55 \\
\hline Customer Brand Loyalty & 0.70 & 0.49 & 0.89 & 0.70 \\
\hline Brand Advertising & 0.64 & & 0.94 & 0.64 \\
\hline Average & & & & 0.56 \\
\hline
\end{tabular}

\section{R-Square Values}

\begin{tabular}{|l|c|}
\hline & R-Square \\
\hline Relationship Quality & 0.43 \\
\hline Brand Personality Connection & 0.21 \\
\hline Customer Brand Loyalty & 0.49 \\
\hline Average & $\mathbf{0 . 3 7 7}$ \\
\hline
\end{tabular}

\section{Goodness of Fit Calculation}

$$
\begin{aligned}
\text { GoF } & =\sqrt{\text { communality } \overline{\times \mathrm{R}^{2}}} \\
& =\sqrt{0.56 \times 0.377} \\
& =0.459
\end{aligned}
$$


Aaker, J. (1997). Dimensions of Brand Personality. Journal of Marketing Research, 34(3), 347-357.

Aaker, J. (1999). The Malleable Self: The Role of Self-Expression in Persuasion. Journal of Marketing Research, 36(1), 45-58.

Aaker, J., Fournier, S., \& Brasel, S. (2004). When Good Brands Do Bad. Journal of Consumer Research, 31, 1-17.

Achrol, R., \& Kotler, P. (1999). Marketing in the Network Economy. Journal of Marketing, 63(Special issue), 146-164.

Aggarwal, P. (2004). The Effects of Brand Relationship Norms on Consumer Attitudes and Behavior. Journal of Consumer Research, 31(1), 87-102.

Aijo, T. (1996). The Theoretical and Philosophical Underpinnings of Relationship Marketing: Environmental Factors Behind the Changing Marketing Paradigm. European Journal of Marketing, 30(2), 8-21.

Air New Zealand (2005). Air New Zealand Celebrates 65 Years of Flying the Tasman Retrieved 28.05.08, from http://www.airnz.co.nz/aboutus/mediacentre/pressreleases 2005/airnz celebrates 6 5years flying tasman.htm

Air New Zealand (2007). Air New Zealand Monthly Investor Update. 30 July, 35.

Air New Zealand (2008). New Zealand Routes Retrieved 28.05.2008, from http://www.airnewzealand.co.nz/before-you-fly/route-maps/new-zealand-routes.htm

Ajzen, I. (2001). Nature and Operation of Attitudes. Annual Review of Psychology, 52, 27-59.

Algesheimer, R., Dholakia, U., \& Herrmann, A. (2005). The Social Influence of Brand Community: Evidence from European Car Clubs. Journal of Marketing, 69(3), 19-34.

American Marketing Association (2007). Dictionary of Marketing Terms Available from www.marketingpower.com/mg-dictionary.php

Andersen, P. (2001). Relationship Development and Marketing Communication: An Integrative Model. The Journal of Business \& Industrial Marketing, 16(3), 167-183.

Arnott, D., \& Bridgewater, S. (2002). Internet, Interaction and Implications for Marketing. Marketing Intelligence \& Planning, 20(2), 86-96.

Artis, A., Stewart, G., Berry, L., Narus, J., \& Sheth, J. (2001). The Future of Relationship Marketing: A Perspective on Ph.D. Research. Paper presented at the American Marketing Association Conference Proceedings, Chicago.

Ataman, B., \& Ulengin, B. (2003). A Note on the Effect of Brand Image on Sales. The Journal of Product and Brand Management, 12(4), 237-251.

Auckland Airport (2008). Flight Information: International Airlines Retrieved 21.05.08, from http://www.auckland-airport.co.nz/FlightInfo/contact international.php

Bagozzi, R., \& Dholakia, U. (2006). Antecedents and Purchase Consequences of Customer Participation in Small Group Brand Communities. International Journal of Research in Marketing, 23(1), 45-61. 
Bagozzi, R., Yi, Y., \& Phillips, L. (1991). Assessing Construct Validity in Organizational Research. Administrative Science Quarterly, 36(3), 421-459.

Ballantyne, D. (2004). Dialogue and Its Role in the Development of Relationship Specific Knowledge. The Journal of Business \& Industrial Marketing, 19(2), 114-123.

Ballantyne, D. (2006). Three Perspectives on Service Management and Marketing: Rival Logics or Part of a Bigger Picture? The Journal of Services Marketing, 20(1), 73-80.

Barclay, D., \& Smith, J. B. (1997). The Effects of Organizational Differences and Trust on the Effectiveness of Selling Partner Relationships. Journal of Marketing, 61(1), 3-21.

Bardakci, A., \& Whitelock, J. (2003). Mass-Customisation in Marketing: The Consumer Perspective. The Journal of Consumer Marketing, 20(4), 463-480.

Baruch, Y. (1999). Response Rates in Academic Studies: A Comparative Analysis. Human Relations, 52, 421-434.

Batra, R., \& Stayman, D. (1990). The Role of Mood in Advertising Effectiveness. Journal of Consumer Research, 17(2), 203-215.

Baumgartner, H., \& Homburg, C. (1996). Applications of Structural Equation Modeling in Marketing and Consumer Research: A Review. International Journal of Research in Marketing, 13(2), 139-152.

Belch, G., \& Belch, M. (2004). Advertising and Promotion: An Integrated Marketing Communications Perspective (6 ed.): McGraw-Hill//rwin.

Bell, S., Auh, S., \& Smalley, K. (2005). Customer Relationship Dynamics: Service Quality and Customer Loyalty in the Context of Varying Levels of Customer Expertise and Switching Costs. Academy of Marketing Science Journal, 33(2), 169-184.

Berry, L., Shostack, G., \& Upah, G. (1983). Emerging Perspectives on Services Marketing. Chicago: American Marketing Association.

Blattberg, R., \& Deighton, J. (1991). Interactive Marketing: Exploiting the New Age of Addressability. Sloan Management Review, 33(1), 5-14.

Brady, M., Saren, M., \& Tzokas, N. (2002). The Assimilation of It into Marketing Practice. Irish Marketing Review, 15(2), 17-24.

Brodie, R., Glynn, M., \& Little, V. (2006). The Service Brand and the Service-Dominant Logic: Missing Fundamental Premise or the Need for Stronger Theory? Marketing Theory, 6(3), 363-379.

Bucic, T., \& Gudergan, S. (2004). Formative Vs Reflective Measurement Implications for Explaining Innovation in Marketing Partnerships. Paper presented at the ANZMAC.

Bush, V., Rose, G., Gilbert, F., \& Ingram, T. (2001). Managing Culturally Diverse Buyer-Seller Relationships: The Role of Intercultural Disposition and Adaptive Selling in Developing Intercultural Communication Competence. Academy of Marketing Science Journal, 29(4), 391-405.

Buzzell, R., \& Wiersema, F. (1981). Successful Share Building Strategies. Harvard Business Review, 59, 135-144.

Chaplin, L., \& John, D. (2005). The Development of Self-Brand Connections in Children and Adolescents. Journal of Consumer Research, 32(1), 119-129. 
Chapman, R. (1993). Brand Performance Comparatives. The Journal of Product and Brand Management, 2(1), 42-51.

Chaudhuri, A., \& Holbrook, M. (2001). The Chain of Effects from Brand Trust and Brand Affect to Brand Performance: The Role of Brand Loyalty. Journal of Marketing, 65(2), 81-92.

Chin, W. (1995). Partial Least Squares Is to Lisrel as Principal Components Analysis Is to Common Factor Analysis. Technology Studies, 2(2), 315-319.

Chin, W., Marcolin, B., \& Newsted, P. (2003). A Partial Least Squares Latent Variable Modeling Approach for Measuring Interaction Effects: Results from a Monte Carlo Simulation Study and an Electronic-Mail Emotion/Adoption Study. Information System Research, 14(2), 189-217.

Chin, W., Peterson, R., \& Brown, S. (2008). Structural Equation Modelling in Marketing: Some Practical Reminders. Journal of Marketing Theory and Practice, 16(4), 287-299.

Churchill, G. (1979). A Paradigm for Developing Better Measures of Marketing Constructs. Journal of Marketing Research, 16(1), 64-74.

Citrin, A., Sprott, D., Silverman, S., \& Stem Jr, D. (2000). Adoption of Internet Shopping: The Role of Consumer Innovativeness. Industrial Management and Data Systems, 100(7), 294-300.

Cohen, P., Cohen, J., Teresi, J., Marchi, M., \& Velez, C. (1990). Problems in the Measurement of Latent Variables in Structural Equations Causal Models. Applied Psychological Measurement, 14(2), 183-196.

Conrades, G. (1998). The Future of the Internet: Predicting the Unpredictable. Vital Speeches of the Day, 64(12), 377-381.

Cook, C., Heath, F., \& Thompson, R. (2000). A Meta-Analysis of Response Rates in Web-or Internet-Based Surveys. Educational and Psychological Measurement, 60(6), 821836.

Cothrel, J., \& Williams, R. (1999). On-Line Communities: Helping Them Form and Grow. Journal of Knowledge Management, 3(1), 54.

Cova, B., \& Cova, V. (2002). Tribal Marketing: The Tribalisation of Society and Its Impact on the Conduct of Marketing. European Journal of Marketing, 36(5), 595-621.

Coviello, N., Brodie, R., Danaher, P., \& Johnston, W. (2002). How Firms Relate to Their Markets: An Empirical Examination of Contemporary Practices. Journal of Marketing, 66(3), 33-47.

Crosby, L., Evans, K., \& Cowles, D. (1990). Relationship Quality in Services Selling: An Interpersonal Influence Perspective. Journal of Marketing, 54(3), 68-82.

Cullen, R. (2001). Addressing the Digital Divide. Online Information Review, 25(5), 311-321.

Day, G. (1990). Market Driven Strategy: Processes for Creating Value. New York: Free Press.

Day, G. (2000). Managing Market Relationships. Academy of Marketing Science Journal, 28(1), 24-33.

Day, G., \& Montgomery, D. (1999). Charting New Directions for Marketing. Journal of Marketing, 63((Special issue)), 3-13. 
De Leeuw, E., Hox, J., \& Dillman, D. (2008). International Handbook of Survey Methodology: Lawrence Erlbaum Associates.

De Wulf, K., Odekerken-Schroder, G., \& Lacobucci, D. (2001). Investments in Consumer Relationships: A Cross-Country and Cross-Industry Exploration. Journal of Marketing, 65(4), 33-51.

Dekimpe, M., \& Hanssens, D. (1999). Sustained Spending and Persistent Response: A New Look at Long-Term Marketing Profitability. Journal of Marketing Research, 36(4), 397412.

Dempster, A., Laird, N., \& Rubin, D. (1977). Maximum Likelihood from Incomplete Data Via the Em Algorithm. Journal of the Royal Statistical Society, 39(1), 38.

Dholakia, U., Bagozzi, R., \& Pearo, L. (2004). A Social Influence Model of Consumer Participation in Network - and Small-Group-Based Virtual Communities. International Journal of Research in Marketing, 21(3), 241-263.

Diamantopoulos, A. (2005). The C-Oar-Se Procedure for Scale Development in Marketing: A Comment. International Journal of Research in Marketing, 22(1), 1-9.

Diamantopoulos, A., \& Winklhofer, H. (2001). Index Construction with Formative Indicators: An Alternative to Scale Development. Journal of Marketing Research, 38(2), 269-277.

Dick, A., \& Basu, K. (1994). Customer Loyalty: Toward an Integrated Conceptual Framework. Academy of Marketing Science Journal, 22(2), 99-114.

Dillman, D. (1978). Mail and Telephone Surveys: The Total Design Method: John Wiley and Sons.

DiMaggio, P., Hargittai, E., Neuman, W., \& Robinson, J. (2001). Social Implications of the Internet. Annual Review of Sociology, 27, 307-337.

Dolich, I. (1969). Congruence Relationships between Self Images and Product Brands. Journal of Marketing Research, 6(1), 80-85.

Dorsch, M., Swanson, S., \& Kelley, S. (1998). The Role of Relationship Quality in the Stratification of Vendors as Perceived by Customers. Academy of Marketing Science Journal, 26(2), 128-143.

Duncan, T., \& Moriarty, S. (1998). A Communication-Based Marketing Model for Managing Relationships. Journal of Marketing, 62(2), 1-13.

Dutta, A., \& Roy, R. (2003). Anticipating Internet Diffusion. Communications of the ACM, 46(2), 66-71.

Dwyer, R., \& Oh, S. (1987). Output Sector Munificence Effects on the Internal Political Economy of Marketing Channels. Journal of Marketing Research, 24(4), 347-359.

Dwyer, R., Schurr, P., \& Oh, S. (1987). Developing Buyer-Seller Relationships. Journal of Marketing, 51(2), 11-28.

Eastman, J., \& Iyer, R. (2004). The Elderly's Uses and Attitudes Towards the Internet. The Journal of Consumer Marketing, 21(2), 208-220.

Elections New Zealand (2007). Enrolling - Frequently Asked Questions Retrieved 26.09.07, from www.elections.org.nz/enrolment/enrolling detailed faq.html

Elections New Zealand (2007). New Zealand's Electoral Agencies Retrieved 03.10.07, from www.elections.org.nz/sitehelp/about contact main.html\#Electoral Enrolment Centre 
Esposito Vinzi, V., Chin, W., Henseler, J., \& Wang, H. (2008). Handbook of Partial Least Squares: Concepts, Methods and Applications in Marketing and Related Fields: Springer.

Eysenck, H., \& Rachman, S. (1965). The Causes and Cures of Neurosis: An Introduction to Modern Behaviour Therapy Based on Learning and the Principles of Conditioning. San Diego: Knapp.

Faircloth, J., Capella, L., \& Alford, B. (2001). The Effect of Brand Attitude and Brand Image on Brand Equity. Journal of Marketing Theory and Practice, 9(3), 61-76.

Fisher, R. (1993). Social Desirability Bias and the Validity of Indirect Questioning. Journal of Consumer Research, 20(2), 303-315.

Fisher, R., Maltz, E., \& Jaworski, B. (1997). Enhancing Communication between Marketing and Engineering: The Moderating Role of Relative Functional Identification. Journal of Marketing, 61(3), 54-71.

Fornell, C., \& Bookstein, F. (1982). Two Structural Equation Models: Lisrel and Pls Applied to Consumer Exit-Voice Theory. Journal of Marketing Research, 19(4), 440-453.

Fournier, S. (1998). Consumers and Their Brands: Developing Relationship Theory in Consumer Research. Journal of Consumer Research, 24(4), 343-374.

Fox, M. (2009). Cadbury Stops Using Palm Oil in Chocolate Retrieved 23.04.10, from www.stuff.co.nz/national/2758975/Cadbury-stops-using-palm-oil-in-chocolate

Garbarino, E., \& Johnson, M. (1999). The Different Roles of Satisfaction, Trust, and Commitment in Customer Relationships. Journal of Marketing, 63(2), 70-88.

Gerbing, D., \& Anderson, J. (1988). An Updated Paradigm for Scale Development Incorporating Unidimensionality and Its Assessment. Journal of Marketing Research, 25(2), 186-194.

Gilbert, D., Powell-Perry, J., \& Widijoso, S. (1999). Approaches by Hotels to Use the Internet as a Relationship Marketing Tool. Journal of Marketing Practice, 5(1), 21-38.

Goldsmith, R. (2001). Using the Domain Specific Innovativeness Scale to Identify Innovative Internet Consumers. Internet Research: Electronic Networking Applications and Policy, 11(2), 149-158.

Goldsmith, R., d'Hauteville, F., \& Flynn, L. (1998). Theory and Measurement of Consumer Innovativeness: A Transnational Evaluation. European Journal of Marketing, 32(3), 340-353.

Goldsmith, R., Flynn, L., \& Goldsmith, E. (2003). Innovative Consumers and Market Mavens. Journal of Marketing Theory and Practice, 11(4), 54-66.

Graeff, T. (1996). Using Promotional Messages to Manage the Effects of Brand and SelfImage on Brand Evaluations. The Journal of Consumer Marketing, 13(3), 4-18.

Gravetter, F., \& Wallnau, L. (2000). Statistics for the Behavioural Sciences (5 ed.). Belmont, CA: Wadsworth.

Green, P., Wind, Y., \& Claycamp, H. (1975). Brand-Features Congruence Mapping. Journal of Marketing Research, 12(3), 306-314.

Gronroos, C. (1980). Designing a Long Range Marketing Strategy for Services. Long Range Planning, 13(2), 36-42. 
Gronroos, C. (1983). Strategic Management and Marketing in the Service Sector. Cambridge: Marketing Science Institute.

Gronroos, C. (1994). From Marketing Mix to Relationship Marketing: Towards a Paradigm Shift in Marketing. Decision Management, 32(2), 4-32.

Gronroos, C. (2004). The Relationship Marketing Process: Communication, Interaction, Dialogue, and Value. The Journal of Business \& Industrial Marketing, 19(2), 99-113.

Grubb, E., \& Hupp, G. (1968). Perception of Self, Generalized Stereotypes, and Brand Selection. Journal of Marketing Research, 5(1), 58-64.

Gruen, T., Summers, J., \& Acito, F. (2000). Relationship Marketing Activities, Commitment, and Membership Behaviours in Professional Associations. Journal of Marketing, 64(3), 34-50.

Gummesson, E. (1983, April). A New Concept of Marketing. Paper presented at the Proceedings of the European Marketing Academy (EMAC), Institut d'Etudes Commerciales de Grenoble, France.

Gummesson, E. (1987). The New Marketing: Developing Long-Term Interactive Relationships. Long Range Planning, 20(4), 10-21.

Gummesson, E. (1994). Making Relationship Marketing Operational. International Journal of Service Industry Management, 5(5), 5-20.

Gummesson, E. (1996). Relationship Marketing and Imaginary Organisations: A Synthesis. European Journal of Marketing, 30(2), 31-44.

Gummesson, E. (1997). Relationship Marketing as a Paradigm Shift: Some Conclusions from the 30r Approach. Management Decision, 35(4), 267-272.

Gundlach, G., Achrol, R., \& Mentzer, J. (1995). The Structure of Commitment in Exchange. Journal of Marketing, 59(1), 78-93.

Gupta, S., \& Zeithaml, V. (2006). Customer Metrics and Their Impact on Financial Performance. Marketing Science, 25(6), 718-742.

Hair, J., Bush, R., \& Ortinau, D. (2000). Marketing Research: A Practical Approach for the New Millennium: McGraw-Hill.

Hakansson, H. (1982). International Marketing and Purchasing of Industrial Goods. New York: Wiley.

Hakansson, H., \& Snehota, I. (1995). Developing Relationships in Business Networks. London: Routledge.

Hammond, K., Pluim, D., \& Eynde, K. (1995). Interactive Mass Media a Review of Evidence and Expert Opinion from the USA and Uk. working paper No. 95-801, Centre for Marketing, London Business School.

Hannemyr, G. (2003). The Internet as Hyperbole: A Critical Examination of Adoption Rules. Information Society, 19(2), 111-121.

Harker, M. (1999). Relationship Marketing Defined? An Examination of Current Relationship Marketing Definitions. Marketing Intelligence \& Planning, 17(1), 13-20.

Hirschman, E. (1980). Innovativeness, Novelty Seeking, and Consumer Creativity. Journal of Consumer Research, 7(3), 283-296. 
Hoey, C. (1998). Maximising the Effectiveness of Web-Based Marketing Communications. Marketing Intelligence \& Planning, 16(1), 31-37.

Hoffman, D., Kalsbeek, W., \& Novak, T. (1996). Internet and Web Use in the U.S. Communications of the ACM, 39(12), 36-47.

Hoffman, D., \& Novak, T. (1996). Marketing in Hypermedia Computer-Mediated Environments: Conceptual Foundations. Journal of Marketing, 60(3), 50-69.

Hoffman, D., Novak, T., \& Venkatesh, A. (2004). Has the Internet Become Indispensable? Communications of the ACM, 47(7), 37-42.

Horne, D. A., \& Horne, D. R. (2002). Database Marketing: When Does Good Practice Become an Invasion of Privacy? Paper presented at the American Marketing Association, Conference Proceedings, Chicago.

Hulbert, J., \& Capon, N. (1972). Interpersonal Communication in Marketing: An Overview. Journal of Marketing Research, 9(1), 27-35.

Hulland, J. (1999). Use of Partial Least Squares (PIs) in Strategic Management Research: A Review of Four Recent Studies. Strategic Management Journal, 20(2), 195-203.

Hulland, J., Chow, Y., \& Lam, S. (1996). Use of Causal Models in Marketing Research: A Review. International Journal of Research in Marketing, 13(2), 181-198.

Hunt, S., Sparkman, R., \& Wilcox, J. (1982). The Pretest in Survey Research: Issues and Preliminary Findings. Journal of Marketing Research, 19(2), 269-274.

Im, S., Bayus, B., \& Mason, C. (2003). An Empirical Study of Innate Consumer Innovativeness, Personal Characteristics, and New-Product Adoption Behaviour. Academy of Marketing Science Journal, 31(1), 61-74.

Interactive Advertising Bureau New Zealand (2010). New Zealand Online Advertising Spend Experiences Healthy Growth in Q1 2010 Retrieved 16.10.2010, 2010, from www.iab.org.nz/news/item/new zealand online advertising spend experiences hea thy growth in q1 2010

Internet World Stats (2006). Internet Usage Statistics Retrieved 03.02.06, 2006, from www.internetworldstats.com/stats.htm

Iyer, R., \& Eastman, J. (2006). The Elderly and Their Attitudes toward the Internet: The Impact on Internet Use, Purchase, and Comparison Shopping. Journal of Marketing Theory and Practice, 14(1), 57-68.

Jackson, C. (2001). The Origins of the Internet. The World \& I, 16(10), 36.

Jacoby, J., Chestnut, R., \& Fisher, W. (1978). A Behavioral Process Approach to Information Acquisition in Nondurable Purchasing. Journal of Marketing Research, 15(4), 532-545.

Jevons, C., Gabbott, M., \& de Chernatony, L. (2005). Customer and Brand Manager Perspectives on Brand Relationships: A Conceptual Framework. The Journal of Product and Brand Management, 14(4), 300-310.

Kardes, F. (1986). Effects of Initial Product Judgments on Subsequent Memory-Based Judgments. Journal of Consumer Research, 13(1), 1-11.

Katsanis, L. (2006). An Assessment of Professional Training for Product Managers in the Pharmaceutical Industry. Journal of Product and Brand Management, 15(5), 324-330. 
Katz, J., \& Aspden, P. (1997). Motives, Hurdles, and Dropouts. Communications of the ACM, 40(4), 97-103.

Katz, J., Rice, R., \& Aspden, P. (2001). The Internet, 1995-2000: Access, Civic Involvement, and Social Interaction. The American Behavioral Scientist, 45(3), 405-419.

Keller, K. (1993). Conceptualizing, Measuring, and Managing Customer-Based Brand Equity. Journal of Marketing, 57(1), 1-22.

Keller, K. (1998). Strategic Brand Management. Upper Saddle River, New Jersey: Prentice Hall.

Keller, K., \& Lehmann, D. (2006). Brands and Branding: Research Findings and Future Priorities. Marketing Science, 25(6), 740-759.

Kerlinger, F. (1986). Foundations of Behavioural Research (3 ed.). New York: Holt, Rinehart \& Winston.

Kiani, G. (1998). Marketing Opportunities in the Digital World. Internet Research, 8(2), 185194.

Kivetz, R., \& Simonson, I. (2002). Earning the Right to Indulge: Effort as a Determinant of Customer Preferences toward Frequency Program Rewards. Journal of Marketing Research, 39(2), 155-170.

Kleine, S., Kleine, R., \& Allen, C. (1995). How Is a Possession "Me" Or "Not Me"? Characterising Types and an Antecedent of Material Possession Attachment. Journal of Consumer Research, 22(3), 327-343.

Koku, E., Nazer, N., \& Wellman, B. (2001). Netting Scholars: Online and Offline. The American Behavioral Scientist, 44(10), 1750-1772.

Kotler, P. (1992). Marketing's New Paradigm: What's Really Happening out There? Planning Review, 20(5), 50-52.

Kressmann, F., Sirgy, M. J., Herrmann, A., Huber, F., Huber, S., \& Lee, D. (2006). Direct and Indirect Effects of Self-Image Congruence on Brand Loyalty. Journal of Business Research, 59(9), 955-964.

Lastovicka, J. (1982). On the Validation of Lifestyle Traits: A Review and Illustration. Journal of Marketing Research, 19(1), 126-138.

Leahy, K. (2000). Multicollinearity: When the Solution Is the Problem. In O. Parr Rud (Ed.), Data Mining Cookbook. New York: Wiley.

Leone, R., Rao, V., Keller, K., Luo, A., McAlister, L., \& Srivastava, R. (2006). Linking Brand Equity to Customer Equity. Journal of Service Research, 9(2), 125-138.

Li, Z., \& Dant, R. (1997). An Exploratory Study of Exclusive Dealing in Channel Relationships. Academy of Marketing Science Journal, 25(3), 201-213.

Liljander, V., \& Roos, I. (2002). Customer-Relationship Levels: From Spurious to True Relationships. The Journal of Services Marketing, 16(7), 593-614.

Liljander, V., \& Strandvik, T. (1997). Emotions in Service Satisfaction. International Journal of Service Industry Management, 8(2), 148-169.

Maclaran, P., \& Catterall, M. (2002). Researching the Social Web: Marketing Information from Virtual Communities. Marketing Intelligence \& Planning, 20(6), 319-326. 
Malhotra, N. (1981). A Scale to Measure Self-Concepts, Person Concepts, and Product Concepts. Journal of Marketing Research, 18(4), 456-464.

Malhotra, N. (1999). Marketing Research: An Applied Orientation (3 ed.): Prentice-Hall.

Marketing Science Institute (2007). Research Priorities: A Guide to Msi Research Programs and Procedures, 2006-2008 Available from www.msi.org

McAlexander, J., Schouten, J., \& Koening, H. (2002). Building Brand Community. Journal of Marketing, 66(1), 38-54.

McGoon, C. (1999). Cutting-Edge Companies Use Integrated Marketing Communication. Communication World, 16(1), 15-19.

McKee, D., Varadarajan, R., \& Pride, W. (1989). Strategic Adaptability and Firm Performance: A Market-Contingent Perspective. Journal of Marketing, 53(3), 21-35.

McKeever, S. (2003). Understanding Web Content Management Systems: Evolution, Lifecycle and Market. Industrial Management and Data Systems, 103(8), 686-692.

McKenna, R. (1992). Relationship Marketing. Small Business Reports, 17(5), 68-72.

McQuitty, S. (1999). Recent Issues in Marketing Scale Testing and Development Using Structural Equations Models. Paper presented at the American Marketing Association, Chicago.

McWilliam, G. (2000). Building Stronger Brands through Online Communities. Sloan Management Review, 41(3), 43-54.

Midgley, D., \& Dowling, G. (1978). Innovativeness: The Concept and Its Measurement. Journal of Consumer Research, 4(4), 229-243.

Mischel, W. (1986). Introduction to Personality: A New Look (4 ed.). New York: Holt, Rinehart, and Winston.

Mohr, J., Fisher, R., \& Nevin, J. (1996). Collaborative Communication in Interfirm Relationships: Moderating Effects of Integration and Control. Journal of Marketing, 60(3), 103-126.

Mohr, J., \& Nevin, J. (1990). Communication Strategies in Marketing Channels: A Theoretical Perspective. Journal of Marketing, 54(4), 36-52.

Moorman, C., Deshpande, R., \& Zaltman, G. (1993). Factors Affecting Trust in Market Research Relationships. Journal of Marketing, 57(1), 81-102.

Morgan, R., \& Hunt, S. (1994). The Commitment-Trust Theory of Relationship Marketing. Journal of Marketing, 58(3), 20-39.

Mossberger, K., Tolbert, C., \& Stansbury, M. (2003). Virtual Inequality: Beyond the Digital Divide. Washington, DC: Georgetown University Press.

Mowen, J., Christia, J., \& Spears, N. (1998). Consumer Innovativeness: A General Consumer Trait or a Product Category Specific Trait. Paper presented at the American Marketing Association Conference Proceedings, Chicago.

Muniz, A., \& O'Guinn, T. (2001). Brand Community. Journal of Consumer Research, 27(4), 412-433.

Narver, J., \& Slater, S. (1990). The Effect of a Market Orientation on Business Profitability. Journal of Marketing, 54(4), 20-35. 
Negroponte, N. (1995). Being Digital. New York: Alfred A. Knopf.

New Zealand Parliament (2005). Electorate Profiles Retrieved 26.09.07, from www.parliament.nz/en-NZ/PubRes/Research/Electorates/Default.htm?ps=0

Newell, S., Goldsmith, R., \& Banzhaf, E. (1998). The Effect of Misleading Environmental Claims on Consumer Perceptions of Advertisements. Journal of Marketing Theory and Practice, 6(2), 48-61.

Ngai, E. (2003). Internet Marketing Research (1987-2000): A Literature Review and Classification. European Journal of Marketing, 37(1), 24-50.

Nunnally, J. (1978). Psychometric Theory. New York: McGraw-Hill.

O'Leary, C., Rao, S., \& Perry, C. (2004). Improving Customer Relationship Management through Database/Internet Marketing: A Theory-Building Action Research Project. European Journal of Marketing, 38(3), 338-354.

O'Malley, L., \& Tynan, C. (2000). Relationship Marketing in Consumer Markets: Rhetoric or Reality? European Journal of Marketing, 34(7), 797-815.

Oliver, R. (1999). Whence Consumer Loyalty? Journal of Marketing, 63((Special issue)), 3344.

Onkvisit, S., \& Shaw, J. (1987). Self-Concept and Image Congruence: Some Research and Managerial Implications. Journal of Consumer Marketing, 4(1), 13-24.

Onkvisit, S., \& Shaw, J. (1994). Consumer Behavior: Strategy and Analysis. New York: Macmillan College Publishing.

Pallab, P. (1996). Marketing on the Internet. The Journal of Consumer Marketing, 13(4), 2737.

Pallant, J. (2001). Spss Survival Manual: A Step by Step Guide to Data Analysis Using Spss: Allen and Unwin.

Palmer, R., Lindgreen, A., \& Vanhamme, J. (2005). Relationship Marketing: Schools of Thought and Future Research Directions. Marketing Intelligence \& Planning, 23(2), 313-330.

Patterson, M., \& O'Malley, L. (2006). Brands, Consumers, and Relationships: A Review. Irish Marketing Review, 18(1), 10-20.

Pels, J., Coviello, N., \& Brodie, R. (2000). Integrating Transactional and Relational Marketing Exchange: A Pluralistic Perspective. Journal of Marketing Theory and Practice, 8(3), 11-20.

Peter, J. (1979). Reliability: A Review of Psychometric Basics and Recent Marketing Practices. Journal of Marketing Research, 16(1), 6-18.

Peter, J. (1981). Construct Validity: A Review of Basic Issues and Marketing Practices. Journal of Marketing Research, 18(2), 133-146.

Peterson, R., Balasubramanian, S., \& Bronnenberg, B. (1997). Exploring the Implications of the Internet for Consumer Marketing. Academy of Marketing Science Journal, 25(4), 329-347. 
Petty, R., Cacioppo, J., \& Schumann, D. (1983). Central and Peripheral Routes to Advertising Effectiveness: The Moderating Role of Involvement. Journal of Consumer Research, 10(2), 135-147.

Plummer, J. (1974). The Concept and Application of Life Style Segmentation. Journal of Marketing, 38(1), 33-38.

Prahalad, C., \& Ramaswamy, V. (2004). Co-Creation Experiences: The Next Practice in Value Creation. Journal of Interactive Marketing, 18(3), 5-14.

Prieger, J. (2003). The Supply Side of the Digital Divide: Is There Equal Availability in the Broadband Internet Access Market? Economic Inquiry, 41(2), 346-364.

Qantas Airlines (2008). Qantas Facts Retrieved 21.05.08, from http://www.qantas.com.au/infodetail/about/FactFiles.pdf

Rao, S., \& Perry, C. (2002). Thinking About Relationship Marketing: Where Are We Now? The Journal of Business \& Industrial Marketing, 17(7), 598-614.

Ravald, A., \& Gronroos, C. (1996). The Value Concept and Relationship Marketing. European Journal of Marketing, 30(2), 19-30.

Ringle, C. M., Wende, S., \& Will, A. (2005). Smartpls 2.0 (M3) Beta. Hamburg.

Roberts, M. (2003). Internet Marketing: Integrating Online and Offline Strategies. New York: McGraw-Hill Irwin.

Rogers, E. (1983). Diffusion of Innovations. New York: The Free Press.

Rogers, E. (2003). Diffusion of Innovations (5 ed.). New York: The Free Press.

Rossiter, J. (2002). The C-Oar-Se Procedure for Scale Development in Marketing. International Journal of Research in Marketing, 19(4), 305-335.

Rowley, J. (2001). Remodelling Marketing Communications in an Internet Environment. Internet Research, 11(3), 203-212.

Russell, C. (1998). The Haves and the Want-Nots. American Demographics, 20(4), 10-12.

Schultz, D. (1999). New Media, Old Problem: Keeping Marcom Integrated. Marketing News, 33(7), 11-13.

Shank, M., \& Langmeyer, L. (1994). Does Personality Influence Brand Image? The Journal of Psychology, 128(2), 157-165.

Sharma, S., Durvasula, S., \& Dillon, W. (1989). Some Results on the Behaviour of Alternate Covariance Structure Estimation Procedures in the Presence of Non-Normal Data. Journal of Marketing Research, 26(2), 214-221.

Sheeran, G. (2007, 26 August). Pacific Blue Nose to Nose with Air Nz. Sunday Star Times, from http://www.stuff.co.nz/sundaystartimes/4178268a22981.html

Sheth, J., \& Parvatiyar, A. (1995). The Evolution of Relationship Marketing. International Business Review, 4(4), 397-418.

Sheth, J., \& Parvatiyar, A. (1995). Relationship Marketing in Consumer Markets: Antecedents and Consequences. Academy of Marketing Science Journal, 23(4), 255-271.

Shih, C. (1998). Conceptualizing Consumer Experiences in Cyberspace. European Journal of Marketing, 32(7), 655-663. 
Singh, J. (1993). Boundary Role Ambiguity: Facts, Determinants, and Impacts. Journal of Marketing, 57(2), 11-32.

Sirdeshmukh, D., Singh, J., \& Sabol, B. (2002). Consumer Trust, Value, and Loyalty in Relational Exchanges. Journal of Marketing, 66(1), 15-38.

Sirgy, M. (1982). Self-Concept in Consumer Behavior: A Critical Review. Journal of Consumer Research, 9(3), 287-301.

Sirgy, M., Grewal, D., Mangleburg, T., Park, J., Chon, K., Claiborne, C., Johar, J., \& Berkman, H. (1997). Assessing the Predictive Validity of Two Methods of Measuring Self-Image Congruence. Academy of Marketing Science Journal, 25(3), 229-241.

Sirgy, M. J., Grewal, D., Mangleburg, T., Park, J., Chon, K., Claiborne, C., Johar, J., \& Berkman, H. (1997). Assessing the Predictive Validity of Two Methods of Measuring Self-Image Congruence. Academy of Marketing Science Journal, 25(3).

Srirojanant, S., \& Thirkell, P. (1998). Relationship Marketing and Its Synergy with Web-Based Technologies. Journal of Market Focused Management, 3(1), 23-46.

Statistics New Zealand (2004). Access to Computers and the Internet Retrieved 06.12.05, 2005, from www.stats.govt.nz/products-and-services/nz-in-the-oecd/accesscomputers-internet.htm

Statistics New Zealand (2004). The Digital Divide Retrieved 06.12.05, 2005, from www.stats.govt.nz/analytical-reports/digital-divide/default.htm

Statistics New Zealand (2006). Age (Single Years) for the Census Usually Resident Population Count 2006 Retrieved 08.10.2008, from www.stats.govt.nz/NR/rdonlyres/FA494C9E-303E-4101-B01B9FD2067427AD/0/03age.xls

Statistics New Zealand (2006). Census Usually Resident Population Count 2006 Retrieved 18.09.07, from www.stats.govt.nz/NR/rdonlyres/FA494C9E-303E-4101-B01B9FD2067427AD/0/03age.xls

Statistics New Zealand (2006). Regional Council by Sex and Age Group for the Census Usually Resident Population Count 2006 Retrieved 08.10.2008, from www.stats.govt.nz/NR/rdonlyres/19D6A4B9-7D98-4AF9-970D5BBD139794CA/O/RegionalSummaryTablesRegionalCouncil.xls

Statistics New Zealand (2006). Sex for the Census Usually Resident Population Count 2006 Retrieved 08.10.2008, from www.stats.govt.nz/NR/rdonlyres/BD5F19B2-09B8-462CAE33-9938B5F12D39/0/34sex.xls

Statistics New Zealand (2006). Total Personal Income for the Census Usually Resident Population Count Aged 15 Years and over 2006 Retrieved 08.10.2008, from http://www.stats.govt.nz/NR/rdonlyres/19D6A4B9-7D98-4AF9-970D5BBD139794CA/O/RegionalSummaryTablesRegionalCouncil.xls

Statistics New Zealand (2007). Media Release: Housing Dominates Household Spending Retrieved 18.10.09, from http://www.stats.govt.nz/ /media/statistics/browse\%20for\%20stats/householdeconom icsurvey/mryejun07/householdeconomicsurveyyejun07mr.aspx

Statistics New Zealand (2008). New Zealand Income Statistics June 2008 Quarter Retrieved 18.10.09, from http://www.stats.govt.nz/ /media/statistics/browse\%20for\%20stats/nzincomesurvey/h otpjun08atr/nzincomesurveyjun08qtrhotprevised.aspx 
Statistics New Zealand (2009). Domestic and International Air Transport in the C.P.I. Retrieved 18.10.09, from

http://www.stats.census.govt.nz/Publications/Prices/domestic-intl-air-transport-in-theCPI.aspx

Statistics New Zealand (2010). Household Use of Information and Communication Technology: 2009 Retrieved 17.10, 2010, from

www.stats.govt.nz/browse for stats/people and communities/Households/Househol dUseoflCT HOTP2009.aspx

Statistics New Zealand (2010). Household Use of Information and Communication Technology: 2009 - Additional Tables Retrieved 16.10, 2010, from www.stats.govt.nz/browse for stats/industry sectors/information technology and C ommunications/hhold-use-of-ict/household-ict-2009-tables.aspx

Stelmack, R. (1981). The Psychophysiology of Extraversion and Neuroticism. In H. Eysenck (Ed.), A Model for Personality. Berlin: Springer-Verlag.

Stern, B. (2006). What Does Brand Mean? Historical-Analysis Method and Construct Definition. Academy of Marketing Science Journal, 34(2), 216-224.

Stewart, D. (1981). The Application and Misapplication of Factor Analysis in Marketing Research. Journal of Marketing Research, 18(1), 51-62.

Stewart, D., \& Pavlou, P. (2002). From Consumer Response to Active Consumer: Measuring the Effectiveness of Interactive Media. Academy of Marketing Science Journal, 30(4), 376-397.

Summers, J. (2001). Guidelines for Conducting Research and Publishing in Marketing: From Conceptualization through the Review Process. Academy of Marketing Science Journal, 29(4), 405-415.

Szmigin, I., Canning, L., \& Reppel, A. (2005). Online Community: Enhancing the Relationship Marketing Concept through Customer Bonding. International Journal of Service Industry Management, 16(5), 480-496.

Tabachnick, B., \& Fidell, L. (1996). Using Multivariate Statistics (3 ed.). New York: HarperCollins.

Tabachnick, B., \& Fidell, L. (2000). Using Multivariate Statistics (4 ed.). Boston: Allyn and Bacon.

Temme, D., Kreis, H., \& Hildebrandt, L. (2006). Pls Path Modeling: A Software Review.

Tenenhaus, M., Vinzi, V., Chatelin, Y., \& Lauro, C. (2005). Pls Path Modeling. Computational Statistics and Data Analysis, 48, 159-205.

Thorbjornsen, H., Supphellen, M., Nysveen, H., \& Pedersen, P. (2002). Building Brand Relationships Online: A Comparison of Two Interactive Applications. Journal of Interactive Marketing, 16(3), 17-34.

Trocchia, P., \& Janda, S. (2000). A Phenomenological Investigation of Internet Usage among Older Individuals. The Journal of Consumer Marketing, 17(7), 605-616.

UC Berkeley (2004). Glossary of Internet and Web Jargon Retrieved 05 April, 2004, from www.lib.berkeley.edu/TeachingLib/Guides/Internet/Glossary.html

Van Waterschoot, W., \& Van den Bulte, C. (1992). The $4 p$ Classification of the Marketing Mix Revisited. Journal of Marketing, 56(4), 83-94. 
Varadarajan, R. (1996). From the Editor: Reflections on Research and Publishing. Journal of Marketing, 60(4), 3-6.

Vargo, S., \& Lusch, R. (2004). Evolving to a New Dominant Logic for Marketing. Journal of Marketing, 68(1), 1-17.

Veloutsou, C., Saren, M., \& Tzokas, N. (2002). Relationship Marketing: What If ...? European Journal of Marketing, 36(4), 433-449.

Virgin Blue (2007). Virgin, Pacific Blue Announce New Domestic Airline Retrieved 21.05.08, from http://www.scoop.co.nz/stories/BU0708/S00439.htm

Virgin Blue (2008). The Virgin Blue History Retrieved 21.05.08, from http://www.pacificblue.co.nz/AboutUs/Virginbluecorporateinformation/TheVirginBluehi story/index.htm

Vyncke, P. (2002). Lifestyle Segmentation: From Attitudes, Interests and Opinions, to Values, Aesthetic Styles, Life Visions and Media Preferences. European Journal of Communication, 17(4), 445-464.

Wang, F., Head, M., \& Archer, N. (2000). A Relationship-Building Model for the Web Retail Marketplace. Internet Research, 10(5), 374-384.

Webster, F. (1992). The Changing Role of Marketing in the Corporation. Journal of Marketing, 56(4), 1-17.

Wellman, B. (2004). Connecting Communities: On and Offline. Contexts, 3(4), 22-28.

Wells, W. (1975). Psychographics: A Critical Review. Journal of Marketing Research, 12(2), 196-213.

Wheeler, S., Petty, R., \& Bizer, G. (2005). Self-Schema Matching and Attitude Change: Situational and Dispositional Determinants of Message Elaboration. Journal of Consumer Research, 31(4), 787-798.

Wikstrom, S. (1996). The Customer as Co-Producer. European Journal of Marketing, 30(4), 6-19.

Wind, Y., \& Mahajan, V. (2002). Convergence Marketing. Journal of Interactive Marketing, 16(2), 64-79.

Wind, Y., Mahajan, V., \& Gunther, R. (2002). Convergence Marketing: Strategies for Reaching the New Hybrid Consumer. New Jersey: Prentice Hall.

Winkler, A., \& McCarthy, P. (2005). Maximising the Value of Missing Data. Journal of Targeting, Measurement and Analysis for Marketing, 13(2), 169-178.

Woo, K., \& Ennew, C. (2004). Business-to-Business Relationship Quality: An Imp InteractionBased Conceptualization and Measurement. European Journal of Marketing, 38(9), 1252-1271.

Woodside, A. (2004). Advancing Means-End Chains by Incorporating Heider's Balance Theory and Fournier's Consumer-Brand Relationship Typology. Psychology \& Marketing, 21(4), 279-294.

Yadav, M., \& Varadarajan, R. (2005). Interactivity in the Electronic Marketplace: An Exposition of the Concept and Implications for Research. Academy of Marketing Science Journal, 33(4), 585-603. 
Yoh, E., Damhorst, M., Sapp, S., \& Laczniak, R. (2003). Consumer Adoption of the Internet: The Case of Apparel Shopping. Psychology \& Marketing, 20(12), 1095-1118.

Young and Rubicam (2010). Mobile Mania: A Manual for the Second Internet Revolution. London: Y\&R EMEA.

Zajonc, R., \& Markus, H. (1982). Affective and Cognitive Factors in Preferences. Journal of Consumer Research, 9(2), 123-132.

Zeithaml, V. (1988). Consumer Perceptions of Price, Quality, and Value: A Means-End Model and Synthesis of Evidence. Journal of Marketing, 52(3), 2-22.

Zeithaml, V., Berry, L., \& Parasuraman, A. (1996). The Behavioural Consequences of Service Quality. Journal of Marketing, 60(2), 31-46.

Zeithaml, V., Parasuraman, A., \& Malhotra, A. (2002). Service Quality Delivery through Web Sites: A Critical Review of Extant Knowledge. Academy of Marketing Science Journal, 30(4), 362-375.

Zikmund, W. (1997). Exploring Marketing Research (6 ed.): The Dryden Press.

Zineldin, M. (2000). Beyond Relationship Marketing: Technologicalship Marketing. Marketing Intelligence \& Planning, 18(1), 9-23. 